\title{
Measurements of transverse beam halo diffusion rates in the LHC with collimator scans
}

\author{
G. Stancari, ${ }^{*}$ V. Previtali, and A. Valishev \\ Fermi National Accelerator Laboratory, P.O. Box 500, Batavia, Illinois 60510, USA \\ R. W. Assmann, F. Burkart, S. Redaelli, B. Salvachua, and G. Valentino ${ }^{\dagger}$ \\ CERN, Geneva, Switzerland
}

(Dated: September 10, 2012)

Measurements of beam halo dynamics were conducted in the LHC on 22 June 2012 at $4 \mathrm{TeV}$ using collimator scans. Four scans were performed: on proton beam 1 with a vertical collimator and on beam 2 with a horizontal collimator, first with squeezed separated beams and subsequently in collision. The time evolution of losses following collimator steps provides experimental estimates of halo diffusion, halo population, impact parameter distributions, and beam jitter. Besides its general interest for beam dynamics and machine performance characterization, this information forms an essential input for the general design of collimation systems, including new methods such as crystal collimators and hollow electron lenses. In this note, the results of an analysis of the data is presented.

\footnotetext{
* Corresponding author; E-mail: stancari@fnal.gov

$\dagger$ Experiment coordinator.
} 


\section{CONTENTS}

I. Introduction

3

II. Model

III. Methods and data sets 6

$\begin{array}{ll}\text { A. Experimental procedure } & 6\end{array}$

$\begin{array}{ll}\text { B. Parameters } & 8\end{array}$

$\begin{array}{lr}\text { C. Measured quantities } & 9\end{array}$

IV. Data Analysis 10

V. Results 20

A. Diffusion Coefficients 20

B. Halo Population 22

C. Impact parameter distributions 23

D. Beam Jitter 23

VI. Conclusions 23

VII. Acknowledgments 25

A. Diagnostic plots 26

B. Table of collimator steps $\quad 86$

C. Table of fit results for each step $\quad 93$

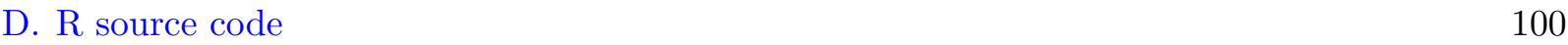

References 


\section{INTRODUCTION}

Understanding particle losses and beam quality degradation is one of the fundamental aspects in the design and operation of accelerators. From the point of view of machine protection, losses must be absorbed by the collimation system to avoid damaging components. Beam lifetimes and emittance growth determine the luminosity of colliders. Knowledge of the machine aperture (physical and dynamical) and of the mechanisms that drive particle loss is essential.

The dynamics of particles in an accelerator can be quite complex. Deviation from linear dynamics can be large, especially in the beam halo. Lattice resonances and nonlinearities, coupling, intrabeam and beam-gas scattering, and the beam-beam force in colliders all contribute to the topology of the particles' phase space, which in general will include regular and chaotic regions, and resonant islands. In addition, various noise sources are present in a real machine, such as ground motion (resulting in orbit and tune jitter) and ripple in the radiofrequency and magnet power supplies. As a result, the macroscopic motion can acquire a stochastic character, which can be described in terms of particle diffusion [1-5].

Calculations of lifetimes, emittance growth rates, and dynamic aperture from various sources are routinely performed in the design stage of all major accelerators, providing the foundation for the choice of operational machine parameters. With these studies, we address the corresponding lack of experimental data on the dynamics of the beam halo, with the goal of relating it to these basic parameters.

It was shown that beam halo diffusion can be observed by observing the time evolution of particle losses during a collimator scan [12]. These phenomena were used to estimate the diffusion rate in the beam halo in the SPS at CERN [7], in HERA at DESY [12], and in RHIC at BNL [8]. An extensive experimental campaign was carried out at the Tevatron in 2011 [11] to characterize the beam dynamics of colliding beams and to study the effects of the novel hollow electron beam collimator concept [9]. Following the results of the Tevatron measurements, similar experiments were proposed in the LHC [15].

This report describes the measurement technique and the data analysis in detail. Numerical calculations, data analysis, and graphics were done with the open-source, multi-platform statistical package R version 2.15 .1 (2012-06-22) [13]. This documentation was produced by integrating $\mathrm{AT}_{\mathrm{E} X}$ with R using the Sweave package [14]. The complete analysis scripts are collected in Appendix D. 


\section{MODEL}

Particle motion at the microscopic level is in general very complex. Two main considerations lead to the ansatz that macroscopic motion in a real machine, especially in the halo, will be mostly stochastic: (1) the central limit theorem applied to the multitude of dynamical effects acting on the beam; (2) the operational experience during collimator setup, which generates loss spikes and loss dips which often decay in time as $1 / \sqrt{t}$.

A diffusion model of the time evolution of loss rates caused by a step in collimator position was developed [10]. It builds upon the model of Ref. [12] and its assumptions: (1) constant diffusion rate within the range of the step and (2) linear halo tails. These hypotheses allow one to obtain analytical expressions for the solutions of the diffusion equation and for the corresponding loss rates vs. time. The present model addresses some of the limitiations of the previous model and expands it in the following ways: (a) losses before, during, and after the step are predicted; (b) different steadystate rates before and after are explained; (c) determination of the model parameters (diffusion coefficient, tail population, detector calibration, and background rate) is more robust and precise. These calculations are the basis for the measurement of transverse beam diffusion rates as a function of particle amplitude with collimator scans.

Following Ref. [12], we consider the evolution in time $t$ of a beam of particles with phase-space density $f(J, t)$ described by the diffusion equation

$$
\partial_{t} f=\partial_{J}\left(D \partial_{J} f\right)
$$

where $J$ is the Hamiltonian action and $D$ the diffusion coefficient. The particle flux at a given location $J=J^{\prime}$ is $\phi=-D \cdot\left[\partial_{J} f\right]_{J=J^{\prime}}$. During a collimator step, the action $J_{c}=x_{c}^{2} / \beta_{c}$, corresponding to the collimator position $x_{c}$ at a ring location where the amplitude function is $\beta_{c}$, changes from its initial value $J_{c i}$ to its final value $J_{c f}$ during a time $\Delta t$. The step in action is $\Delta J \equiv J_{c f}-J_{c i}$. In the Tevatron, typical steps are $50 \mu \mathrm{m}$ in $0.2 \mathrm{~s}$, and the amplitude function is tens of meters. It is assumed that the collimator steps are small enough so that the diffusion coefficient can be treated as a constant in that region. This hypothesis is justified by the fact that the fractional change in action is of the order of $\Delta J_{c} / J_{c} \sim(2)(25 \mu \mathrm{m}) /(2 \mathrm{~mm})=2.5 \%$. Because the diffusion coefficient is a strong function of action $\left(D \sim J^{4}\right)$, this translates into a variation of $10 \%$ in the diffusion rate, an acceptable systematic in a quantity that varies by orders of magnitude. If $D$ is constant, the diffusion equation becomes $\partial_{t} f=D \partial_{J J} f$. With these definitions, the particle loss rate at the collimator is equal to the flux at that location: $L=-D \cdot\left[\partial_{J} f\right]_{J=J c}$. Particle showers caused by 
the loss of beam are measured with scintillator counters placed close to the collimator jaw. The observed shower rate is parameterized as

$$
S=k L+B
$$

where $k$ is a normalization constant including detector acceptance and efficiency and $B$ is a background term which includes, for instance, the effect of residual activation.

Under the hypotheses described above, the diffusion equation can be solved analytically using the method of Green's functions, subject to the boundary condition of vanishing density at the collimator and beyond. Details are given in Ref. [10].

An example of the evolution of the phase-space density according to this model is shown in Figure 1. A few representative snapshots in time are chosen: during collimator movement $(0 \leq t \leq$ $\Delta t)$; a short time after the step, with a time scale determined by $\left|J_{c i}-J_{c f}\right|^{2} / D=10 \mathrm{~s}$; and a long time after the step, with a characteristic time $J_{c}^{2} / D=160 \mathrm{~s}$.
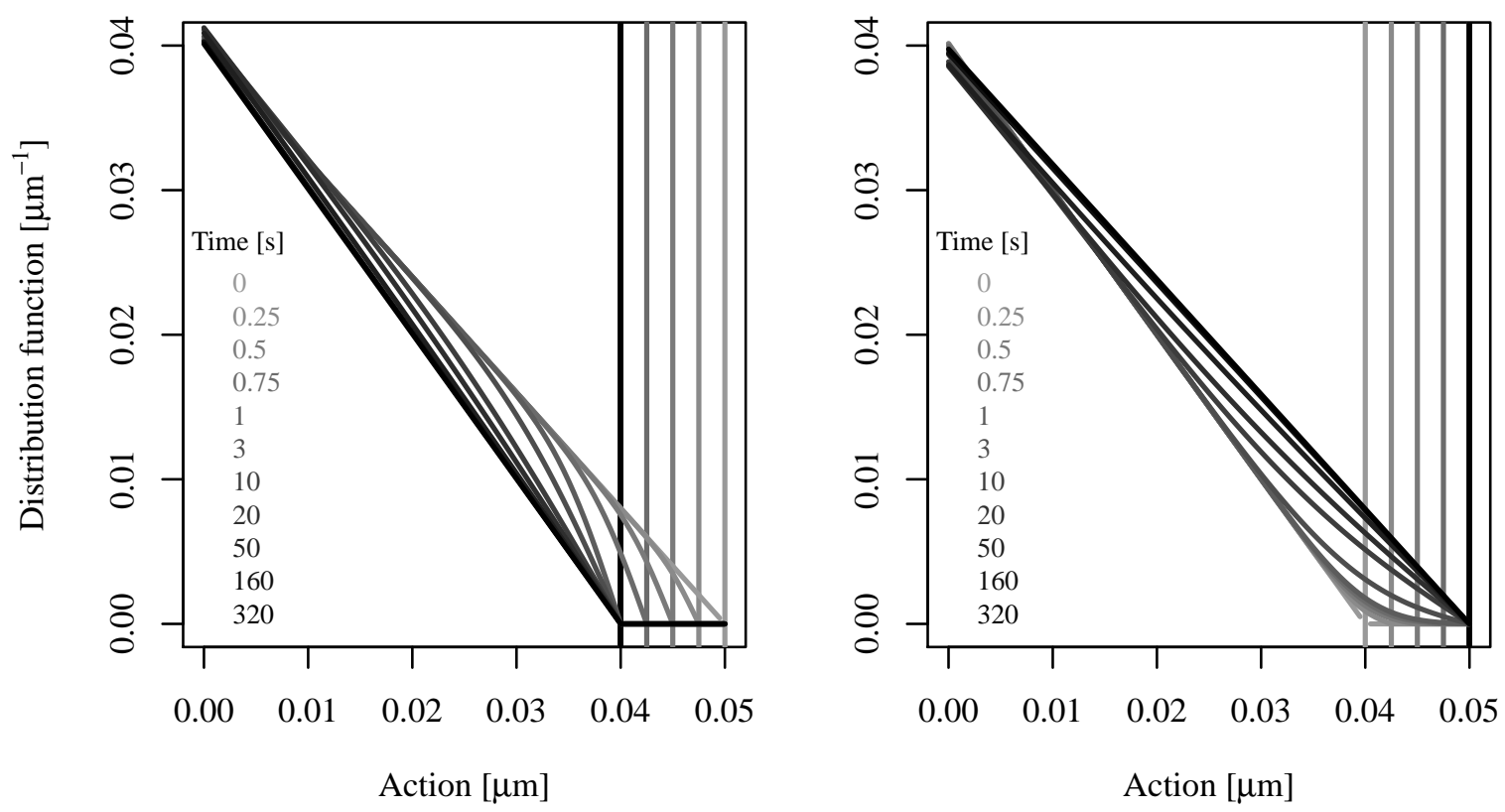

FIG. 1. Evolution of distribution function during collimator step: $f_{I}(J, t)$ (inward, left) and $f_{O}(J, t)$ (outward, right). The vertical lines represent the positions of the collimator vs. time. Collimator action varies between $J_{c i}=0.05 \mu \mathrm{m}$ and $J_{c f}=0.04 \mu \mathrm{m}$ in the inward case (viceversa in the outward case) in a time $\Delta t=1 \mathrm{~s}$. The slopes of the tails are $A_{i}=0.8 \mu \mathrm{m}^{-2}$ and $A_{f}=1 \mu \mathrm{m}^{-2}$ in the inward case (viceversa outwards). The diffusion coefficient is $D=10^{-5} \mu \mathrm{m}^{2} / \mathrm{s}$.

Local losses are proportional to the gradient of the distribution function at the collimator. The gradients differ in the two cases of inward and outward step, denoted by the $I$ and $O$ subscripts, 
respectively:

$$
\begin{array}{r}
\partial_{J} f_{I}\left(J_{c}, t\right)=-A_{i}+2\left(A_{i}-A_{c}\right) P\left(\frac{-J_{c}}{\sigma}\right)+\frac{1}{\sqrt{2 \pi} \sigma} \\
\left\{-2 A_{i}\left(J_{c i}-J_{c}\right)+2\left(A_{i} J_{c i}-A_{c} J_{c}\right) \exp \left[-\frac{1}{2}\left(\frac{J_{c}}{\sigma}\right)^{2}\right]\right\} \\
\partial_{J} f_{O}\left(J_{c}, t\right)=-2 A_{i} P\left(\frac{J_{c i}-J_{c}}{\sigma}\right)+2\left(A_{i}-A_{c}\right) P\left(\frac{-J_{c}}{\sigma}\right)+ \\
+2 \frac{A_{i} J_{c i}-A_{c} J_{c}}{\sqrt{2 \pi} \sigma} \exp \left[-\frac{1}{2}\left(\frac{J_{c}}{\sigma}\right)^{2}\right] .
\end{array}
$$

The parameters $A_{i}$ and $A_{f}$ are the slopes of the distribution function before and after the step, whereas $A_{c}$ varies linearly between $A_{i}$ and $A_{f}$ as the collimator moves. The parameter $\sigma$ is defined as $\sigma \equiv \sqrt{2 D t}$; its effect is to expose the dependence of losses on the inverse square root of time, as is typical for diffusion processes. The function $P(x)$ is the S-shaped cumulative Gaussian distribution function: $P(-\infty)=0, P(0)=1 / 2$, and $P(\infty)=1$.

The above expressions are used to model the measured shower rates. A few examples are plotted in Figure 2.

Parameters are estimated from a least-squares fit to the experimental data. The background $B$ is measured before and after the scan when the jaws are retracted. The calibration of $k A_{i}$ and $k A_{f}$ is estimated by comparing the level of losses with beam intensity and lifetime. In practice, $D$ is determined by both the measured relaxation time and by the value of the peak (or dip) in losses.

The model explains the data very well when the diffusion time is long compared to the duration of the step. With this technique, the diffusion rate can be measured over a wide range of amplitudes. At large amplitudes, the method is limited by the vanishing beam population and by the fast diffusion times. The limit at small amplitudes is given by the level of tolerable loss spikes.

\section{METHODS AND DATA SETS}

\section{A. Experimental procedure}

The experimental procedure is schematically shown in Figure 3. The LHC experiments (MD of 22 June 2012) were described in Ref. [16]. The experimental procedure is reproduced here for convenience. One nominal bunch $\left(1.15 \times 10^{11}\right.$ protons $)$ per beam was used. The study started with squeezed, separated beams at $4 \mathrm{TeV}$. Orbit stabilization was turned off. The IR7 primary and secondary collimators were retracted from their nominal settings of $4.3 \sigma$ and $6.3 \sigma$ respectively to 


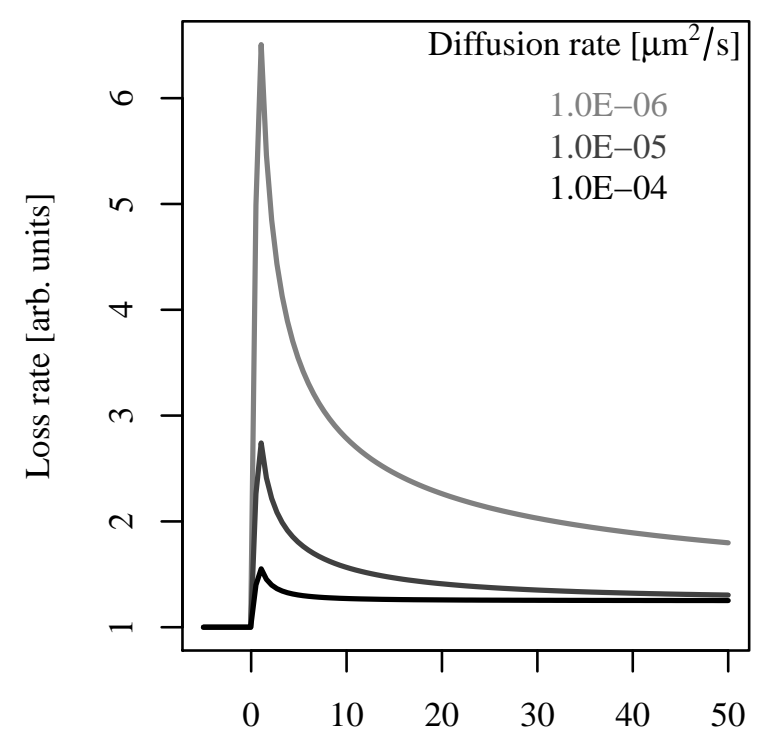

Time $[\mathrm{s}]$

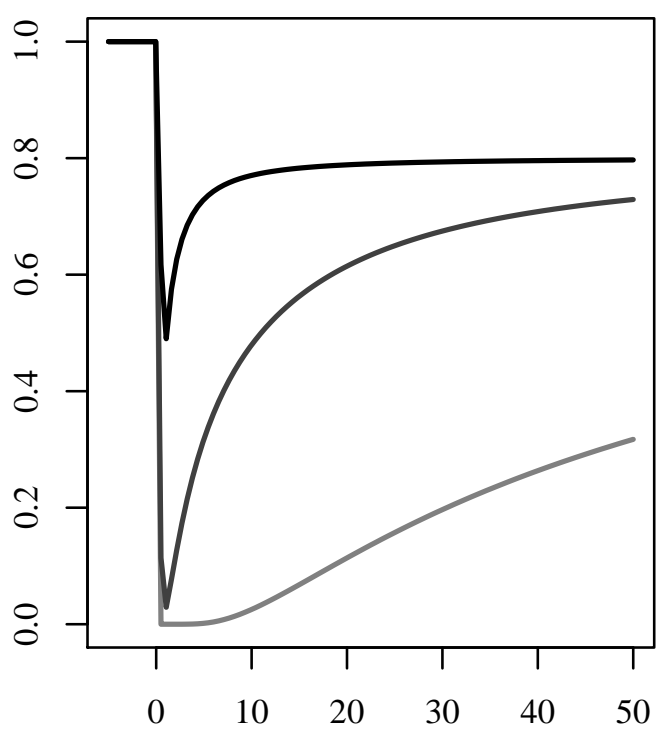

Time $[\mathrm{s}]$

FIG. 2. Calculated evolution of loss rates $L(t)$ during a collimator step according to Eqs. 2 and 3: inward (left) and outward (right). Collimator action varies between $J_{c i}=0.05 \mu \mathrm{m}$ and $J_{c f}=0.04 \mu \mathrm{m}$ in the inward case (viceversa in the outward case) in a time $\Delta t=1 \mathrm{~s} \mathrm{(see} \mathrm{also} \mathrm{Figure} \mathrm{1).} \mathrm{The} \mathrm{effect} \mathrm{of} 3$ different values of the diffusion coefficient $D$ is shown. The slopes of the tails are scaled so that the initial and final steady-state loss rates are the same in all cases: $A_{i}=1 / D, A_{f}=A_{i} J_{c i} / J_{c f}$.

a half gap of $7 \sigma$. The left jaw of the TCP.D6L7.B1 (beam 1, vertical plane) and the TCP.C6R7.B2 (beam 2, horizontal plane) primary collimators were moved in small steps. The collimators were selected from different beams to be able to perform the scrapings in parallel without inducing cross-talk in the BLM signals. The jaws were moved after waiting for the beam losses from the previous step to reach a steady-state (approximately every 10 to 40 seconds). The jaws were left for a few minutes in the beam after they had reached their final inward position, to allow the losses to stabilize. Subsequently, the jaws were moved out in small steps, again after waiting for the transient to decay. The procedure of inward and outward steps was then repeated after bringing the beams into collision.

The electronic logbook is accessible from outside CERN through the following link: https:// ab-dep-op-elogbook.web.cern.ch/ab-dep-op-elogbook/elogbook/secure/eLogbook.php, by selecting the LHC OP e-log and the date of the shift. 

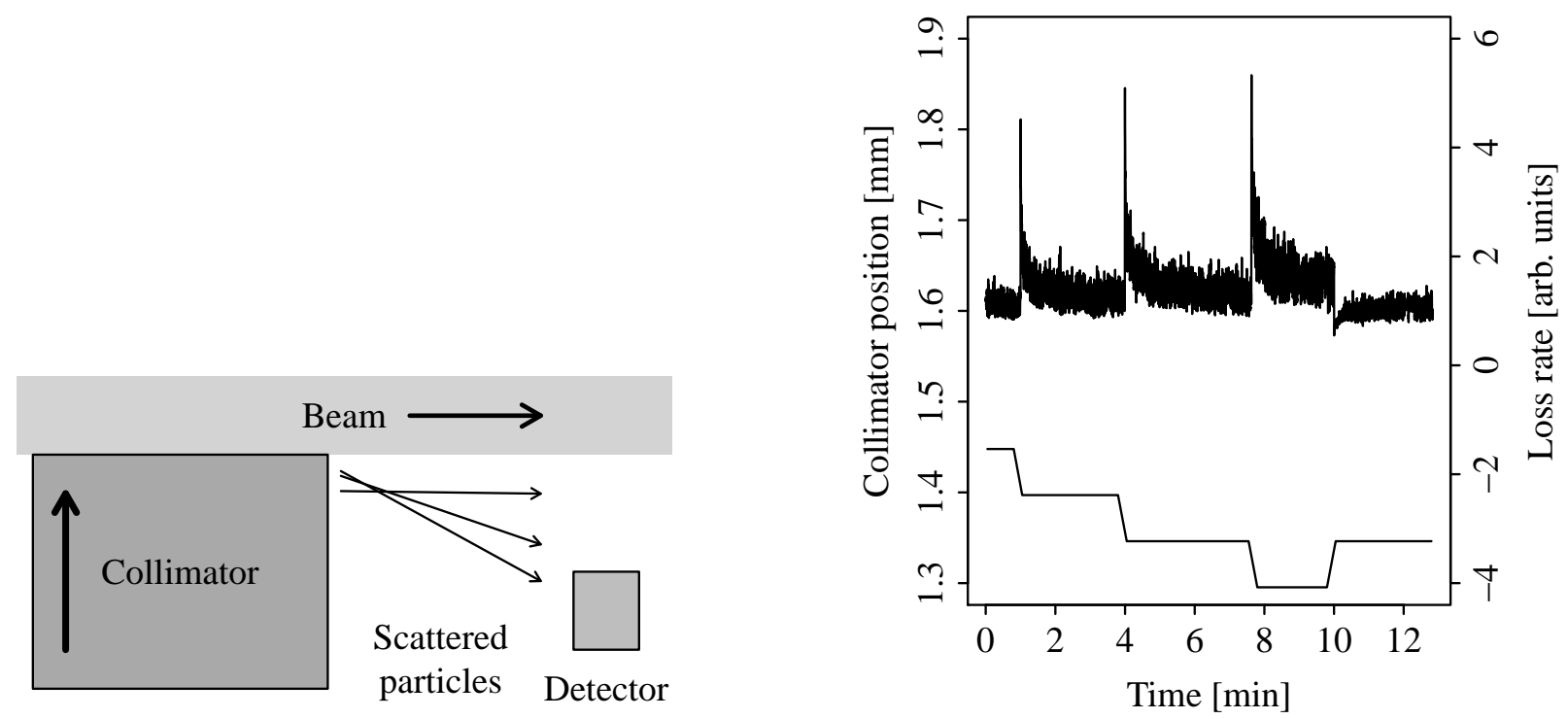

FIG. 3. Schematic diagram of the apparatus (left). Example of the response of local loss rates to inward and outward collimator steps (right).

\section{B. Parameters}

The constant parameters used in this analysis are defined here: kinetic energy $4 \mathrm{TeV}$; relativistic factor $\gamma_{r}=4264$; nominal emittances $3.75 \mu \mathrm{m}$ (normalized), 8.79e-10 $\mathrm{m}$ (geometrical); momentum spread 1.10e-04.

\begin{tabular}{lccccccc}
\hline \hline & $\mathrm{s}[\mathrm{m}]$ & $\beta_{x}[\mathrm{~m}]$ & $\beta_{y}[\mathrm{~m}]$ & $D_{x}[\mathrm{~m}]$ & $D_{y}[\mathrm{~m}]$ & $\sigma_{x}^{\text {nom }}[\mathrm{mm}]$ & $\sigma_{y}^{\text {nom }}[\mathrm{mm}]$ \\
\hline TCP.B1.h & 19791.2 & 150.5 & 82.8 & 0.33 & 0.00 & 0.366 & 0.270 \\
TCP.B1.v & 19789.2 & 158.8 & 78.3 & 0.34 & 0.00 & 0.376 & 0.262 \\
TCP.B2.h & 6461.7 & 150.4 & 82.8 & -0.14 & 0.00 & 0.364 & 0.270 \\
TCP.B2.v & 6459.7 & 158.7 & 78.3 & -0.15 & 0.00 & 0.374 & 0.262 \\
\hline \hline
\end{tabular}

TABLE I. Lattice functions and nominal beam sizes at the collimators of interest.

The lattice functions at the collimators are reported in Table I, together with the nominal beam sizes.

The beam centers from the March 2012 collimator alignment campaign are $0.24 \mathrm{~mm}$ (B1, vertical) and $0.52 \mathrm{~mm}$ (B2, horizontal). The calibration constant of losses at the TCP.C collimators is approximately $1.250 e+12 \mathrm{p} / \mathrm{Gy}$. 


\section{Measured quantities}

The halo diffusion measurements rely on beam intensities, emittances, bunch length and momentum spread. Moreover, the collimator positions and local losses need to be accurately recorded. Here is a detailed description of the variables used. In particular, these measurements were made possible by the BLM data logged at $12.5 \mathrm{~Hz}$. From inside CERN, the datalogger is accessible at the following link: http://www.cern.ch/timber.

Intensity: The beam current transformer data (BCT) is normally logged every $1 \mathrm{~s}$. For this particular study it was also logged every 20 ms (as suggested by Massimo Giovannozzi, using Riccardo De Maria's dedicated acquisition program). The 20-ms data was missing for about 10 minutes (due to a data acquisition program crash). The format of the BCT data is usually in 2 columns: Unix time stamp (milliseconds since 1970-01-01 00:00 UTC for the 1-Hz data, nanoseconds for the 20-ms data) and number of particles. The 20-ms data tables show some repeated values.

Wire-scan emittances: Three sets of wire scans (WS) were taken: 1) squeezed beams, before scrape; 2) squeezed beams, after scrape; 3) colliding beams before scrape. Some measurements may not be accurate due to saturation (peak values above $8 \times 10^{3}$ arb. units).

Synchrotron-light emittances: Synchrotron-light emittance measurements (BSRT) were logged continuously every $3 \mathrm{~s}$. The raw data files report the Unix time, the measured distribution r.m.s., and the calculated emittance.

Bunch length: Profiles from the longitudinal density monitor (LDM) for both beams were taken at flat top and after the scrape with squeezed beams. Data files include sampled data for a full turn $(89 \mu \mathrm{s})$ every 25 ps. Bunch length r.m.s. is about 0.3 ns. Satellite bunches are present but likely negligible for our purposes. Estimates of the momentum spread can be obtained from the longitudinal profile and from the parameters of the accelerating cavities.

Momentum spread: Measured in SPS?

Collimator positions: All collimators were moved out after the ramp, starting around 7 times the nominal $\sigma$. Collimator scans were done with TCP.D6L7.B1 (vertical, beam 1) and TCP.C6L7.B2 (horizontal, beam 2). Positions were logged every second. The variable labeled MOTOR is the set point, LVDT is the readback. LU is left jaw, upstream; analogously for LD, RU, and RD. Upstream and downstream ends were moved in parallel. 
Losses: The beam loss monitor (BLM) data was used. The typical background is $2 \times 10^{-7} \mathrm{~Gy} / \mathrm{s}$, noise is $10^{-8} \mathrm{~Gy} / \mathrm{s}$, and the signal varies from $10^{-7} \mathrm{~Gy} / \mathrm{s}$ to about $10^{-3} \mathrm{~Gy} / \mathrm{s}$ (close to the beam abort threshold). The BLM description file contains BLM name, position along the ring, and a flag $(0=$ cold magnet, $1=$ warm magnet, $3=$ collimator $)$. BLMs were logged both at $1 \mathrm{~Hz}$ and at $12.5 \mathrm{~Hz}$. The $1-\mathrm{Hz}$ data has an integration time of $1.3 \mathrm{~s}$. Data files were saved every $10 \mathrm{~min}$. They only contain ionization-chamber data. The $12.5-\mathrm{Hz}$ BLM data has an integration time of $82 \mathrm{~ms}$. Fast BLM files have columns labeled by $s$-position. All detectors are included. If there are two columns with the same position, the first one is the ionization chamber (BLMEI) and the second one is the SEM (BLMES, not used). All measurements are in $\mathrm{Gy} / \mathrm{s}$.

\section{DATA ANALYSIS}

The evolution of the beam intensity and of the collimator positions during the study is shown in Figure 4. (There is a discrepancy between the 1-s and the 20-ms intensity data. Moreover, the 1-s data shows abrupt spurious dips which are not correlated to losses. The 20-ms data will be used in the analysis.)

An overview of the collimator scans is shown in Figures 5 (separated beams) and 6 (colliding beams). Local losses are defined as the sum of the BLMs closest to the primary collimator of interest: BLMEI.06L7.B1E10 TCP.[A,B,C,D]6L7.B1 (table columns 2811, 2809, 2807, and 2805 in Gianluca's files) for TCP.D6L7.B1 and BLMEI.06R7.B2I10 TCP.[A,B,C,D]6R7.B1 (table columns 2970, 2972, 2974, and 2976) for TCP.C6R7.B2. A comparison of the responses of the 4 BLMs closest to the collimator of interest is shown in Figure 7. The closest BLM is not the most sensitive (D for vertical, C for horizontal); the most sensitive is usually A (4-6 m downstream of the jaw), probably because of the forward evolution of the particle shower.

The background losses are determined during "quiet time," with no beam in the machine (between 2012-06-22 05:28:00 and 2012-06-22 05:48:00). For the local B1 BLMs the background level is $1.81 e-06 \mathrm{~Gy} / \mathrm{s}$, and $1.06 e-06 \mathrm{~Gy} / \mathrm{s}$ for beam 2 . For total losses, it is $0.929 \mathrm{~Gy} / \mathrm{s}$.

For calibrating the response of this group of BLMs (conversion from Gy/s to protons/s), the experiment time is subdivided into 20-s intervals to obtain the average collimator position, local loss rate, and intensity decay rate. The BLM loss rate vs. total particle loss rate is shown in Figure 8. As expected, there is a systematic shift between separated and colliding beams in the total loss rate (all BLMs around the ring), due to luminosity. The local losses (4 BLMs as defined 


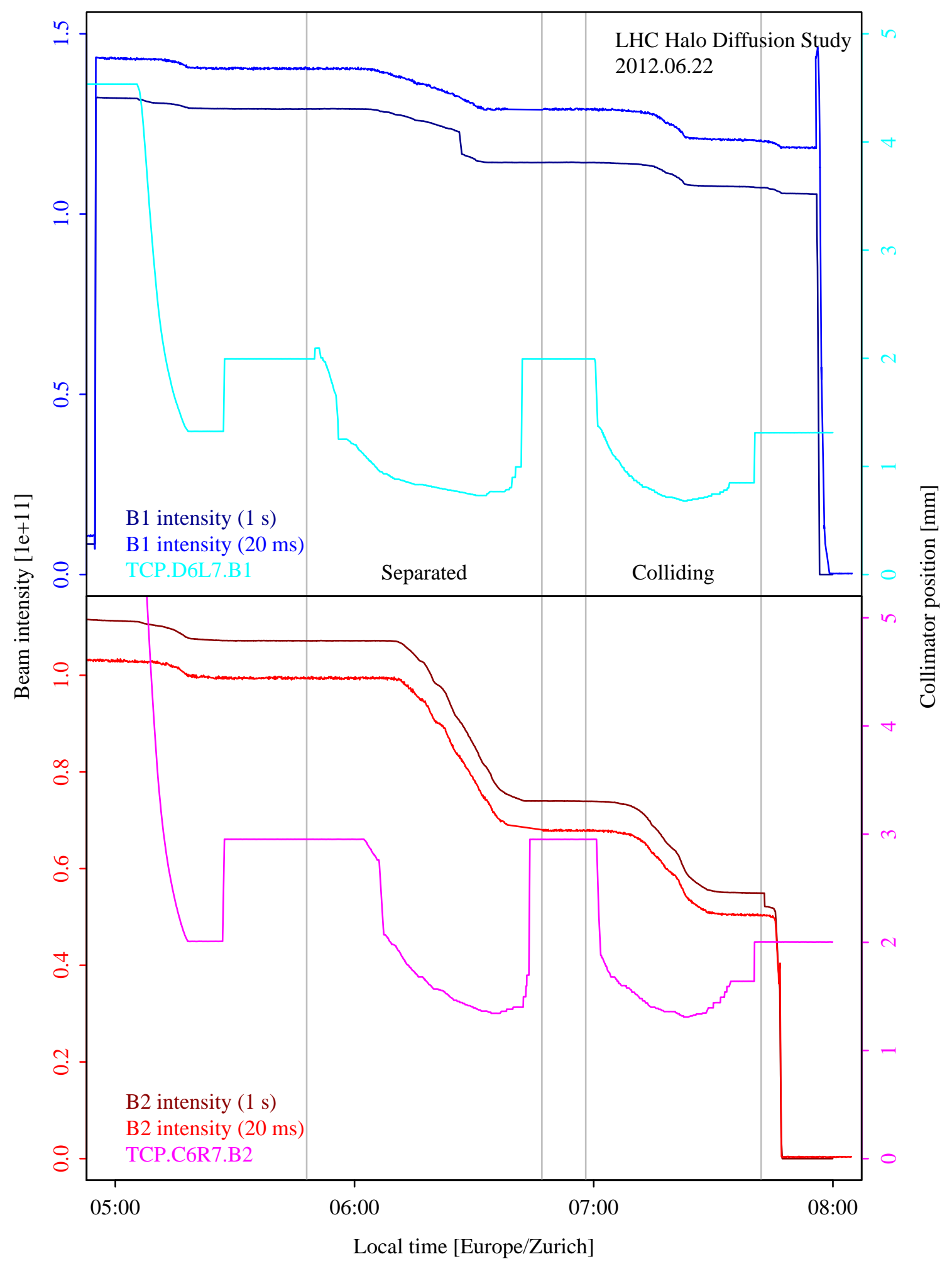

FIG. 4. Beam intensities and collimator positions over the course of the study. 


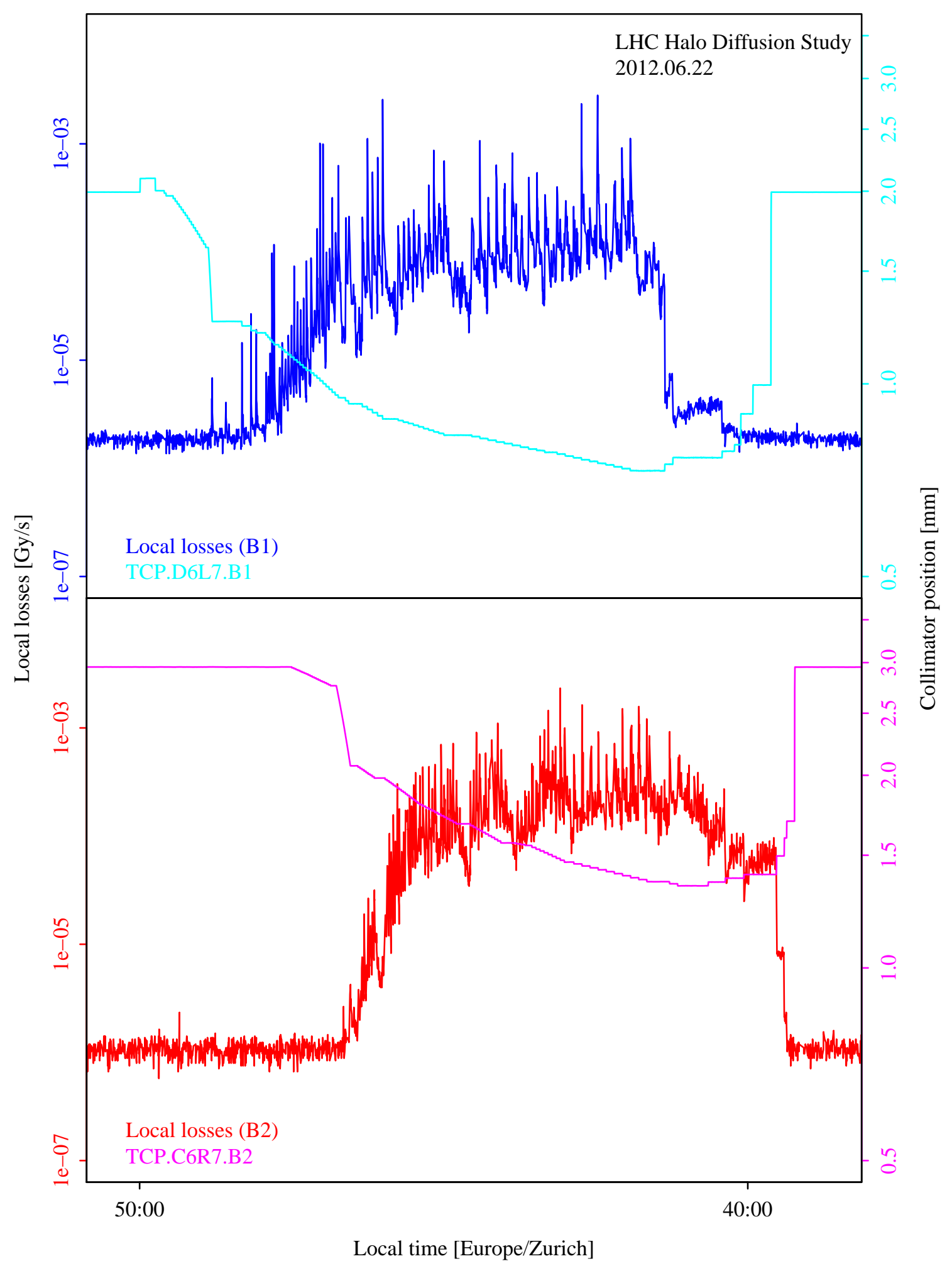

FIG. 5. Local losses and collimator positions during the collimator scan with separated beams. 


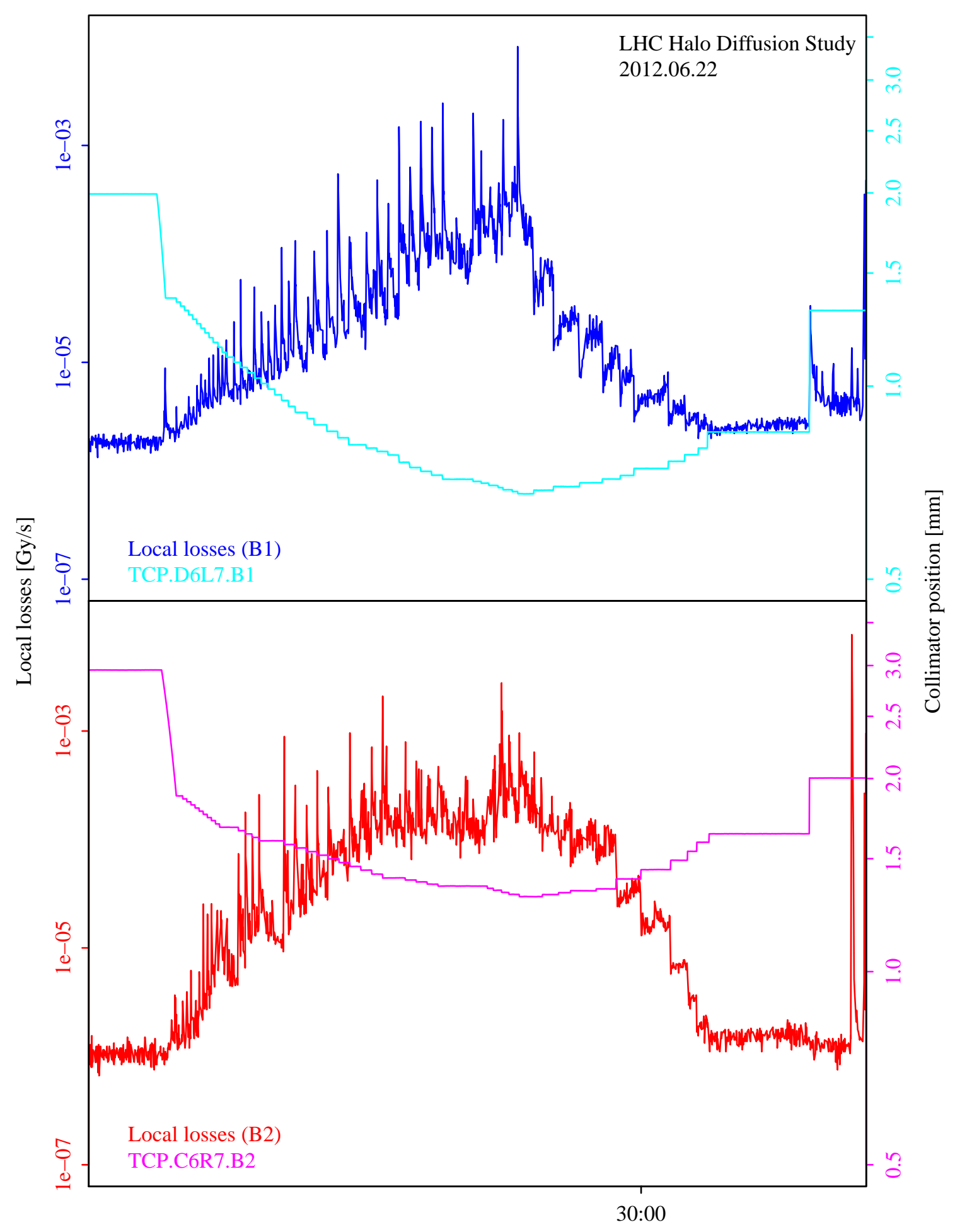

Local time [Europe/Zurich]

FIG. 6. Local losses and collimator positions during the collimator scan with colliding beams. 


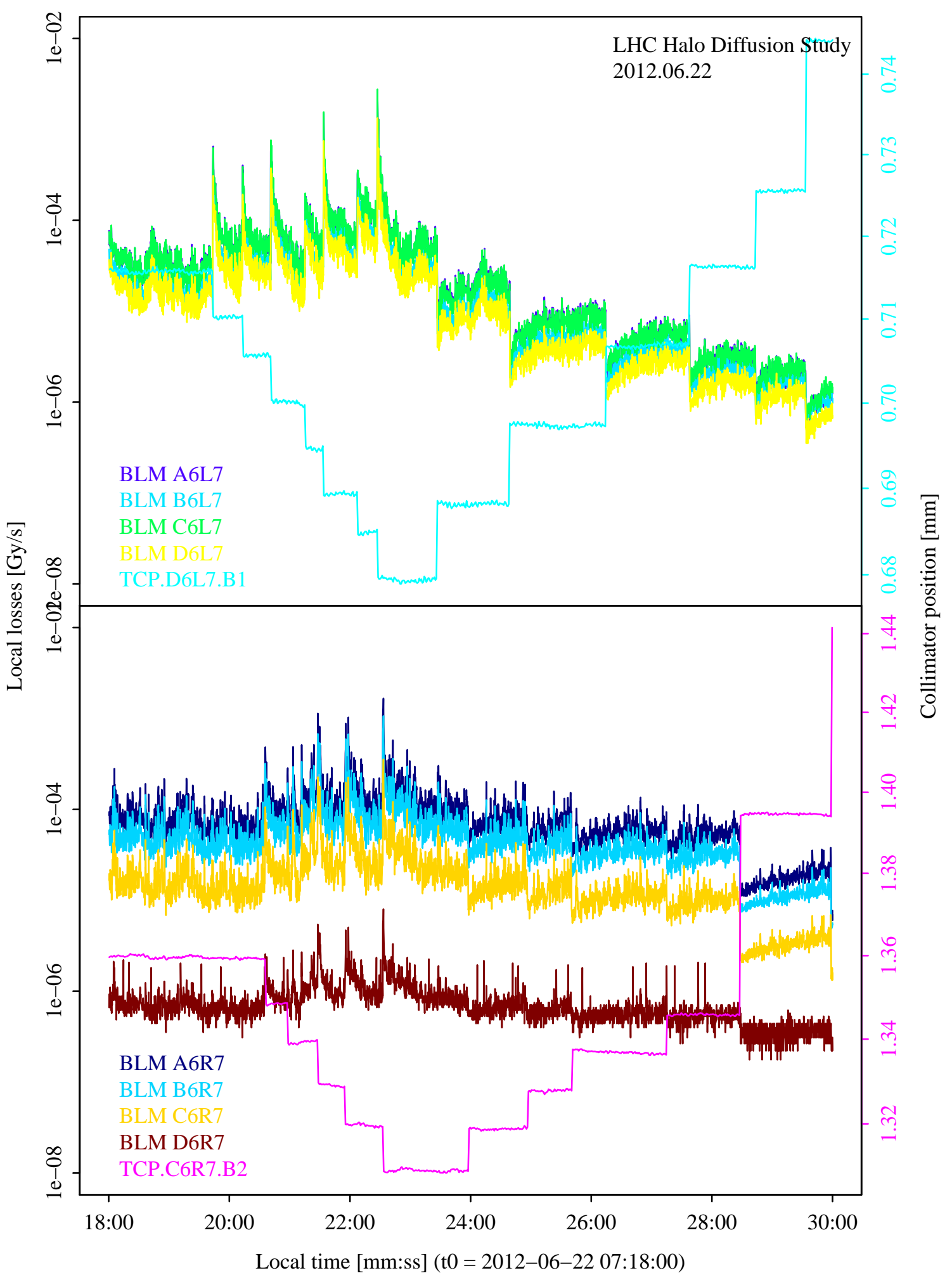

FIG. 7. Comparison of local loss monitors for a portion of the collimator scan. 

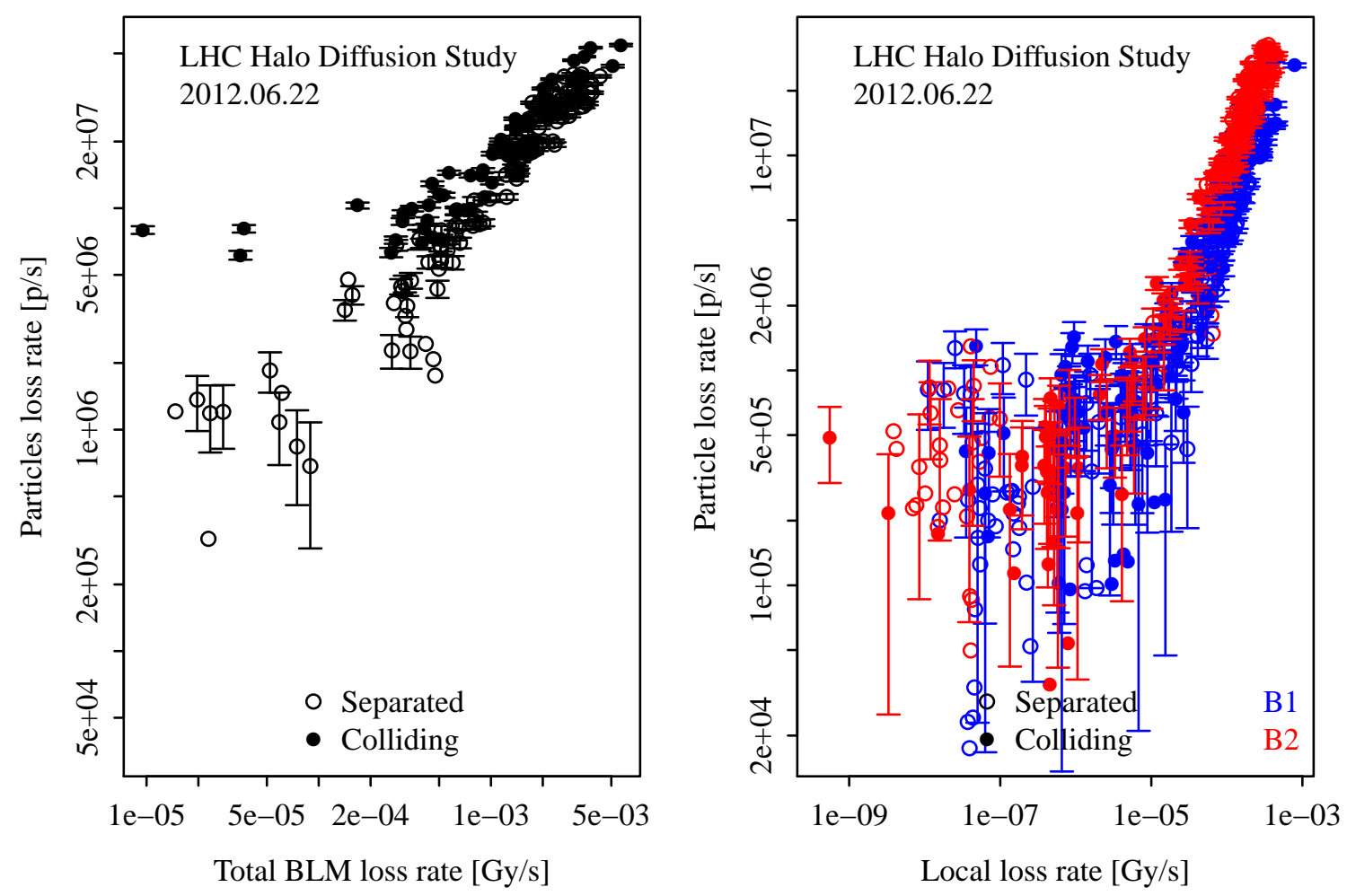

FIG. 8. Particle loss rates vs. BLM loss rates: total (all BLMs, both beams) on the left; divided by beam (only local primary BLMs) on the left.

above) appear to scale linearly with proton losses when the collimator of interest is the leading jaw.

Figures 9 and 10 show the variation of the BLM calibration constant as a function of collimator half gap. During each 20-s interval, the average collimator position is recorded. Measurements are then grouped in $40-\mu \mathrm{m}$ half-gap intervals. The central value and the spread are shown in the plots.

The calibration factor, or "local loss detection efficiency", varies by more than 2 orders of magnitude. It clearly exposes the threshold when the collimator becomes the leading edge - a half gap of $0.8 \mathrm{~mm}$ in the vertical plane and $1.5 \mathrm{~mm}$ horizontally. As expected, the efficiency in collisions is lower, when a larger beam fraction is lost at the collider detectors. This is particularly obvious in the horizontal case.

For the purposes of the diffusion analysis, these numbers are an experimental measurement of the $k$ parameter in Eq. 1. In Figures 9 and 10, the measurements of $k$ as a function of collimator position are interpolated with a smooth spline with 4 degrees of freedom. This empirical interpolation is used in Section $\mathrm{V}$ to extract the values of the particle fluxes $\left(D A_{i}, D A_{f}\right)$ and beam distribution slopes $\left(A_{i}, A_{f}\right)$. 


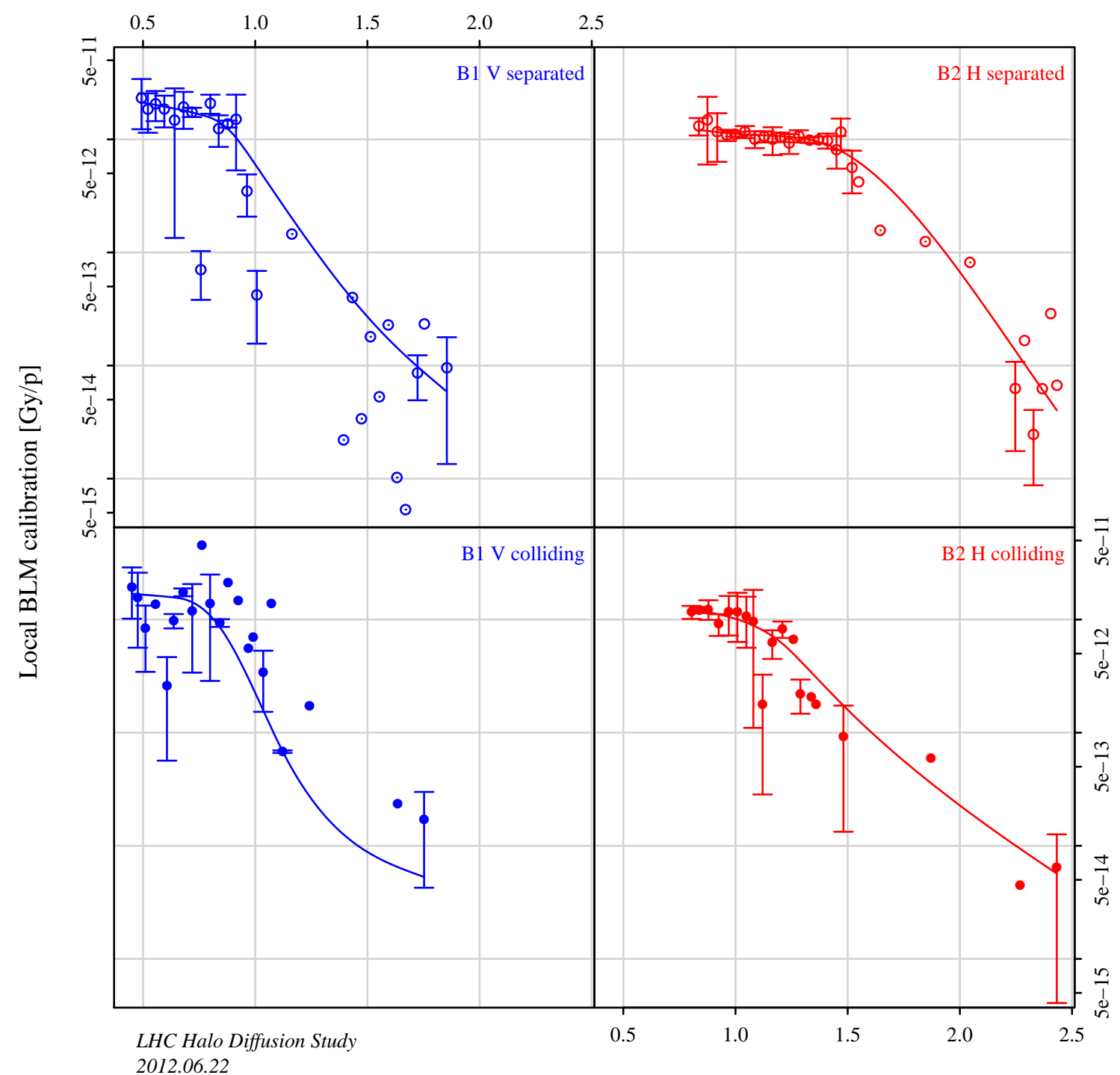

Collimator half gap [mm]

FIG. 9. Local loss monitor calibration vs. collimator position (log scale).

The initial emittances are calculated from the wire-scan and the synchrotron-light data. Both wire scan and sync-light emittance measurements are affected by the scraping of the tails (Figure 11). Emittances before 2012-06-22 06:08:00 (separated beams, before shaving; dashed line in Figure 11) are used to convert collimator gaps into beam sigmas. The first wire-scan measurements are used (first line in Table II). The statistical uncertainty is calculated from the difference between inward and outward fly. The average of the sync-light measurements is used, with a statistical uncertainty deduced from the spread in data points. The final emittance value is obtained by averaging wire scan and synch-light data. Its error is the combination in quadrature of the statistical errors plus a systematic error due to the difference between the two techniques. Results 


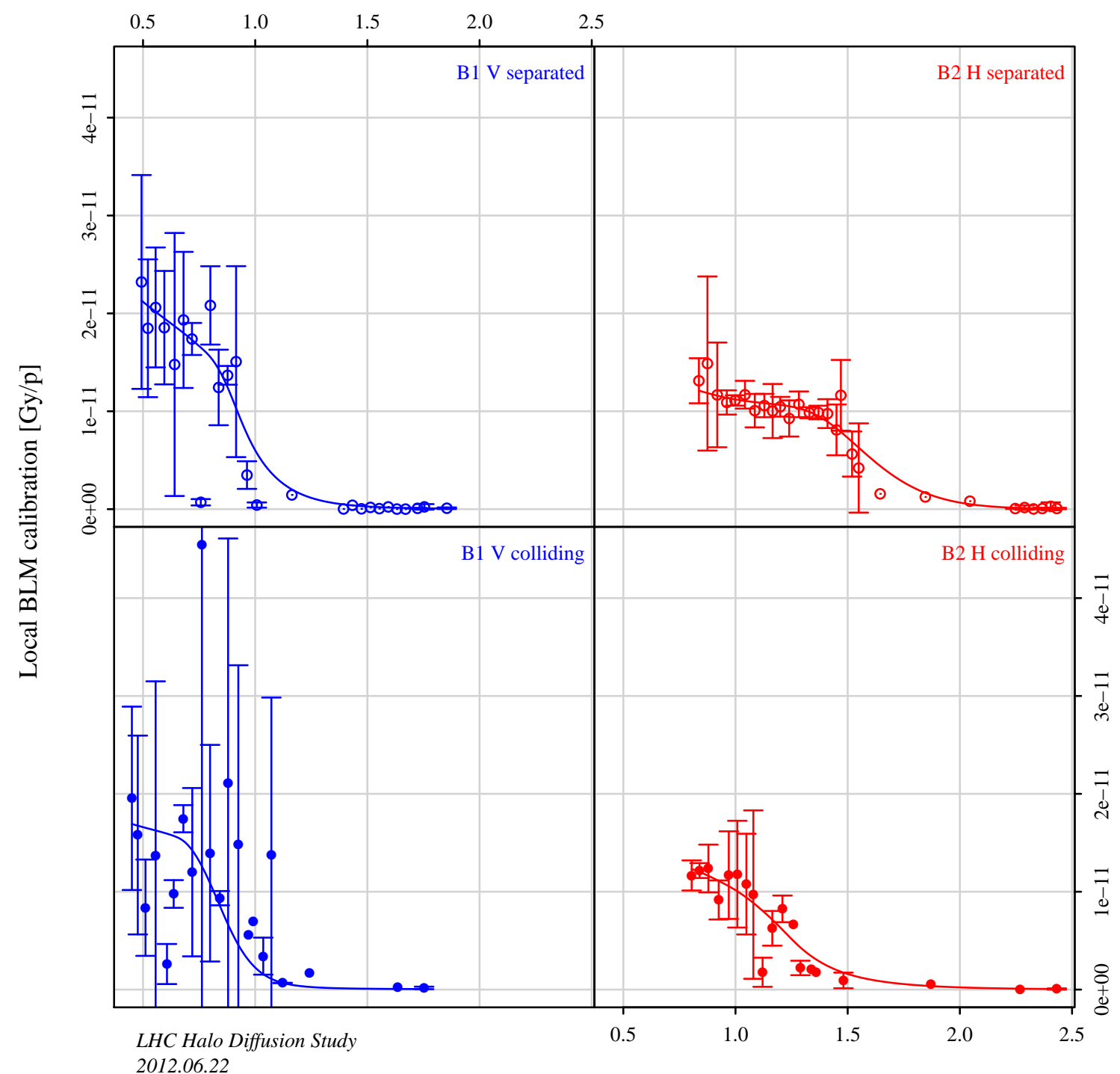

Collimator half gap [mm]

FIG. 10. Local loss monitor calibration vs. collimator position (linear scale).

are reported in Table III. The beam sizes at the collimators calculated from the initial emittances are $0.156 \mathrm{~mm}$ (B1 vertical) and $0.270 \mathrm{~mm}$ (B2 horizontal).

The emittance growth rates $\gamma \equiv \dot{\varepsilon} / \varepsilon$ are deduced from the slope of the sync-light data before 2012-06-22 06:08:00 (Figure 11, red lines). From them, the expected slope of the diffusion coefficient in the beam core is calculated: $D^{\prime} \equiv d D / d J=\dot{\varepsilon}$ (geometrical emittance). These numbers are also reported in Table III and will be compared with the measured diffusion rates.

Collimator steps are defined within the experiment intervals: between 2012-06-22 05:48:00 and 2012-06-22 06:47:00 for separated beams, and between 2012-06-22 06:58:00 and 2012-06-22 07:42:00 for colliding beams. Collimator steps and their properties are listed in Table IV in Appendix B. 


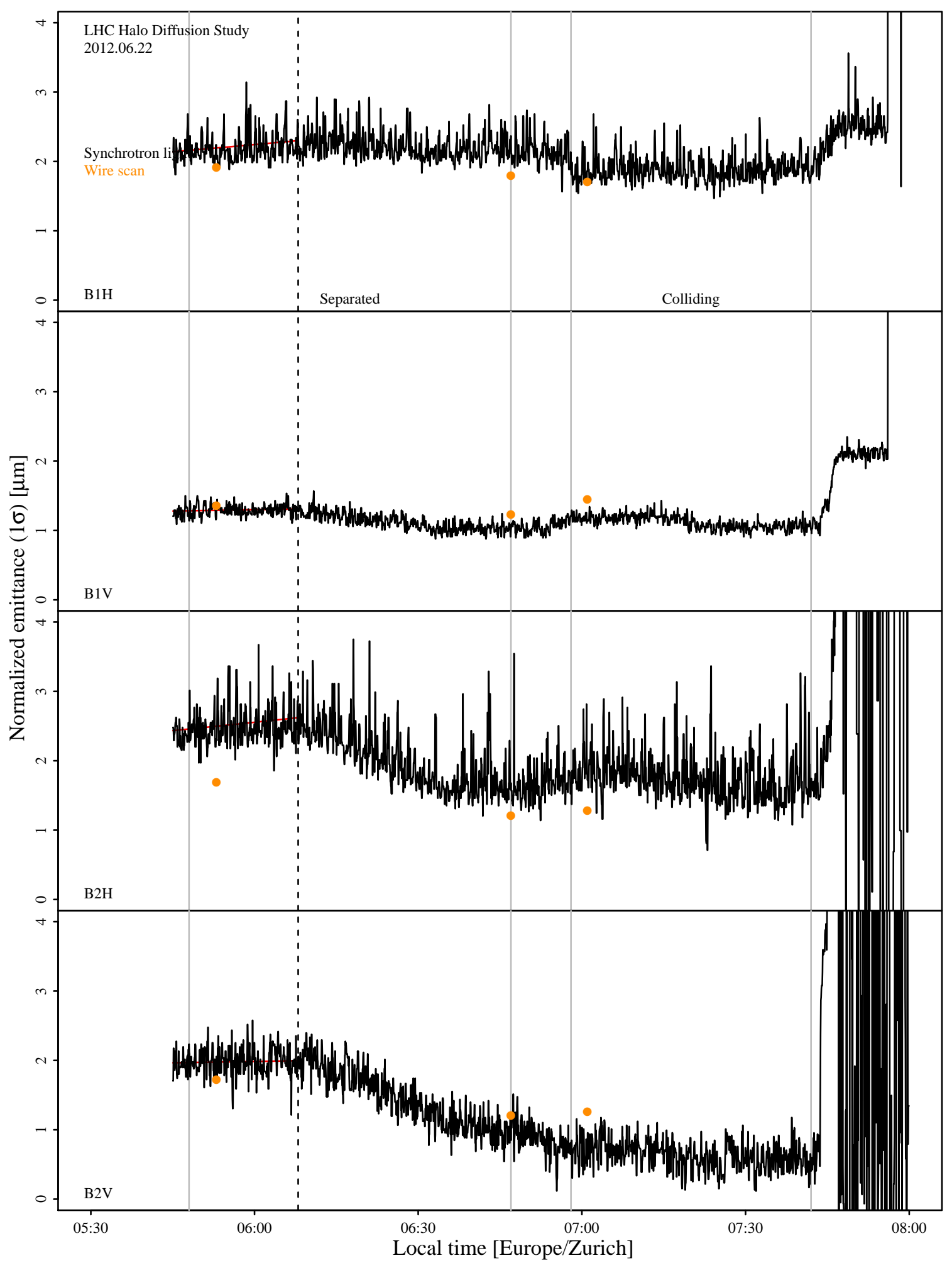

FIG. 11. Synchrotron-light and wire-scan emittances over the course of the study. 


\begin{tabular}{cccccl}
\hline \hline & $\varepsilon_{x}^{\mathrm{B} 1}[\mu \mathrm{m}]$ & $\varepsilon_{y}^{\mathrm{B} 1}[\mu \mathrm{m}]$ & $\varepsilon_{x}^{\mathrm{B} 2}[\mu \mathrm{m}]$ & $\varepsilon_{y}^{\mathrm{B} 2}[\mu \mathrm{m}]$ & Notes \\
\hline $05: 53$ & 1.92 & 1.36 & 1.69 & 1.73 & Squeezed, separated beams, before scrape \\
$06: 47$ & 1.8 & 1.23 & 1.2 & 1.21 & Squeezed, separated beams, after scrape \\
$07: 01$ & 1.71 & 1.45 & 1.28 & 1.26 & Colliding beams, before scrape \\
\hline \hline
\end{tabular}

TABLE II. Normalized, $1 \sigma$ wire-scan emittances.

\begin{tabular}{lccccccccccc}
\hline \hline & $\varepsilon_{\mathrm{ws}}[\mu \mathrm{m}]$ & $\delta \varepsilon_{\mathrm{ws}}[\mu \mathrm{m}]$ & $\varepsilon_{\mathrm{sl}}[\mu \mathrm{m}]$ & $\delta \varepsilon_{\mathrm{sl}}[\mu \mathrm{m}]$ & $\varepsilon[\mu \mathrm{m}]$ & $\delta \varepsilon[\mu \mathrm{m}]$ & $\gamma[1 / \mathrm{s}]$ & $\delta \gamma[1 / \mathrm{s}]$ & $D^{\prime}[\mu \mathrm{m} / \mathrm{s}]$ & $\delta D^{\prime}[\mu \mathrm{m} / \mathrm{s}]$ \\
\hline B1.h & 1.92 & 0.013 & 2.15 & 0.0096 & 2.03 & 0.07 & $5.23 \mathrm{e}-05$ & $1.5 \mathrm{e}-05$ & $2.49 \mathrm{e}-08$ & $7.4 \mathrm{e}-09$ \\
B1.v & 1.36 & 0.002 & 1.29 & 0.0047 & 1.33 & 0.02 & $1.7 \mathrm{e}-05$ & $1 \mathrm{e}-05$ & $5.27 \mathrm{e}-09$ & $3.2 \mathrm{e}-09$ \\
B2.h & 1.69 & 0.0066 & 2.43 & 0.013 & 2.06 & 0.21 & $5.37 \mathrm{e}-05$ & $1.9 \mathrm{e}-05$ & $2.6 \mathrm{e}-08$ & $9.6 \mathrm{e}-09$ \\
B2.v & 1.73 & 0.046 & 1.98 & 0.012 & 1.85 & 0.087 & $1.1 \mathrm{e}-05$ & $1.7 \mathrm{e}-05$ & $4.79 \mathrm{e}-09$ & $7.2 \mathrm{e}-09$ \\
\hline \hline
\end{tabular}

TABLE III. Initial emittances (wire scan, synchrotron light, average), emittance growth rates $\gamma$, and core diffusion slopes $D^{\prime}$.

The model described in Section II is used to describe the step data and to extract its main parameters: the diffusion coefficients $D$ and the steady-state loss rates before and after the step, $k D A_{i}$ and $k D A_{f}$, respectively.

Initial values for the parameters are determined as follows. The steady-state rates are evaluated by averaging losses before the step (-0.5 s from the step or earlier) and after (4 s after or later). The starting point for the diffusion coefficient is the value obtained from the decay $3 \mathrm{~s}$ after the step $($ losses $\approx 1 / \sqrt{t})$. The time of the step, $t_{0}$, is known from the time stamps of the collimator position (1 s resolution) and from the increase in losses (1/12.5 Hz resolution). The duration of the step $\Delta t$ is estimated from the step size and the nominal jaw speed, $2 \mathrm{~mm} / \mathrm{s}$. (This may not be accurate for small steps.) Step time and duration can also be left as free parameters within some reasonable limits.

The distribution of the response variable (loss rate) is not Gaussian, as one can see for instance from Figure 7, because of instrumental effects (such as beam jitter and mechanical vibrations) and because of the Poissonian nature of the shower process. For this reason, fit parameters are determined by minimizing not a $\chi^{2}$, but the sum of absolute deviations of the model from the data (robust estimation). For the same reson, a first estimate of the statistical errors comes from the Hessian matrix of the $\chi^{2}$ function, but the final error analysis is done by bootstrapping. For each step, bootstrapping is done by resampling the data points with replacement and repeating the fit 
18 times with the same initial parameters. The final results are the median of the fit results and the uncertainties come from their spread.

From the diffusion model fits to the loss rate evolution, one can calculate the particle fluxes

$$
\phi=(k D A) / k
$$

where the parameter $(k D A)$ comes from the fit, and the value of $k$ is taken from the loss rate calibration (Figures 9 and 10).

In the diffusion model, the steady-state beam density distribution $\left(\partial_{t} f=0\right)$ for a given collimator position is a function of the particle flux at the collimator and of the diffusion coefficient as a function of amplitude:

$$
f\left(J_{a}, J\right)=\phi_{a} \int_{J}^{J_{a}} \frac{1}{D\left(J^{\prime}\right)} d J^{\prime}
$$

\section{RESULTS}

\section{A. Diffusion Coefficients}

The results of the fits are plotted in Appendix A and listed in Table V of Appendix C. Not all fits converged during this preliminary analysis. Moreover, in some cases, the model cannot explain the first few seconds of losses after the step. This seems to be due to the losses decaying differently from $1 / \sqrt{t}$, as shown in the first column of diagnostic plots (Appendix A). This fact could be a combination of instrumental effects (the details of the collimator movement) and pure beam removal/cleaning. But, in general, by looking at all 239 steps, the model seems to reproduce the main features of the loss evolution with time quite well.

The diffusion coefficients as a function of action are shown in Figure 12 for all 4 cases: horizontal and vertical, separated and colliding beams. In the horizontal plane, there seems to be little difference between the separated and colliding cases. In the vertical plane, collisions enhance diffusion by about 2 orders of magnitude. A significant systematic effect are the larger diffusion rates obtained from the outward steps. They are not understood, but are probably due to the fact that, after scraping, a different, quickly-diffusing beam population is being sampled.

The grey curves in Figure 12 are not an interpolation of the data: they represent the dependence $D(J)$ that one would obtain from the core emittance growth rates (Table III). This comparison allows one to draw several conclusions: (1) the diffusion rates measured with the collimator scan technique have reasonable values; (2) without collisions, the beam halo in the LHC diffuses almost 


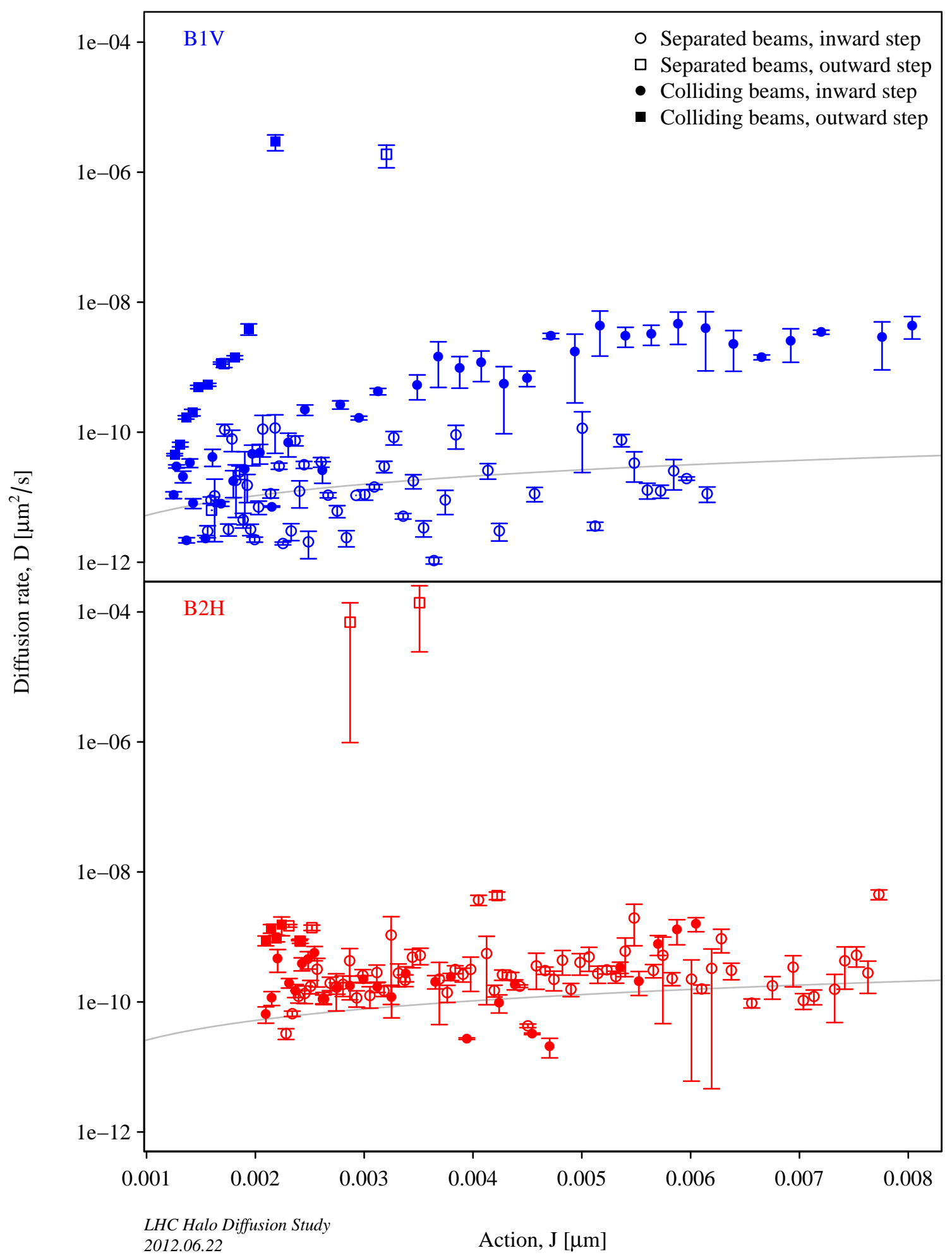

FIG. 12. Diffusion coefficient vs. action from the collimator scan (points) compared with the expectation from core emittance growth rates (lines). 


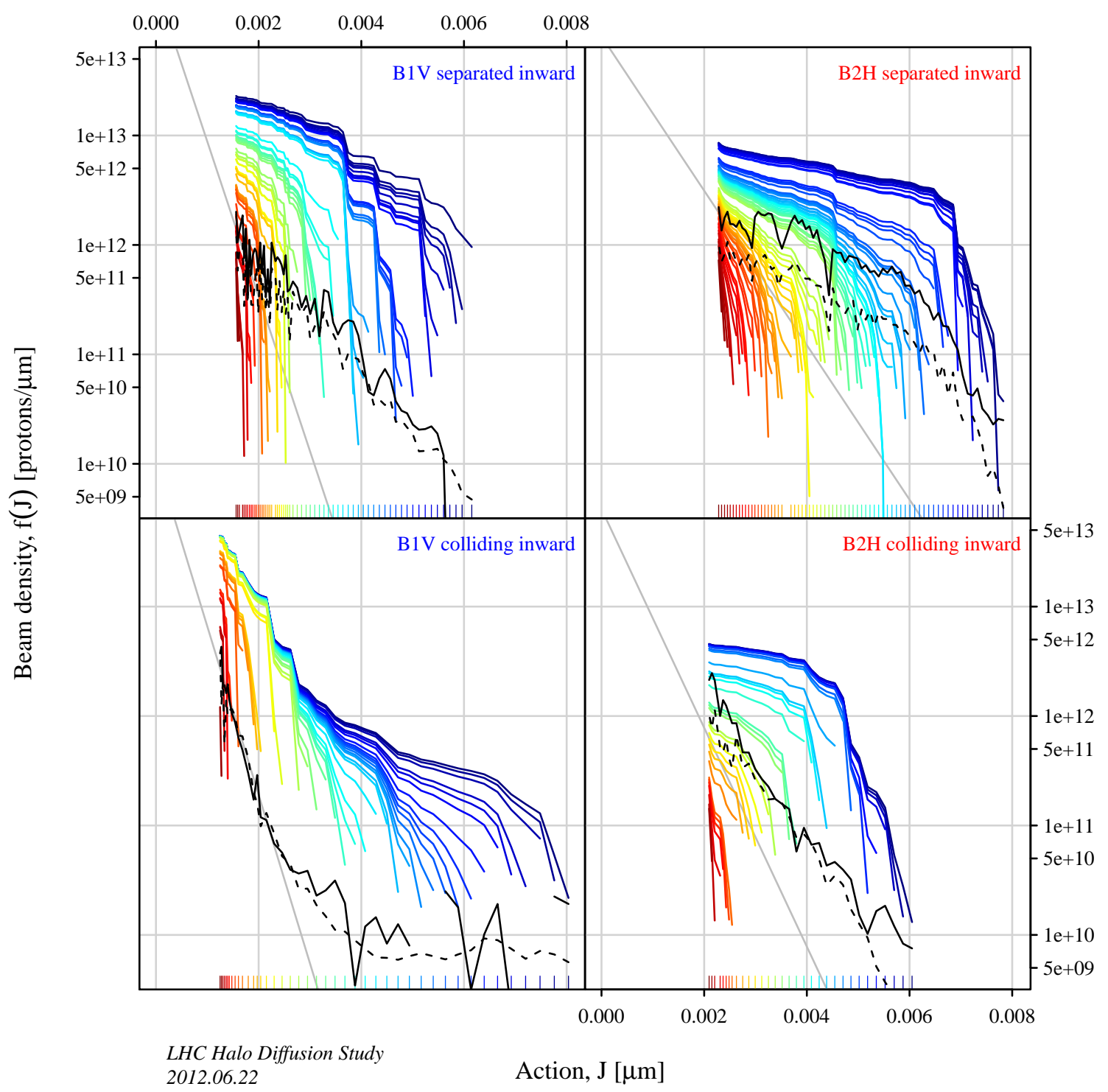

FIG. 13. Calculated beam distributions as a function of collimator position during the inward scans: from intensity loss (solid black); from integrated losses (dashed black); from the diffusion coefficient, unnormalized (from blue to red). The gray line denotes a Gaussian core with the measured beam emittance. The colored vertical tick marks indicate the corresponding collimator positions.

like the core up to large amplitudes; (3) no significant dynamic aperture effects (sharp rises in diffusion rate) are observed in the amplitude range explored in these experiments.

\section{B. Halo Population}

In the approximation of static beam distributions, the beam densities can be calculated from the measured intensity loss during a short interval (4 $\mathrm{s}$ in this analysis) centered around the collimator 
movement. The results are shown in Figure 13 (solid black lines). Similar results are obtained by integrating the calibrated losses over the same short interval (Figure 13, dashed black lines). For comparison, a Gaussian core with the measured beam emittance is also shown in Figure 13 (gray line). It is interesting to note the depletion in the case of collisions compared with separated beams.

In the diffusion model, beam distributions evolve with the collimator position. The collimator determines the boudary condition for the density $\left(f\left(J_{c}\right)=0\right)$. Densities as a function of collimator position are calculated according to Eq. 5. Figure 13 shows the results (not normalized, for the moment). One can see how the distribution is cut as the collimators move in. Apart from the arbitrary normalization factor, the initial distributions (in blue) exibit trends similar to the ones deduced from intensities and losses.

\section{Impact parameter distributions}

To do: impact parameter distribution from diffusion coefficients, following Ref. [12].

\section{Beam Jitter}

The time structure of losses with tight collimator settings is a sensitive probe of beam vibrations. As an example, Figure 14 shows the fast Fourier transform spectrum of losses when the collimator positions were closer than $3.75 \sigma$. In the horizontal plane, a sharp line around $5.8 \mathrm{~Hz}$ is visible. The vertical plane shows some activity around $2 \mathrm{~Hz}$ and a prominent peak at $4.6 \mathrm{~Hz}$. In the Tevatron, the latter peak was also present. It was attributed to mechanical vibrations of the compressors in the Central Helium Liquefier. Does the LHC cryogenic system operate at similar frequencies?

By comparing the amplitude of the peaks with the amplitude of the DC component and of the loss spikes for a known collimator step, one may estimate the amplitude of these vibrations. A rough calibration indicates amplitudes of at least a few nanometers at the collimator jaw.

\section{CONCLUSIONS}

For the first time in the LHC, transverse beam halo diffusion rates were measured. Separated beam exibited a slow halo diffusion, comparable with the emittance growth from the core. No dynamic aperture effects were observed up to about $7 \sigma$. This can be interpreted as a confirmation 


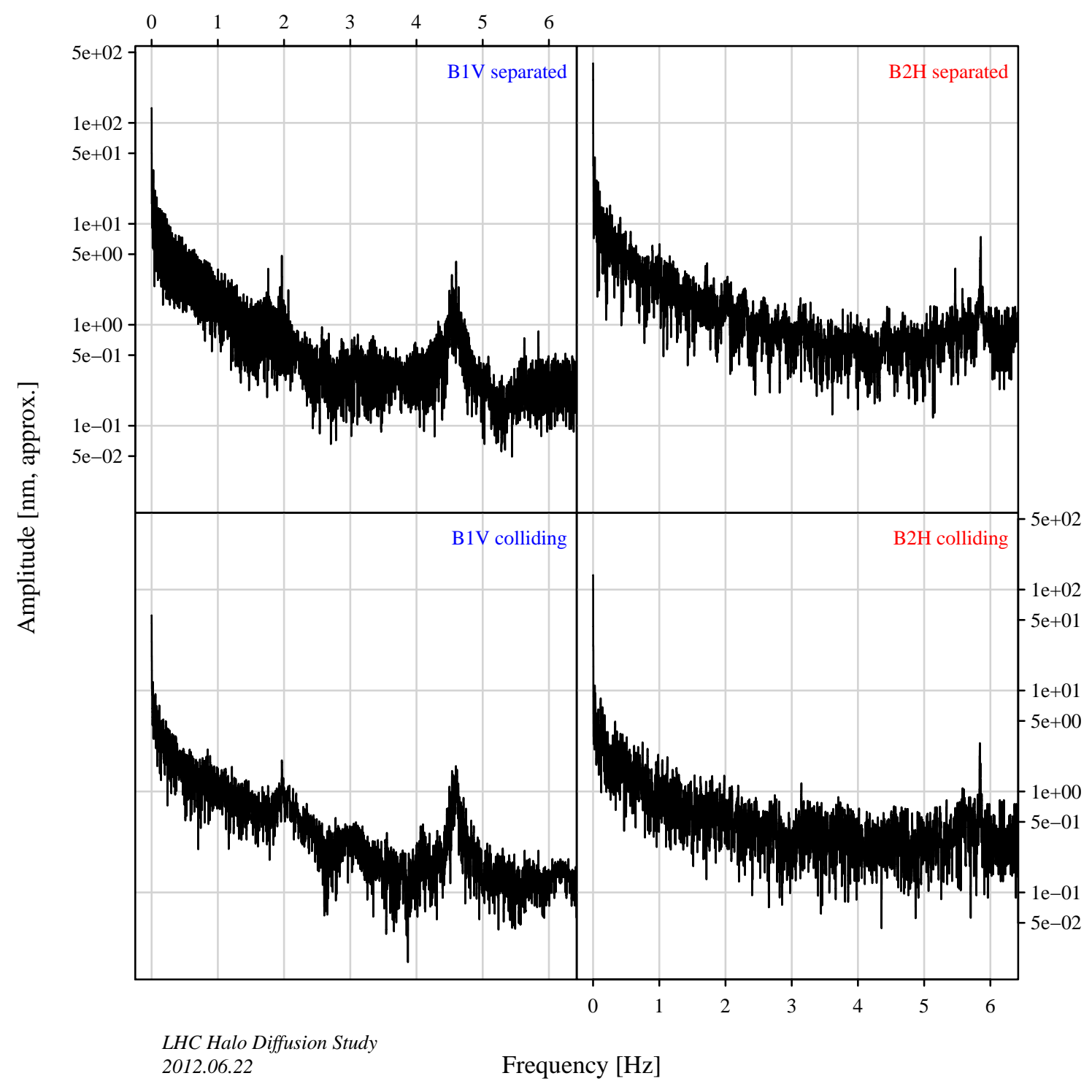

FIG. 14. Beam jitter FFTs.

of the extremely good quality of the magnetic fields in the machine. Collisions enhanced halo diffusion in the vertical plane by about 2 orders of magnitude.

From the measured diffusion coefficents, estimates of beam impact parameters on the primary collimator jaws are possible (work in progress).

Beam population measurements exposed the presence and magnitude of non-Gaussian tails.

The frequency spectrum of losses with tight collimator settings was used as a very sensitive probe of low-frequency beam vibrations, showing clear indications of small beam jitter of a few nanometers in amplitude.

These measurements shed light on the relationship between halo population and dynamics, 
emittance growth, beam lifetime, and collimation efficiency. They are also important inputs for collimator system design and upgrades, including new methods such as crystal channeling or hollow electron lenses.

\section{ACKNOWLEDGMENTS}

These measurements would not have been possible without the help of the LHC operators on shift during the experiments: S. Cettour Cave, A. MacPherson, D. Jacquet, and M. Solfaroli. R. De Maria provided the software infrastructure to acquire beam current data at high frequency.

Fermi Research Alliance, LLC operates Fermilab under Contract No. DE-AC02-07CH11359 with the United States Department of Energy. 
Appendix A: Diagnostic plots
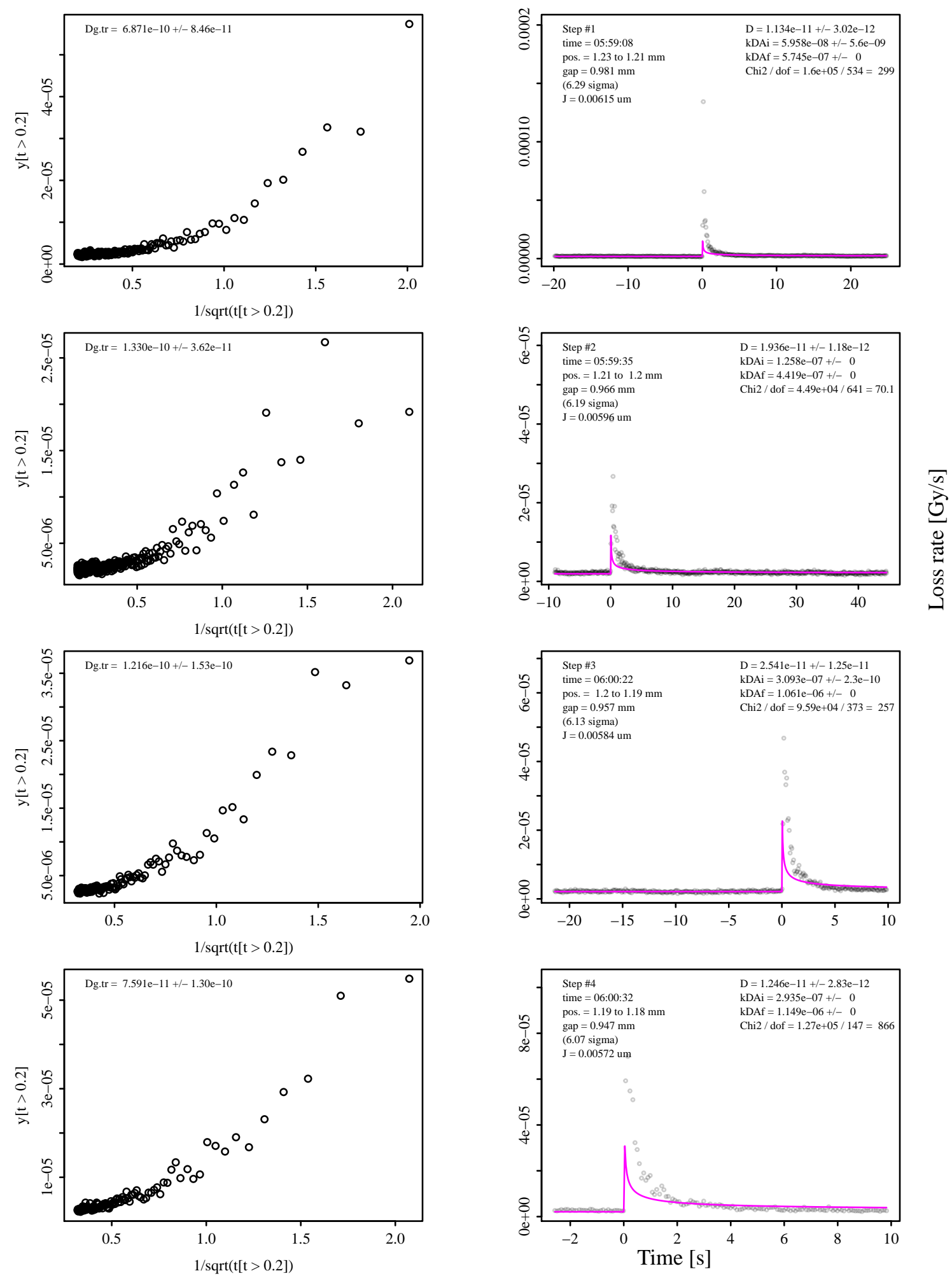

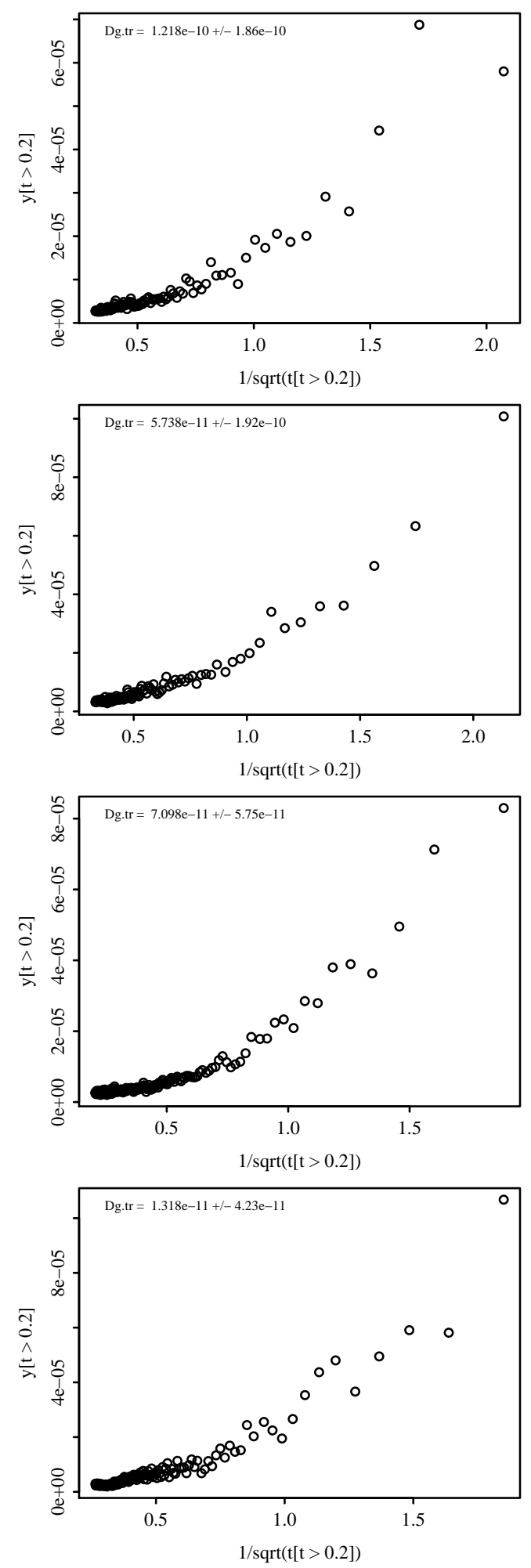
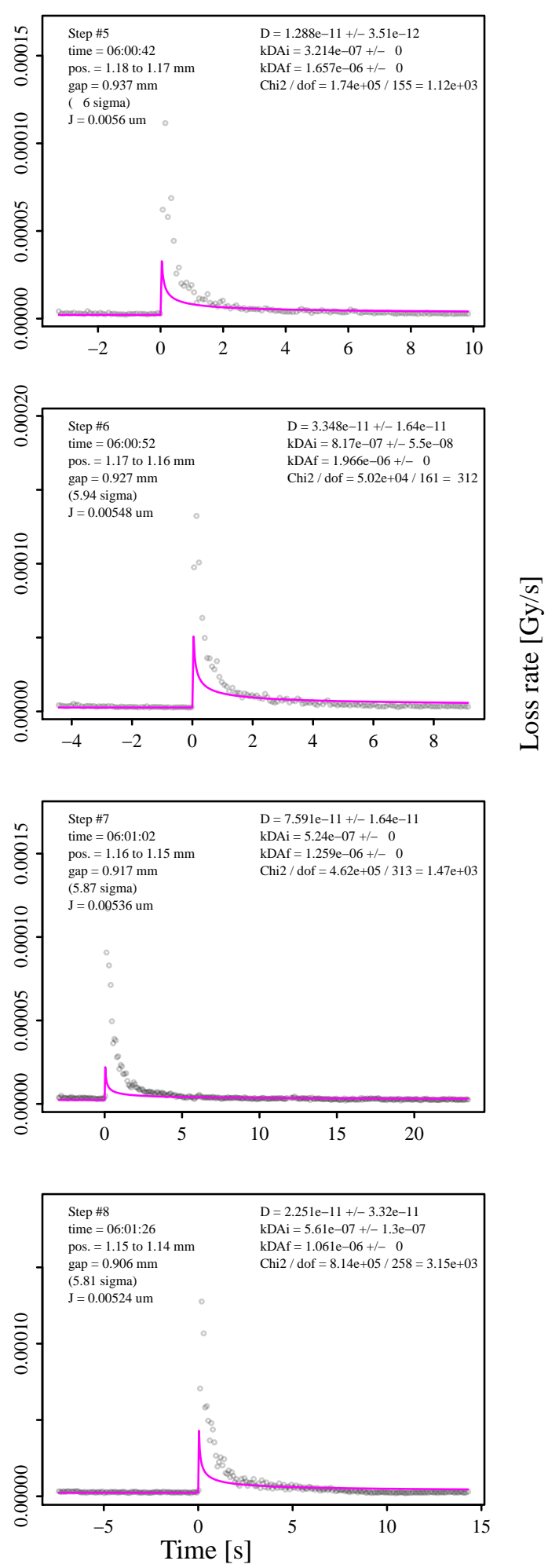

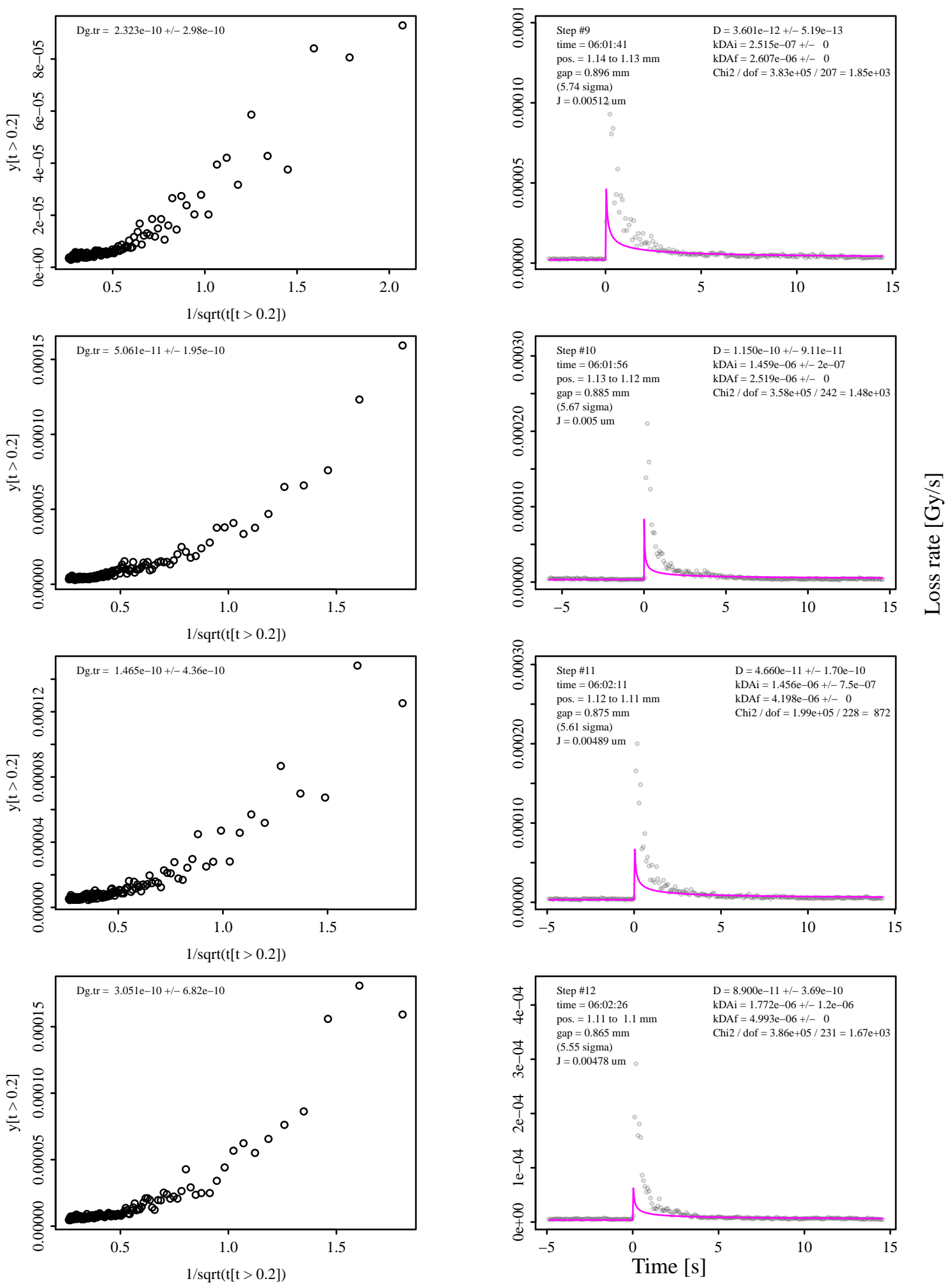

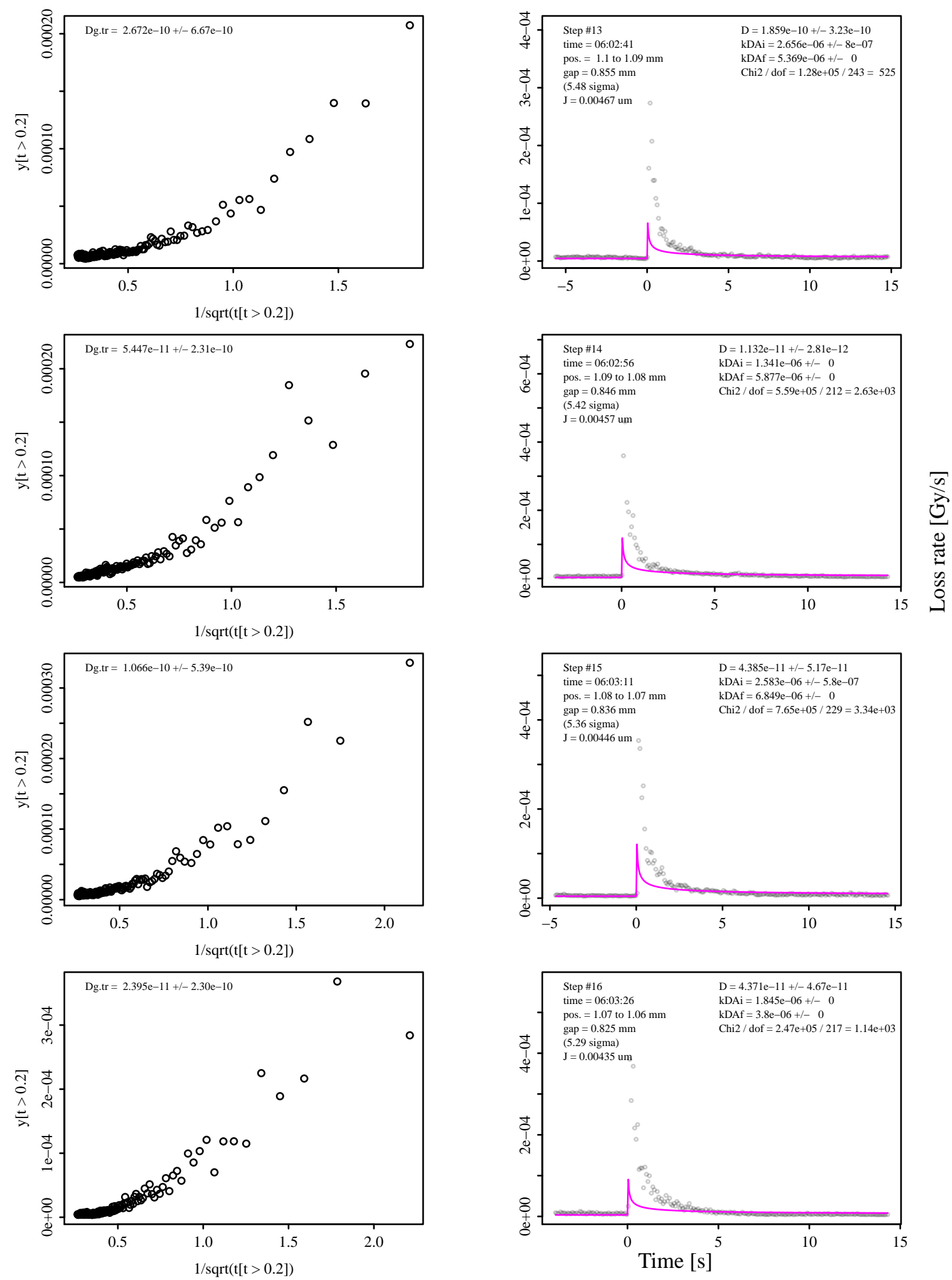

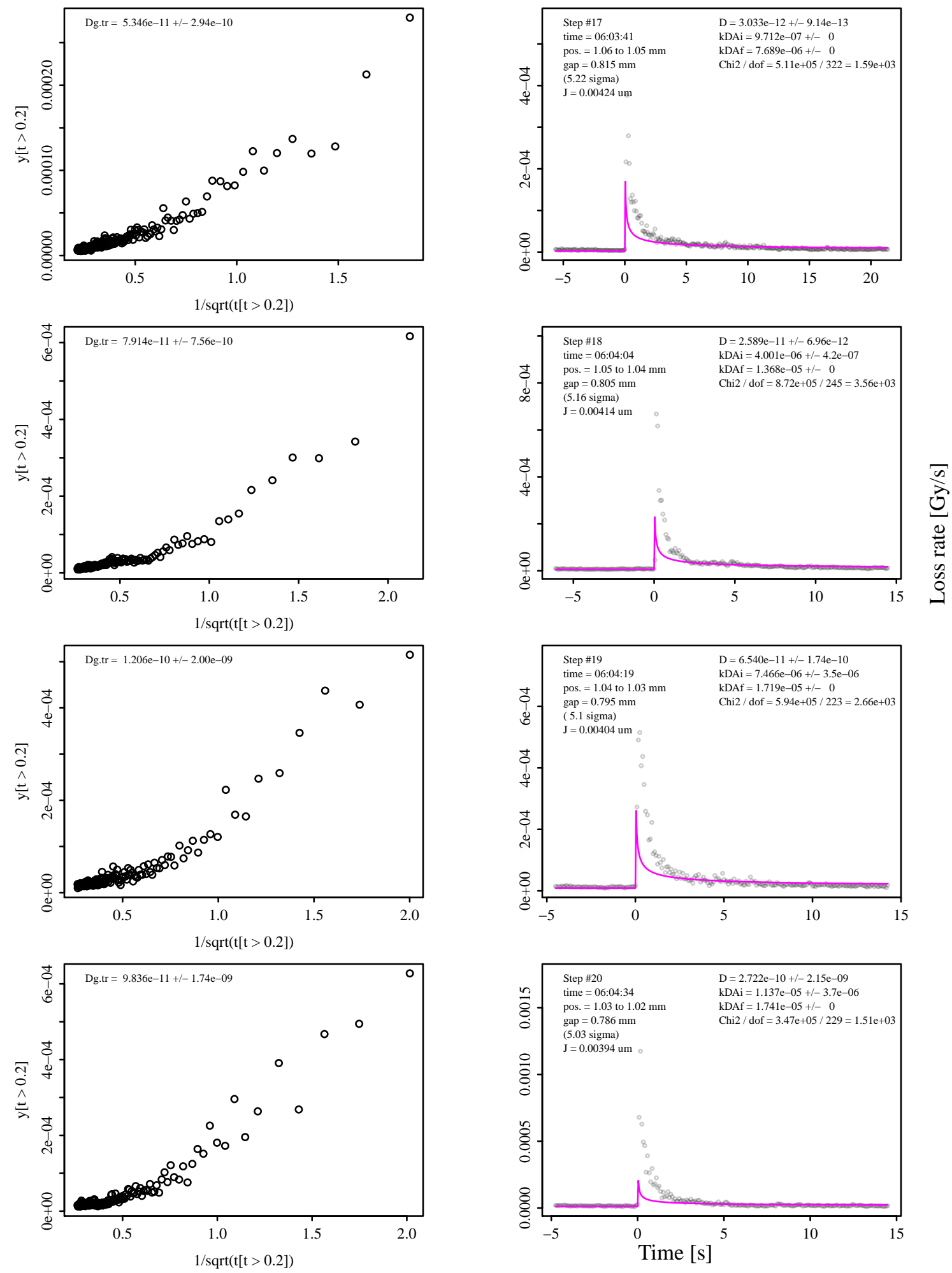

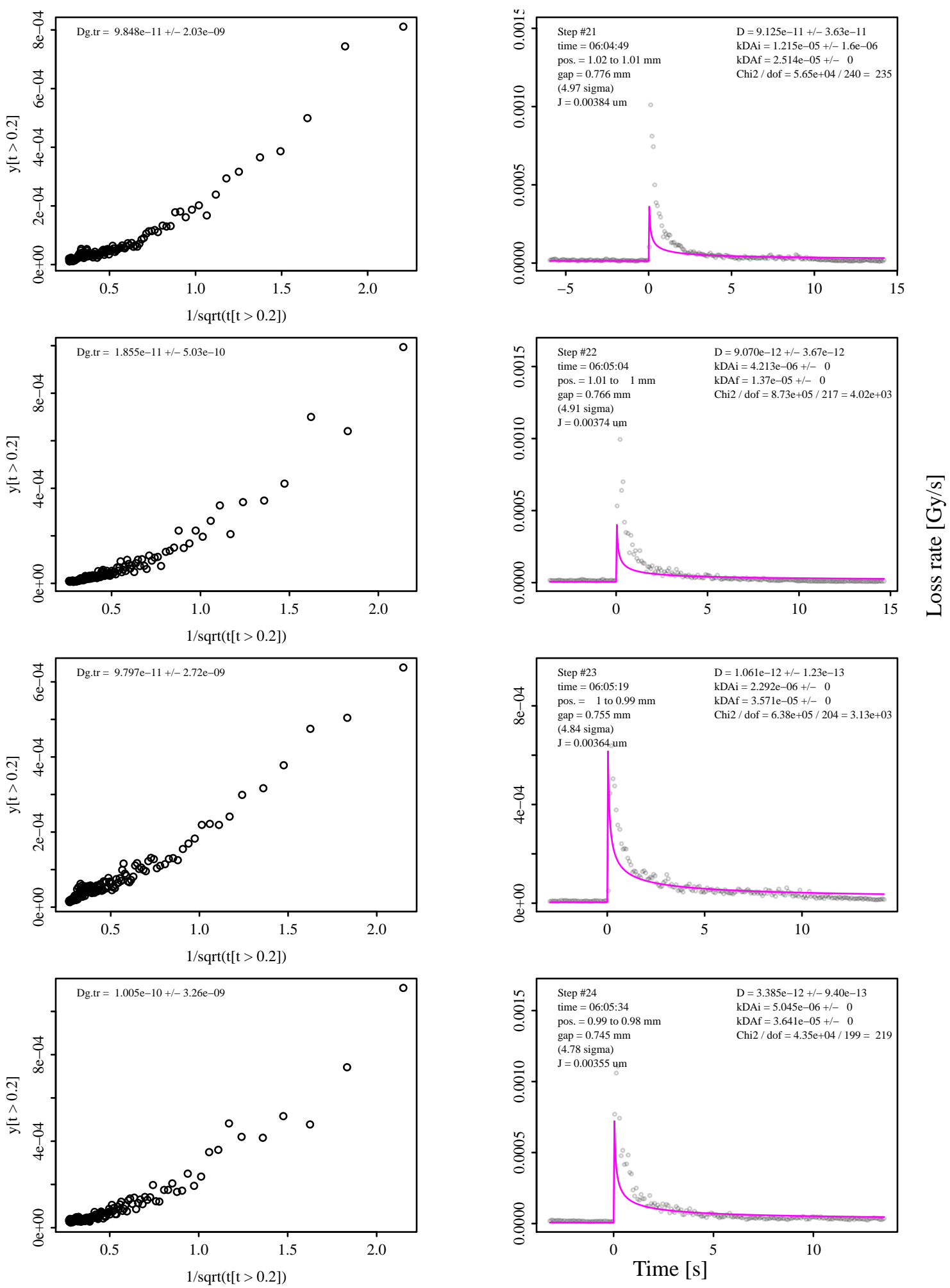

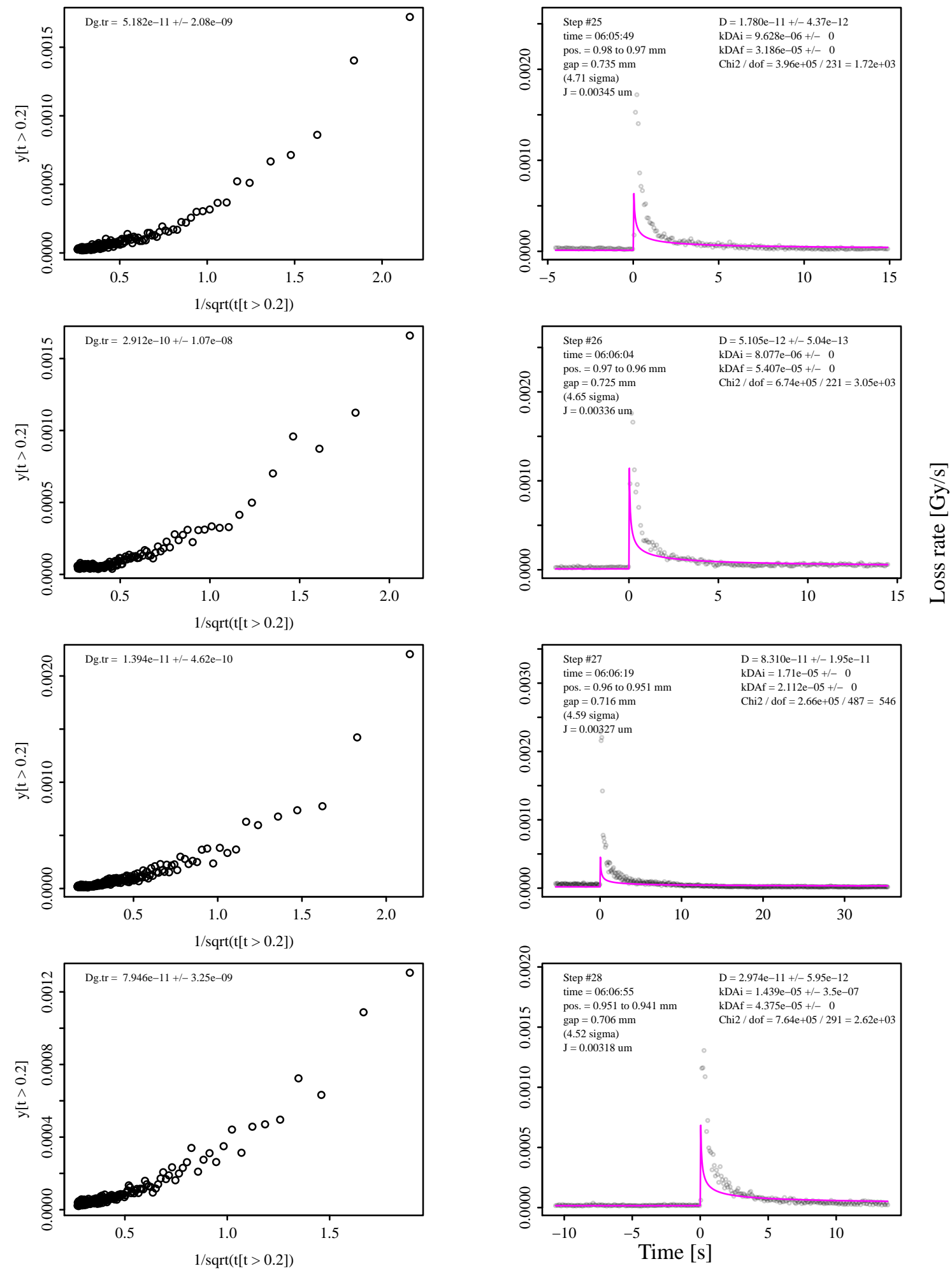

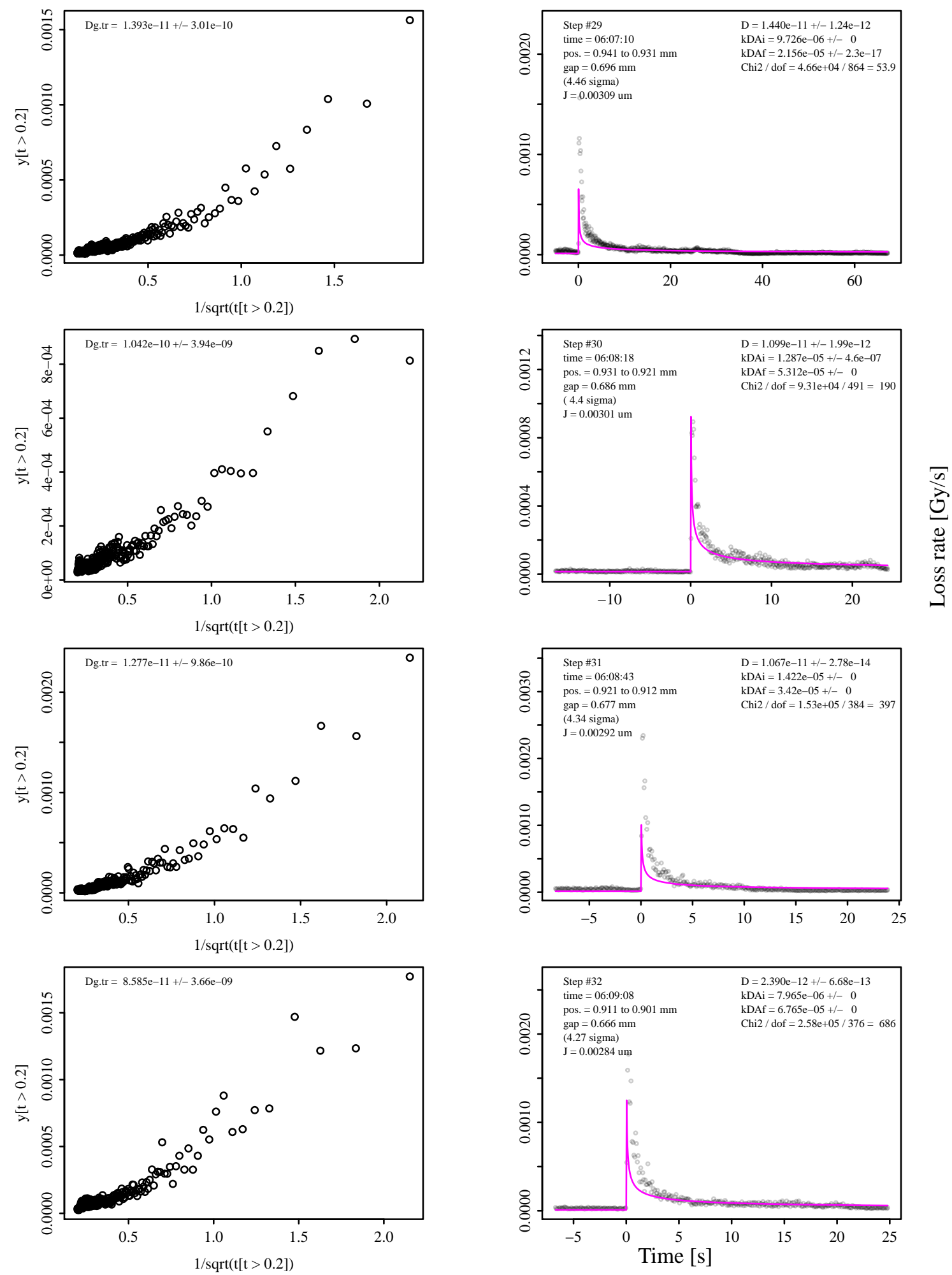

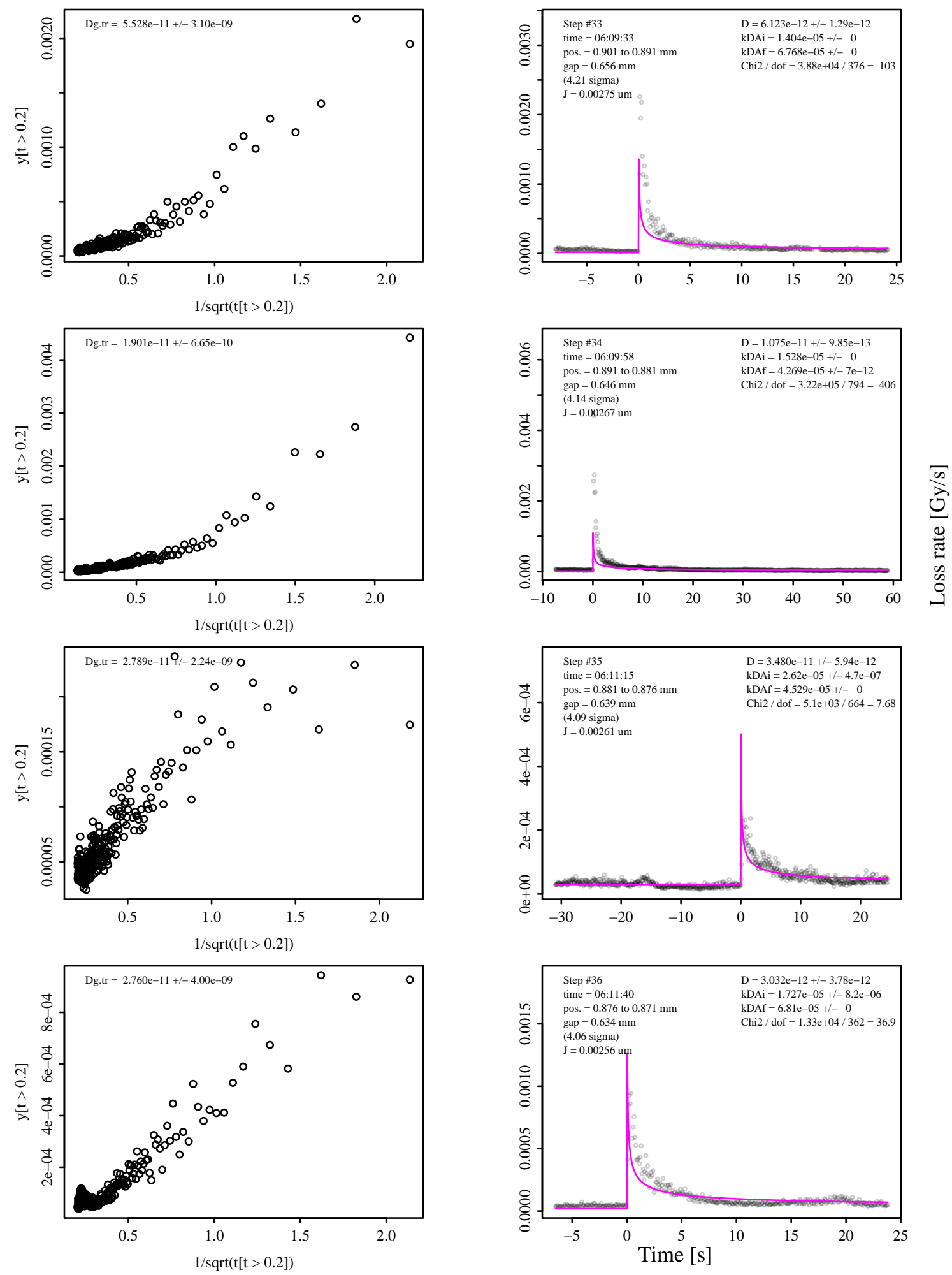

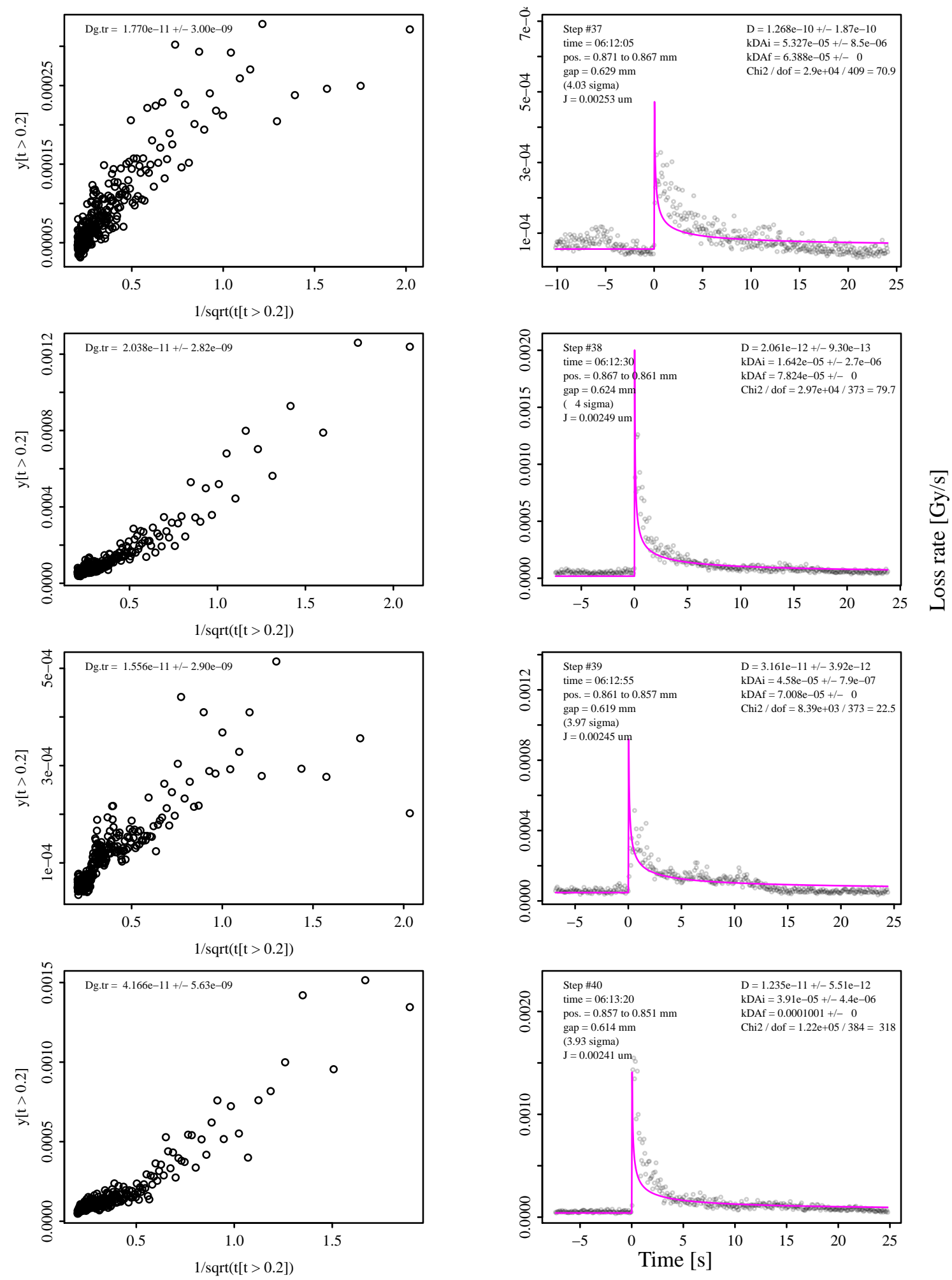

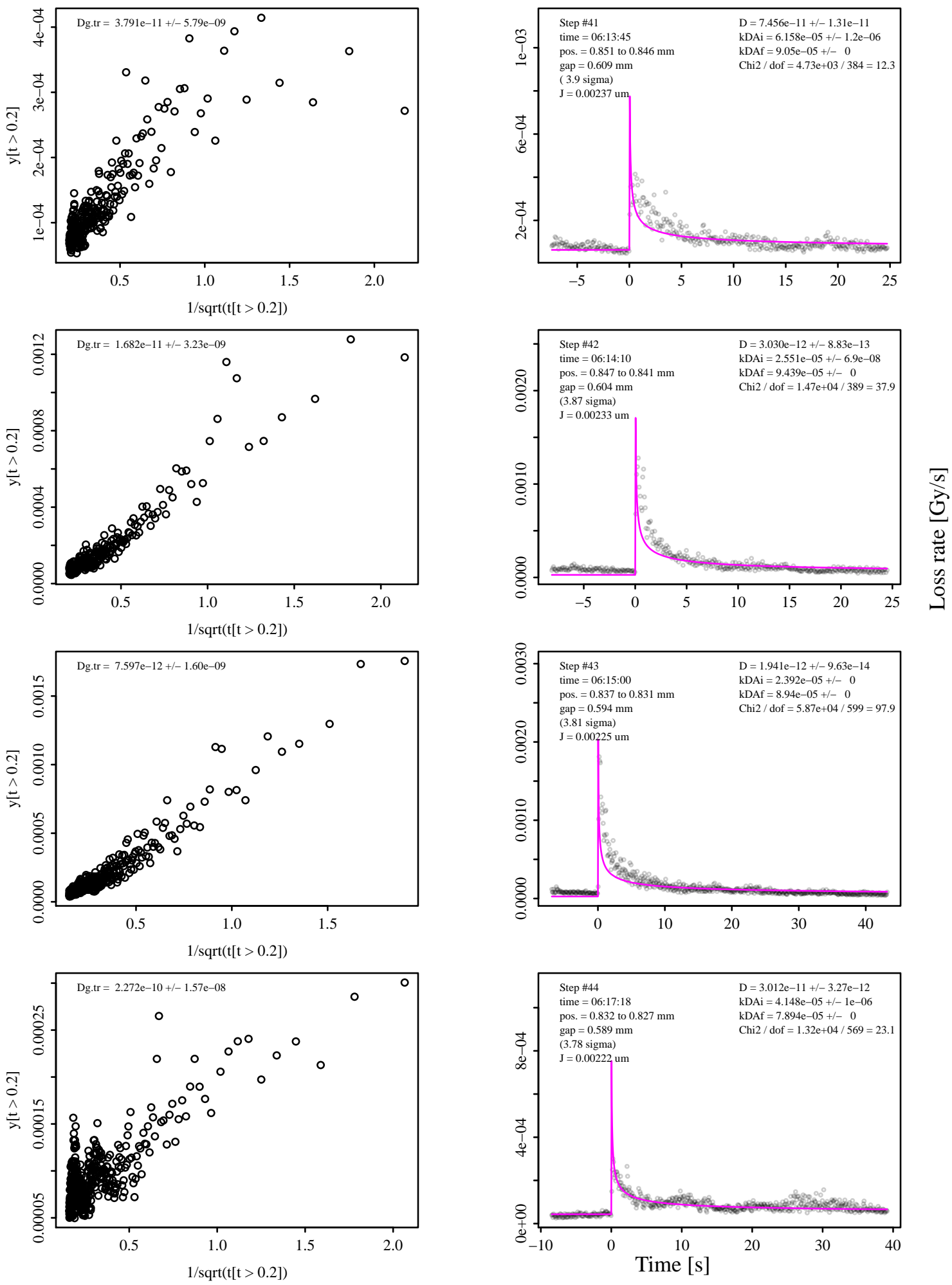

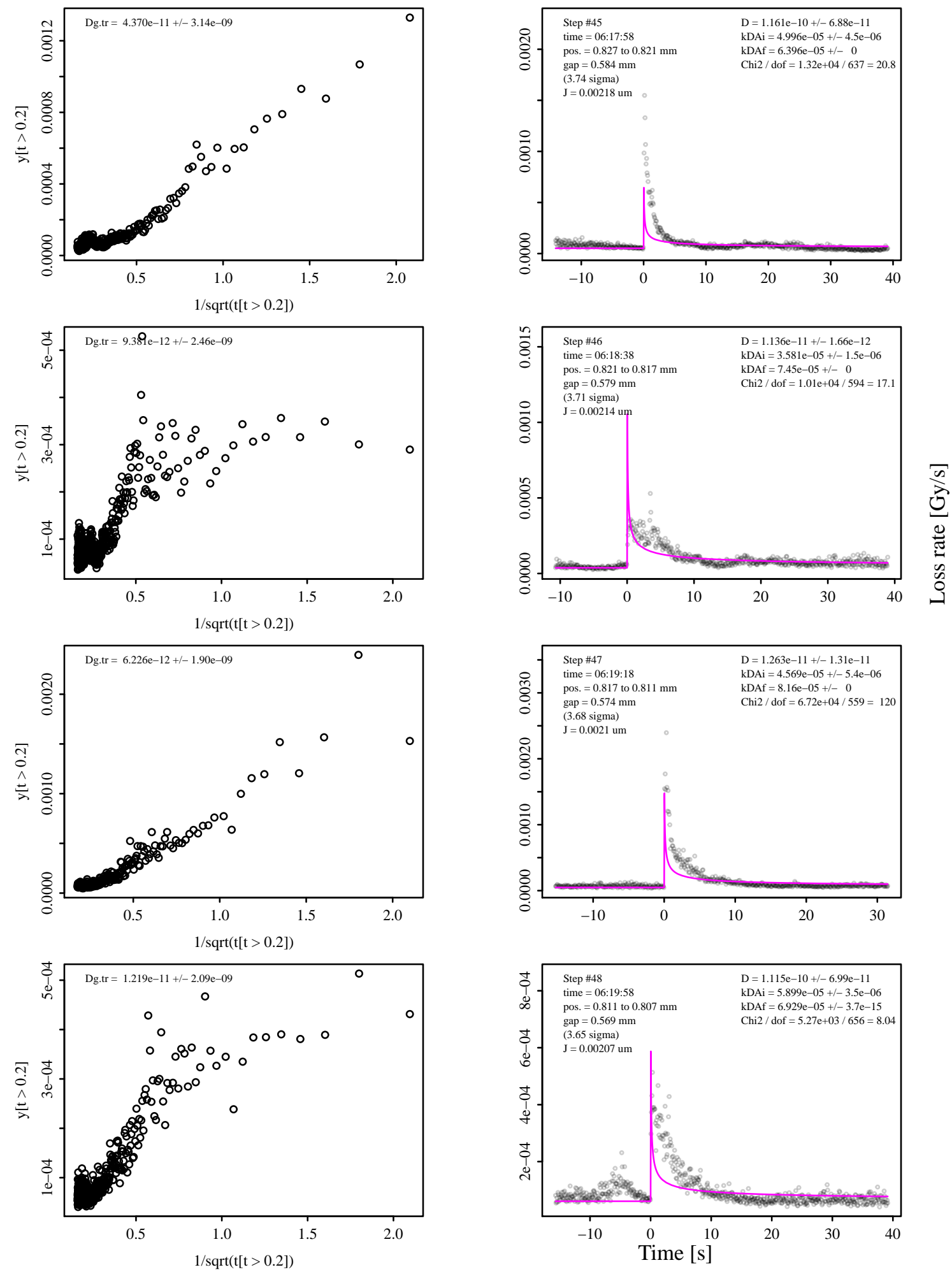

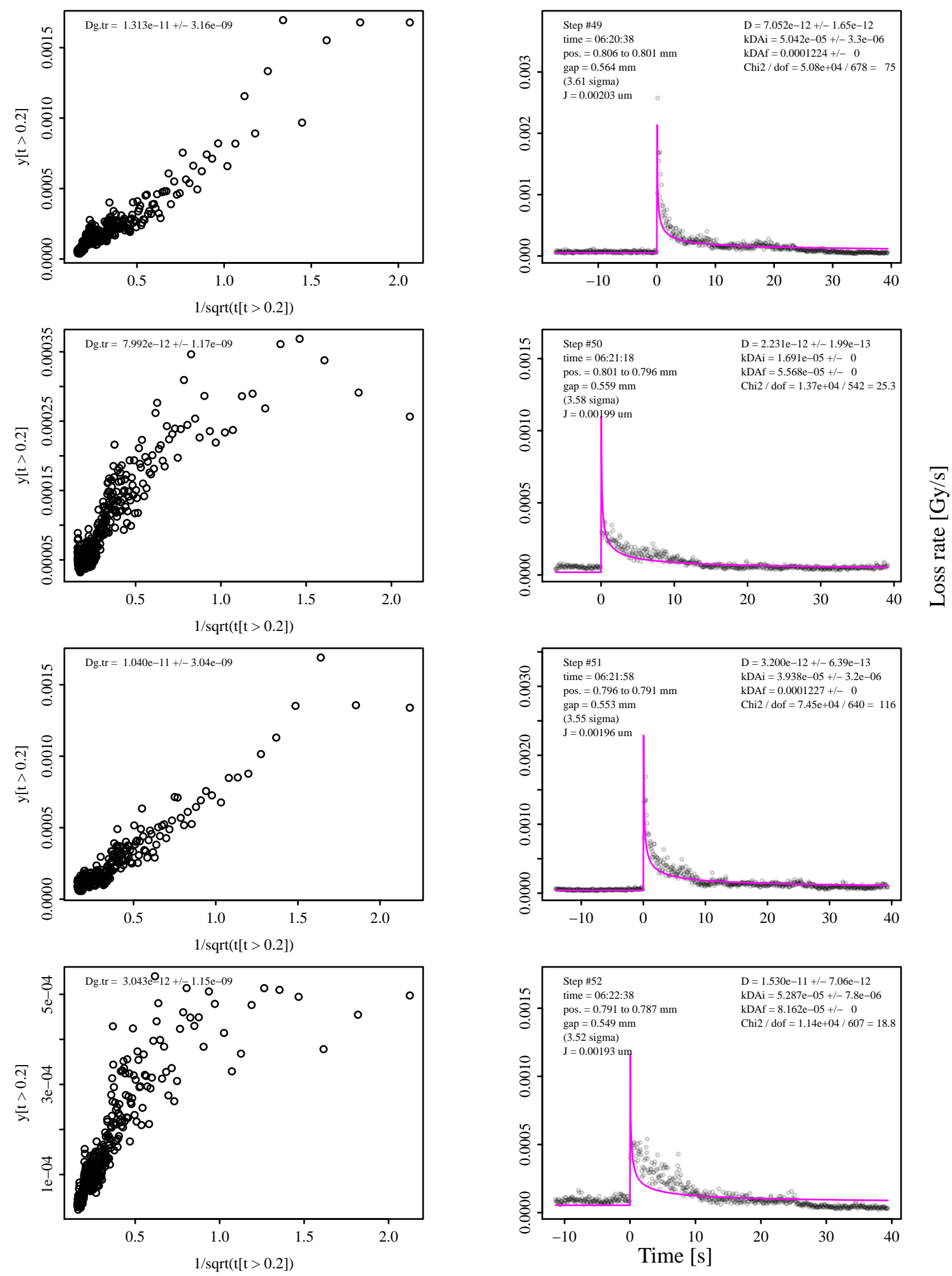

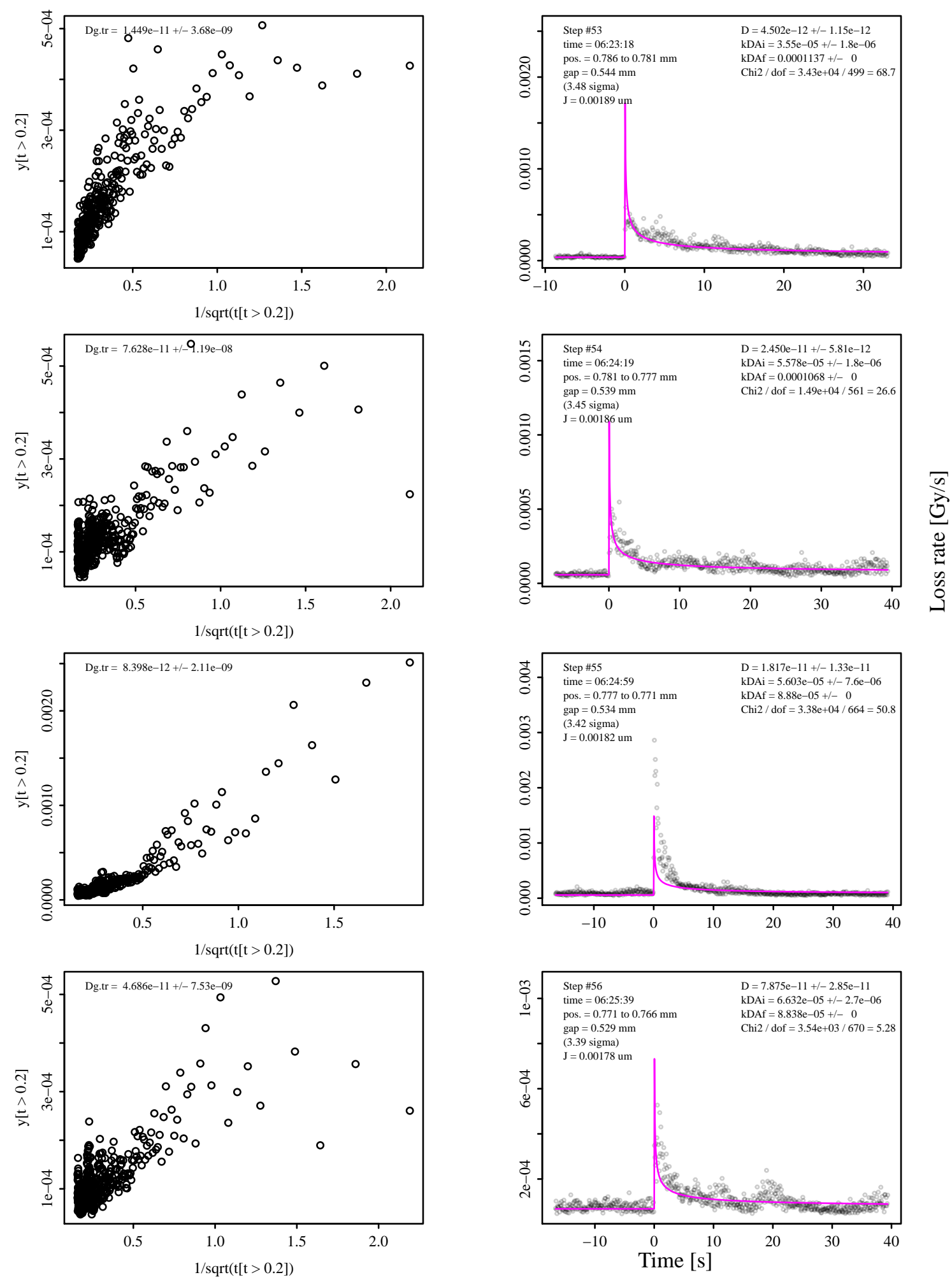

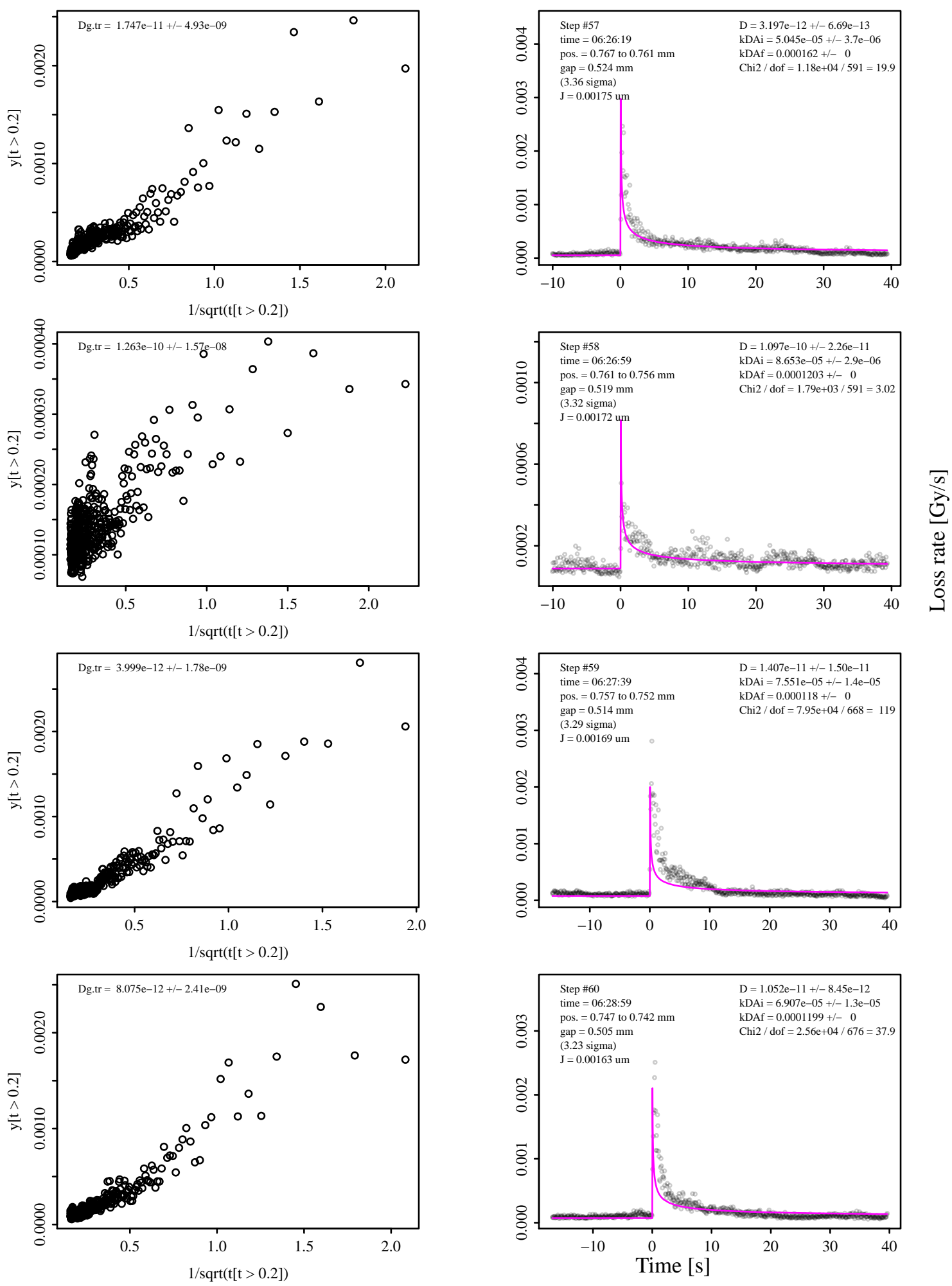

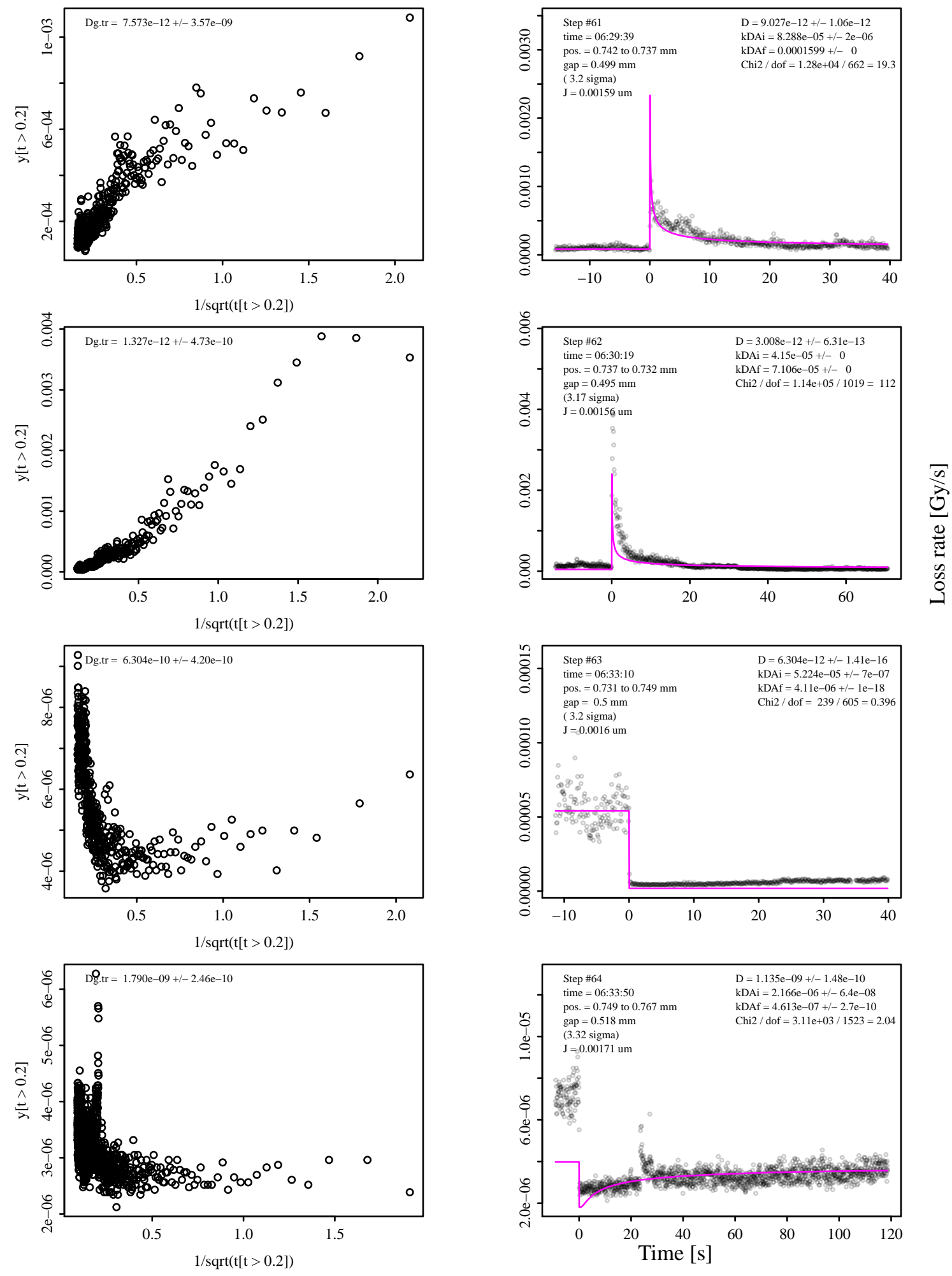

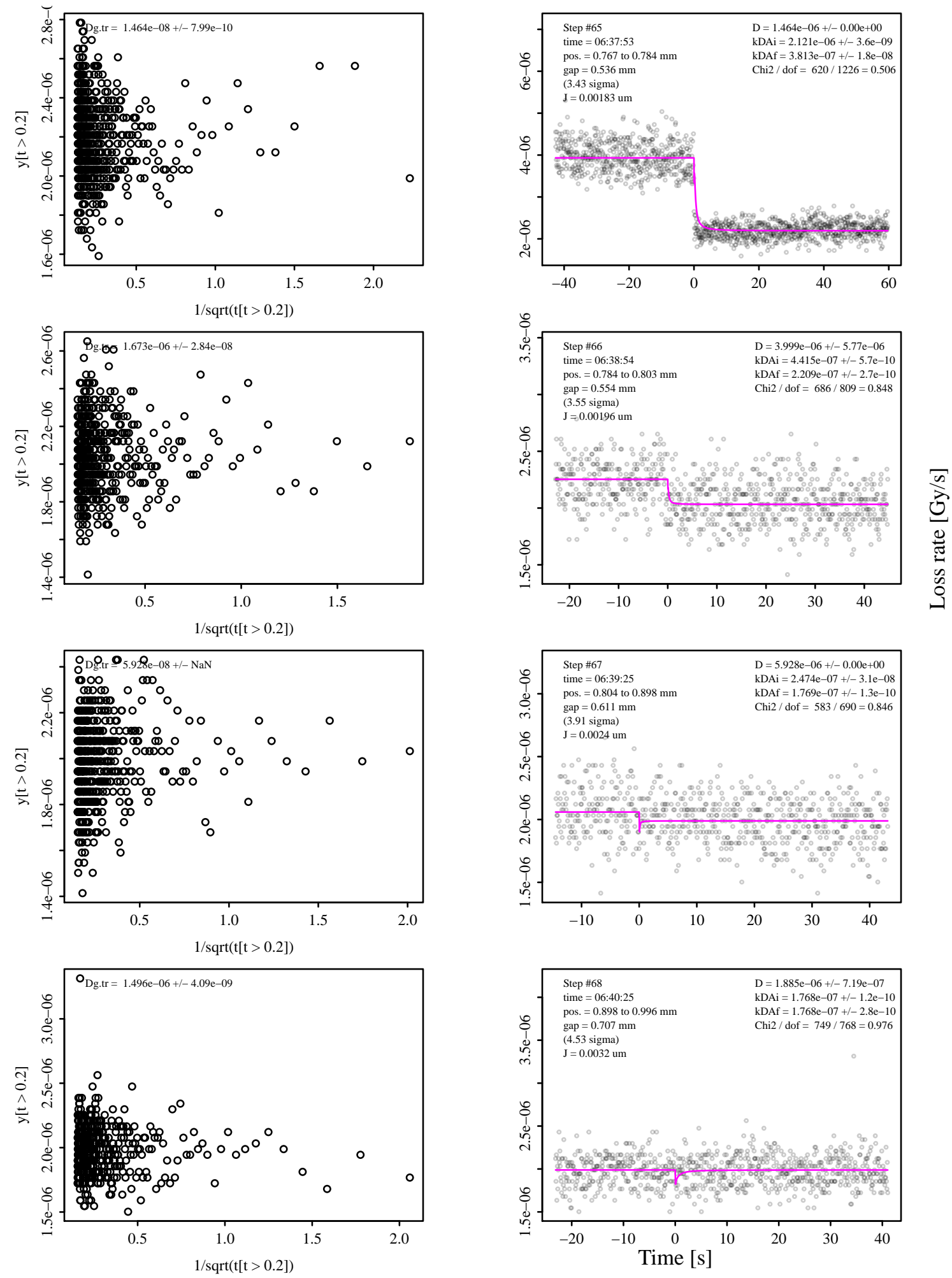

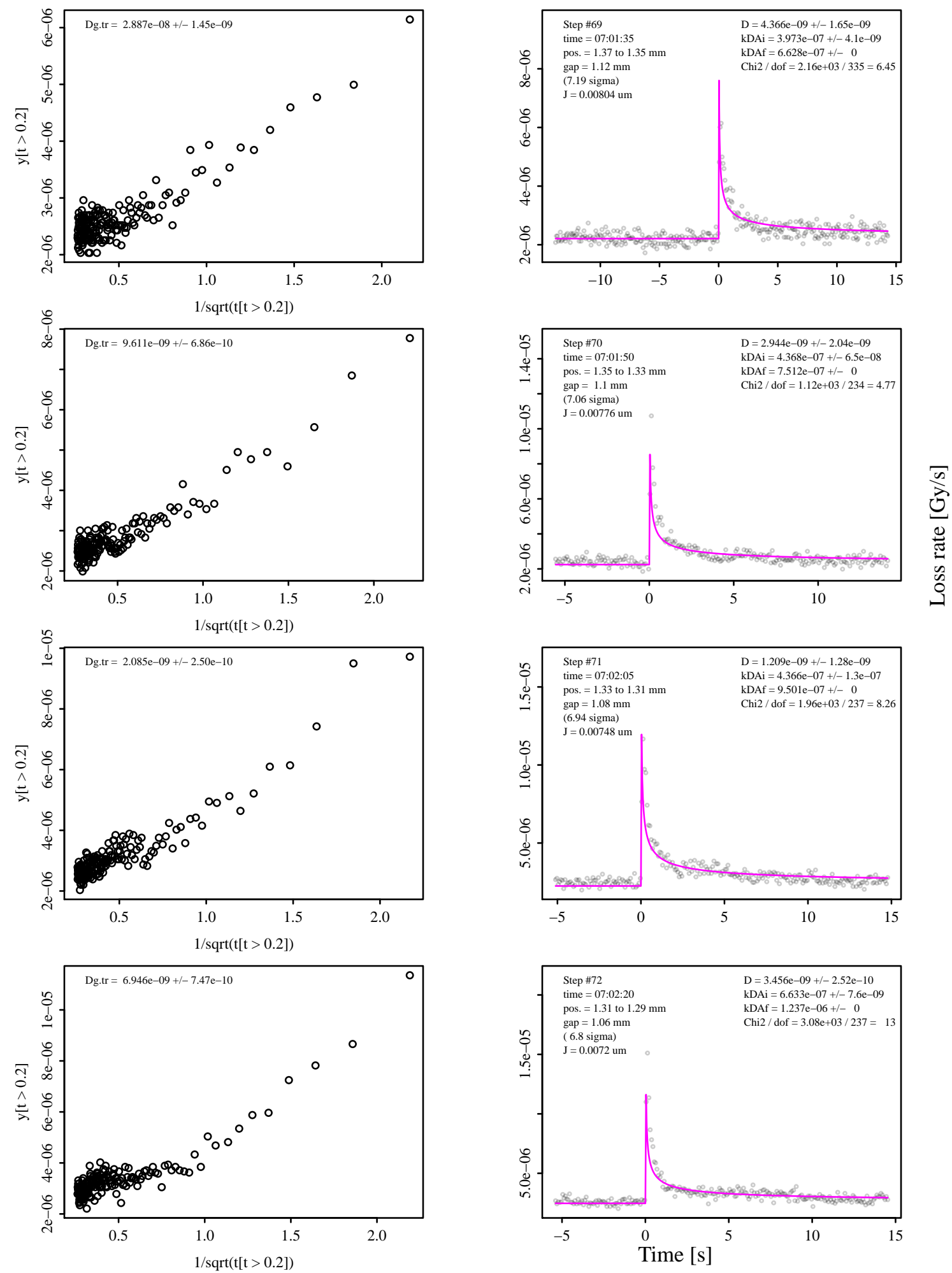

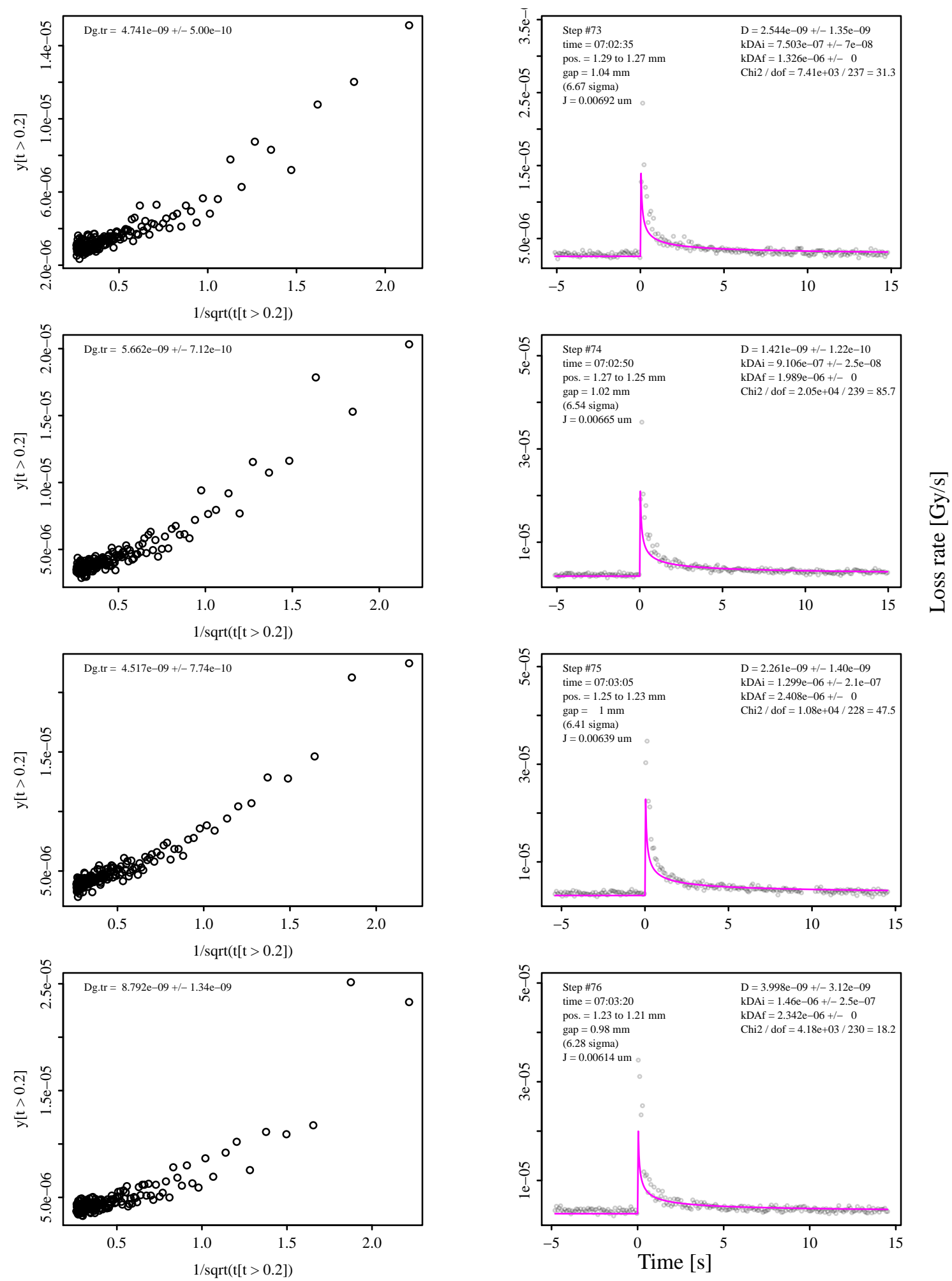

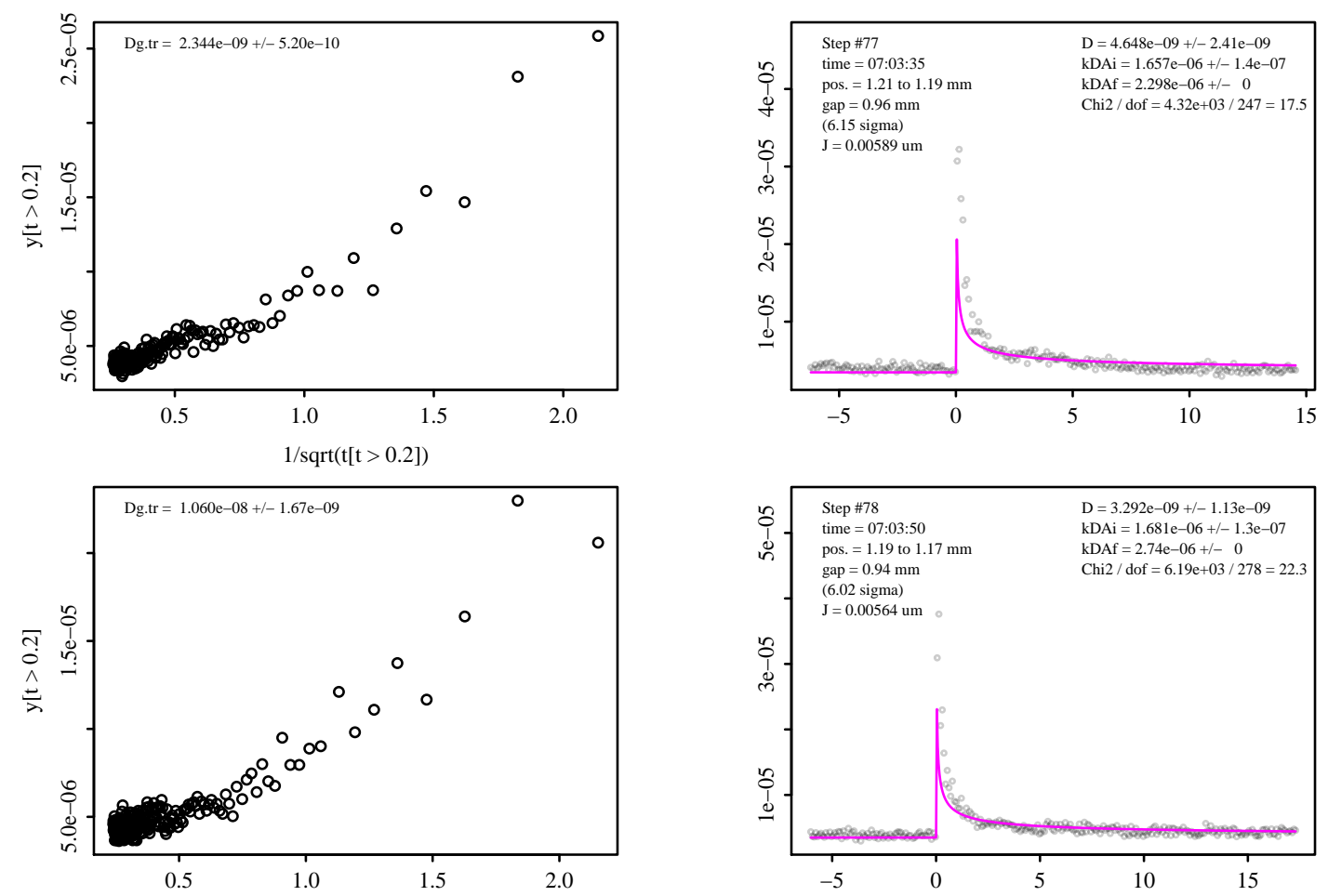

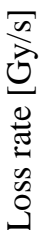
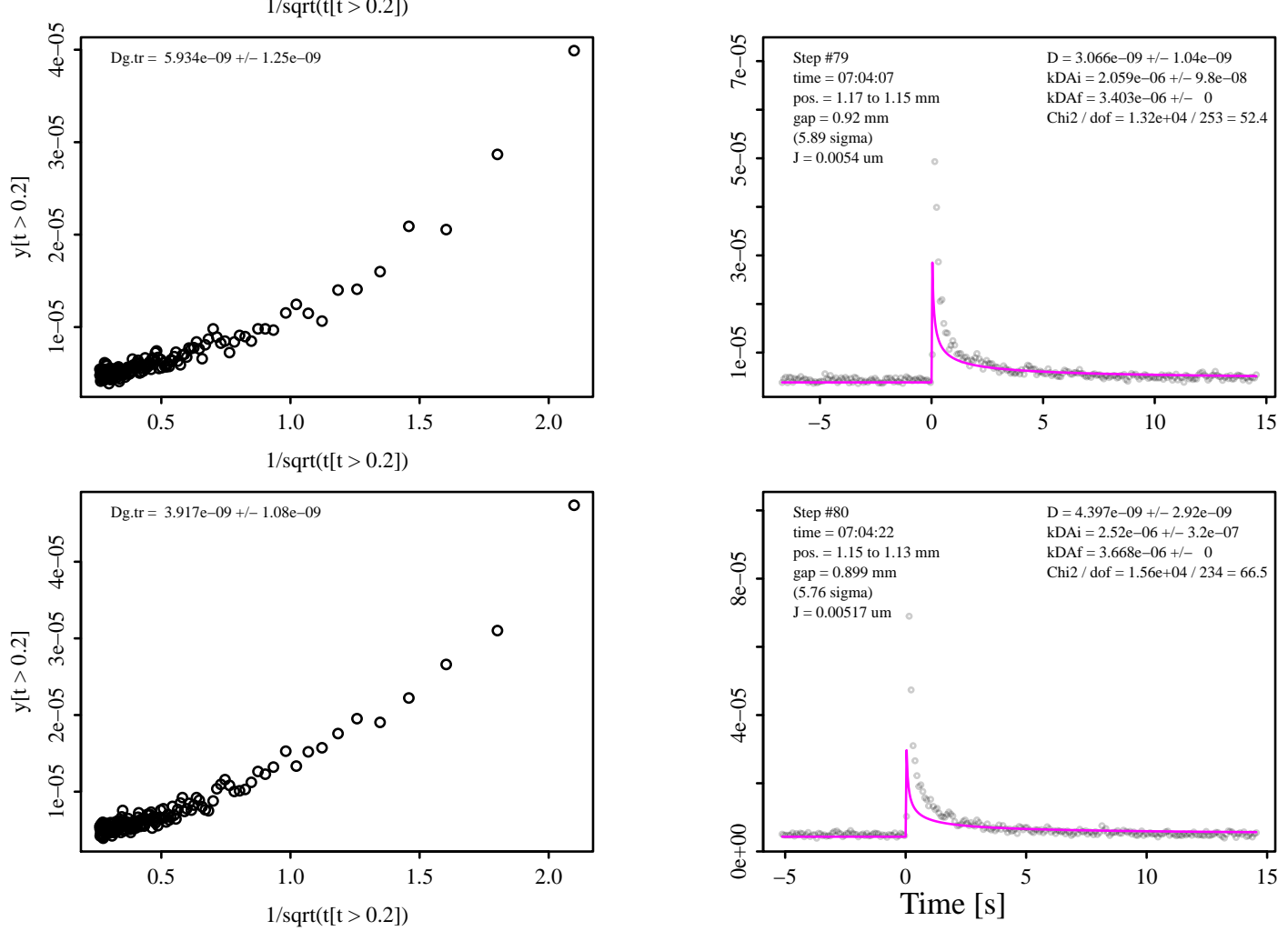

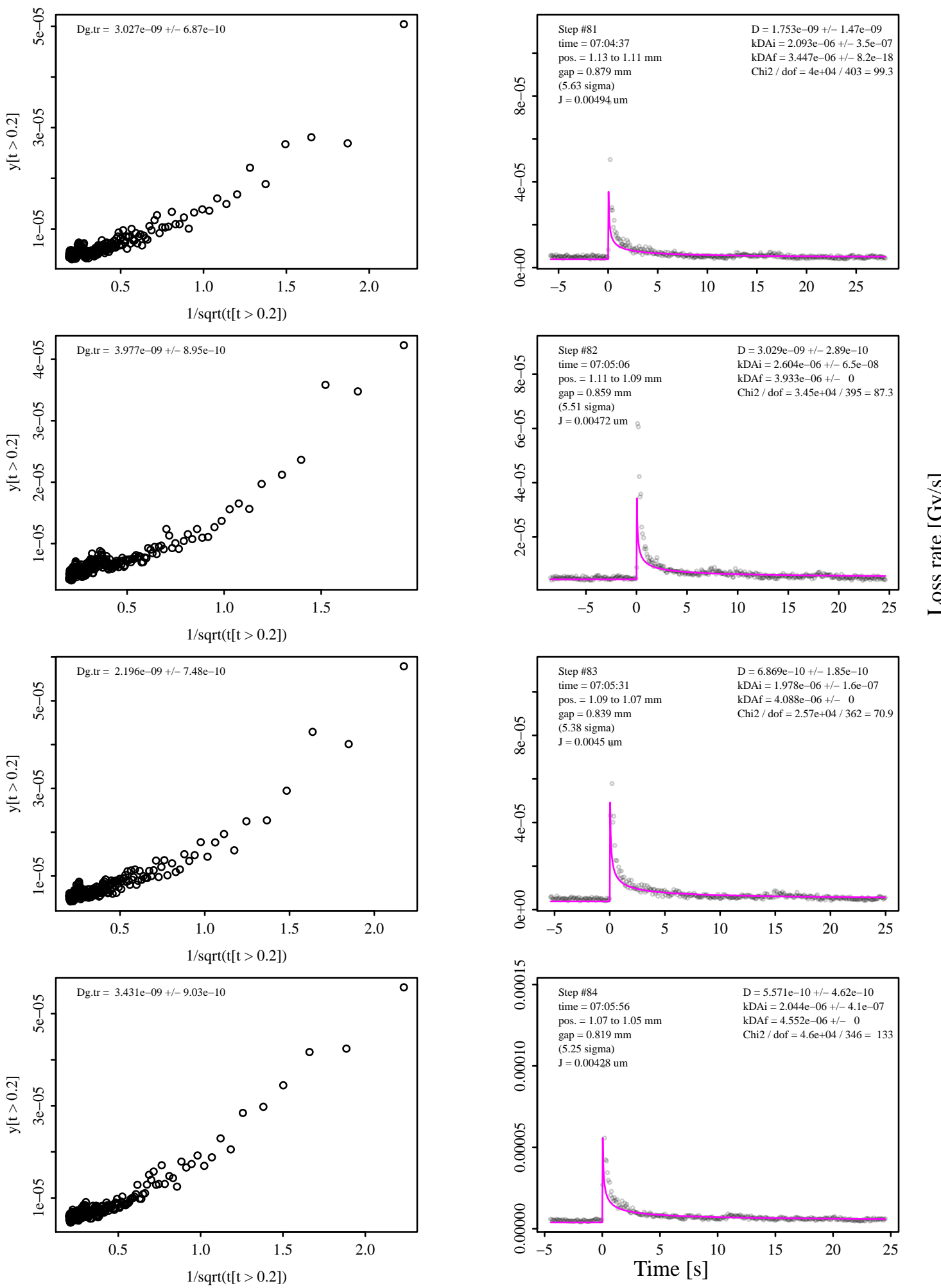

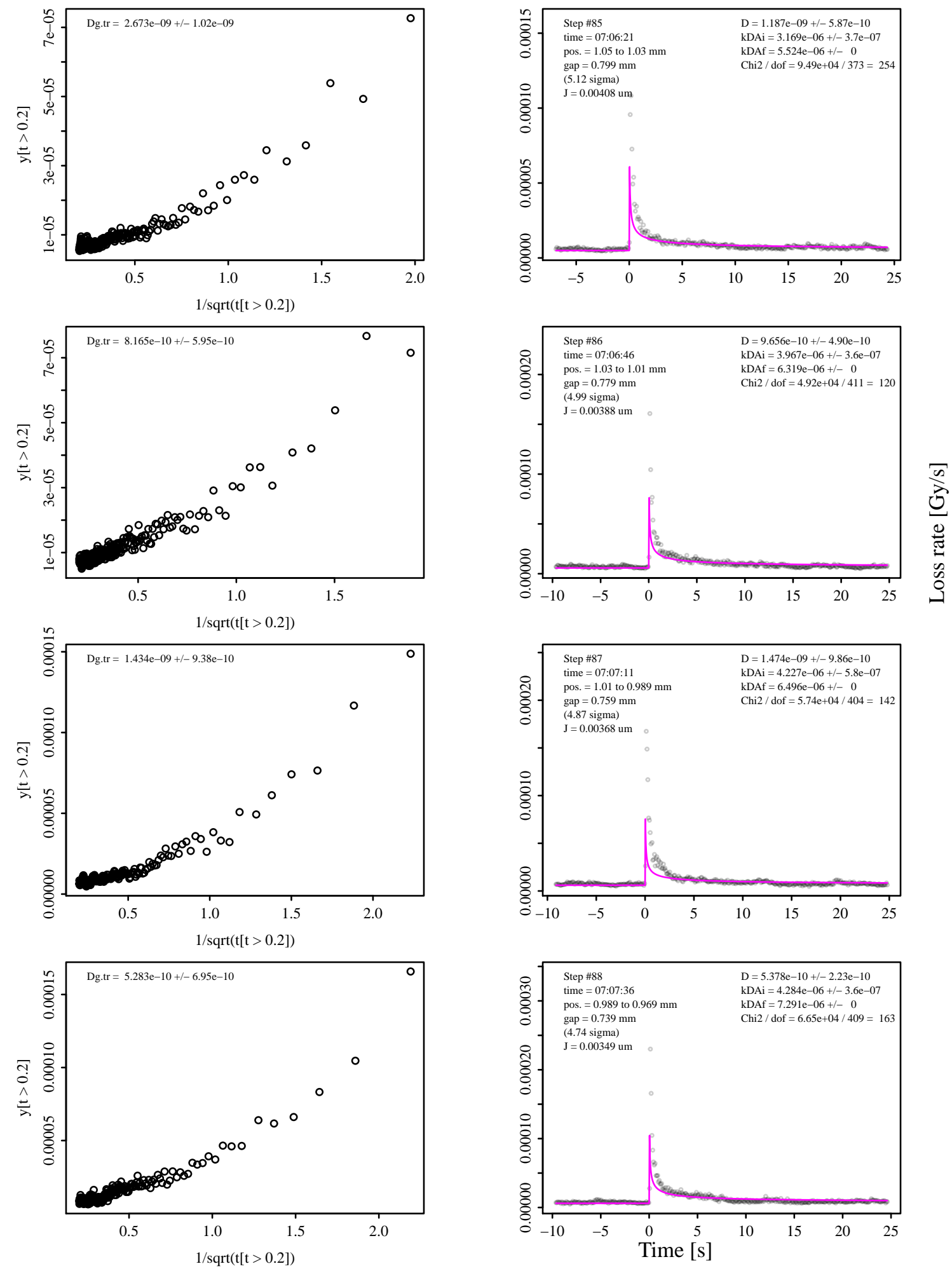

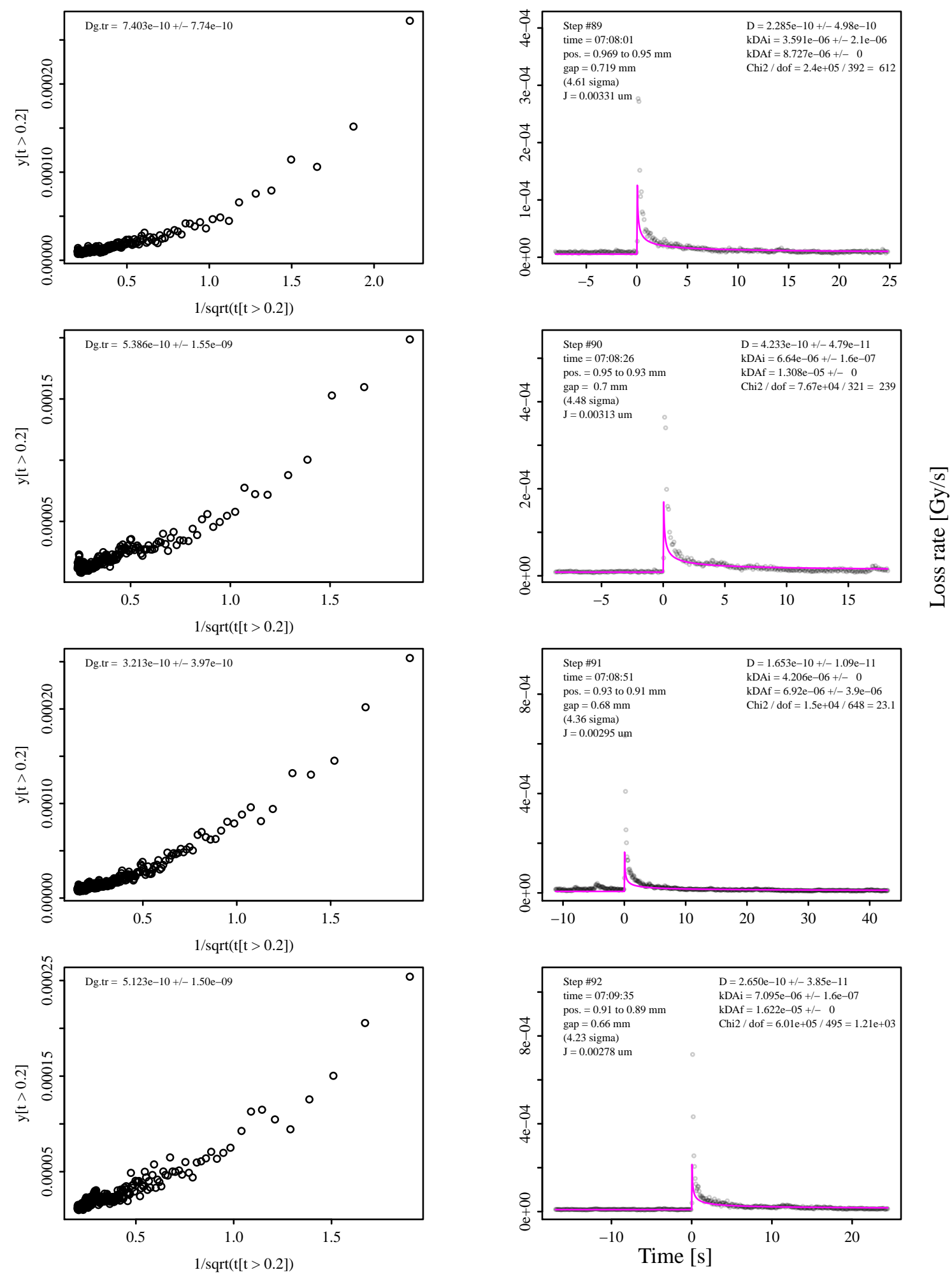

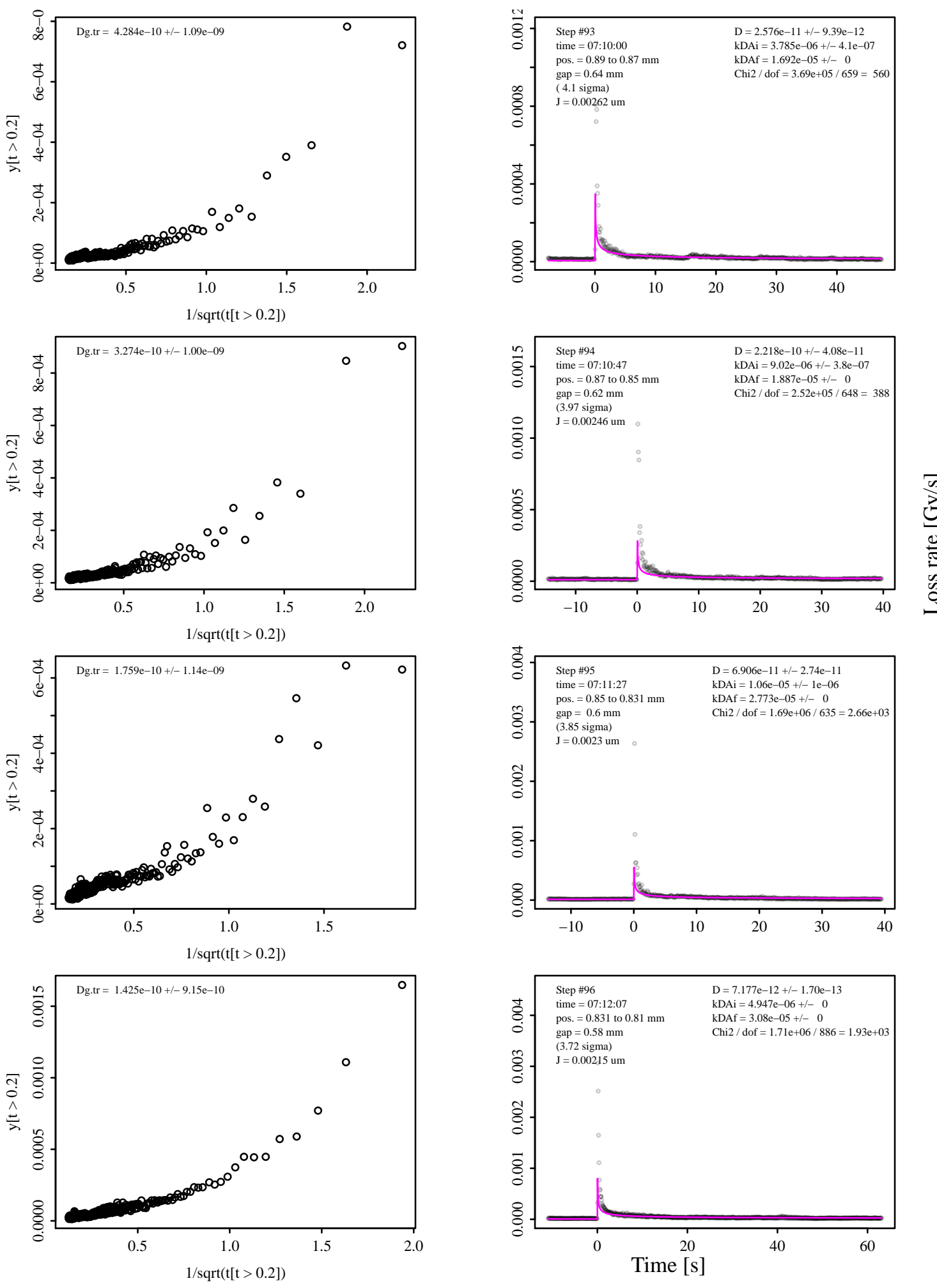

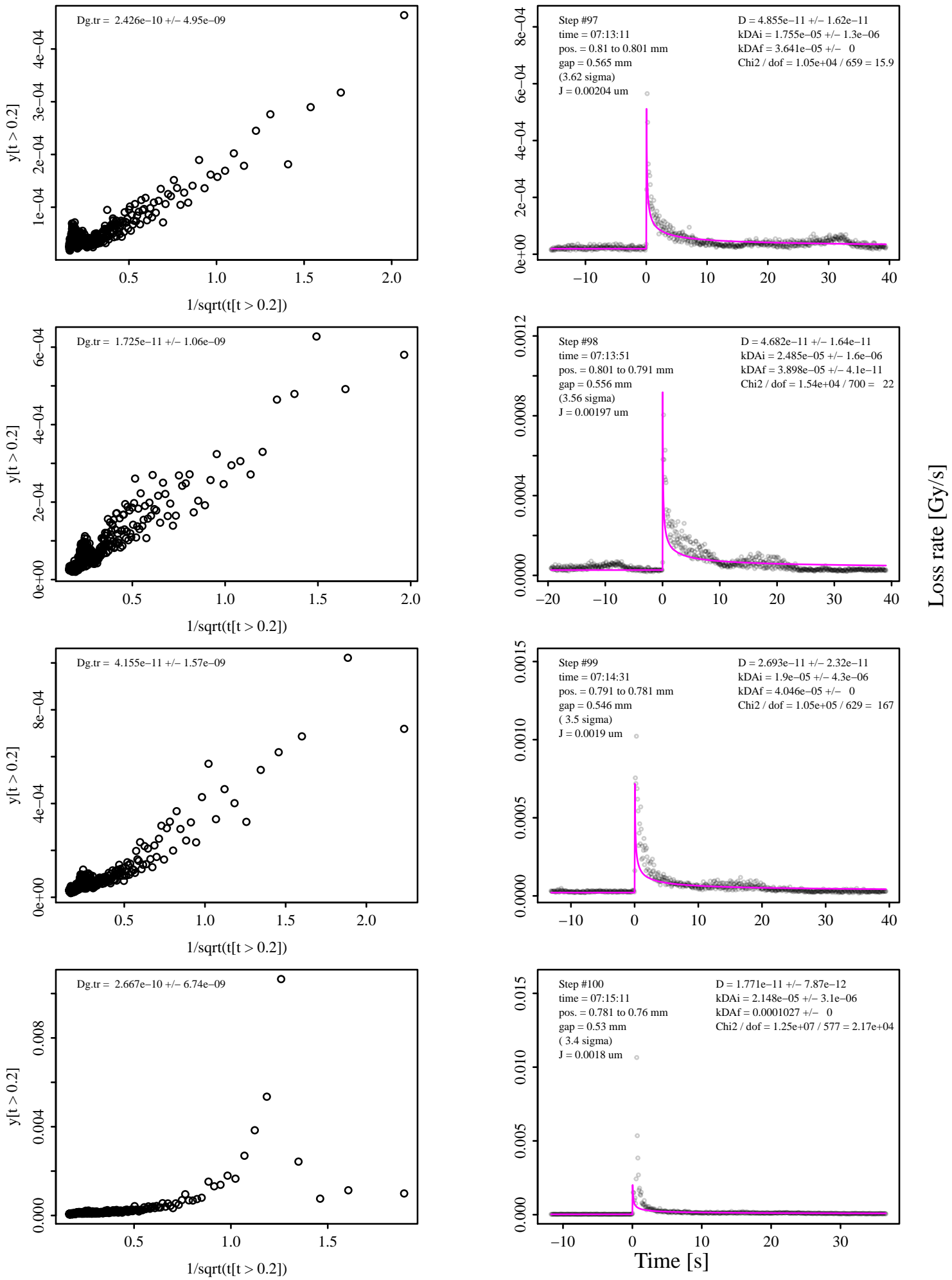

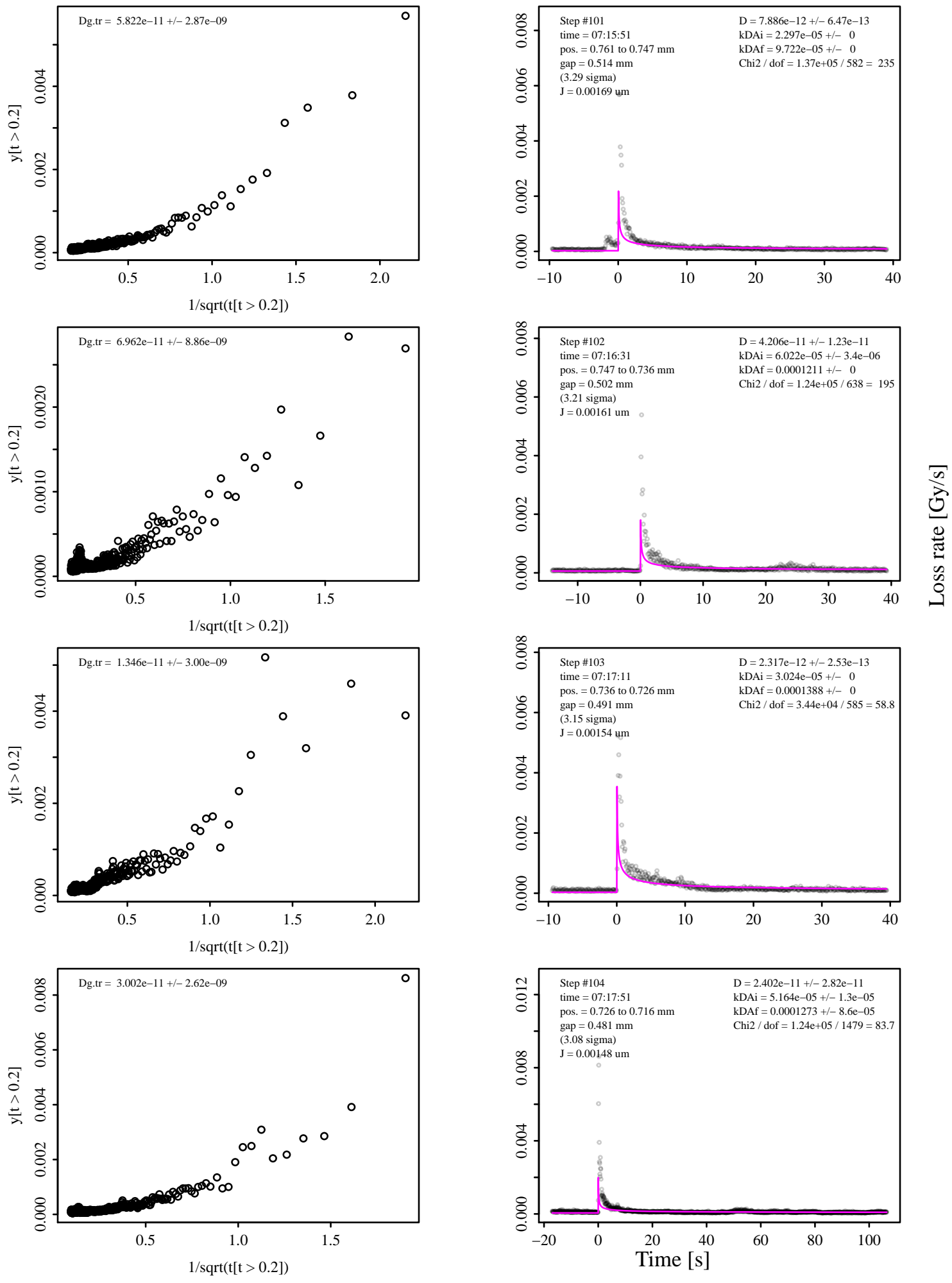

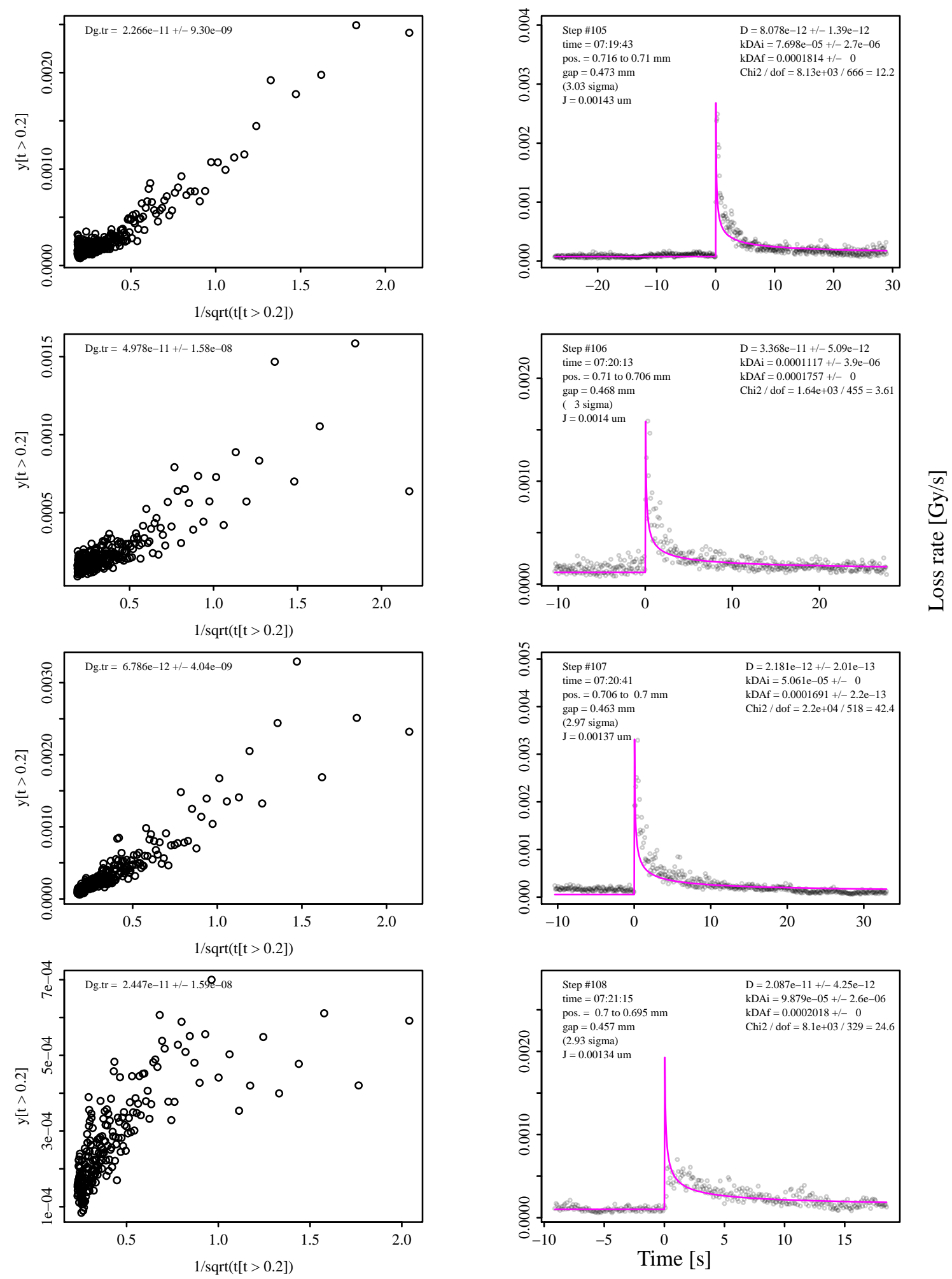

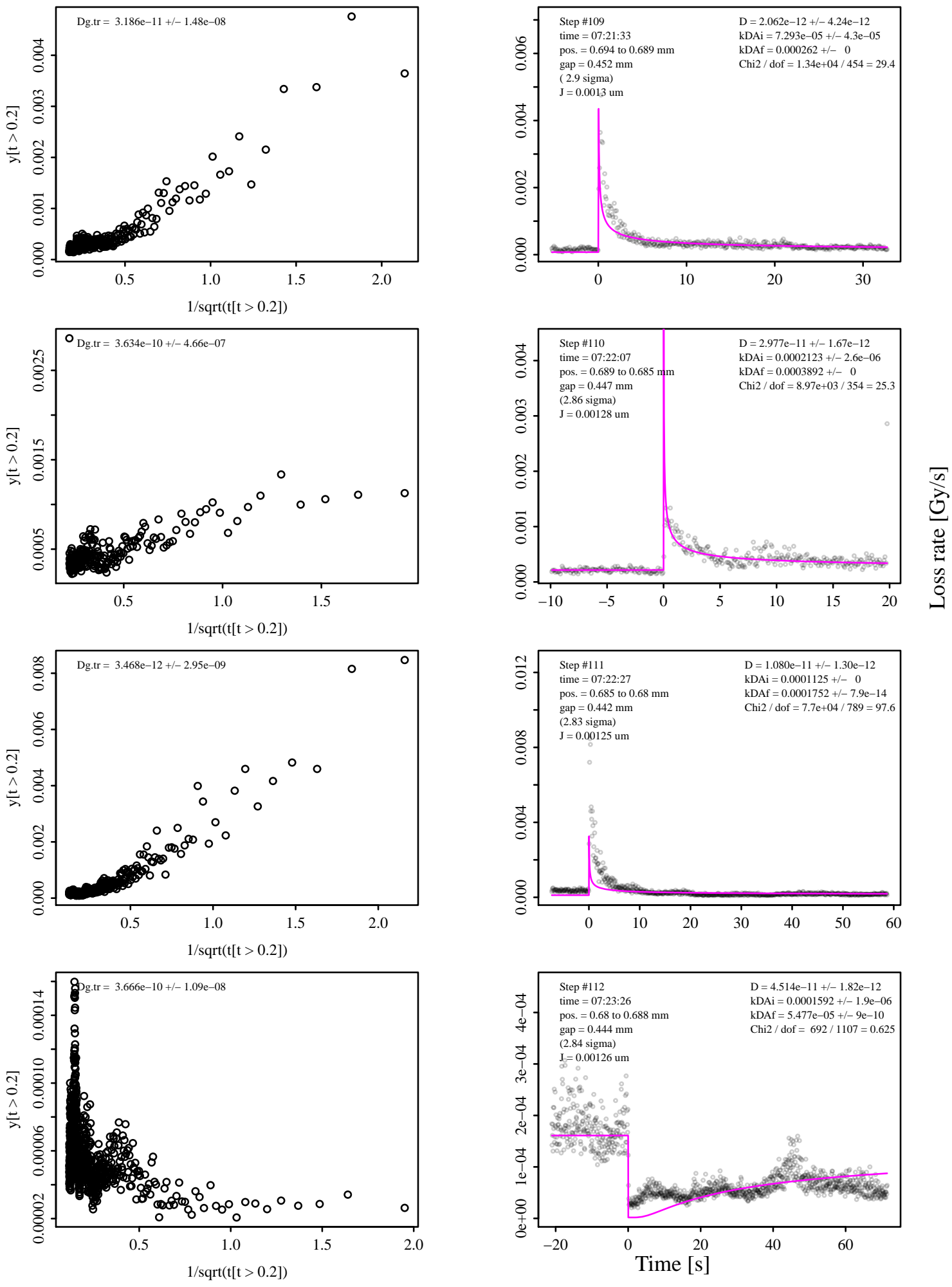

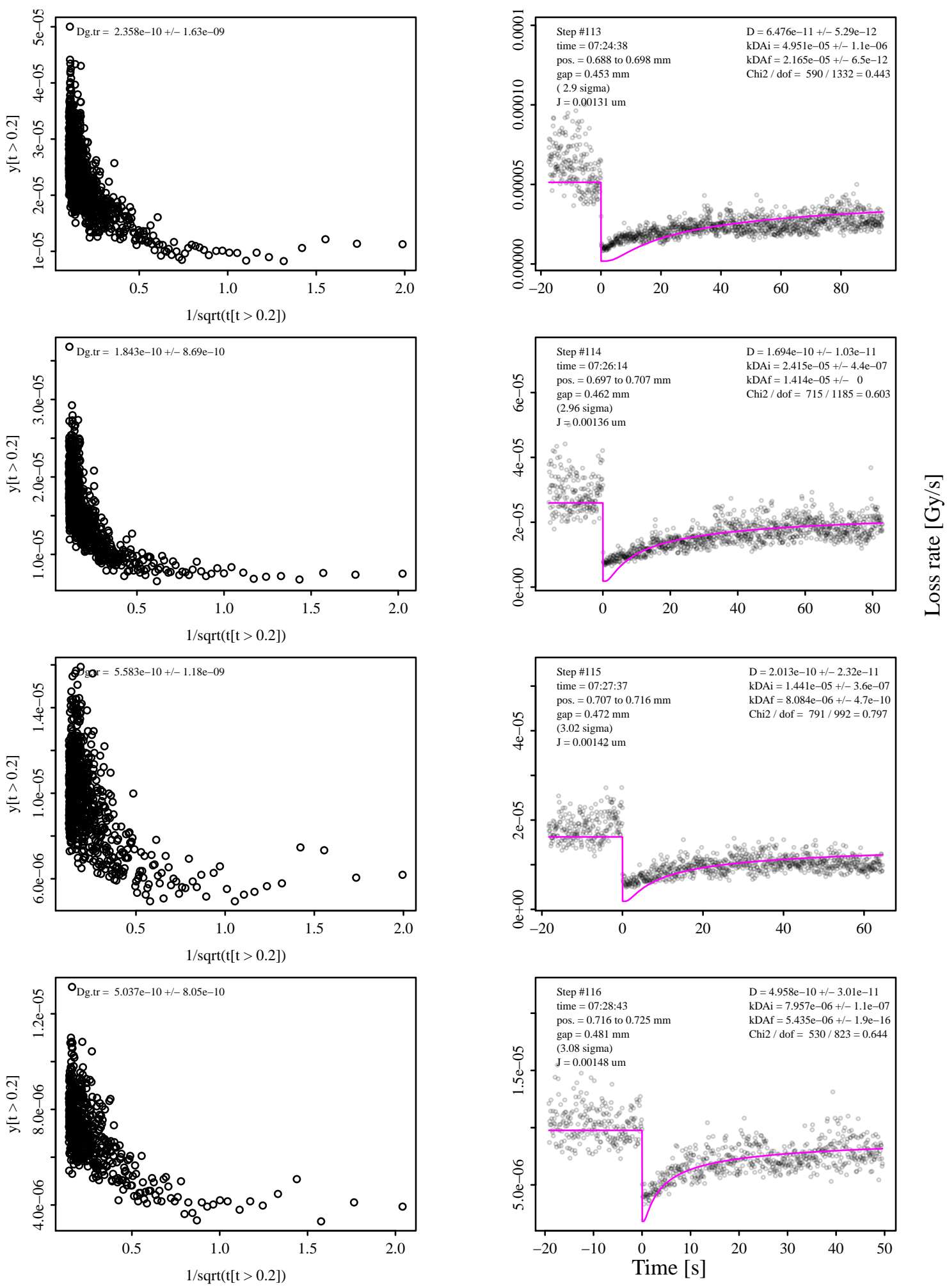

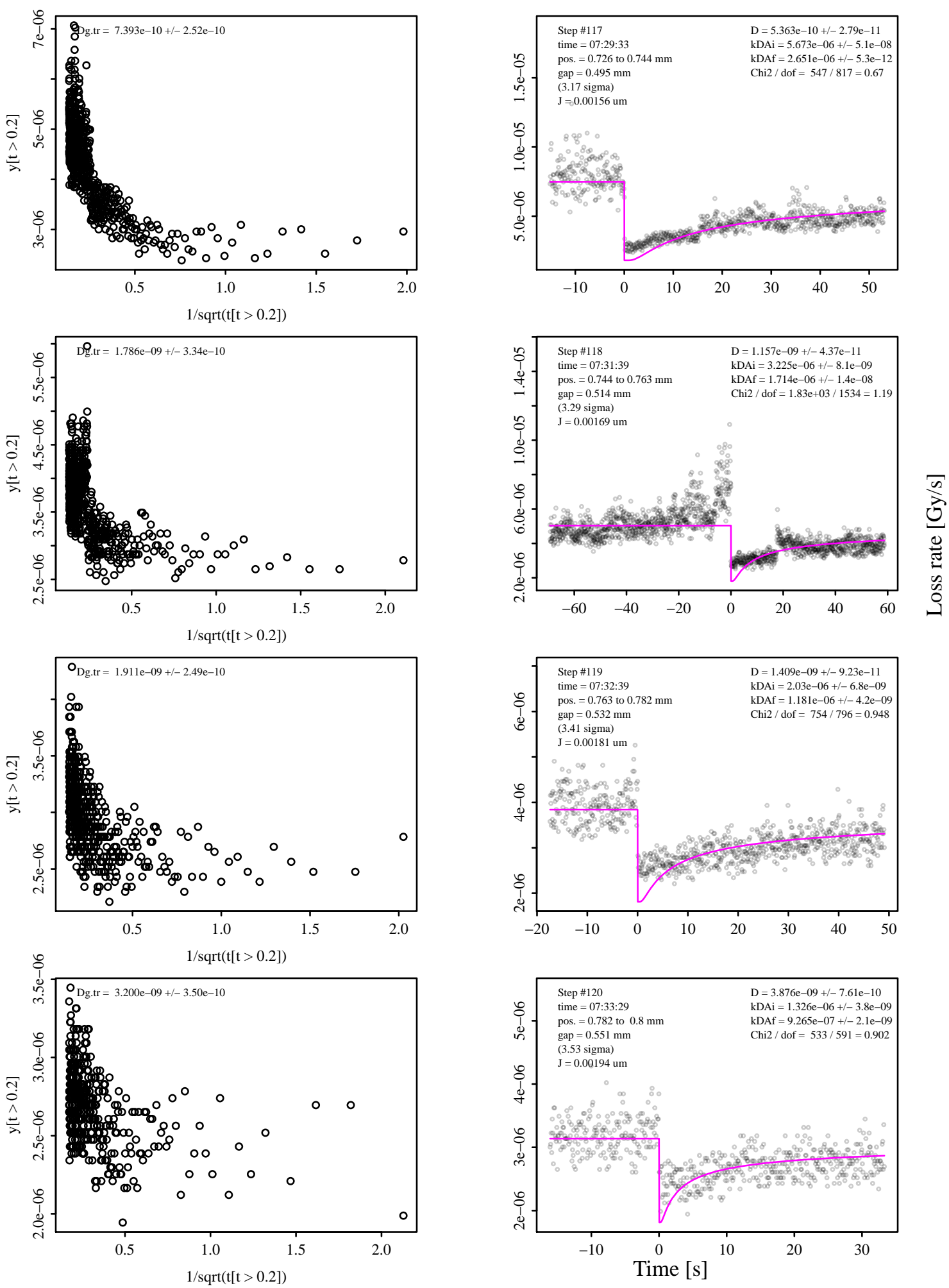

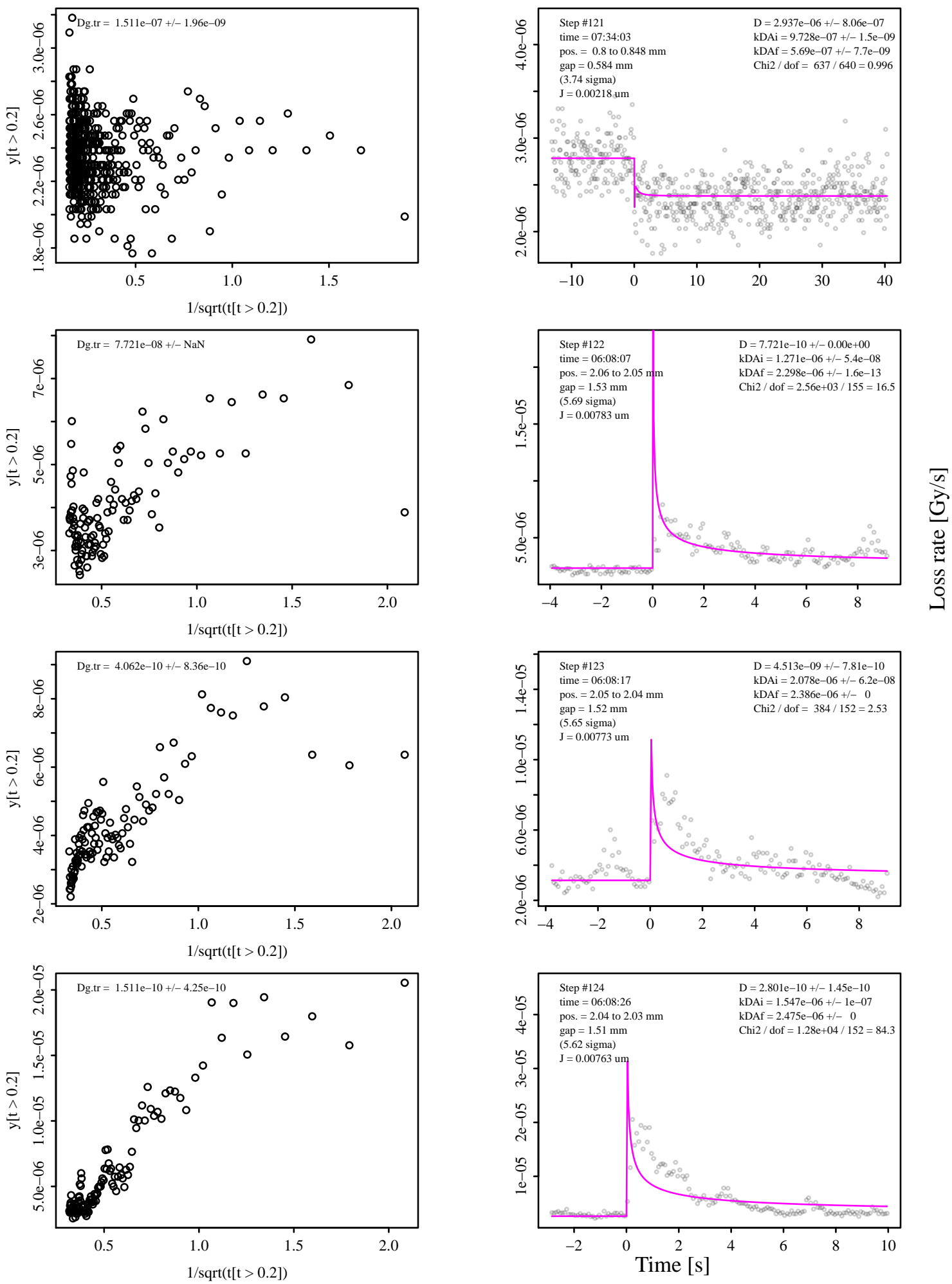

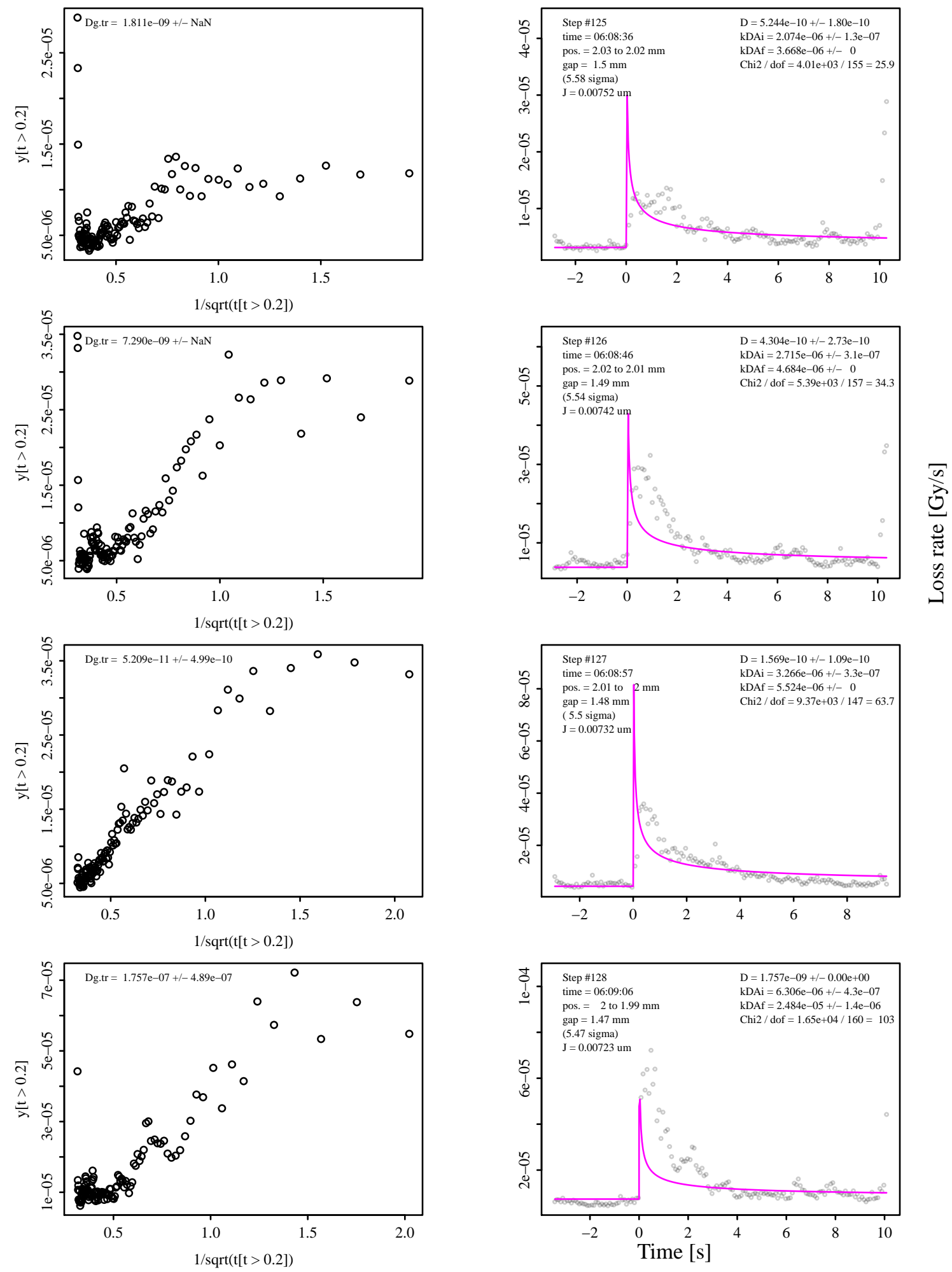

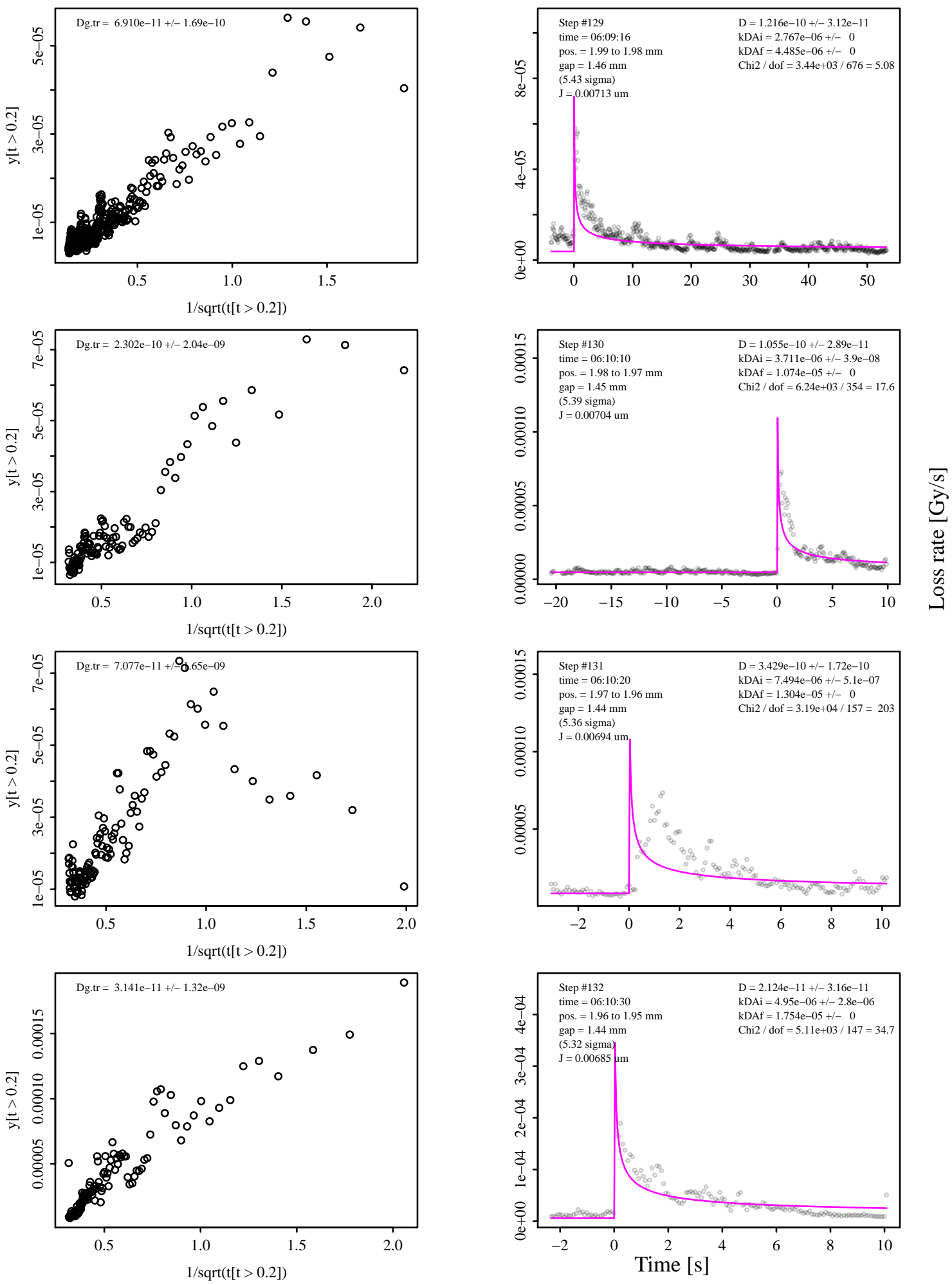

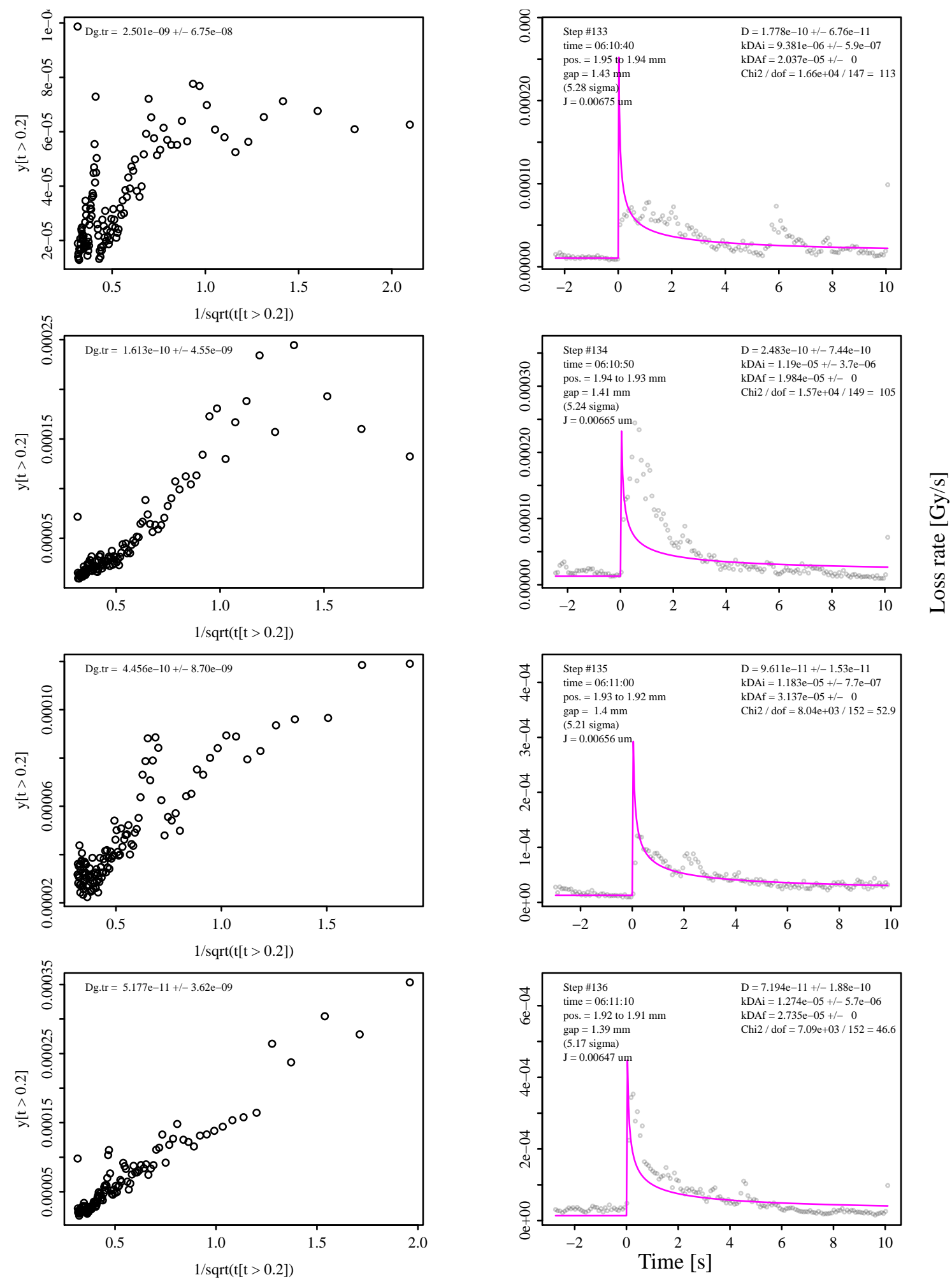

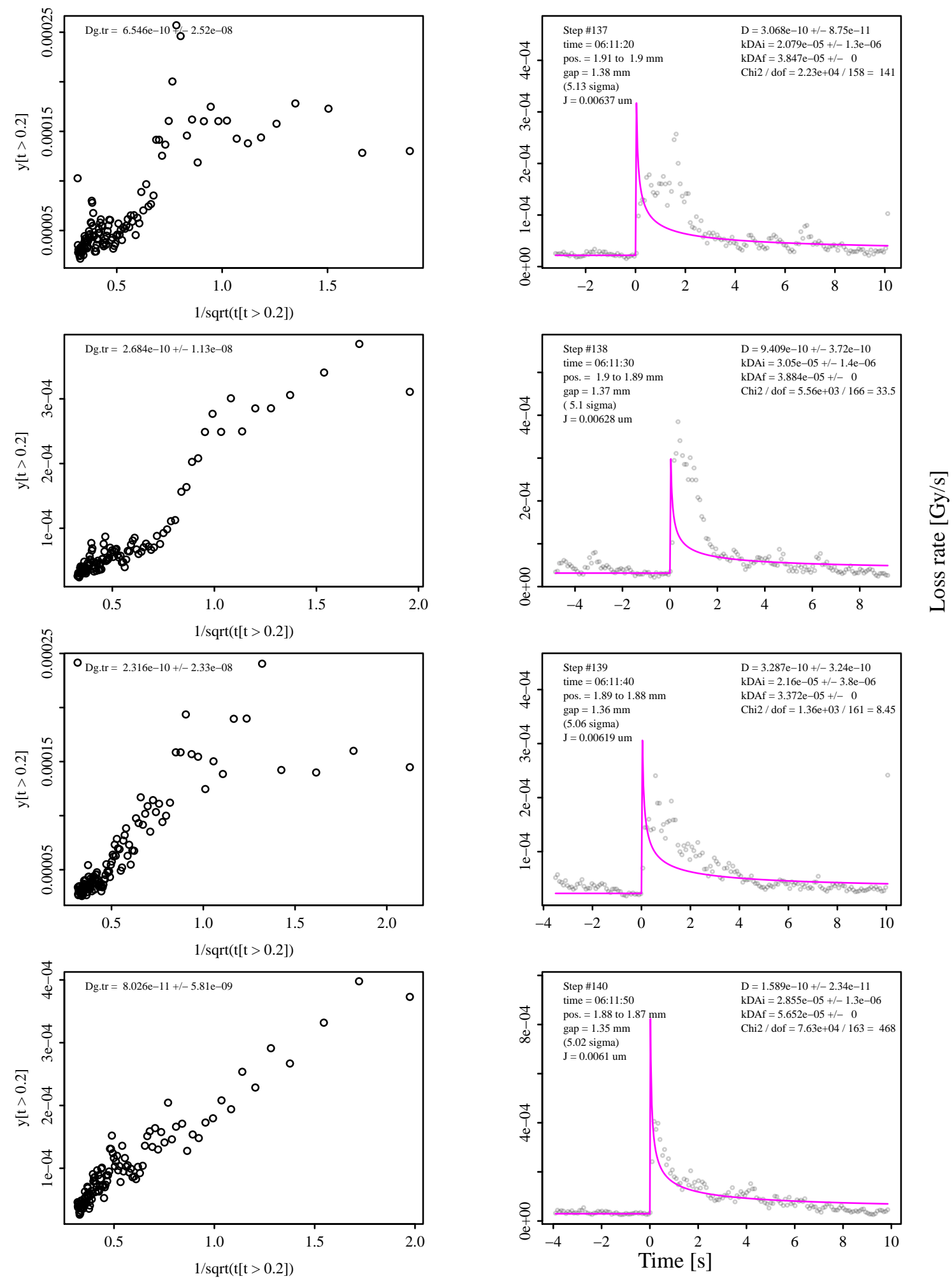

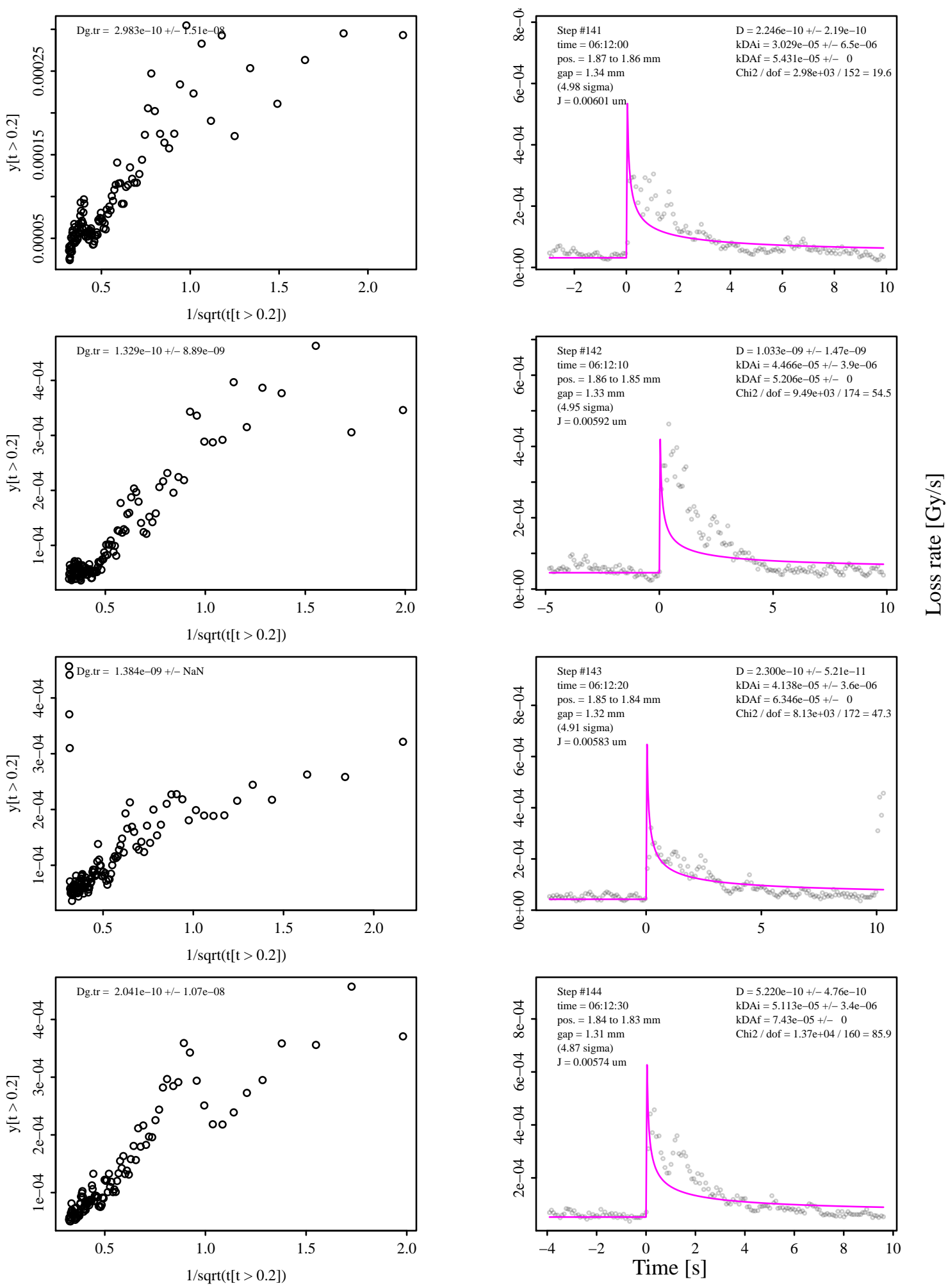

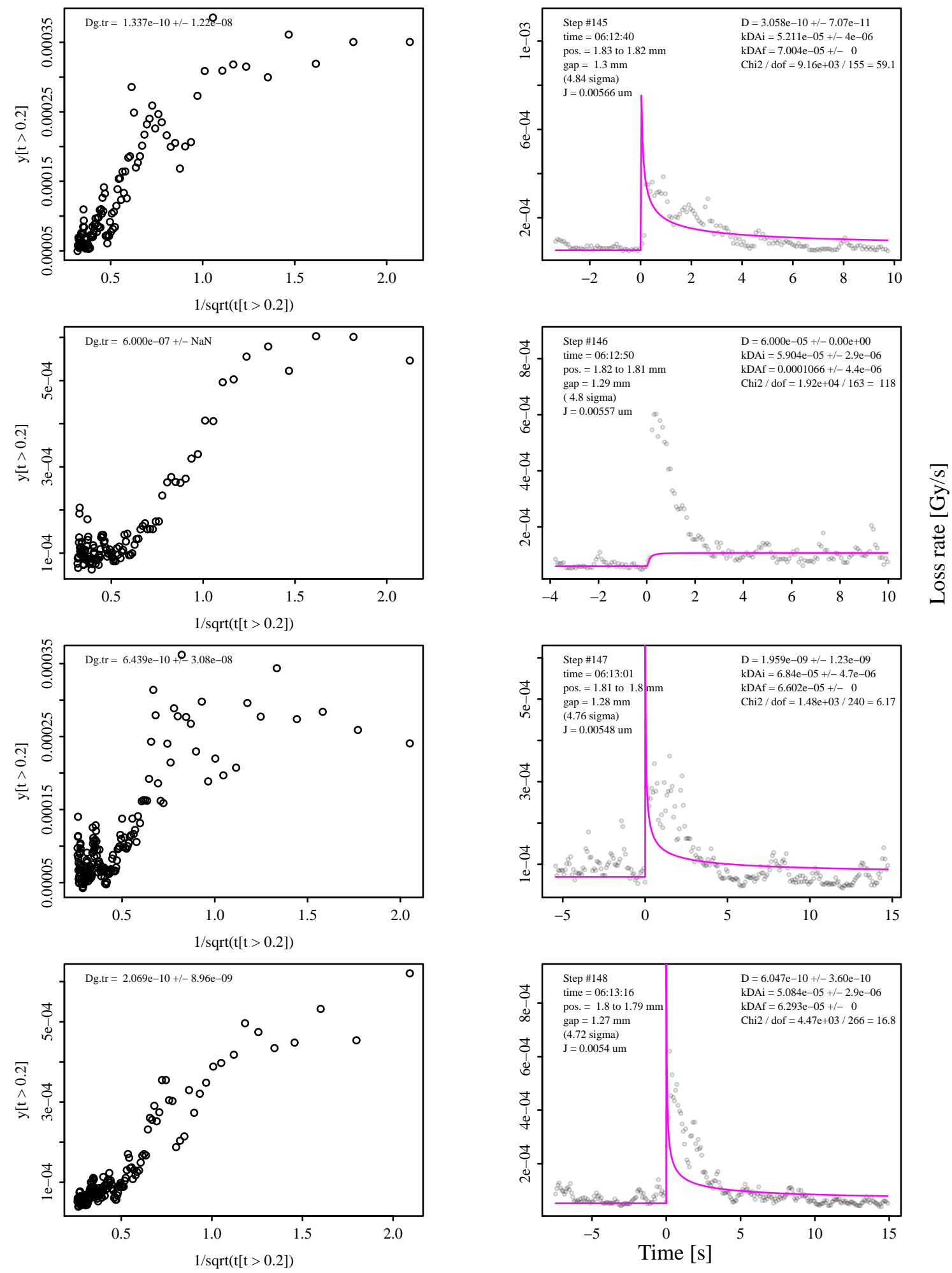

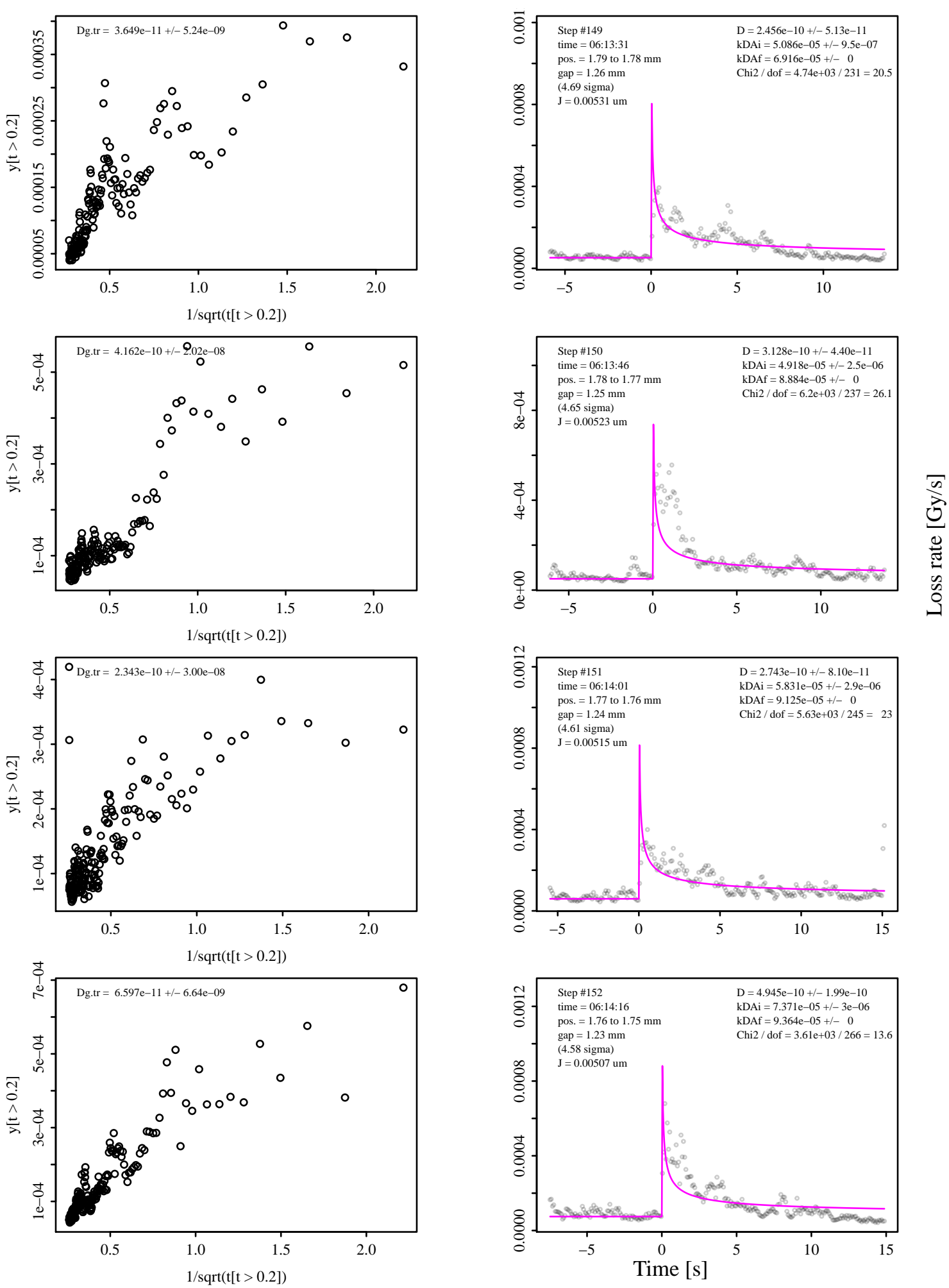

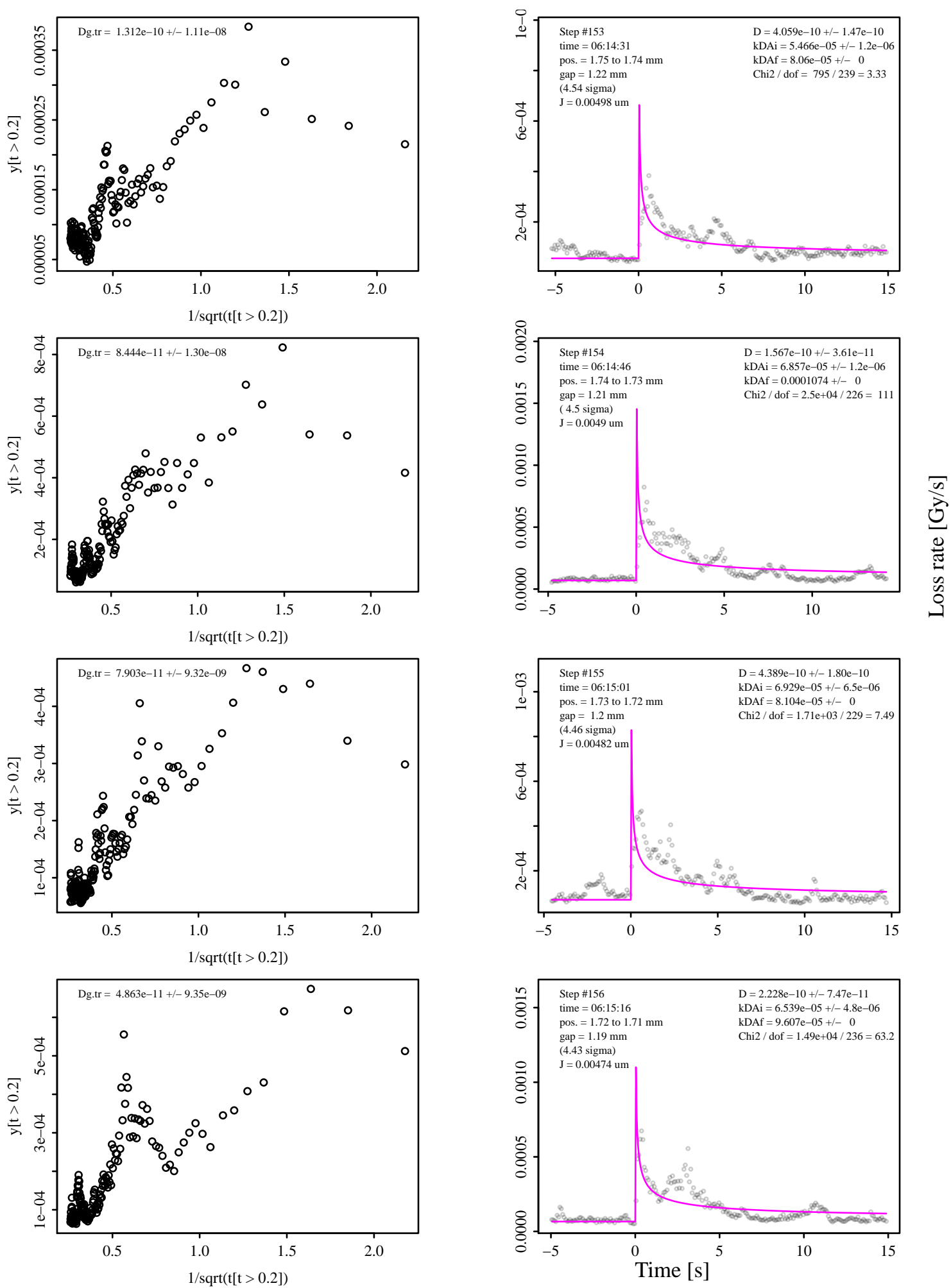

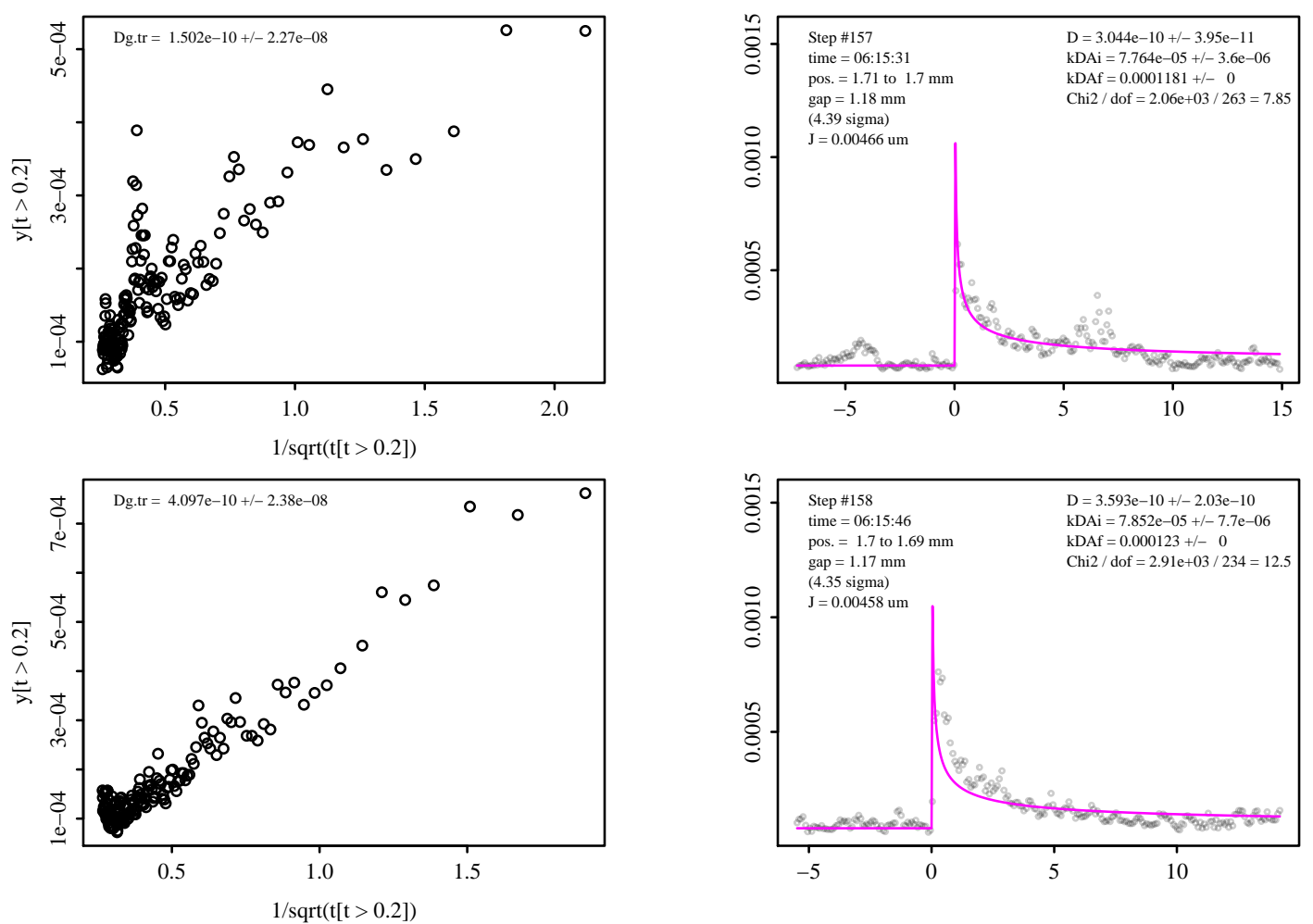

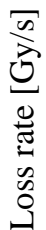
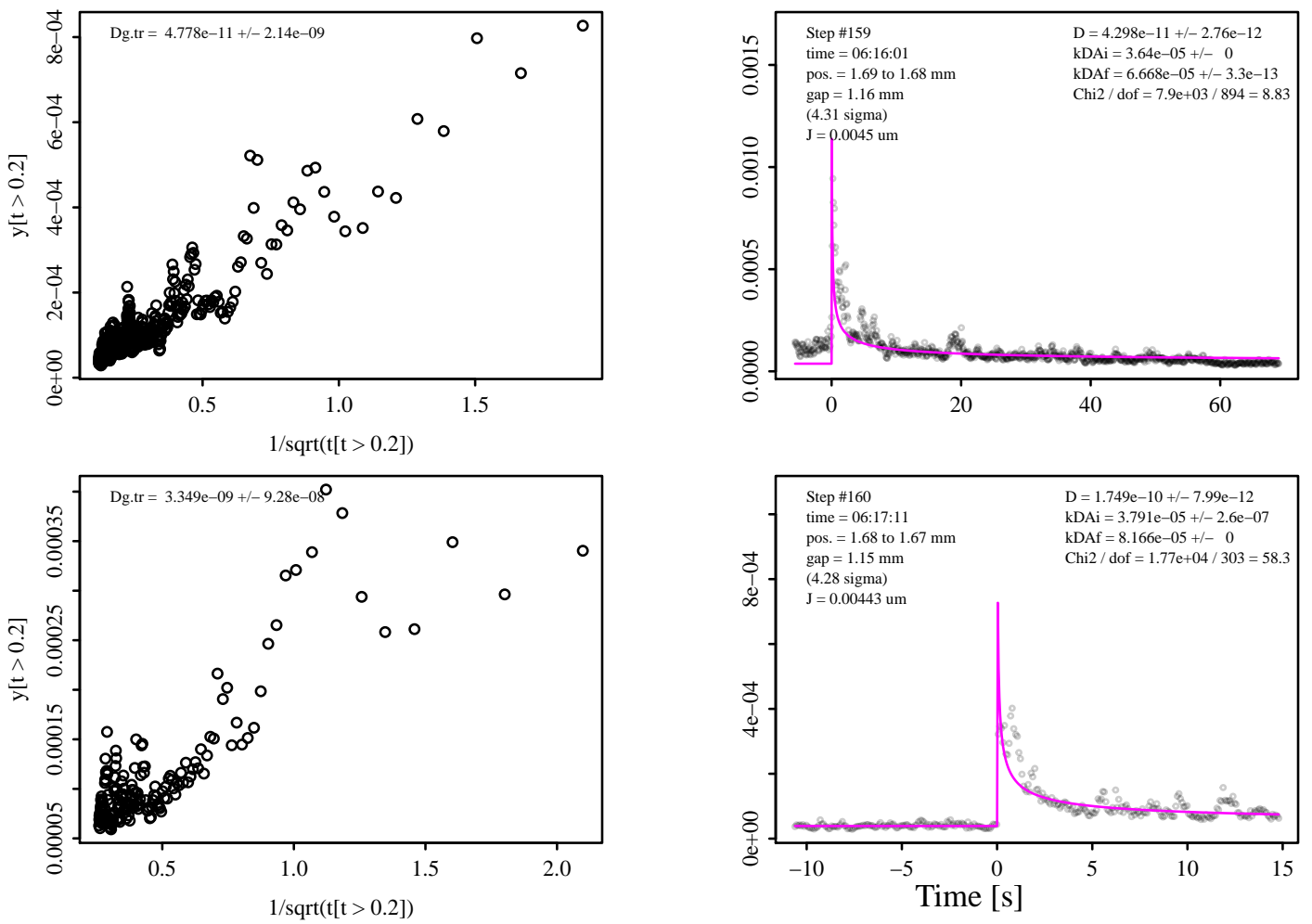

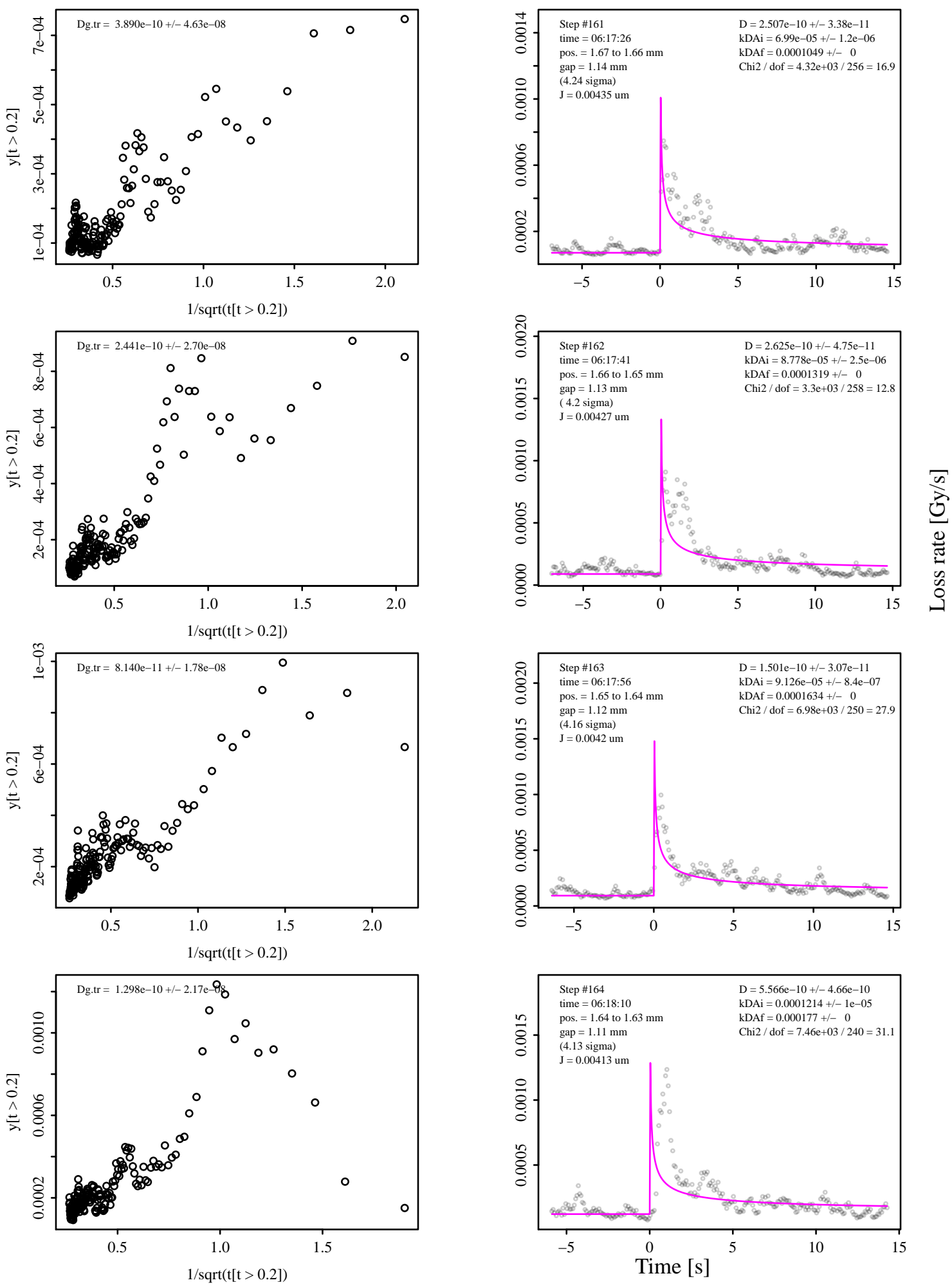

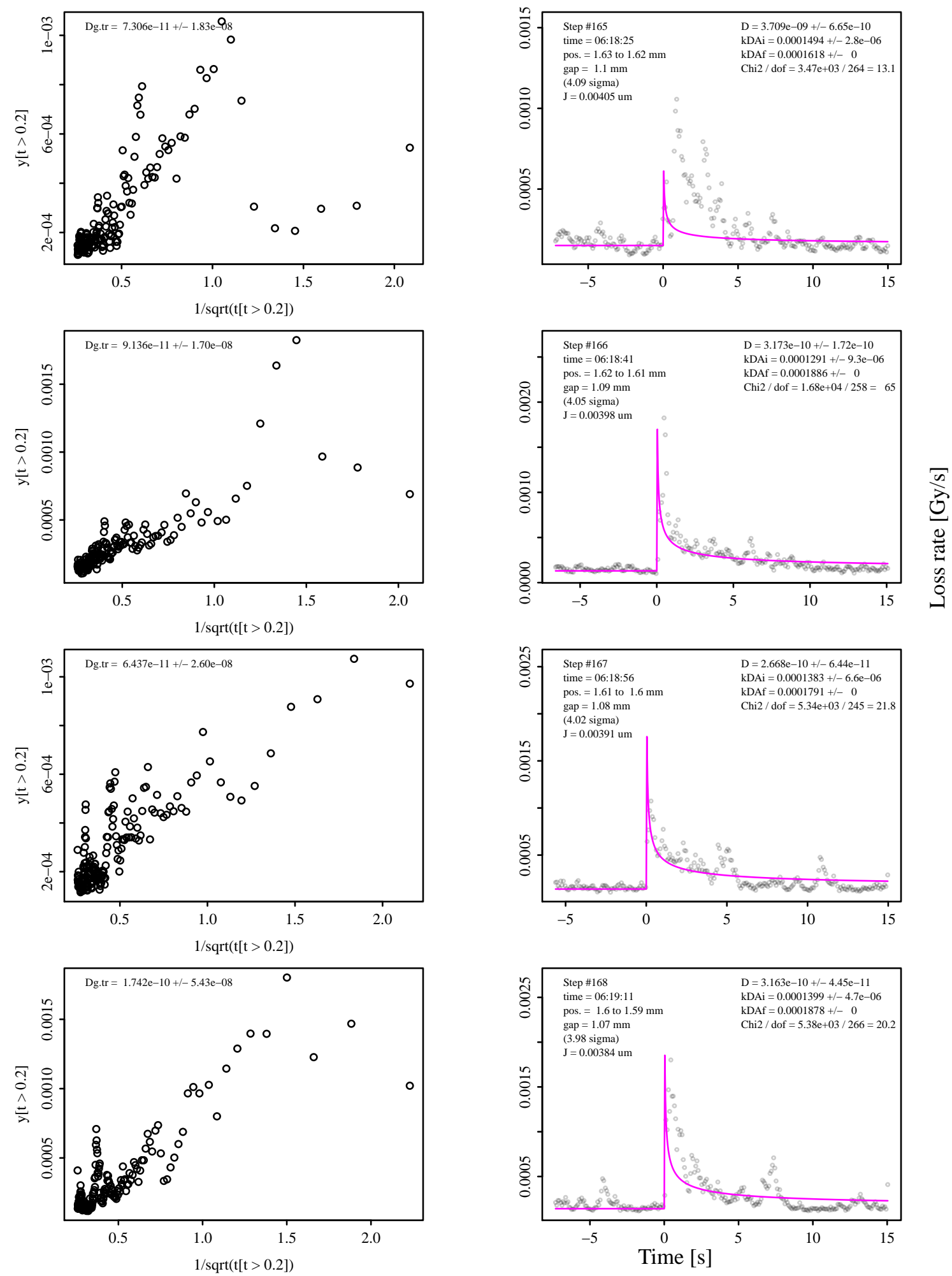

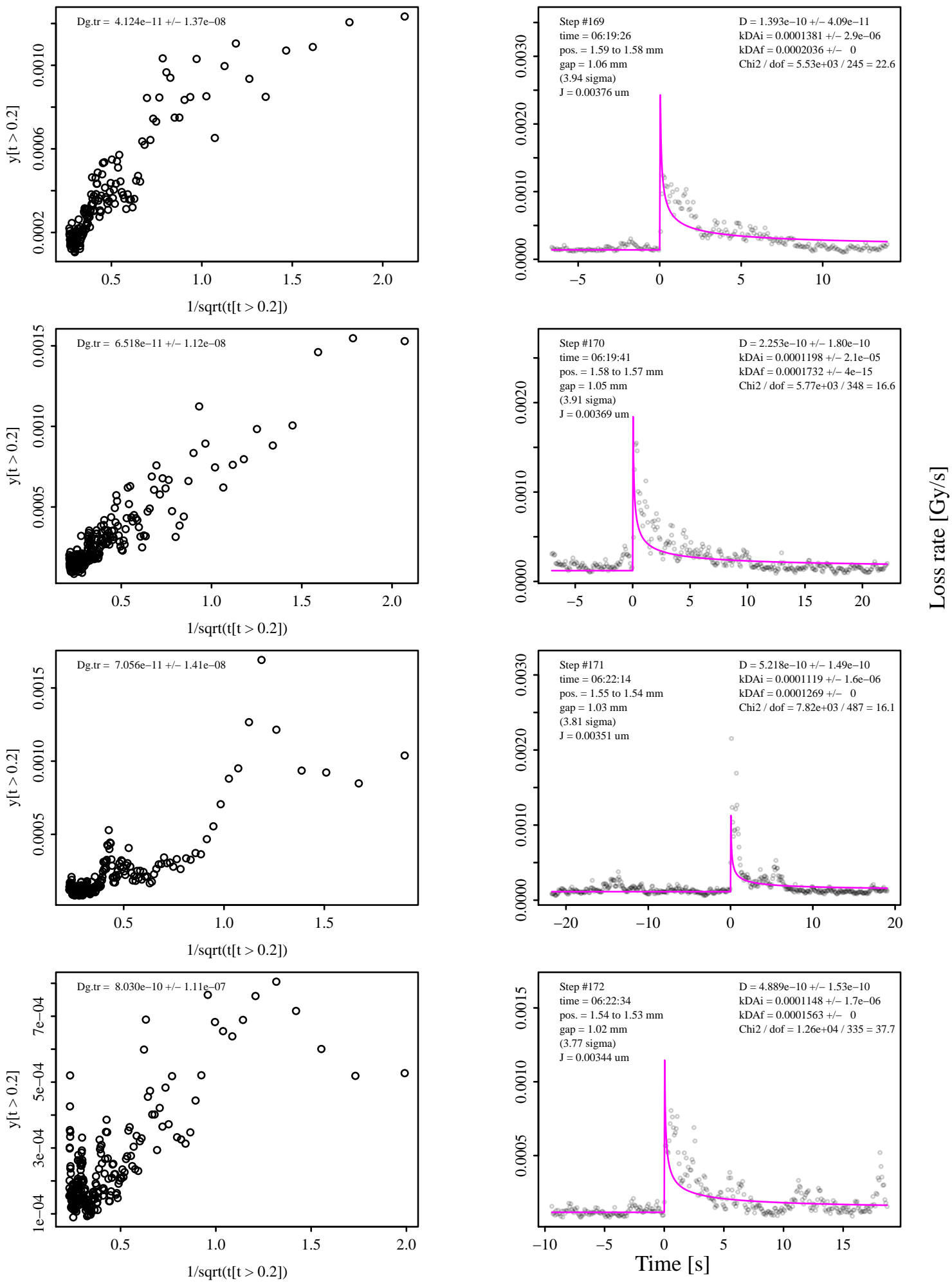

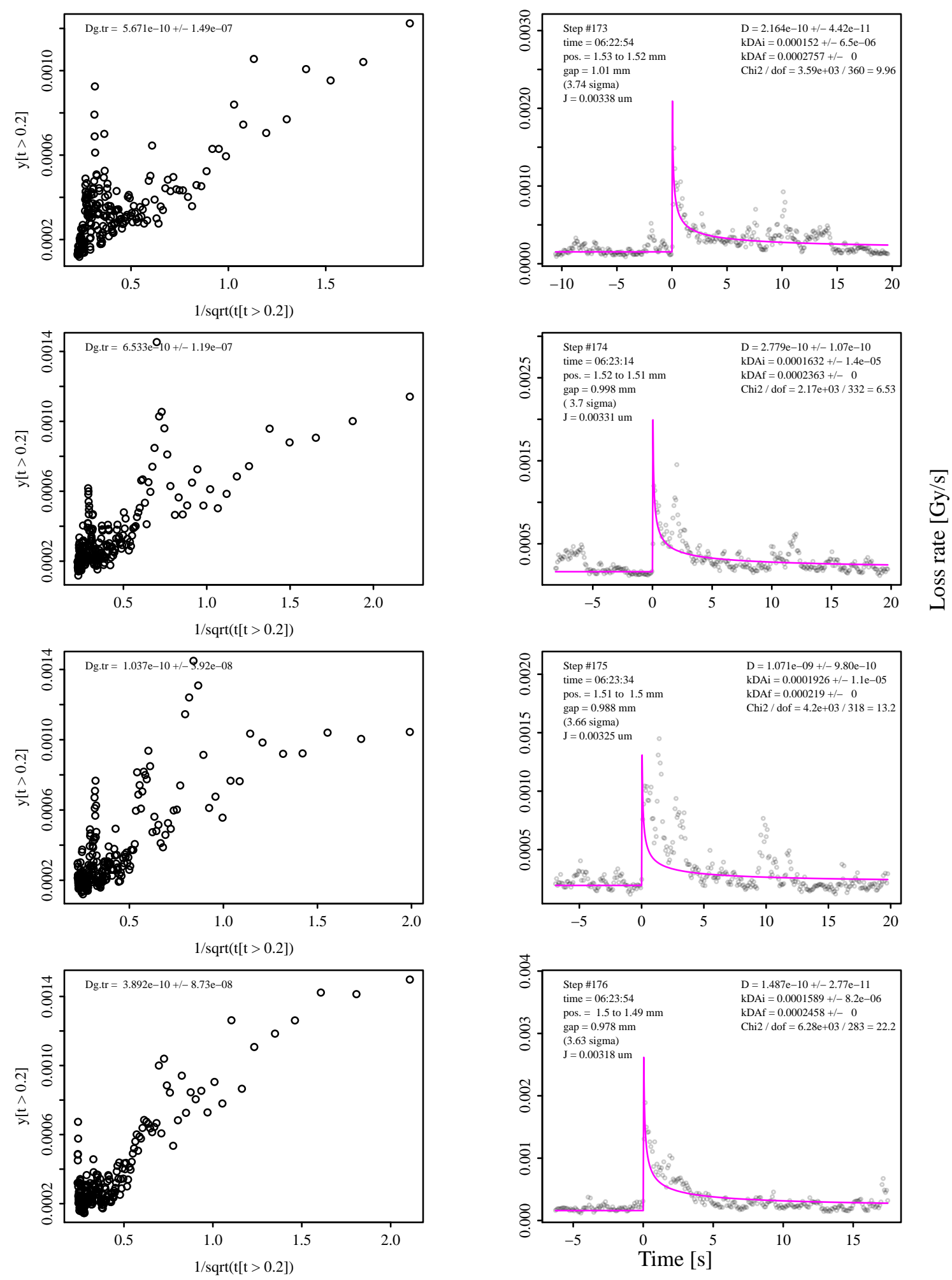

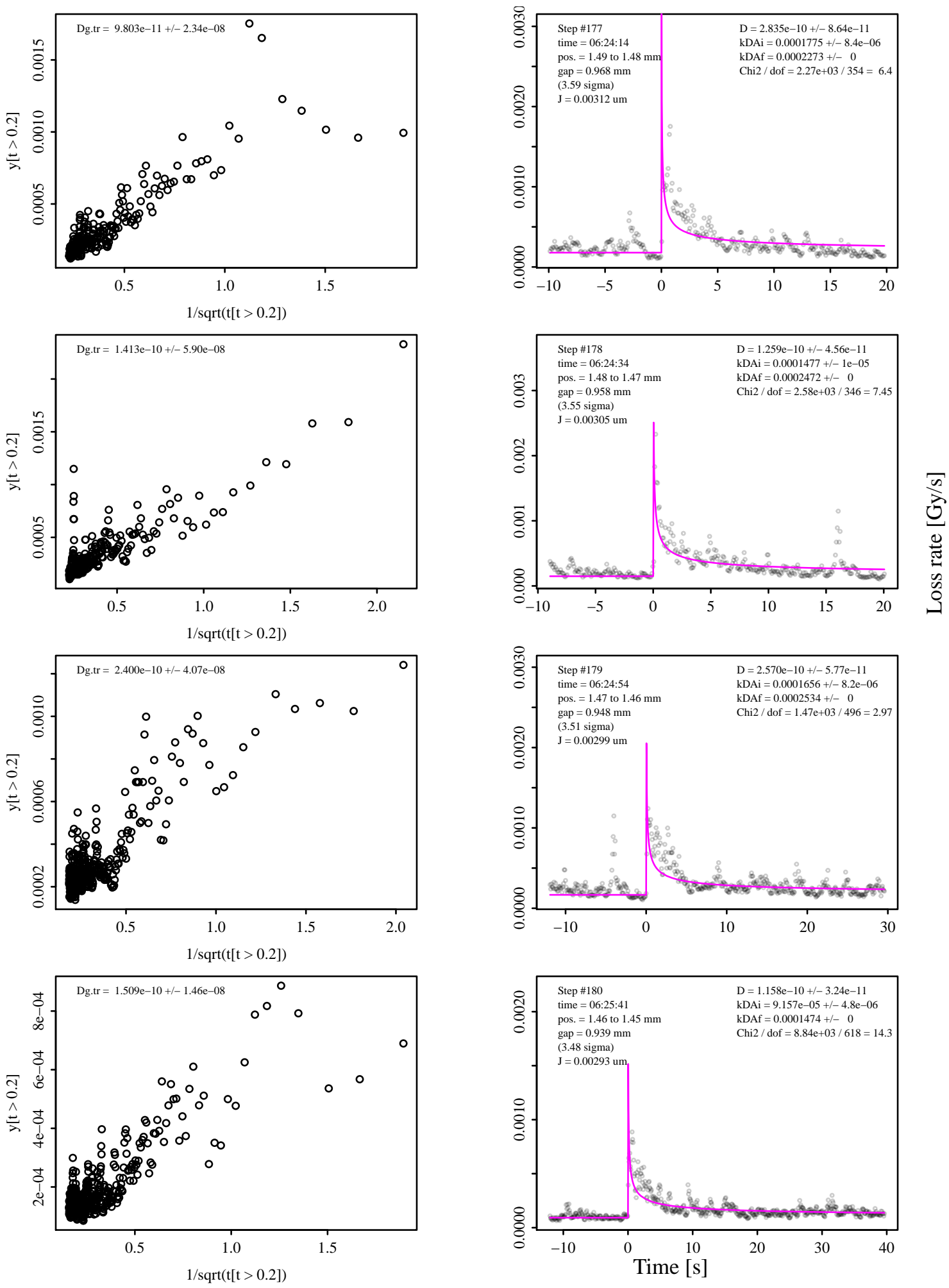

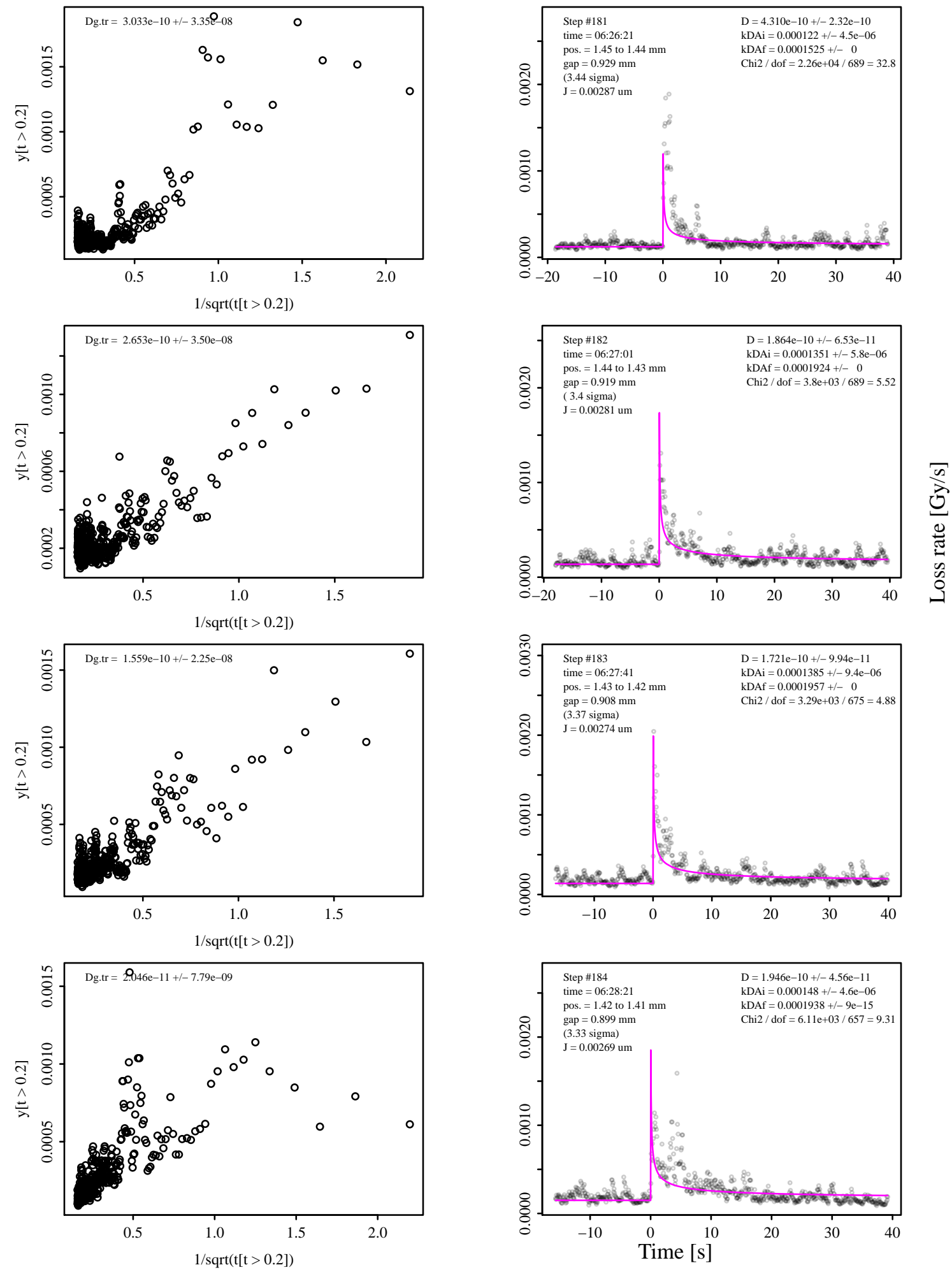

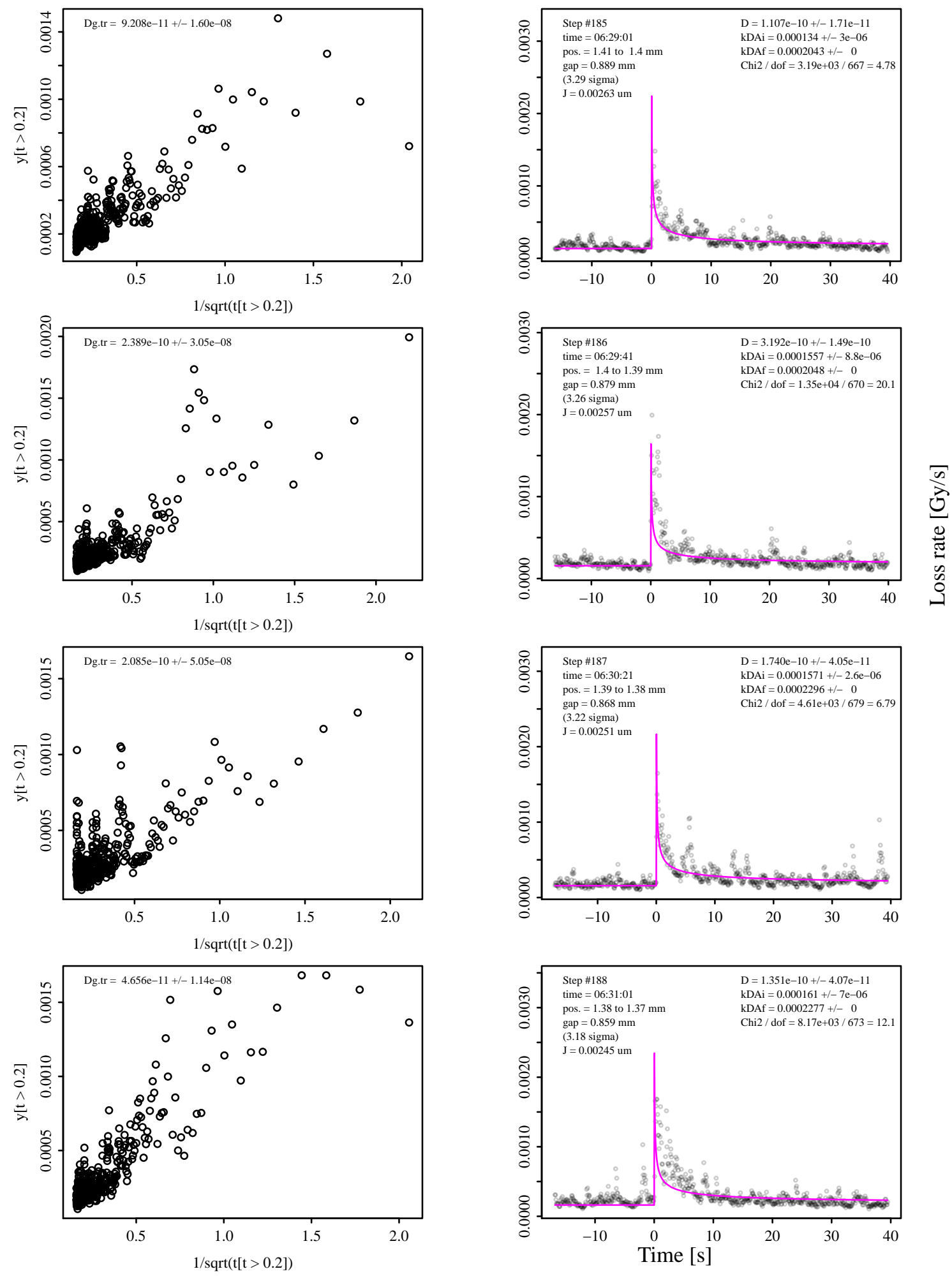

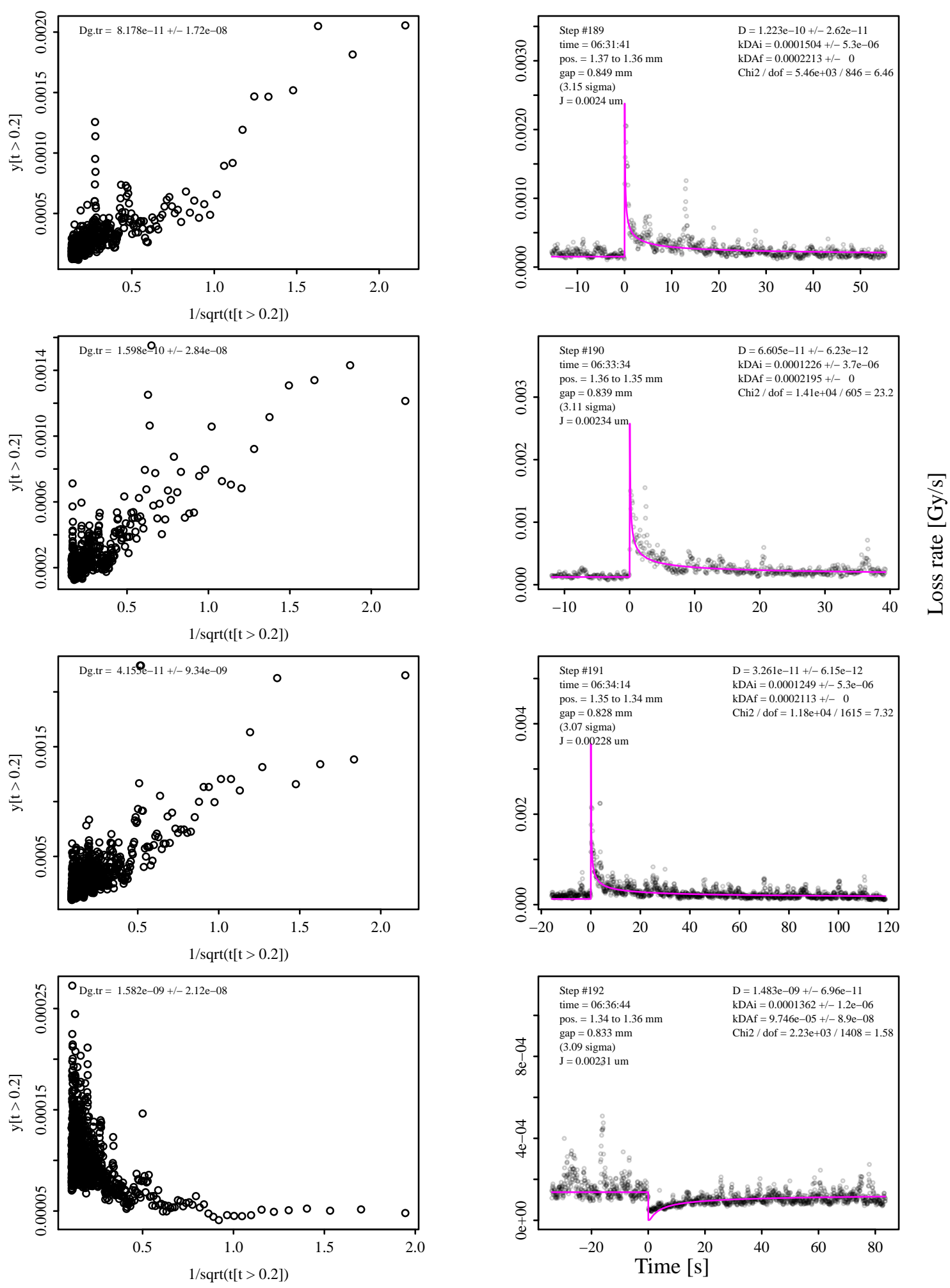

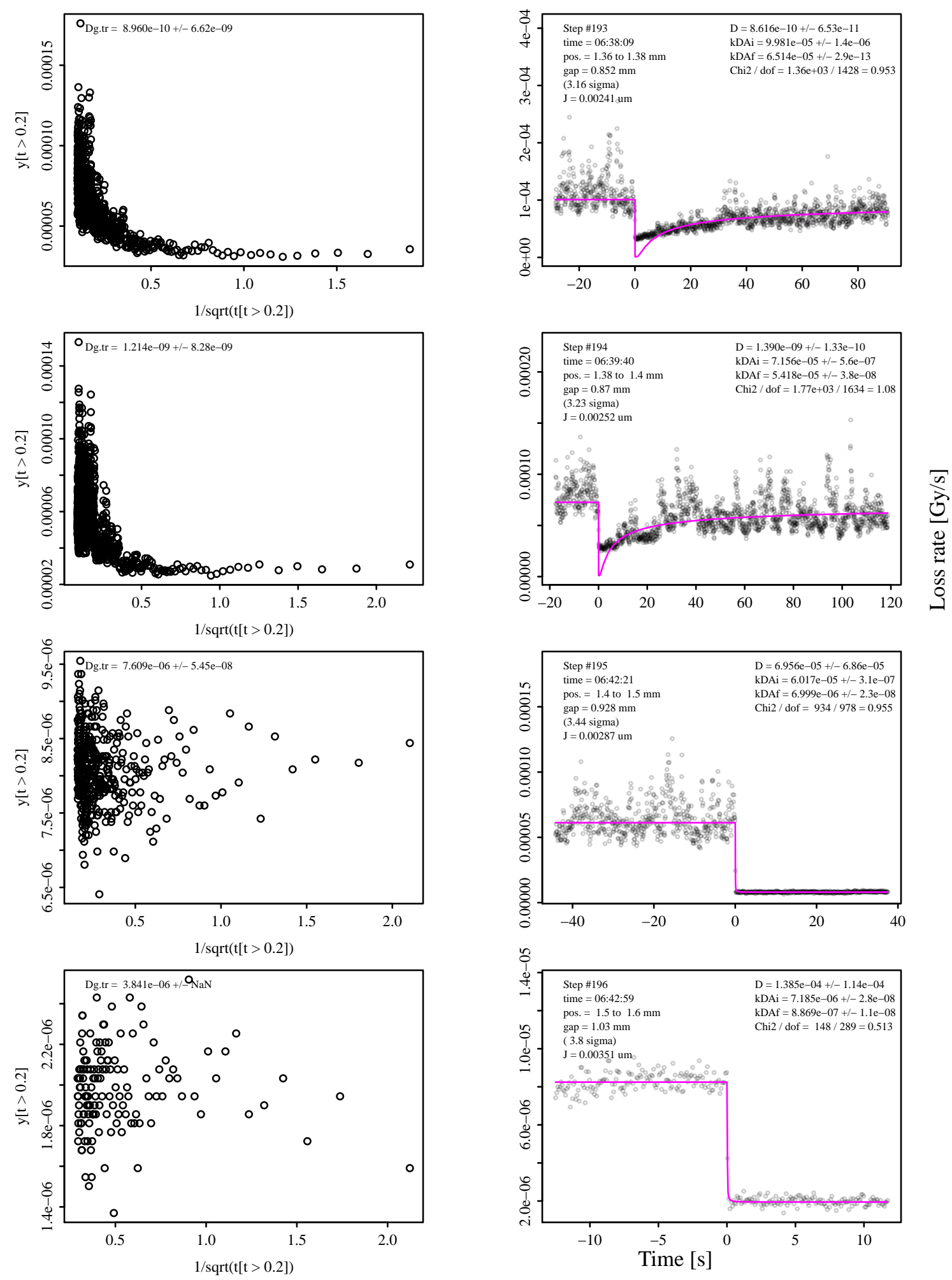

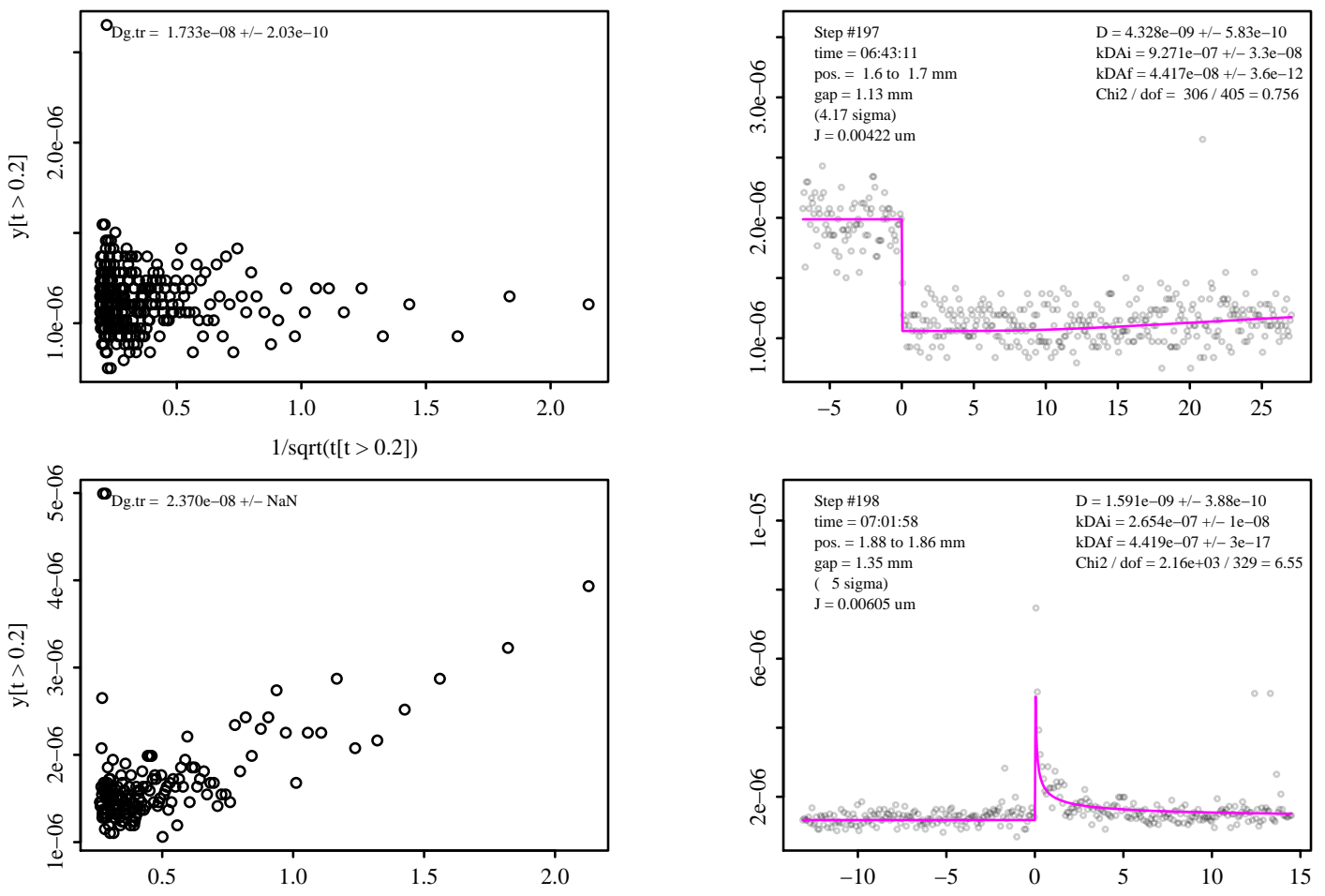

$\frac{\pi}{3}$
$\frac{0}{0}$
0
0
0
0
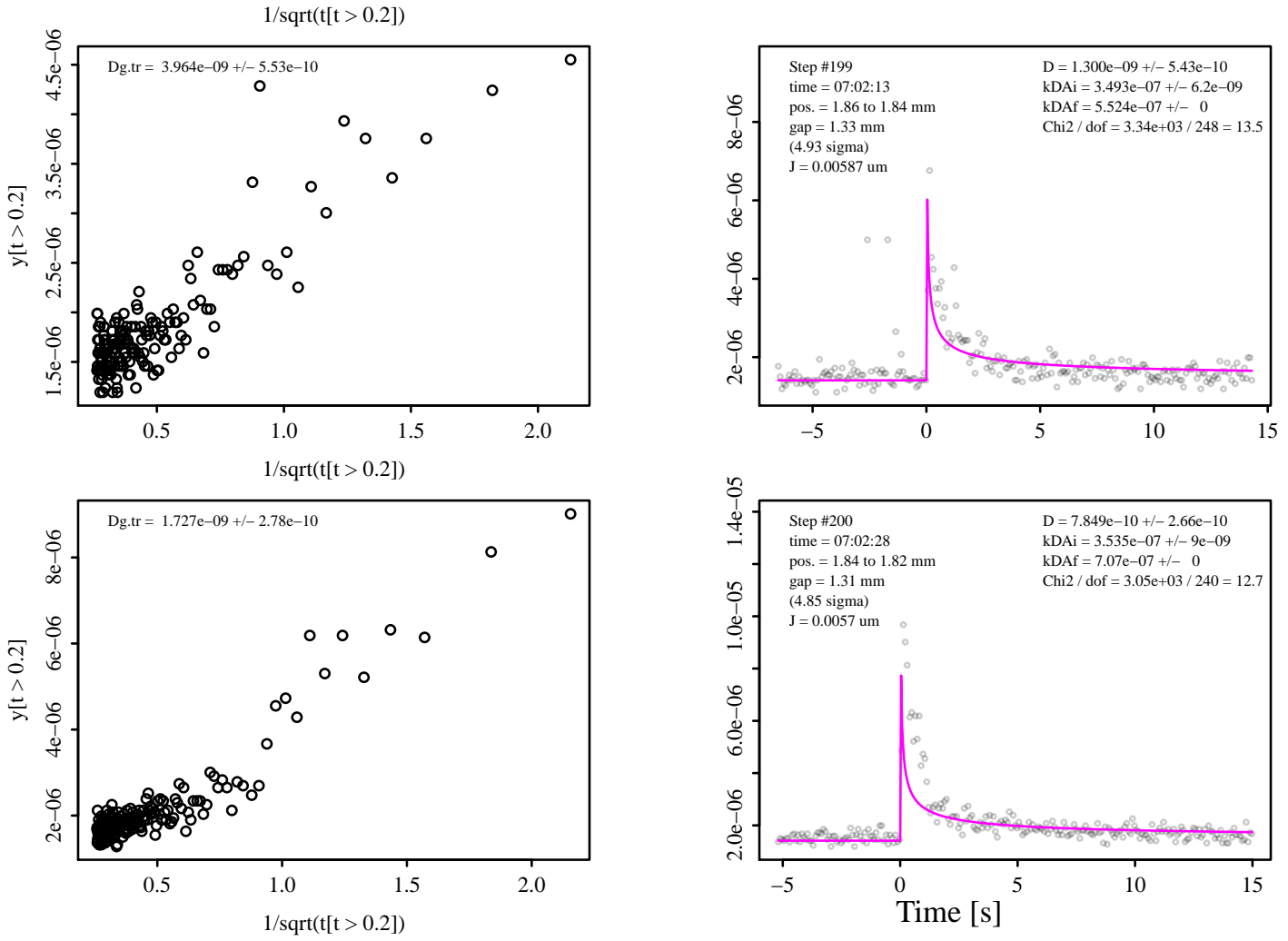

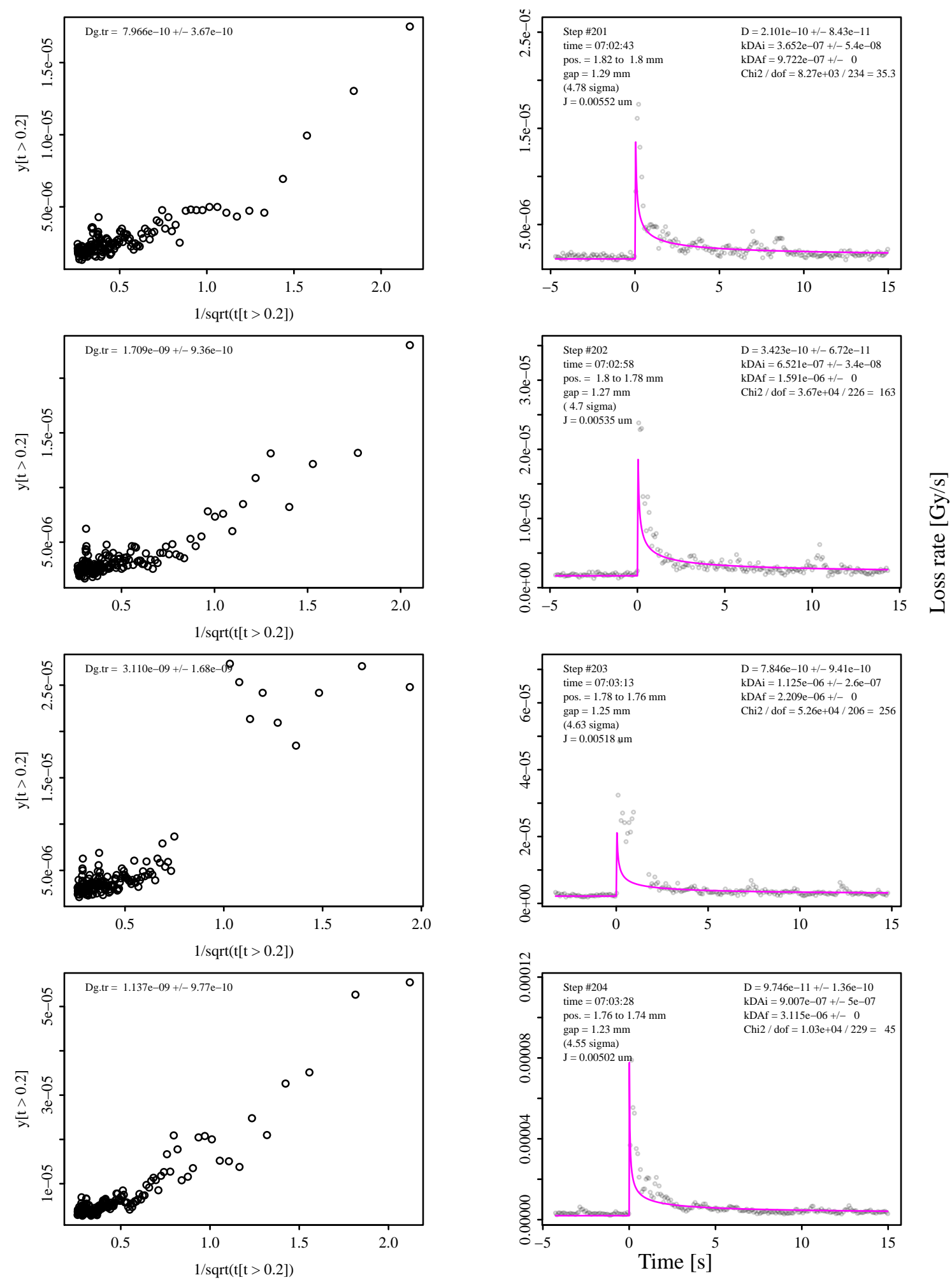

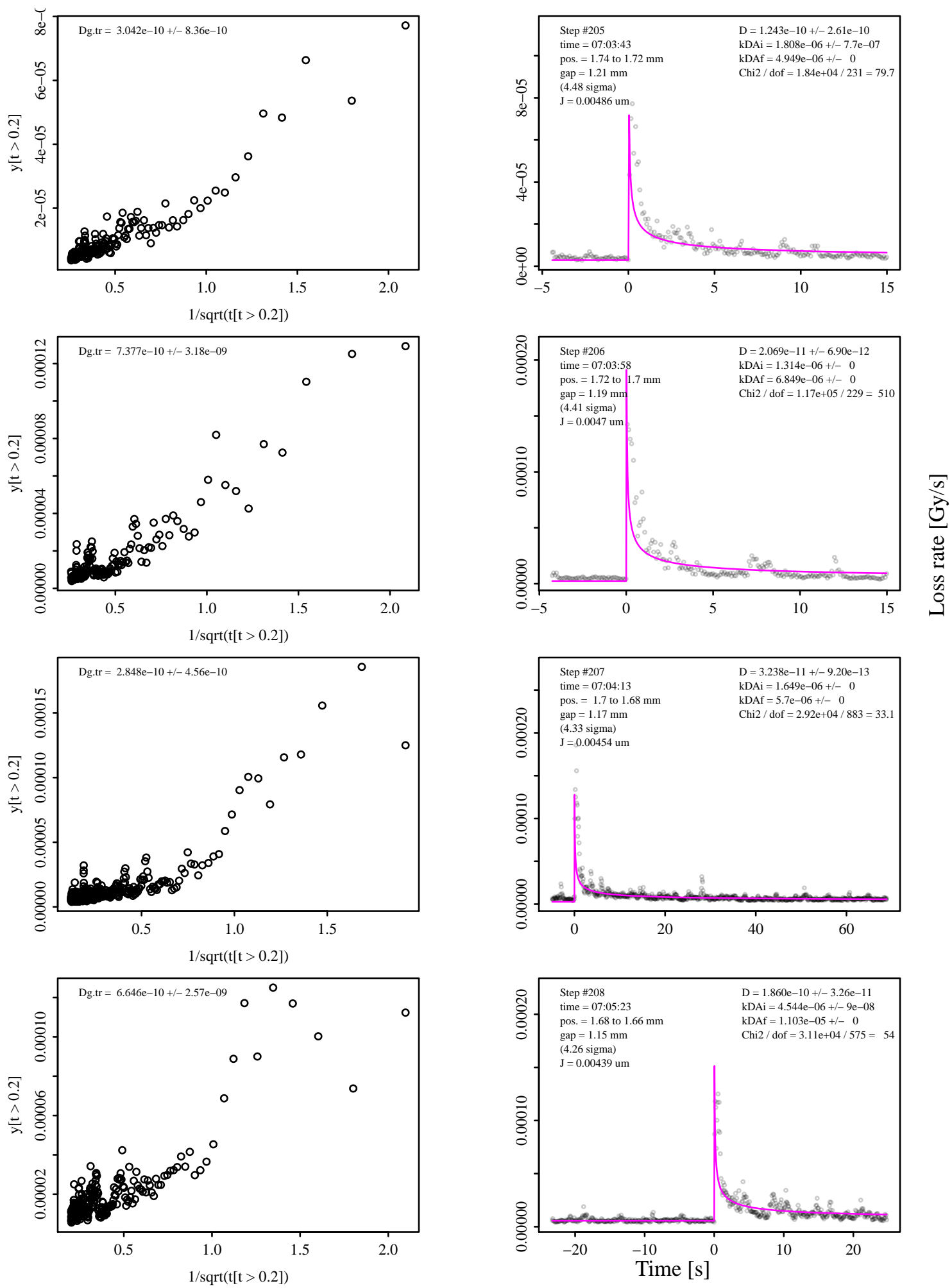

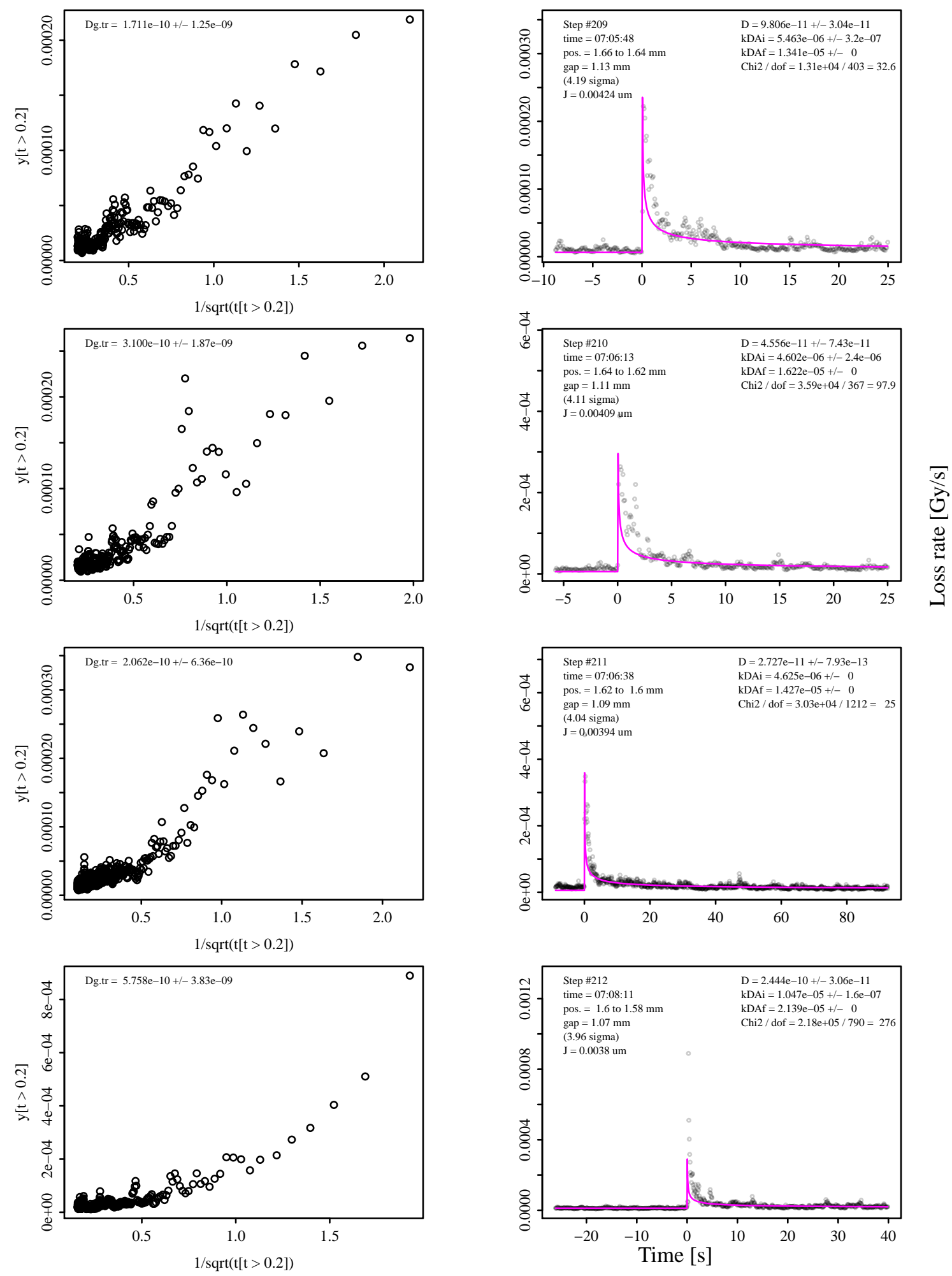

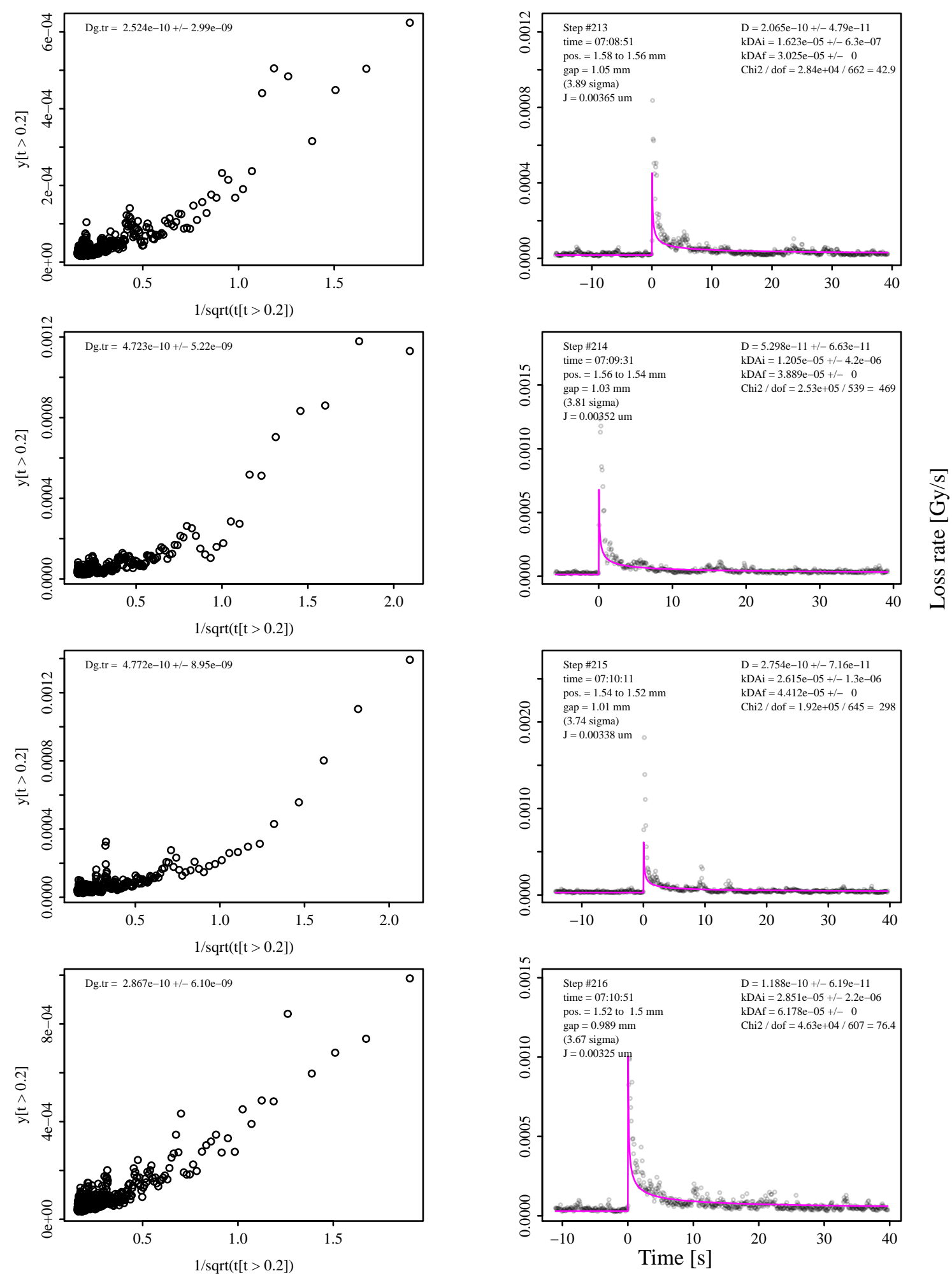

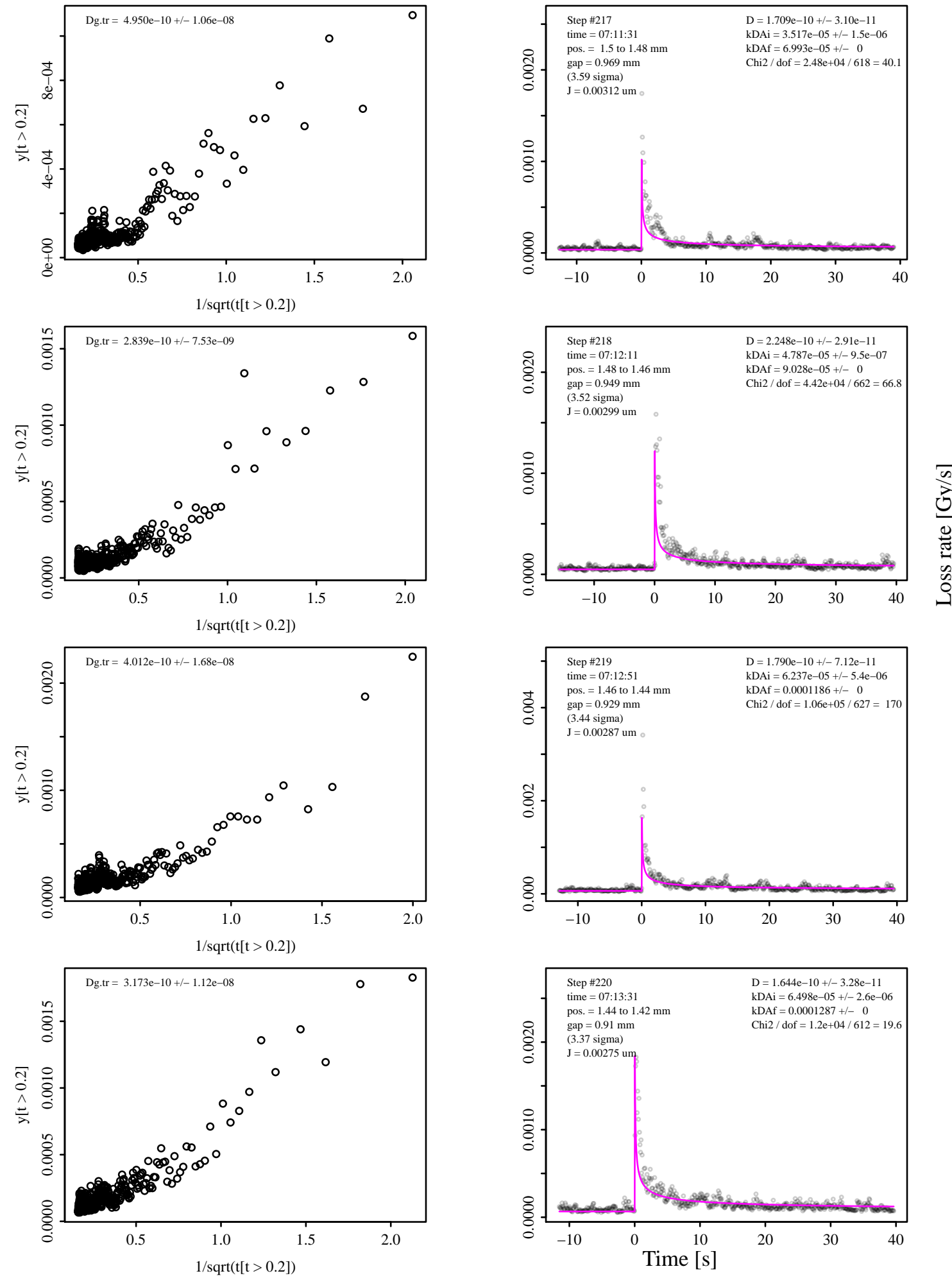

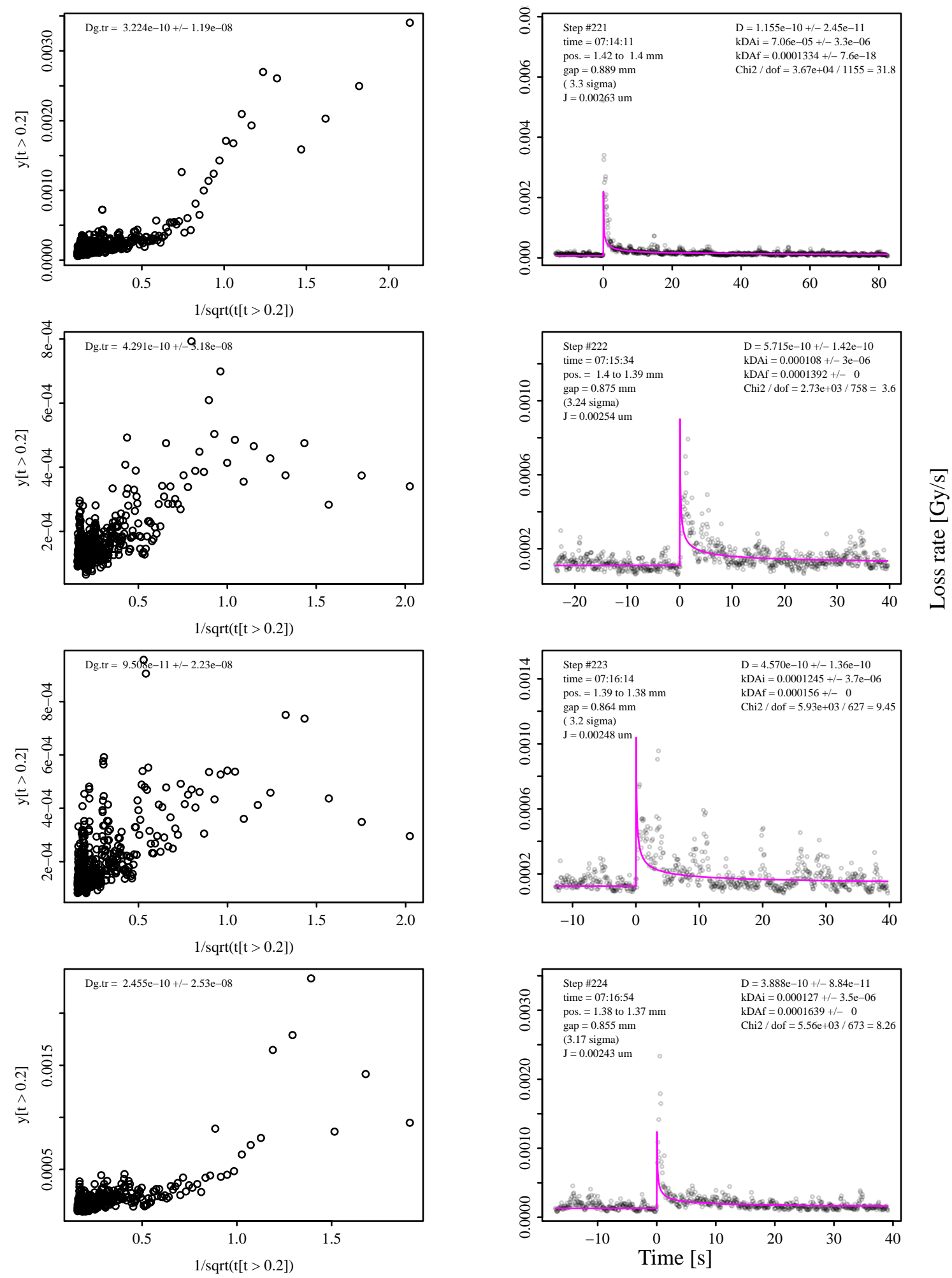

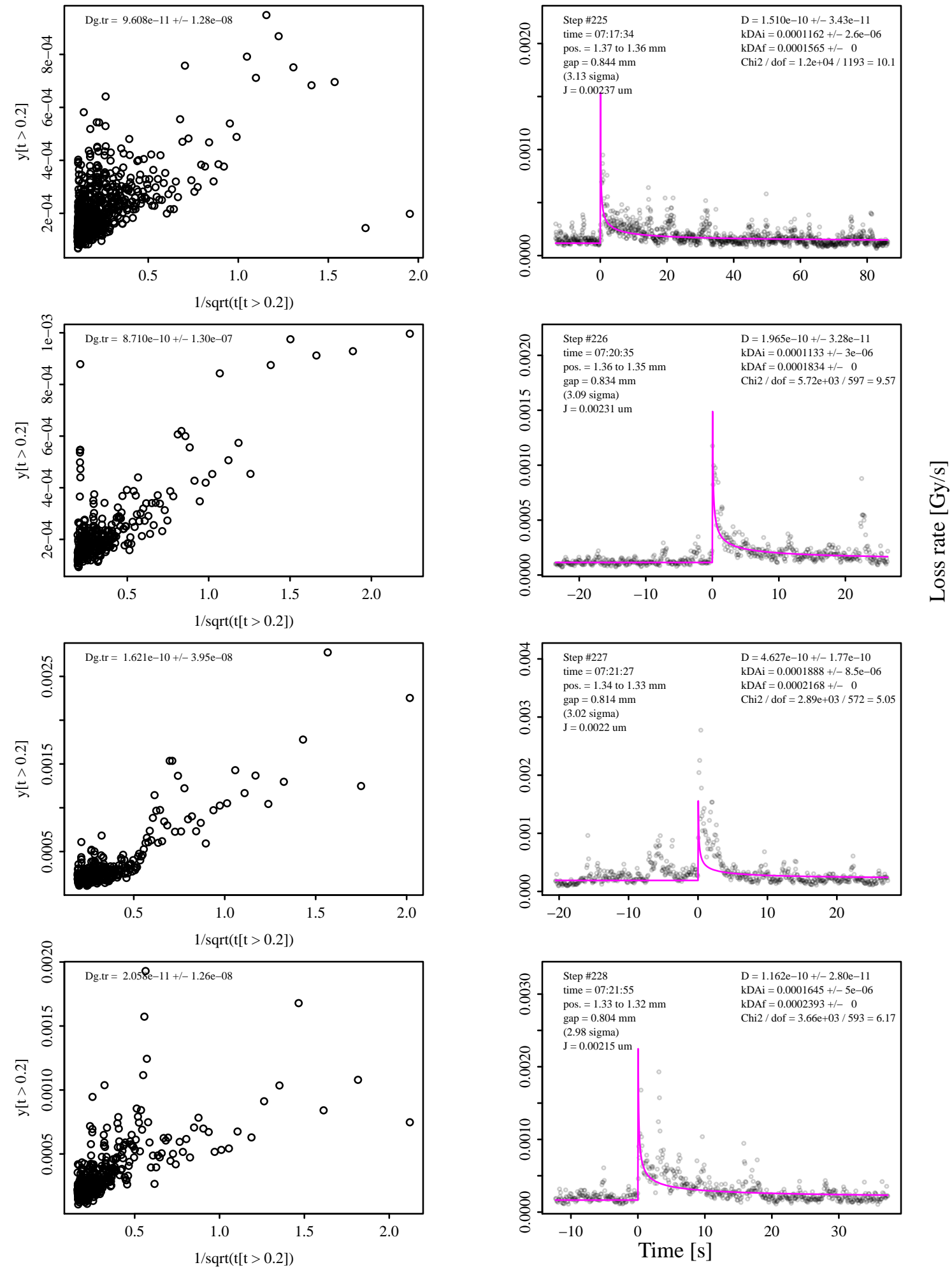

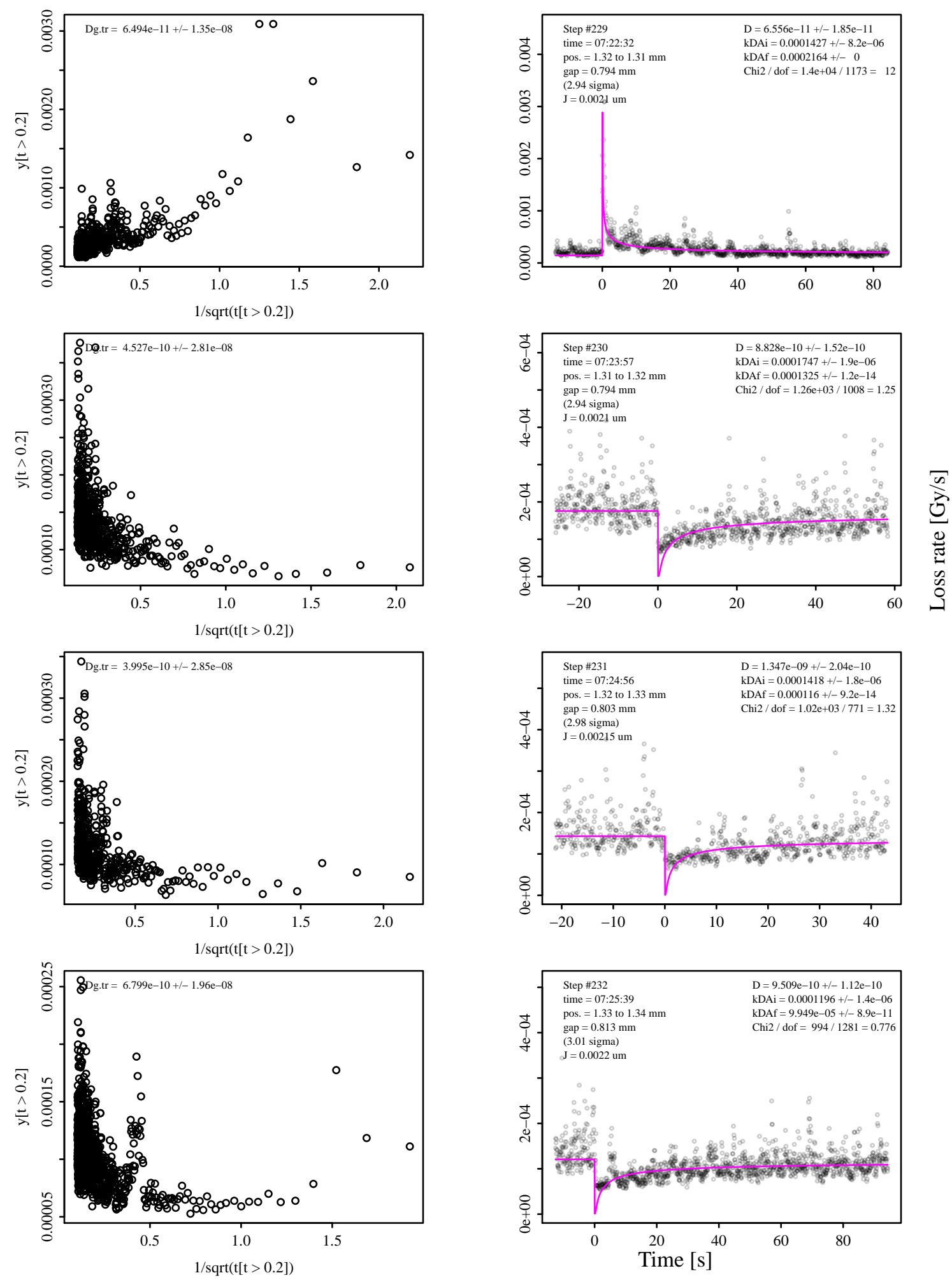

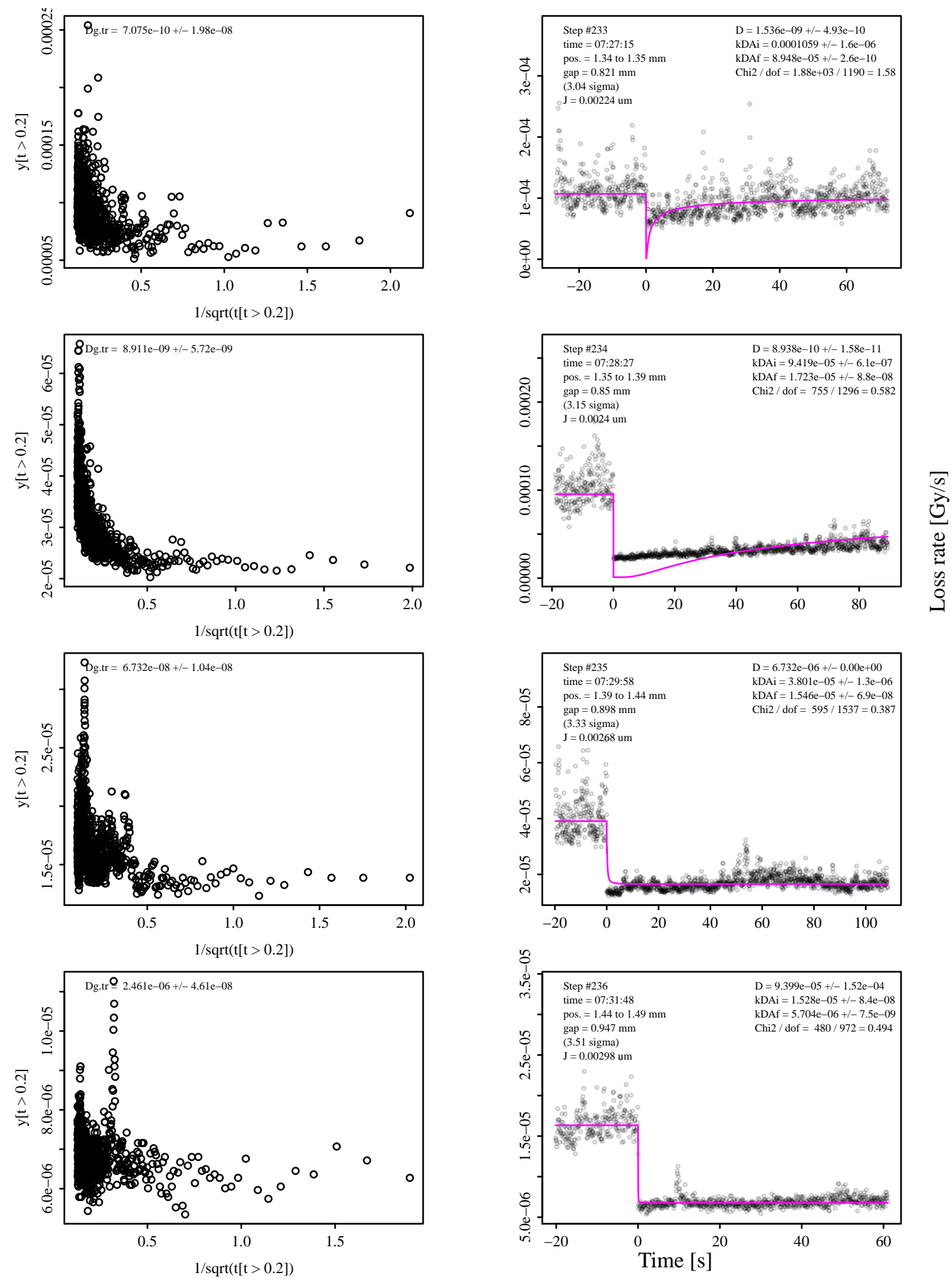

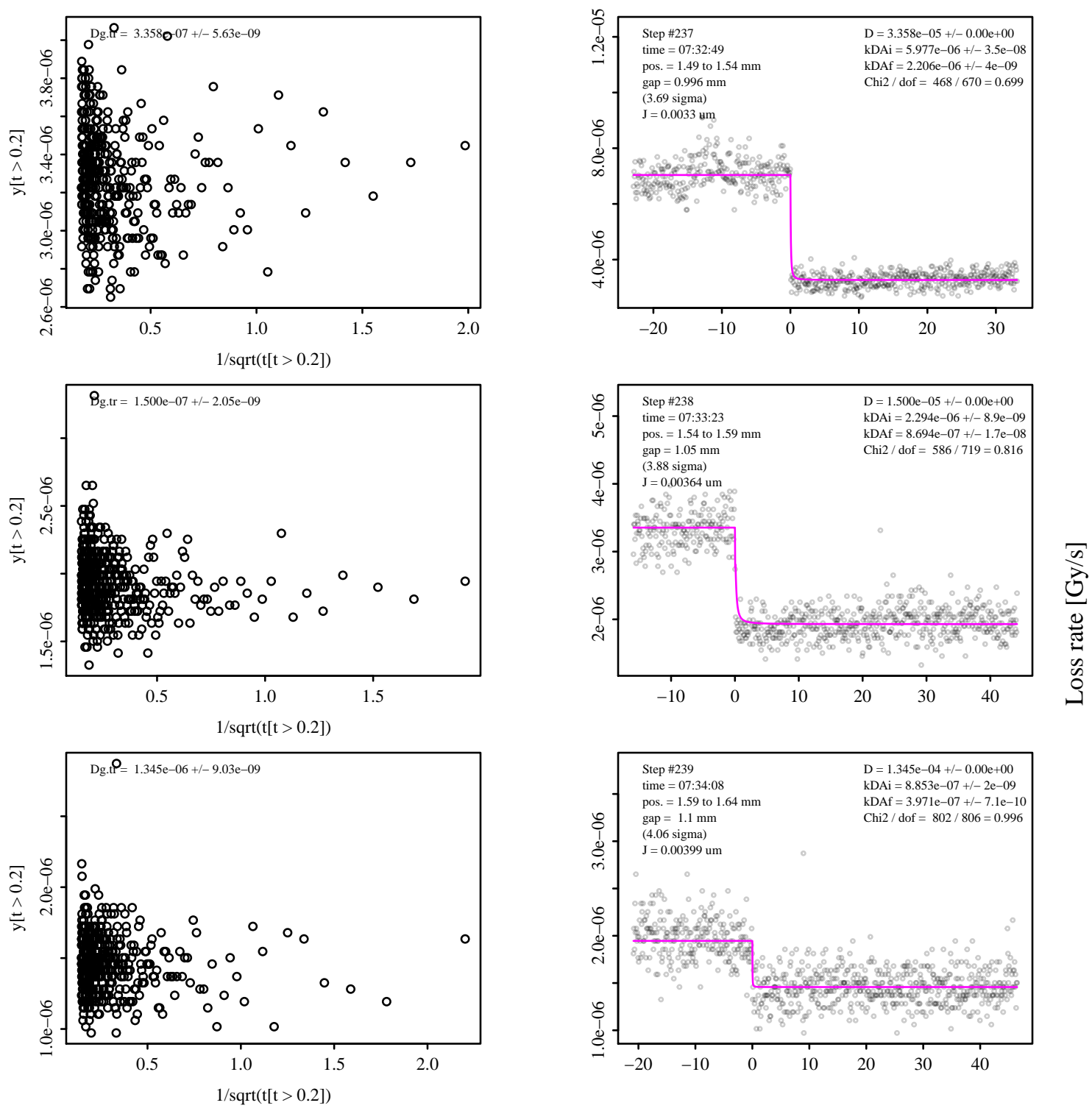

Time [s] 


\section{Appendix B: Table of collimator steps}

Unix time $[\mathrm{s}]$ Local time Size $[\mu \mathrm{m}]$ Init. half gap $[\mathrm{mm}]$ Collisions? Beam/plane

\begin{tabular}{|c|c|c|c|c|c|}
\hline 11340337548.833 & 05:59:08 & -20.9 & 0.992 & $\mathrm{~F}$ & $\mathrm{~B} 1 \mathrm{~V}$ \\
\hline 21340337575.097 & $05: 59: 35$ & -9.81 & 0.971 & $\mathrm{~F}$ & $\mathrm{~B} 1 \mathrm{~V}$ \\
\hline 31340337622.708 & $06: 00: 22$ & -9.71 & 0.962 & $\mathrm{~F}$ & $\mathrm{~B} 1 \mathrm{~V}$ \\
\hline 41340337632.739 & $06: 00: 32$ & -10.1 & 0.952 & $\mathrm{~F}$ & $\mathrm{~B} 1 \mathrm{~V}$ \\
\hline 51340337642.739 & 06:00:42 & -10.1 & 0.942 & $\mathrm{~F}$ & $\mathrm{~B} 1 \mathrm{~V}$ \\
\hline 61340337652.752 & 06:00:52 & -10.2 & 0.932 & $\mathrm{~F}$ & $\mathrm{~B} 1 \mathrm{~V}$ \\
\hline 71340337662.691 & 06:01:02 & -9.91 & 0.922 & $\mathrm{~F}$ & $\mathrm{~B} 1 \mathrm{~V}$ \\
\hline 81340337686.789 & $06: 01: 26$ & -10.5 & 0.912 & $\mathrm{~F}$ & B1V \\
\hline 91340337701.848 & 06:01:41 & -10.3 & 0.901 & $\mathrm{~F}$ & $\mathrm{~B} 1 \mathrm{~V}$ \\
\hline 101340337716.774 & $06: 01: 56$ & -10.3 & 0.89 & $\mathrm{~F}$ & $\mathrm{~B} 1 \mathrm{~V}$ \\
\hline 111340337731.791 & 06:02:11 & -9.43 & 0.88 & $\mathrm{~F}$ & $\mathrm{~B} 1 \mathrm{~V}$ \\
\hline 121340337746.774 & $06: 02: 26$ & -10.1 & 0.87 & $\mathrm{~F}$ & B1V \\
\hline 131340337761.786 & 06:02:41 & -10.2 & 0.861 & $\mathrm{~F}$ & B1V \\
\hline 141340337776.790 & $06: 02: 56$ & -9.51 & 0.85 & $\mathrm{~F}$ & $\mathrm{~B} 1 \mathrm{~V}$ \\
\hline 151340337791.754 & 06:03:11 & -9.91 & 0.841 & $\mathrm{~F}$ & $\mathrm{~B} 1 \mathrm{~V}$ \\
\hline 161340337806.767 & $06: 03: 26$ & -10.5 & 0.831 & $\mathrm{~F}$ & $\mathrm{~B} 1 \mathrm{~V}$ \\
\hline 171340337821.790 & 06:03:41 & -10.2 & 0.82 & $\mathrm{~F}$ & $\mathrm{~B} 1 \mathrm{~V}$ \\
\hline 181340337844.426 & 06:04:04 & -9.79 & 0.81 & $\mathrm{~F}$ & $\mathrm{~B} 1 \mathrm{~V}$ \\
\hline 191340337859.398 & 06:04:19 & -9.51 & 0.8 & $\mathrm{~F}$ & $\mathrm{~B} 1 \mathrm{~V}$ \\
\hline 201340337874.402 & 06:04:34 & -9.85 & 0.791 & $\mathrm{~F}$ & $\mathrm{~B} 1 \mathrm{~V}$ \\
\hline 211340337889.443 & 06:04:49 & -9.75 & 0.781 & $\mathrm{~F}$ & $\mathrm{~B} 1 \mathrm{~V}$ \\
\hline $22 \quad 1340337904.430$ & 06:05:04 & -10.2 & 0.771 & $\mathrm{~F}$ & $\mathrm{~B} 1 \mathrm{~V}$ \\
\hline 231340337919.432 & 06:05:19 & -10.1 & 0.76 & $\mathrm{~F}$ & $\mathrm{~B} 1 \mathrm{~V}$ \\
\hline 241340337934.432 & $06: 05: 34$ & -9.71 & 0.75 & $\mathrm{~F}$ & $\mathrm{~B} 1 \mathrm{~V}$ \\
\hline 251340337949.433 & 06:05:49 & -10.3 & 0.74 & $\mathrm{~F}$ & $\mathrm{~B} 1 \mathrm{~V}$ \\
\hline 261340337964.424 & 06:06:04 & -9.73 & 0.73 & $\mathrm{~F}$ & B1V \\
\hline 271340337979.430 & 06:06:19 & -8.95 & 0.72 & $\mathrm{~F}$ & $\mathrm{~B} 1 \mathrm{~V}$ \\
\hline 281340338015.612 & $06: 06: 55$ & -9.95 & 0.711 & $\mathrm{~F}$ & $\mathrm{~B} 1 \mathrm{~V}$ \\
\hline 291340338030.615 & 06:07:10 & -10 & 0.701 & $\mathrm{~F}$ & $\mathrm{~B} 1 \mathrm{~V}$ \\
\hline 301340338098.519 & 06:08:18 & -9.47 & 0.691 & $\mathrm{~F}$ & $\mathrm{~B} 1 \mathrm{~V}$ \\
\hline 311340338123.509 & $06: 08: 43$ & -9.34 & 0.681 & $\mathrm{~F}$ & $\mathrm{~B} 1 \mathrm{~V}$ \\
\hline 321340338148.513 & 06:09:08 & -10 & 0.671 & $\mathrm{~F}$ & $\mathrm{~B} 1 \mathrm{~V}$ \\
\hline 331340338173.509 & 06:09:33 & -10 & 0.661 & $\mathrm{~F}$ & $\mathrm{~B} 1 \mathrm{~V}$ \\
\hline 341340338198.526 & 06:09:58 & -9.97 & 0.651 & $\mathrm{~F}$ & $\mathrm{~B} 1 \mathrm{~V}$ \\
\hline
\end{tabular}




\begin{tabular}{|c|c|c|c|c|c|}
\hline 351340338275.519 & $06: 11: 15$ & -4.63 & 0.641 & $\mathrm{~F}$ & $\mathrm{~B} 1 \mathrm{~V}$ \\
\hline 361340338300.591 & $06: 11: 40$ & -5.51 & 0.636 & $\mathrm{~F}$ & $\mathrm{~B} 1 \mathrm{~V}$ \\
\hline 371340338325.565 & 06:12:05 & -3.89 & 0.631 & $\mathrm{~F}$ & $\mathrm{~B} 1 \mathrm{~V}$ \\
\hline 381340338350.582 & $06: 12: 30$ & -5.31 & 0.627 & $\mathrm{~F}$ & $\mathrm{~B} 1 \mathrm{~V}$ \\
\hline 391340338375.487 & $06: 12: 55$ & -4.8 & 0.621 & $\mathrm{~F}$ & $\mathrm{~B} 1 \mathrm{~V}$ \\
\hline 401340338400.532 & $06: 13: 20$ & -5.56 & 0.617 & $\mathrm{~F}$ & $\mathrm{~B} 1 \mathrm{~V}$ \\
\hline 411340338425.599 & $06: 13: 45$ & -4.55 & 0.611 & $\mathrm{~F}$ & $\mathrm{~B} 1 \mathrm{~V}$ \\
\hline 421340338450.591 & $06: 14: 10$ & -5.27 & 0.607 & $\mathrm{~F}$ & $\mathrm{~B} 1 \mathrm{~V}$ \\
\hline 431340338500.534 & 06:15:00 & -5.46 & 0.597 & $\mathrm{~F}$ & $\mathrm{~B} 1 \mathrm{~V}$ \\
\hline 441340338638.009 & $06: 17: 18$ & -4.42 & 0.592 & $\mathrm{~F}$ & $\mathrm{~B} 1 \mathrm{~V}$ \\
\hline 451340338678.012 & $06: 17: 58$ & -6.08 & 0.587 & $\mathrm{~F}$ & $\mathrm{~B} 1 \mathrm{~V}$ \\
\hline 461340338718.016 & $06: 18: 38$ & -4.59 & 0.581 & $\mathrm{~F}$ & $\mathrm{~B} 1 \mathrm{~V}$ \\
\hline 471340338758.016 & $06: 19: 18$ & -5.38 & 0.577 & $\mathrm{~F}$ & $\mathrm{~B} 1 \mathrm{~V}$ \\
\hline 481340338798.015 & $06: 19: 58$ & -4.6 & 0.571 & $\mathrm{~F}$ & $\mathrm{~B} 1 \mathrm{~V}$ \\
\hline 491340338838.009 & $06: 20: 38$ & -5.4 & 0.566 & $\mathrm{~F}$ & $\mathrm{~B} 1 \mathrm{~V}$ \\
\hline 501340338878.018 & $06: 21: 18$ & -4.73 & 0.561 & $\mathrm{~F}$ & $\mathrm{~B} 1 \mathrm{~V}$ \\
\hline 511340338918.033 & $06: 21: 58$ & -5.12 & 0.556 & $\mathrm{~F}$ & $\mathrm{~B} 1 \mathrm{~V}$ \\
\hline 521340338958.022 & $06: 22: 38$ & -4.15 & 0.551 & $\mathrm{~F}$ & $\mathrm{~B} 1 \mathrm{~V}$ \\
\hline 531340338998.024 & $06: 23: 18$ & -5.12 & 0.546 & $\mathrm{~F}$ & $\mathrm{~B} 1 \mathrm{~V}$ \\
\hline 541340339059.019 & $06: 24: 19$ & -4.71 & 0.541 & $\mathrm{~F}$ & $\mathrm{~B} 1 \mathrm{~V}$ \\
\hline 551340339099.046 & $06: 24: 59$ & -5.65 & 0.537 & $\mathrm{~F}$ & $\mathrm{~B} 1 \mathrm{~V}$ \\
\hline 561340339139.035 & $06: 25: 39$ & -4.67 & 0.531 & $\mathrm{~F}$ & $\mathrm{~B} 1 \mathrm{~V}$ \\
\hline 571340339179.020 & $06: 26: 19$ & -5.49 & 0.527 & $\mathrm{~F}$ & $\mathrm{~B} 1 \mathrm{~V}$ \\
\hline 581340339219.041 & $06: 26: 59$ & -4.72 & 0.521 & $\mathrm{~F}$ & $\mathrm{~B} 1 \mathrm{~V}$ \\
\hline 591340339259.059 & $06: 27: 39$ & -5.16 & 0.517 & $\mathrm{~F}$ & $\mathrm{~B} 1 \mathrm{~V}$ \\
\hline 601340339339.012 & $06: 28: 59$ & -5.25 & 0.507 & $\mathrm{~F}$ & $\mathrm{~B} 1 \mathrm{~V}$ \\
\hline 611340339379.013 & $06: 29: 39$ & -4.53 & 0.502 & $\mathrm{~F}$ & $\mathrm{~B} 1 \mathrm{~V}$ \\
\hline 621340339419.036 & $06: 30: 19$ & -5.53 & 0.497 & $\mathrm{~F}$ & $\mathrm{~B} 1 \mathrm{~V}$ \\
\hline 631340339590.660 & $06: 33: 10$ & 17.6 & 0.491 & $\mathrm{~F}$ & $\mathrm{~B} 1 \mathrm{~V}$ \\
\hline 641340339630.617 & $06: 33: 50$ & 18.4 & 0.509 & $\mathrm{~F}$ & $\mathrm{~B} 1 \mathrm{~V}$ \\
\hline 651340339873.123 & $06: 37: 53$ & 17.7 & 0.527 & $\mathrm{~F}$ & $\mathrm{~B} 1 \mathrm{~V}$ \\
\hline 661340339934.797 & $06: 38: 54$ & 18.9 & 0.544 & $\mathrm{~F}$ & $\mathrm{~B} 1 \mathrm{~V}$ \\
\hline 671340339965.834 & $06: 39: 25$ & 94.2 & 0.564 & $\mathrm{~F}$ & $\mathrm{~B} 1 \mathrm{~V}$ \\
\hline 681340340025.845 & $06: 40: 25$ & 98 & 0.658 & $\mathrm{~F}$ & $\mathrm{~B} 1 \mathrm{~V}$ \\
\hline 691340341295.191 & $07: 01: 35$ & -19.8 & 1.13 & $\mathrm{~T}$ & $\mathrm{~B} 1 \mathrm{~V}$ \\
\hline 701340341310.200 & 07:01:50 & -19.7 & 1.11 & $\mathrm{~T}$ & $\mathrm{~B} 1 \mathrm{~V}$ \\
\hline 711340341325.193 & 07:02:05 & -19.8 & 1.09 & $\mathrm{~T}$ & $\mathrm{~B} 1 \mathrm{~V}$ \\
\hline
\end{tabular}




\begin{tabular}{|c|c|c|c|c|c|}
\hline 721340341340.197 & $07: 02: 20$ & -21.2 & 1.07 & $\mathrm{~T}$ & $\mathrm{~B} 1 \mathrm{~V}$ \\
\hline 731340341355.185 & $07: 02: 35$ & -20.4 & 1.05 & $\mathrm{~T}$ & $\mathrm{~B} 1 \mathrm{~V}$ \\
\hline 741340341370.193 & $07: 02: 50$ & -20.5 & 1.03 & $\mathrm{~T}$ & $\mathrm{~B} 1 \mathrm{~V}$ \\
\hline 751340341385.197 & 07:03:05 & -20 & 1.01 & $\mathrm{~T}$ & $\mathrm{~B} 1 \mathrm{~V}$ \\
\hline 761340341400.202 & 07:03:20 & -20.5 & 0.991 & $\mathrm{~T}$ & $\mathrm{~B} 1 \mathrm{~V}$ \\
\hline 771340341415.185 & 07:03:35 & -20.4 & 0.97 & $\mathrm{~T}$ & $\mathrm{~B} 1 \mathrm{~V}$ \\
\hline 781340341430.189 & 07:03:50 & -19.8 & 0.949 & $\mathrm{~T}$ & $\mathrm{~B} 1 \mathrm{~V}$ \\
\hline 791340341447.935 & 07:04:07 & -20 & 0.93 & $\mathrm{~T}$ & B1V \\
\hline 801340341462.935 & 07:04:22 & -20.6 & 0.91 & $\mathrm{~T}$ & $\mathrm{~B} 1 \mathrm{~V}$ \\
\hline 811340341477.957 & $07: 04: 37$ & -19.9 & 0.889 & $\mathrm{~T}$ & $\mathrm{~B} 1 \mathrm{~V}$ \\
\hline 821340341506.378 & 07:05:06 & -20.4 & 0.869 & $\mathrm{~T}$ & $\mathrm{~B} 1 \mathrm{~V}$ \\
\hline 831340341531.437 & 07:05:31 & -19.9 & 0.849 & $\mathrm{~T}$ & $\mathrm{~B} 1 \mathrm{~V}$ \\
\hline 841340341556.448 & 07:05:56 & -20.3 & 0.829 & $\mathrm{~T}$ & B1V \\
\hline 851340341581.392 & $07: 06: 21$ & -20.2 & 0.809 & $\mathrm{~T}$ & $\mathrm{~B} 1 \mathrm{~V}$ \\
\hline 861340341606.367 & 07:06:46 & -19.6 & 0.789 & $\mathrm{~T}$ & $\mathrm{~B} 1 \mathrm{~V}$ \\
\hline 871340341631.366 & 07:07:11 & -19.9 & 0.769 & $\mathrm{~T}$ & $\mathrm{~B} 1 \mathrm{~V}$ \\
\hline 881340341656.359 & $07: 07: 36$ & -20 & 0.749 & $\mathrm{~T}$ & $\mathrm{~B} 1 \mathrm{~V}$ \\
\hline 891340341681.364 & 07:08:01 & -19.5 & 0.729 & $\mathrm{~T}$ & $\mathrm{~B} 1 \mathrm{~V}$ \\
\hline 901340341706.371 & 07:08:26 & -19.8 & 0.71 & $\mathrm{~T}$ & B1V \\
\hline 911340341731.377 & 07:08:51 & -19.7 & 0.69 & $\mathrm{~T}$ & $\mathrm{~B} 1 \mathrm{~V}$ \\
\hline 921340341775.047 & 07:09:35 & -19.9 & 0.67 & $\mathrm{~T}$ & $\mathrm{~B} 1 \mathrm{~V}$ \\
\hline 931340341800.040 & 07:10:00 & -19.9 & 0.65 & $\mathrm{~T}$ & $\mathrm{~B} 1 \mathrm{~V}$ \\
\hline 941340341847.691 & $07: 10: 47$ & -20 & 0.63 & $\mathrm{~T}$ & $\mathrm{~B} 1 \mathrm{~V}$ \\
\hline 951340341887.698 & $07: 11: 27$ & -19.5 & 0.61 & $\mathrm{~T}$ & $\mathrm{~B} 1 \mathrm{~V}$ \\
\hline 961340341927.705 & 07:12:07 & -20.5 & 0.591 & $\mathrm{~T}$ & $\mathrm{~B} 1 \mathrm{~V}$ \\
\hline 971340341991.739 & $07: 13: 11$ & -9.6 & 0.57 & $\mathrm{~T}$ & $\mathrm{~B} 1 \mathrm{~V}$ \\
\hline 981340342031.713 & $07: 13: 51$ & -9.77 & 0.561 & $\mathrm{~T}$ & $\mathrm{~B} 1 \mathrm{~V}$ \\
\hline 991340342071.691 & $07: 14: 31$ & -9.68 & 0.551 & $\mathrm{~T}$ & $\mathrm{~B} 1 \mathrm{~V}$ \\
\hline 1001340342111.693 & $07: 15: 11$ & -20.4 & 0.541 & $\mathrm{~T}$ & $\mathrm{~B} 1 \mathrm{~V}$ \\
\hline 1011340342151.675 & $07: 15: 51$ & -14.2 & 0.521 & $\mathrm{~T}$ & $\mathrm{~B} 1 \mathrm{~V}$ \\
\hline 1021340342191.702 & $07: 16: 31$ & -10.4 & 0.507 & $\mathrm{~T}$ & $\mathrm{~B} 1 \mathrm{~V}$ \\
\hline 1031340342231.681 & $07: 17: 11$ & -9.98 & 0.496 & $\mathrm{~T}$ & B1V \\
\hline 1041340342271.696 & $07: 17: 51$ & -10.6 & 0.486 & $\mathrm{~T}$ & $\mathrm{~B} 1 \mathrm{~V}$ \\
\hline 1051340342383.511 & 07:19:43 & -5.64 & 0.476 & $\mathrm{~T}$ & B1V \\
\hline 1061340342413.192 & $07: 20: 13$ & -4.51 & 0.47 & $\mathrm{~T}$ & $\mathrm{~B} 1 \mathrm{~V}$ \\
\hline 1071340342441.185 & 07:20:41 & -5.71 & 0.466 & $\mathrm{~T}$ & $\mathrm{~B} 1 \mathrm{~V}$ \\
\hline 1081340342475.084 & $07: 21: 15$ & -5.13 & 0.46 & $\mathrm{~T}$ & $\mathrm{~B} 1 \mathrm{~V}$ \\
\hline
\end{tabular}




\begin{tabular}{|c|c|c|c|c|c|}
\hline 1091340342493.590 & $07: 21: 33$ & -5.17 & 0.454 & $\mathrm{~T}$ & $\mathrm{~B} 1 \mathrm{~V}$ \\
\hline 1101340342527.377 & $07: 22: 07$ & -4.42 & 0.449 & $\mathrm{~T}$ & $\mathrm{~B} 1 \mathrm{~V}$ \\
\hline 1111340342547.110 & $07: 22: 27$ & -5.29 & 0.445 & $\mathrm{~T}$ & $\mathrm{~B} 1 \mathrm{~V}$ \\
\hline 1121340342606.709 & $07: 23: 26$ & 8.72 & 0.44 & $\mathrm{~T}$ & $\mathrm{~B} 1 \mathrm{~V}$ \\
\hline 1131340342678.828 & $07: 24: 38$ & 9.35 & 0.448 & $\mathrm{~T}$ & $\mathrm{~B} 1 \mathrm{~V}$ \\
\hline 1141340342774.161 & $07: 26: 14$ & 9.29 & 0.457 & $\mathrm{~T}$ & $\mathrm{~B} 1 \mathrm{~V}$ \\
\hline 1151340342857.830 & $07: 27: 37$ & 9.54 & 0.467 & $\mathrm{~T}$ & $\mathrm{~B} 1 \mathrm{~V}$ \\
\hline 1161340342923.165 & $07: 28: 43$ & 9.22 & 0.476 & $\mathrm{~T}$ & $\mathrm{~B} 1 \mathrm{~V}$ \\
\hline 1171340342973.231 & $07: 29: 33$ & 18.5 & 0.486 & $\mathrm{~T}$ & $\mathrm{~B} 1 \mathrm{~V}$ \\
\hline 1181340343099.747 & $07: 31: 39$ & 19.1 & 0.504 & $\mathrm{~T}$ & $\mathrm{~B} 1 \mathrm{~V}$ \\
\hline 1191340343159.647 & $07: 32: 39$ & 18.3 & 0.523 & $\mathrm{~T}$ & $\mathrm{~B} 1 \mathrm{~V}$ \\
\hline 1201340343209.508 & $07: 33: 29$ & 18.6 & 0.542 & $\mathrm{~T}$ & $\mathrm{~B} 1 \mathrm{~V}$ \\
\hline 1211340343243.045 & 07:34:03 & 47.7 & 0.56 & $\mathrm{~T}$ & $\mathrm{~B} 1 \mathrm{~V}$ \\
\hline 1221340338087.014 & 06:08:07 & -10 & 1.54 & $\mathrm{~F}$ & $\mathrm{~B} 2 \mathrm{H}$ \\
\hline 1231340338097.009 & $06: 08: 17$ & -9.04 & 1.53 & $\mathrm{~F}$ & $\mathrm{~B} 2 \mathrm{H}$ \\
\hline 1241340338106.932 & $06: 08: 26$ & -10.9 & 1.52 & $\mathrm{~F}$ & $\mathrm{~B} 2 \mathrm{H}$ \\
\hline 1251340338116.975 & $06: 08: 36$ & -10.5 & 1.51 & $\mathrm{~F}$ & $\mathrm{~B} 2 \mathrm{H}$ \\
\hline 1261340338126.971 & $06: 08: 46$ & -10.7 & 1.5 & $\mathrm{~F}$ & $\mathrm{~B} 2 \mathrm{H}$ \\
\hline 1271340338137.011 & $06: 08: 57$ & -8.15 & 1.49 & $\mathrm{~F}$ & $\mathrm{~B} 2 \mathrm{H}$ \\
\hline 1281340338146.999 & 06:09:06 & -10.4 & 1.48 & $\mathrm{~F}$ & $\mathrm{~B} 2 \mathrm{H}$ \\
\hline 1291340338156.968 & 06:09:16 & -9.9 & 1.47 & $\mathrm{~F}$ & $\mathrm{~B} 2 \mathrm{H}$ \\
\hline 1301340338210.518 & $06: 10: 10$ & -10.6 & 1.46 & $\mathrm{~F}$ & $\mathrm{~B} 2 \mathrm{H}$ \\
\hline 1311340338220.314 & $06: 10: 20$ & -9.06 & 1.45 & $\mathrm{~F}$ & $\mathrm{~B} 2 \mathrm{H}$ \\
\hline 1321340338230.574 & $06: 10: 30$ & -10.5 & 1.44 & $\mathrm{~F}$ & $\mathrm{~B} 2 \mathrm{H}$ \\
\hline 1331340338240.582 & $06: 10: 40$ & -9.85 & 1.43 & $\mathrm{~F}$ & $\mathrm{~B} 2 \mathrm{H}$ \\
\hline 1341340338250.537 & $06: 10: 50$ & -10.9 & 1.42 & $\mathrm{~F}$ & $\mathrm{~B} 2 \mathrm{H}$ \\
\hline 1351340338260.531 & 06:11:00 & -8.79 & 1.41 & $\mathrm{~F}$ & $\mathrm{~B} 2 \mathrm{H}$ \\
\hline 1361340338270.550 & $06: 11: 10$ & -11 & 1.4 & $\mathrm{~F}$ & $\mathrm{~B} 2 \mathrm{H}$ \\
\hline 1371340338280.530 & $06: 11: 20$ & -9.58 & 1.39 & $\mathrm{~F}$ & $\mathrm{~B} 2 \mathrm{H}$ \\
\hline 1381340338290.549 & $06: 11: 30$ & -10.4 & 1.38 & $\mathrm{~F}$ & $\mathrm{~B} 2 \mathrm{H}$ \\
\hline 1391340338300.589 & $06: 11: 40$ & -9.29 & 1.37 & $\mathrm{~F}$ & $\mathrm{~B} 2 \mathrm{H}$ \\
\hline 1401340338310.553 & $06: 11: 50$ & -10.9 & 1.36 & $\mathrm{~F}$ & $\mathrm{~B} 2 \mathrm{H}$ \\
\hline 1411340338320.522 & $06: 12: 00$ & -9.87 & 1.35 & $\mathrm{~F}$ & $\mathrm{~B} 2 \mathrm{H}$ \\
\hline 1421340338330.557 & $06: 12: 10$ & -10.8 & 1.34 & $\mathrm{~F}$ & $\mathrm{~B} 2 \mathrm{H}$ \\
\hline 1431340338340.596 & $06: 12: 20$ & -8.92 & 1.33 & $\mathrm{~F}$ & $\mathrm{~B} 2 \mathrm{H}$ \\
\hline 1441340338350.555 & $06: 12: 30$ & -10.4 & 1.32 & $\mathrm{~F}$ & $\mathrm{~B} 2 \mathrm{H}$ \\
\hline 1451340338360.427 & $06: 12: 40$ & -9.61 & 1.31 & $\mathrm{~F}$ & $\mathrm{~B} 2 \mathrm{H}$ \\
\hline
\end{tabular}




\begin{tabular}{|c|c|c|c|c|c|}
\hline 1461340338370.427 & $06: 12: 50$ & -11 & 1.3 & $\mathrm{~F}$ & $\mathrm{~B} 2 \mathrm{H}$ \\
\hline 1471340338381.167 & 06:13:01 & -9.39 & 1.29 & $\mathrm{~F}$ & $\mathrm{~B} 2 \mathrm{H}$ \\
\hline 1481340338396.177 & $06: 13: 16$ & -10.5 & 1.28 & $\mathrm{~F}$ & $\mathrm{~B} 2 \mathrm{H}$ \\
\hline 1491340338411.190 & $06: 13: 31$ & -9.77 & 1.27 & $\mathrm{~F}$ & $\mathrm{~B} 2 \mathrm{H}$ \\
\hline 1501340338426.192 & $06: 13: 46$ & -10.5 & 1.26 & $\mathrm{~F}$ & $\mathrm{~B} 2 \mathrm{H}$ \\
\hline 1511340338441.199 & 06:14:01 & -9.19 & 1.25 & $\mathrm{~F}$ & $\mathrm{~B} 2 \mathrm{H}$ \\
\hline 1521340338456.202 & $06: 14: 16$ & -10.5 & 1.24 & $\mathrm{~F}$ & $\mathrm{~B} 2 \mathrm{H}$ \\
\hline 1531340338471.190 & $06: 14: 31$ & -9.75 & 1.23 & $\mathrm{~F}$ & $\mathrm{~B} 2 \mathrm{H}$ \\
\hline 1541340338486.198 & $06: 14: 46$ & -10 & 1.22 & $\mathrm{~F}$ & $\mathrm{~B} 2 \mathrm{H}$ \\
\hline 1551340338501.197 & 06:15:01 & -9.17 & 1.21 & $\mathrm{~F}$ & $\mathrm{~B} 2 \mathrm{H}$ \\
\hline 1561340338516.194 & $06: 15: 16$ & -10.5 & 1.2 & $\mathrm{~F}$ & $\mathrm{~B} 2 \mathrm{H}$ \\
\hline 1571340338531.182 & $06: 15: 31$ & -9.94 & 1.19 & $\mathrm{~F}$ & $\mathrm{~B} 2 \mathrm{H}$ \\
\hline 1581340338546.209 & $06: 15: 46$ & -10.6 & 1.18 & $\mathrm{~F}$ & $\mathrm{~B} 2 \mathrm{H}$ \\
\hline 1591340338561.127 & 06:16:01 & -9.08 & 1.17 & $\mathrm{~F}$ & $\mathrm{~B} 2 \mathrm{H}$ \\
\hline 1601340338631.097 & $06: 17: 11$ & -11.1 & 1.16 & $\mathrm{~F}$ & $\mathrm{~B} 2 \mathrm{H}$ \\
\hline 1611340338646.099 & $06: 17: 26$ & -9.9 & 1.15 & $\mathrm{~F}$ & $\mathrm{~B} 2 \mathrm{H}$ \\
\hline 1621340338661.004 & $06: 17: 41$ & -10.8 & 1.14 & $\mathrm{~F}$ & $\mathrm{~B} 2 \mathrm{H}$ \\
\hline 1631340338676.034 & $06: 17: 56$ & -8.83 & 1.13 & $\mathrm{~F}$ & $\mathrm{~B} 2 \mathrm{H}$ \\
\hline 1641340338690.695 & $06: 18: 10$ & -10.8 & 1.12 & $\mathrm{~F}$ & $\mathrm{~B} 2 \mathrm{H}$ \\
\hline 1651340338705.418 & $06: 18: 25$ & -9.08 & 1.11 & $\mathrm{~F}$ & $\mathrm{~B} 2 \mathrm{H}$ \\
\hline 1661340338721.008 & $06: 18: 41$ & -10.5 & 1.1 & $\mathrm{~F}$ & $\mathrm{~B} 2 \mathrm{H}$ \\
\hline 1671340338736.109 & $06: 18: 56$ & -9.4 & 1.09 & $\mathrm{~F}$ & $\mathrm{~B} 2 \mathrm{H}$ \\
\hline 1681340338751.042 & $06: 19: 11$ & -10.8 & 1.08 & $\mathrm{~F}$ & $\mathrm{~B} 2 \mathrm{H}$ \\
\hline 1691340338766.021 & $06: 19: 26$ & -9.8 & 1.07 & $\mathrm{~F}$ & $\mathrm{~B} 2 \mathrm{H}$ \\
\hline 1701340338781.010 & 06:19:41 & -10.9 & 1.06 & $\mathrm{~F}$ & $\mathrm{~B} 2 \mathrm{H}$ \\
\hline 1711340338934.452 & $06: 22: 14$ & -10.7 & 1.03 & $\mathrm{~F}$ & $\mathrm{~B} 2 \mathrm{H}$ \\
\hline 1721340338954.396 & $06: 22: 34$ & -10.4 & 1.02 & $\mathrm{~F}$ & $\mathrm{~B} 2 \mathrm{H}$ \\
\hline 1731340338974.380 & $06: 22: 54$ & -9.93 & 1.01 & $\mathrm{~F}$ & $\mathrm{~B} 2 \mathrm{H}$ \\
\hline 1741340338994.445 & $06: 23: 14$ & -9.97 & 1 & $\mathrm{~F}$ & $\mathrm{~B} 2 \mathrm{H}$ \\
\hline 1751340339014.396 & $06: 23: 34$ & -10.2 & 0.994 & $\mathrm{~F}$ & $\mathrm{~B}$ \\
\hline 1761340339034.423 & $06: 23: 54$ & -10.3 & 0.983 & $\mathrm{~F}$ & $\mathrm{~B} 2 \mathrm{H}$ \\
\hline 1771340339054.368 & $06: 24: 14$ & -9.82 & 0.973 & $\mathrm{~F}$ & B \\
\hline 1781340339074.351 & $06: 24: 34$ & -9.97 & 0.963 & $\mathrm{~F}$ & $\mathrm{~B} 2 \mathrm{H}$ \\
\hline 1791340339094.408 & $06: 24: 54$ & -10.3 & 0.953 & $\mathrm{~F}$ & $\mathrm{~B}$ \\
\hline 1801340339141.531 & $06: 25: 41$ & -9.5 & 0.944 & $\mathrm{~F}$ & \\
\hline 1811340339181.511 & $06: 26: 21$ & -10.5 & 0.934 & $\mathrm{~F}$ & \\
\hline 1821340339221.530 & $06: 27: 01$ & -9.39 & 0.923 & $\mathrm{~F}$ & $\mathrm{~B} 2 \mathrm{H}$ \\
\hline
\end{tabular}




\begin{tabular}{|c|c|c|c|c|c|}
\hline 1831340339261.532 & $06: 27: 41$ & -10.3 & 0.914 & $\mathrm{~F}$ & $\mathrm{~B} 2 \mathrm{H}$ \\
\hline 1841340339301.522 & $06: 28: 21$ & -9.52 & 0.904 & $\mathrm{~F}$ & $\mathrm{~B} 2 \mathrm{H}$ \\
\hline 1851340339341.570 & 06:29:01 & -9.92 & 0.894 & $\mathrm{~F}$ & $\mathrm{~B} 2 \mathrm{H}$ \\
\hline 1861340339381.523 & $06: 29: 41$ & -10.3 & 0.884 & $\mathrm{~F}$ & $\mathrm{~B} 2 \mathrm{H}$ \\
\hline 1871340339421.505 & $06: 30: 21$ & -10.4 & 0.874 & $\mathrm{~F}$ & $\mathrm{~B} 2 \mathrm{H}$ \\
\hline 1881340339461.493 & 06:31:01 & -9.78 & 0.864 & $\mathrm{~F}$ & $\mathrm{~B} 2 \mathrm{H}$ \\
\hline 1891340339501.514 & $06: 31: 41$ & -10.3 & 0.854 & $\mathrm{~F}$ & $\mathrm{~B} 2 \mathrm{H}$ \\
\hline 1901340339614.119 & $06: 33: 34$ & -10.3 & 0.844 & $\mathrm{~F}$ & $\mathrm{~B} 2 \mathrm{H}$ \\
\hline 1911340339654.108 & $06: 34: 14$ & -10.1 & 0.834 & $\mathrm{~F}$ & $\mathrm{~B} 2 \mathrm{H}$ \\
\hline 1921340339804.898 & $06: 36: 44$ & 17.9 & 0.824 & $\mathrm{~F}$ & $\mathrm{~B} 2 \mathrm{H}$ \\
\hline 1931340339889.045 & 06:38:09 & 19 & 0.842 & $\mathrm{~F}$ & $\mathrm{~B} 2 \mathrm{H}$ \\
\hline 1941340339980.444 & 06:39:40 & 18.3 & 0.861 & $\mathrm{~F}$ & $\mathrm{~B} 2 \mathrm{H}$ \\
\hline 1951340340141.665 & $06: 42: 21$ & 96.4 & 0.88 & $\mathrm{~F}$ & $\mathrm{~B} 2 \mathrm{H}$ \\
\hline 1961340340179.750 & $06: 42: 59$ & 99.6 & 0.976 & $\mathrm{~F}$ & $\mathrm{~B} 2 \mathrm{H}$ \\
\hline 1971340340191.594 & $06: 43: 11$ & 99.5 & 1.08 & $\mathrm{~F}$ & $\mathrm{~B} 2 \mathrm{H}$ \\
\hline 1981340341318.670 & 07:01:58 & -20.5 & 1.36 & $\mathrm{~T}$ & $\mathrm{~B} 2 \mathrm{H}$ \\
\hline 1991340341333.670 & 07:02:13 & -19.1 & 1.34 & $\mathrm{~T}$ & $\mathrm{~B} 2 \mathrm{H}$ \\
\hline 2001340341348.676 & $07: 02: 28$ & -20.4 & 1.32 & $\mathrm{~T}$ & $\mathrm{~B} 2 \mathrm{H}$ \\
\hline 2011340341363.678 & $07: 02: 43$ & -19.9 & 1.3 & $\mathrm{~T}$ & $\mathrm{~B} 2 \mathrm{H}$ \\
\hline 2021340341378.653 & $07: 02: 58$ & -20 & 1.28 & $\mathrm{~T}$ & $\mathrm{~B} 2 \mathrm{H}$ \\
\hline 2031340341393.626 & 07:03:13 & -20.1 & 1.26 & $\mathrm{~T}$ & $\mathrm{~B} 2 \mathrm{H}$ \\
\hline 2041340341408.668 & $07: 03: 28$ & -20.4 & 1.24 & $\mathrm{~T}$ & $\mathrm{~B} 2 \mathrm{H}$ \\
\hline 2051340341423.663 & 07:03:43 & -18.7 & 1.22 & $\mathrm{~T}$ & $\mathrm{~B} 2 \mathrm{H}$ \\
\hline 2061340341438.661 & 07:03:58 & -20.9 & 1.2 & $\mathrm{~T}$ & $\mathrm{~B} 2 \mathrm{H}$ \\
\hline 2071340341453.620 & 07:04:13 & -19.7 & 1.18 & $\mathrm{~T}$ & $\mathrm{~B} 2 \mathrm{H}$ \\
\hline 2081340341523.097 & $07: 05: 23$ & -20.3 & 1.16 & $\mathrm{~T}$ & $\mathrm{~B} 2 \mathrm{H}$ \\
\hline 2091340341548.108 & $07: 05: 48$ & -19.6 & 1.14 & $\mathrm{~T}$ & $\mathrm{~B} 2 \mathrm{H}$ \\
\hline 2101340341573.069 & 07:06:13 & -20.5 & 1.12 & $\mathrm{~T}$ & $\mathrm{~B} 2 \mathrm{H}$ \\
\hline 2111340341598.112 & 07:06:38 & -19.6 & 1.1 & $\mathrm{~T}$ & $\mathrm{~B} 2 \mathrm{H}$ \\
\hline 2121340341691.297 & 07:08:11 & -20.8 & 1.08 & $\mathrm{~T}$ & $\mathrm{~B} 2 \mathrm{H}$ \\
\hline 2131340341731.450 & 07:08:51 & -19.6 & 1.06 & $\mathrm{~T}$ & $\mathrm{~B} 2 \mathrm{H}$ \\
\hline 2141340341771.501 & 07:09:31 & -20.8 & 1.04 & $\mathrm{~T}$ & $\mathrm{~B} 2 \mathrm{H}$ \\
\hline 2151340341811.507 & 07:10:11 & -19.5 & 1.02 & $\mathrm{~T}$ & $\mathrm{~B} 2 \mathrm{H}$ \\
\hline 2161340341851.453 & 07:10:51 & -20.1 & 0.999 & $\mathrm{~T}$ & $\mathrm{~B} 2 \mathrm{H}$ \\
\hline 2171340341891.493 & 07:11:31 & -20.1 & 0.979 & $\mathrm{~T}$ & $\mathrm{~B} 2 \mathrm{H}$ \\
\hline 2181340341931.408 & $07: 12: 11$ & -20.6 & 0.959 & $\mathrm{~T}$ & $\mathrm{~B} 2 \mathrm{H}$ \\
\hline 2191340341971.479 & $07: 12: 51$ & -19.3 & 0.939 & $\mathrm{~T}$ & $\mathrm{~B} 2 \mathrm{H}$ \\
\hline
\end{tabular}




\begin{tabular}{lllllll}
220 & 1340342011.508 & $07: 13: 31$ & -20.5 & 0.92 & $\mathrm{~T}$ & $\mathrm{~B} 2 \mathrm{H}$ \\
221 & 1340342051.508 & $07: 14: 11$ & -19.4 & 0.899 & $\mathrm{~T}$ & $\mathrm{~B} 2 \mathrm{H}$ \\
222 & 1340342134.323 & $07: 15: 34$ & -10.7 & 0.88 & $\mathrm{~T}$ & $\mathrm{~B} 2 \mathrm{H}$ \\
223 & 1340342174.242 & $07: 16: 14$ & -9.67 & 0.869 & $\mathrm{~T}$ & $\mathrm{~B} 2 \mathrm{H}$ \\
2241340342214.375 & $07: 16: 54$ & -10.7 & 0.86 & $\mathrm{~T}$ & $\mathrm{~B} 2 \mathrm{H}$ \\
225 & 1340342254.062 & $07: 17: 34$ & -9.47 & 0.849 & $\mathrm{~T}$ & $\mathrm{~B} 2 \mathrm{H}$ \\
2261340342435.448 & $07: 20: 35$ & -10.9 & 0.839 & $\mathrm{~T}$ & $\mathrm{~B} 2 \mathrm{H}$ \\
2271340342487.835 & $07: 21: 27$ & -10.2 & 0.819 & $\mathrm{~T}$ & $\mathrm{~B} 2 \mathrm{H}$ \\
228 & 1340342515.264 & $07: 21: 55$ & -9.04 & 0.809 & $\mathrm{~T}$ & $\mathrm{~B} 2 \mathrm{H}$ \\
229 & 1340342552.683 & $07: 22: 32$ & -10.5 & 0.799 & $\mathrm{~T}$ & $\mathrm{~B} 2 \mathrm{H}$ \\
230 & 1340342637.579 & $07: 23: 57$ & 9.91 & 0.789 & $\mathrm{~T}$ & $\mathrm{~B} 2 \mathrm{H}$ \\
231 & 1340342696.352 & $07: 24: 56$ & 9.03 & 0.799 & $\mathrm{~T}$ & $\mathrm{~B} 2 \mathrm{H}$ \\
232 & 1340342739.892 & $07: 25: 39$ & 9.6 & 0.808 & $\mathrm{~T}$ & $\mathrm{~B} 2 \mathrm{H}$ \\
233 & 1340342835.020 & $07: 27: 15$ & 9.2 & 0.816 & $\mathrm{~T}$ & $\mathrm{~B} 2 \mathrm{H}$ \\
234 & 1340342907.989 & $07: 28: 27$ & 48.9 & 0.826 & $\mathrm{~T}$ & $\mathrm{~B} 2 \mathrm{H}$ \\
2351340342998.485 & $07: 29: 58$ & 47.4 & 0.874 & $\mathrm{~T}$ & $\mathrm{~B} 2 \mathrm{H}$ \\
236 & 1340343108.127 & $07: 31: 48$ & 50 & 0.922 & $\mathrm{~T}$ & $\mathrm{~B} 2 \mathrm{H}$ \\
237 & 1340343169.989 & $07: 32: 49$ & 48.7 & 0.971 & $\mathrm{~T}$ & $\mathrm{~B} 2 \mathrm{H}$ \\
238 & 1340343203.540 & $07: 33: 23$ & 50.6 & 1.02 & $\mathrm{~T}$ & $\mathrm{~B} 2 \mathrm{H}$ \\
239 & 1340343248.766 & $07: 34: 08$ & 48.8 & 1.07 & $\mathrm{~T}$ & $\mathrm{~B} 2 \mathrm{H}$ \\
\hline
\end{tabular}

TABLE IV: Table of collimator steps (negative size means inward). 


\section{Appendix C: Table of fit results for each step}

\begin{tabular}{|c|c|c|c|c|c|c|c|c|c|c|}
\hline & Local time & Action $[\mu \mathrm{m}]$ & Half gap $[\sigma]$ & $D\left[\mu \mathrm{m}^{2} / \mathrm{s}\right]$ & $\delta D k D A$ & $i[\mathrm{~Gy} / \mathrm{s}]$ & $\delta k D A_{i}$ & $k D A_{f}$ & $\delta k D A_{f}$ & dof \\
\hline 1 & 05:59:08 & 0.00615 & 6.29 & $1.13 \mathrm{e}-11$ & $3 \mathrm{e}-12$ & $6 \mathrm{e}-08$ & $6 \mathrm{e}-09$ & $5.7 \mathrm{e}-07$ & $01.6 \mathrm{e}+05$ & 534 \\
\hline 2 & 05:59:35 & 0.00596 & 6.19 & $1.94 \mathrm{e}-11$ & $1.2 \mathrm{e}-12$ & $1.3 \mathrm{e}-07$ & 0 & $4.4 \mathrm{e}-07$ & $04.5 \mathrm{e}+04$ & 641 \\
\hline 3 & 06:00:22 & 0.00584 & 6.13 & $2.54 \mathrm{e}-11$ & $1.2 \mathrm{e}-11$ & $3.1 \mathrm{e}-07$ & $2 \mathrm{e}-10$ & $1.1 \mathrm{e}-06$ & $09.6 \mathrm{e}+04$ & 373 \\
\hline 4 & 06:00:32 & 0.00572 & 6.07 & $1.25 \mathrm{e}-11$ & $2.8 \mathrm{e}-12$ & $2.9 \mathrm{e}-07$ & 0 & $1.1 \mathrm{e}-06$ & $01.3 \mathrm{e}+05$ & 147 \\
\hline 5 & 06:00:42 & 0.0056 & 6 & $1.29 \mathrm{e}-11$ & $3.5 \mathrm{e}-12$ & $3.2 \mathrm{e}-07$ & 0 & $1.7 \mathrm{e}-06$ & $01.7 \mathrm{e}+05$ & 155 \\
\hline 6 & 06:00:52 & 0.00548 & 5.94 & $3.35 \mathrm{e}-11$ & $1.6 \mathrm{e}-11$ & $8.2 \mathrm{e}-07$ & $6 \mathrm{e}-08$ & $2 \mathrm{e}-06$ & $0 \quad 5 \mathrm{e}+04$ & 161 \\
\hline 7 & 06:01:02 & 0.00536 & 5.87 & $7.59 \mathrm{e}-11$ & $1.6 \mathrm{e}-11$ & $5.2 \mathrm{e}-07$ & 0 & $1.3 \mathrm{e}-06$ & $04.6 \mathrm{e}+05$ & 313 \\
\hline 8 & 06:01:26 & 0.00524 & 5.81 & $2.25 \mathrm{e}-11$ & $3.3 \mathrm{e}-11$ & $5.6 \mathrm{e}-07$ & $1 \mathrm{e}-07$ & $1.1 \mathrm{e}-06$ & $08.1 \mathrm{e}+05$ & 258 \\
\hline 9 & 06:01:41 & 0.00512 & 5.74 & $3.6 \mathrm{e}-12$ & $5.2 \mathrm{e}-13$ & $2.5 \mathrm{e}-07$ & 0 & $2.6 \mathrm{e}-06$ & $03.8 \mathrm{e}+05$ & 207 \\
\hline 10 & 06:01:56 & 0.005 & 5.67 & $1.15 \mathrm{e}-10$ & $9.1 \mathrm{e}-11$ & $1.5 \mathrm{e}-06$ & $2 \mathrm{e}-07$ & $2.5 \mathrm{e}-06$ & $03.6 \mathrm{e}+05$ & 242 \\
\hline 11 & 06:02:11 & 0.00489 & 5.61 & $4.66 \mathrm{e}-11$ & $1.7 \mathrm{e}-10$ & $1.5 \mathrm{e}-06$ & $7 \mathrm{e}-07$ & $4.2 \mathrm{e}-06$ & $0 \quad 2 \mathrm{e}+05$ & 228 \\
\hline 12 & $06: 02: 26$ & 0.00478 & 5.55 & $8.9 \mathrm{e}-11$ & $3.7 \mathrm{e}-10$ & $1.8 \mathrm{e}-06$ & $1 \mathrm{e}-06$ & $5 \mathrm{e}-06$ & $03.9 \mathrm{e}+05$ & 231 \\
\hline 13 & 06:02:41 & 0.00467 & 5.48 & $1.86 \mathrm{e}-10$ & $3.2 \mathrm{e}-10$ & $2.7 \mathrm{e}-06$ & $8 \mathrm{e}-07$ & $5.4 \mathrm{e}-06$ & $01.3 \mathrm{e}+05$ & 243 \\
\hline 14 & 06:02:56 & 0.00457 & 5.42 & $1.13 \mathrm{e}-11$ & $2.8 \mathrm{e}-12$ & $1.3 \mathrm{e}-06$ & 0 & $5.9 \mathrm{e}-06$ & $05.6 \mathrm{e}+05$ & 212 \\
\hline 15 & 06:03:11 & 0.00446 & 5.36 & $4.39 \mathrm{e}-11$ & $5.2 \mathrm{e}-11$ & $2.6 \mathrm{e}-06$ & $6 \mathrm{e}-07$ & $6.8 \mathrm{e}-06$ & $07.6 \mathrm{e}+05$ & 229 \\
\hline 16 & 06:03:26 & 0.00435 & 5.29 & $4.37 \mathrm{e}-11$ & $4.7 \mathrm{e}-11$ & $1.8 \mathrm{e}-06$ & 0 & $3.8 \mathrm{e}-06$ & $02.5 \mathrm{e}+05$ & 217 \\
\hline 17 & 06:03:41 & 0.00424 & 5.22 & $3.03 \mathrm{e}-12$ & $9.1 \mathrm{e}-13$ & $9.7 \mathrm{e}-07$ & 0 & 7.7e-06 & $05.1 \mathrm{e}+05$ & 322 \\
\hline 18 & 06:04:04 & 0.00414 & 5.16 & $2.59 \mathrm{e}-11$ & $7 e-12$ & $4 \mathrm{e}-06$ & $4 \mathrm{e}-07$ & $1.4 \mathrm{e}-05$ & $08.7 \mathrm{e}+05$ & 245 \\
\hline 19 & 06:04:19 & 0.00404 & 5.1 & $6.54 \mathrm{e}-11$ & $1.7 \mathrm{e}-10$ & $7.5 \mathrm{e}-06$ & $3 \mathrm{e}-06$ & $1.7 \mathrm{e}-05$ & $05.9 \mathrm{e}+05$ & 223 \\
\hline 20 & 06:04:34 & 0.00394 & 5.03 & $2.72 \mathrm{e}-10$ & $2.1 \mathrm{e}-09$ & $1.1 \mathrm{e}-05$ & $4 \mathrm{e}-06$ & $1.7 \mathrm{e}-05$ & $03.5 \mathrm{e}+05$ & 229 \\
\hline 21 & 06:04:49 & 0.00384 & 4.97 & $9.12 \mathrm{e}-11$ & $3.6 \mathrm{e}-11$ & $1.2 \mathrm{e}-05$ & $2 \mathrm{e}-06$ & $2.5 \mathrm{e}-05$ & $05.6 \mathrm{e}+04$ & 240 \\
\hline 22 & 06:05:04 & 0.00374 & 4.91 & $9.07 \mathrm{e}-12$ & $3.7 \mathrm{e}-12$ & $4.2 \mathrm{e}-06$ & 0 & $1.4 \mathrm{e}-05$ & $08.7 \mathrm{e}+05$ & 217 \\
\hline 23 & 06:05:19 & 0.00364 & 4.84 & $1.06 \mathrm{e}-12$ & $1.2 \mathrm{e}-13$ & $2.3 \mathrm{e}-06$ & 0 & $3.6 \mathrm{e}-05$ & $06.4 \mathrm{e}+05$ & 204 \\
\hline 24 & 06:05:34 & 0.00355 & 4.78 & $3.39 \mathrm{e}-12$ & $9.4 \mathrm{e}-13$ & $5 \mathrm{e}-06$ & 0 & $3.6 \mathrm{e}-05$ & $04.4 \mathrm{e}+04$ & 199 \\
\hline 25 & 06:05:49 & 0.00345 & 4.71 & $1.78 \mathrm{e}-11$ & $4.4 \mathrm{e}-12$ & $9.6 \mathrm{e}-06$ & 0 & $3.2 \mathrm{e}-05$ & $0 \quad 4 \mathrm{e}+05$ & 231 \\
\hline 26 & 06:06:04 & 0.00336 & 4.65 & $5.1 \mathrm{e}-12$ & $5 e-13$ & $8.1 \mathrm{e}-06$ & 0 & $5.4 \mathrm{e}-05$ & $06.7 \mathrm{e}+05$ & 221 \\
\hline 27 & 06:06:19 & 0.00327 & 4.59 & $8.31 \mathrm{e}-11$ & $2 \mathrm{e}-11$ & $1.7 \mathrm{e}-05$ & 0 & $2.1 \mathrm{e}-05$ & $02.7 \mathrm{e}+05$ & 487 \\
\hline 28 & $06: 06: 55$ & 0.00318 & 4.52 & $2.97 \mathrm{e}-11$ & $5.9 \mathrm{e}-12$ & $1.4 \mathrm{e}-05$ & $4 \mathrm{e}-07$ & $4.4 \mathrm{e}-05$ & $07.6 \mathrm{e}+05$ & 291 \\
\hline 29 & 06:07:10 & 0.00309 & 4.46 & $1.44 \mathrm{e}-11$ & $1.2 \mathrm{e}-12$ & $9.7 \mathrm{e}-06$ & 0 & $2.2 \mathrm{e}-05$ & $2 \mathrm{e}-174.7 \mathrm{e}+04$ & 864 \\
\hline 30 & 06:08:18 & 0.00301 & 4.4 & $1.1 \mathrm{e}-11$ & $2 \mathrm{e}-12$ & $1.3 \mathrm{e}-05$ & $5 \mathrm{e}-07$ & $5.3 \mathrm{e}-05$ & $09.3 \mathrm{e}+04$ & 491 \\
\hline 31 & 06:08:43 & 0.00292 & 4.34 & $1.07 \mathrm{e}-11$ & $2.8 \mathrm{e}-14$ & $1.4 \mathrm{e}-05$ & 0 & $3.4 \mathrm{e}-05$ & $01.5 \mathrm{e}+05$ & 384 \\
\hline 32 & 06:09:08 & 0.00284 & 4.27 & $2.39 \mathrm{e}-12$ & $6.7 \mathrm{e}-13$ & $8 \mathrm{e}-06$ & 0 & $6.8 \mathrm{e}-05$ & $02.6 \mathrm{e}+05$ & 376 \\
\hline 33 & 06:09:33 & 0.00275 & 4.21 & $6.12 \mathrm{e}-12$ & $1.3 \mathrm{e}-12$ & $1.4 \mathrm{e}-05$ & 0 & $6.8 \mathrm{e}-05$ & $03.9 \mathrm{e}+04$ & 376 \\
\hline 34 & 06:09:58 & 0.00267 & 4.14 & $1.07 \mathrm{e}-11$ & $9.9 \mathrm{e}-13$ & $1.5 \mathrm{e}-05$ & 0 & $4.3 \mathrm{e}-05$ & $7 \mathrm{e}-12 \quad 3.2 \mathrm{e}+05$ & 794 \\
\hline
\end{tabular}




\begin{tabular}{|c|c|c|c|c|c|c|c|c|c|c|}
\hline 35 & $06: 11: 15$ & 0.00261 & 4.09 & $3.48 \mathrm{e}-11$ & $5.9 \mathrm{e}-12$ & $2.6 \mathrm{e}-05$ & $5 \mathrm{e}-07$ & $4.5 \mathrm{e}-05$ & $05.1 \mathrm{e}+03$ & 664 \\
\hline 36 & $06: 11: 40$ & 0.00256 & 4.06 & $3.03 \mathrm{e}-12$ & $3.8 \mathrm{e}-12$ & $1.7 \mathrm{e}-05$ & $8 \mathrm{e}-06$ & $6.8 \mathrm{e}-05$ & $01.3 \mathrm{e}+04$ & 362 \\
\hline 37 & 06:12:05 & 0.00253 & 4.03 & $1.27 \mathrm{e}-10$ & $1.9 \mathrm{e}-10$ & $5.3 \mathrm{e}-05$ & $9 \mathrm{e}-06$ & $6.4 \mathrm{e}-05$ & $02.9 \mathrm{e}+04$ & 409 \\
\hline 38 & $06: 12: 30$ & 0.00249 & 4 & $2.06 \mathrm{e}-12$ & $9.3 \mathrm{e}-13$ & $1.6 \mathrm{e}-05$ & $3 \mathrm{e}-06$ & $7.8 \mathrm{e}-05$ & $0 \quad 3 e+04$ & 373 \\
\hline 30 & $06: 12: 55$ & 0.00245 & 3.97 & $3.16 \mathrm{e}-11$ & $3.9 \mathrm{e}-12$ & $4.6 \mathrm{e}-05$ & $8 \mathrm{e}-07$ & $7 \mathrm{e}-05$ & $08.4 \mathrm{e}+03$ & 373 \\
\hline 40 & $06: 13: 20$ & 0.00241 & 3.93 & $1.23 \mathrm{e}-11$ & $5.5 \mathrm{e}-12$ & $3.9 \mathrm{e}-05$ & $4 \mathrm{e}-06$ & 0.0001 & $01.2 \mathrm{e}+05$ & 384 \\
\hline 41 & $06: 13: 45$ & 0.00237 & 3.9 & $7.46 \mathrm{e}-11$ & $1.3 \mathrm{e}-11$ & $6.2 \mathrm{e}-05$ & $1 \mathrm{e}-06$ & $9 \mathrm{e}-05$ & $04.7 \mathrm{e}+03$ & 384 \\
\hline 42 & $06: 14: 10$ & 0.00233 & 3.87 & $3.03 \mathrm{e}-12$ & $8.8 \mathrm{e}-13$ & $2.6 \mathrm{e}-05$ & $7 \mathrm{e}-08$ & $9.4 \mathrm{e}-05$ & $01.5 \mathrm{e}+04$ & 389 \\
\hline 43 & 06:15:00 & 0.00225 & 3.81 & $1.94 \mathrm{e}-12$ & $9.6 \mathrm{e}-14$ & $2.4 \mathrm{e}-05$ & 0 & $8.9 \mathrm{e}-05$ & $05.9 \mathrm{e}+04$ & 599 \\
\hline 44 & $06: 17: 18$ & 0.00222 & 3.78 & $3.01 \mathrm{e}-11$ & $3.3 \mathrm{e}-12$ & $4.1 \mathrm{e}-05$ & $1 \mathrm{e}-06$ & $7.9 \mathrm{e}-05$ & $01.3 \mathrm{e}+04$ & 569 \\
\hline 45 & $06: 17: 58$ & 0.00218 & 3.74 & $1.16 \mathrm{e}-10$ & $6.9 \mathrm{e}-11$ & $5 \mathrm{e}-05$ & $4 \mathrm{e}-06$ & $6.4 \mathrm{e}-05$ & $01.3 \mathrm{e}+04$ & 637 \\
\hline 46 & $06: 18: 38$ & 0.00214 & 3.71 & $1.14 \mathrm{e}-11$ & $1.7 \mathrm{e}-12$ & $3.6 \mathrm{e}-05$ & $2 \mathrm{e}-06$ & $7.5 \mathrm{e}-05$ & $0 \quad 1 \mathrm{e}+04$ & 594 \\
\hline 47 & $06: 19: 18$ & 0.0021 & 3.68 & $1.26 \mathrm{e}-11$ & $1.3 \mathrm{e}-11$ & $4.6 \mathrm{e}-05$ & $5 \mathrm{e}-06$ & $8.2 \mathrm{e}-05$ & $06.7 \mathrm{e}+04$ & 559 \\
\hline 48 & $06: 19: 58$ & 0.00207 & 3.65 & $1.12 \mathrm{e}-10$ & $7 e-11$ & $5.9 \mathrm{e}-05$ & $3 \mathrm{e}-06$ & $6.9 \mathrm{e}-05$ & $4 \mathrm{e}-15 \quad 5.3 \mathrm{e}+03$ & 656 \\
\hline 49 & $06: 20: 38$ & 0.00203 & 3.61 & $7.05 \mathrm{e}-12$ & $1.7 \mathrm{e}-12$ & $5 e-05$ & $3 \mathrm{e}-06$ & 0.00012 & $05.1 \mathrm{e}+04$ & 678 \\
\hline 50 & $06: 21: 18$ & 0.00199 & 3.58 & $2.23 \mathrm{e}-12$ & $2 \mathrm{e}-13$ & $1.7 \mathrm{e}-05$ & 0 & $5.6 \mathrm{e}-05$ & $01.4 \mathrm{e}+04$ & 542 \\
\hline 51 & $06: 21: 58$ & 0.00196 & 3.55 & $3.2 \mathrm{e}-12$ & $6.4 \mathrm{e}-13$ & $3.9 \mathrm{e}-05$ & $3 e-06$ & 0.00012 & $07.4 \mathrm{e}+04$ & 640 \\
\hline 52 & $06: 22: 38$ & 0.00193 & 3.52 & $1.53 \mathrm{e}-11$ & $7.1 \mathrm{e}-12$ & $5.3 \mathrm{e}-05$ & $8 \mathrm{e}-06$ & $8.2 \mathrm{e}-05$ & $01.1 \mathrm{e}+04$ & 607 \\
\hline 53 & $06: 23: 18$ & 0.00189 & 3.48 & $4.5 \mathrm{e}-12$ & $1.1 \mathrm{e}-12$ & $3.6 \mathrm{e}-05$ & $2 \mathrm{e}-06$ & 0.00011 & $03.4 \mathrm{e}+04$ & 499 \\
\hline 54 & $06: 24: 19$ & 0.00186 & 3.45 & $2.45 \mathrm{e}-11$ & $5.8 \mathrm{e}-12$ & $5.6 \mathrm{e}-05$ & $2 \mathrm{e}-06$ & 0.00011 & $01.5 \mathrm{e}+04$ & 561 \\
\hline 55 & $06: 24: 59$ & 0.00182 & 3.42 & $1.82 \mathrm{e}-11$ & $1.3 \mathrm{e}-11$ & $5.6 \mathrm{e}-05$ & $8 \mathrm{e}-06$ & $8.9 \mathrm{e}-05$ & $03.4 \mathrm{e}+04$ & 664 \\
\hline 56 & $06: 25: 39$ & 0.00178 & 3.39 & $7.88 \mathrm{e}-11$ & $2.9 \mathrm{e}-11$ & $6.6 \mathrm{e}-05$ & $3 \mathrm{e}-06$ & $8.8 \mathrm{e}-05$ & $03.5 \mathrm{e}+03$ & 670 \\
\hline 57 & $06: 26: 19$ & 0.00175 & 3.36 & $3.2 \mathrm{e}-12$ & $6.7 \mathrm{e}-13$ & $5 \mathrm{e}-05$ & $4 \mathrm{e}-06$ & 0.00016 & $01.2 \mathrm{e}+04$ & 591 \\
\hline 58 & $06: 26: 59$ & 0.00172 & 3.32 & $1.1 \mathrm{e}-10$ & $2.3 \mathrm{e}-11$ & $8.7 \mathrm{e}-05$ & $3 \mathrm{e}-06$ & 0.00012 & $01.8 \mathrm{e}+03$ & 591 \\
\hline 59 & $06: 27: 39$ & 0.00169 & 3.29 & $1.41 \mathrm{e}-11$ & $1.5 \mathrm{e}-11$ & $7.6 \mathrm{e}-05$ & $1 \mathrm{e}-05$ & 0.00012 & $07.9 \mathrm{e}+04$ & 668 \\
\hline 60 & $06: 28: 59$ & 0.00163 & 3.23 & $1.05 \mathrm{e}-11$ & $8.4 \mathrm{e}-12$ & $6.9 \mathrm{e}-05$ & $1 \mathrm{e}-05$ & 0.00012 & $02.6 \mathrm{e}+04$ & 676 \\
\hline 61 & $06: 29: 39$ & 0.00159 & 3.2 & $9.03 \mathrm{e}-12$ & $1.1 \mathrm{e}-12$ & $8.3 \mathrm{e}-05$ & $2 \mathrm{e}-06$ & 0.00016 & $01.3 \mathrm{e}+04$ & 662 \\
\hline 62 & 06:30:19 & 0.00156 & 3.17 & $3.01 \mathrm{e}-12$ & $6.3 \mathrm{e}-13$ & $4.2 \mathrm{e}-05$ & 0 & $7.1 \mathrm{e}-05$ & $01.1 \mathrm{e}+05$ & 1019 \\
\hline 63 & $06: 33: 10$ & 0.0016 & 3.2 & $6.3 \mathrm{e}-12$ & $1.4 \mathrm{e}-16$ & $5.2 \mathrm{e}-05$ & $7 \mathrm{e}-07$ & $4.1 \mathrm{e}-06$ & $1 \mathrm{e}-18 \quad 2.4 \mathrm{e}+02$ & 605 \\
\hline 64 & $06: 33: 50$ & 0.00171 & 3.32 & $1.14 \mathrm{e}-09$ & $1.5 \mathrm{e}-10$ & $2.2 \mathrm{e}-06$ & $6 \mathrm{e}-08$ & $4.6 \mathrm{e}-07$ & $3 e-103.1 e+03$ & 1523 \\
\hline 65 & $06: 37: 53$ & 0.00183 & 3.43 & $1.46 \mathrm{e}-06$ & 0 & $2.1 \mathrm{e}-06$ & $4 \mathrm{e}-09$ & $3.8 \mathrm{e}-07$ & $2 \mathrm{e}-08 \quad 6.2 \mathrm{e}+02$ & 1226 \\
\hline 66 & $06: 38: 54$ & 0.00196 & 3.55 & $4 \mathrm{e}-06$ & $5.8 \mathrm{e}-06$ & $4.4 \mathrm{e}-07$ & $6 e-10$ & $2.2 \mathrm{e}-07$ & $3 \mathrm{e}-10 \quad 6.9 \mathrm{e}+02$ & 809 \\
\hline 67 & $06: 39: 25$ & 0.0024 & 3.91 & $5.93 \mathrm{e}-06$ & 0 & $2.5 \mathrm{e}-07$ & $3 e-08$ & $1.8 \mathrm{e}-07$ & $1 \mathrm{e}-10 \quad 5.8 \mathrm{e}+02$ & 690 \\
\hline$c o$ & $06: 40: 25$ & 0.0032 & 4.53 & $1.89 \mathrm{e}-06$ & $7.2 \mathrm{e}-07$ & $1.8 \mathrm{e}-07$ & $1 \mathrm{e}-10$ & $1.8 \mathrm{e}-07$ & $3 \mathrm{e}-107.5 \mathrm{e}+02$ & 768 \\
\hline 69 & $07: 01: 35$ & 0.00804 & 7.19 & $4.37 \mathrm{e}-09$ & $1.7 \mathrm{e}-09$ & $4 \mathrm{e}-07$ & $4 \mathrm{e}-09$ & $6.6 \mathrm{e}-07$ & $02.2 \mathrm{e}+03$ & 335 \\
\hline 70 & 07:01:50 & 0.00776 & 7.06 & $2.94 \mathrm{e}-09$ & $2 \mathrm{e}-09$ & $4.4 \mathrm{e}-07$ & $6 \mathrm{e}-08$ & $7.5 \mathrm{e}-07$ & $01.1 \mathrm{e}+03$ & 234 \\
\hline 71 & 07:02:05 & 0.00748 & 6.94 & $1.21 \mathrm{e}-09$ & $1.3 \mathrm{e}-09$ & $4.4 \mathrm{e}-07$ & $1 \mathrm{e}-07$ & $9.5 \mathrm{e}-07$ & $0 \quad 2 \mathrm{e}+03$ & 237 \\
\hline
\end{tabular}




\begin{tabular}{|c|c|c|c|c|c|c|c|c|c|c|}
\hline 72 & 07:02:20 & 0.0072 & 6.8 & $3.46 \mathrm{e}-09$ & $2.5 \mathrm{e}-10$ & $6.6 \mathrm{e}-07$ & $8 \mathrm{e}-09$ & $1.2 \mathrm{e}-06$ & $03.1 \mathrm{e}+03$ & 237 \\
\hline 73 & 07:02:35 & 0.00692 & 6.67 & $2.54 \mathrm{e}-09$ & $1.4 \mathrm{e}-09$ & $7.5 \mathrm{e}-07$ & $7 \mathrm{e}-08$ & $1.3 \mathrm{e}-06$ & $07.4 \mathrm{e}+03$ & 237 \\
\hline 74 & 07:02:50 & 0.00665 & 6.54 & $1.42 \mathrm{e}-09$ & $1.2 \mathrm{e}-10$ & $9.1 \mathrm{e}-07$ & $3 \mathrm{e}-08$ & $2 \mathrm{e}-06$ & $0 \quad 2 \mathrm{e}+04$ & 239 \\
\hline 75 & 07:03:05 & 0.00639 & 6.41 & $2.26 \mathrm{e}-09$ & $1.4 \mathrm{e}-09$ & $1.3 \mathrm{e}-06$ & $2 \mathrm{e}-07$ & $2.4 \mathrm{e}-06$ & $01.1 \mathrm{e}+04$ & 228 \\
\hline 76 & 07:03:20 & 0.00614 & 6.28 & $4 \mathrm{e}-09$ & $3.1 \mathrm{e}-09$ & $1.5 \mathrm{e}-06$ & $3 \mathrm{e}-07$ & $2.3 \mathrm{e}-06$ & $04.2 \mathrm{e}+03$ & 230 \\
\hline 77 & 07:03:35 & 0.00589 & 6.15 & $4.65 \mathrm{e}-09$ & $2.4 \mathrm{e}-09$ & $1.7 \mathrm{e}-06$ & $1 \mathrm{e}-07$ & $2.3 \mathrm{e}-06$ & $04.3 \mathrm{e}+03$ & 247 \\
\hline 78 & 07:03:50 & 0.00564 & 6.02 & $3.29 \mathrm{e}-09$ & $1.1 \mathrm{e}-09$ & $1.7 \mathrm{e}-06$ & $1 \mathrm{e}-07$ & $2.7 \mathrm{e}-06$ & $06.2 \mathrm{e}+03$ & 278 \\
\hline 79 & 07:04:07 & 0.0054 & 5.89 & $3.07 \mathrm{e}-09$ & 1e-09 & $2.1 \mathrm{e}-06$ & $1 \mathrm{e}-07$ & $3.4 \mathrm{e}-06$ & $01.3 \mathrm{e}+04$ & 253 \\
\hline 80 & 07:04:22 & 0.00517 & 5.76 & $4.4 \mathrm{e}-09$ & $2.9 \mathrm{e}-09$ & $2.5 \mathrm{e}-06$ & $3 \mathrm{e}-07$ & $3.7 \mathrm{e}-06$ & $01.6 \mathrm{e}+04$ & 234 \\
\hline 81 & 07:04:37 & 0.00494 & 5.63 & $1.75 \mathrm{e}-09$ & $1.5 \mathrm{e}-09$ & $2.1 \mathrm{e}-06$ & $4 \mathrm{e}-07$ & $3.4 \mathrm{e}-06$ & $8 \mathrm{e}-18 \quad 4 \mathrm{e}+04$ & 403 \\
\hline 82 & 07:05:06 & 0.00472 & 5.51 & $3.03 \mathrm{e}-09$ & $2.9 \mathrm{e}-10$ & $2.6 \mathrm{e}-06$ & $6 \mathrm{e}-08$ & $3.9 \mathrm{e}-06$ & $03.4 \mathrm{e}+04$ & 395 \\
\hline 83 & 07:05:31 & 0.0045 & 5.38 & $6.87 \mathrm{e}-10$ & $1.8 \mathrm{e}-10$ & $2 \mathrm{e}-06$ & $2 \mathrm{e}-07$ & $4.1 \mathrm{e}-06$ & $02.6 \mathrm{e}+04$ & 362 \\
\hline 84 & 07:05:56 & 0.00428 & 5.25 & $5.57 \mathrm{e}-10$ & $4.6 \mathrm{e}-10$ & $2 \mathrm{e}-06$ & $4 \mathrm{e}-07$ & $4.6 \mathrm{e}-06$ & $04.6 \mathrm{e}+04$ & 346 \\
\hline 85 & 07:06:21 & 0.00408 & 5.12 & $1.19 \mathrm{e}-09$ & $5.9 \mathrm{e}-10$ & $3.2 \mathrm{e}-06$ & $4 \mathrm{e}-07$ & $5.5 \mathrm{e}-06$ & $09.5 \mathrm{e}+04$ & 373 \\
\hline 86 & 07:06:46 & 0.00388 & 4.99 & $9.66 \mathrm{e}-10$ & $4.9 \mathrm{e}-10$ & $4 \mathrm{e}-06$ & $4 \mathrm{e}-07$ & $6.3 \mathrm{e}-06$ & $04.9 \mathrm{e}+04$ & 411 \\
\hline 87 & 07:07:11 & 0.00368 & 4.87 & $1.47 \mathrm{e}-09$ & $9.9 \mathrm{e}-10$ & $4.2 \mathrm{e}-06$ & $6 \mathrm{e}-07$ & $6.5 \mathrm{e}-06$ & $05.7 \mathrm{e}+04$ & 404 \\
\hline 88 & $07: 07: 36$ & 0.00349 & 4.74 & $5.38 \mathrm{e}-10$ & $2.2 \mathrm{e}-10$ & $4.3 \mathrm{e}-06$ & $4 \mathrm{e}-07$ & $7.3 \mathrm{e}-06$ & $06.7 \mathrm{e}+04$ & 409 \\
\hline 89 & 07:08:01 & 0.00331 & 4.61 & $2.29 \mathrm{e}-10$ & $5 \mathrm{e}-10$ & $3.6 \mathrm{e}-06$ & $2 \mathrm{e}-06$ & $8.7 \mathrm{e}-06$ & $02.4 \mathrm{e}+05$ & 392 \\
\hline 90 & 07:08:26 & 0.00313 & 4.48 & $4.23 \mathrm{e}-10$ & $4.8 \mathrm{e}-11$ & $6.6 \mathrm{e}-06$ & $2 \mathrm{e}-07$ & $1.3 \mathrm{e}-05$ & $07.7 \mathrm{e}+04$ & 321 \\
\hline 91 & 07:08:51 & 0.00295 & 4.36 & $1.65 \mathrm{e}-10$ & $1.1 \mathrm{e}-11$ & $4.2 \mathrm{e}-06$ & 0 & $6.9 \mathrm{e}-06$ & $4 \mathrm{e}-06 \quad 1.5 \mathrm{e}+04$ & 648 \\
\hline 92 & 07:09:35 & 0.00278 & 4.23 & $2.65 \mathrm{e}-10$ & $3.8 \mathrm{e}-11$ & 7.1e-06 & $2 \mathrm{e}-07$ & $1.6 \mathrm{e}-05$ & $0 \quad 6 \mathrm{e}+05$ & 495 \\
\hline 93 & 07:10:00 & 0.00262 & 4.1 & $2.58 \mathrm{e}-11$ & $9.4 \mathrm{e}-12$ & $3.8 \mathrm{e}-06$ & $4 \mathrm{e}-07$ & $1.7 \mathrm{e}-05$ & $03.7 \mathrm{e}+05$ & 659 \\
\hline 94 & 07:10:47 & 0.00246 & 3.97 & $2.22 \mathrm{e}-10$ & $4.1 \mathrm{e}-11$ & $9 \mathrm{e}-06$ & $4 \mathrm{e}-07$ & $1.9 \mathrm{e}-05$ & $02.5 \mathrm{e}+05$ & 648 \\
\hline 95 & $07: 11: 27$ & 0.0023 & 3.85 & $6.91 \mathrm{e}-11$ & $2.7 \mathrm{e}-11$ & $1.1 \mathrm{e}-05$ & $1 \mathrm{e}-06$ & $2.8 \mathrm{e}-05$ & $01.7 \mathrm{e}+06$ & 635 \\
\hline 96 & 07:12:07 & 0.00215 & 3.72 & $7.18 \mathrm{e}-12$ & $1.7 \mathrm{e}-13$ & $4.9 \mathrm{e}-06$ & 0 & $3.1 \mathrm{e}-05$ & $01.7 \mathrm{e}+06$ & 886 \\
\hline 97 & 07:13:11 & 0.00204 & 3.62 & $4.85 \mathrm{e}-11$ & $1.6 \mathrm{e}-11$ & $1.8 \mathrm{e}-05$ & $1 \mathrm{e}-06$ & $3.6 \mathrm{e}-05$ & $0 \quad 1 e+04$ & 659 \\
\hline 98 & 07:13:51 & 0.00197 & 3.56 & $4.68 \mathrm{e}-11$ & $1.6 \mathrm{e}-11$ & $2.5 \mathrm{e}-05$ & $2 \mathrm{e}-06$ & $3.9 \mathrm{e}-05$ & $4 \mathrm{e}-111.5 \mathrm{e}+04$ & 700 \\
\hline 99 & 07:14:31 & 0.0019 & 3.5 & $2.69 \mathrm{e}-11$ & $2.3 \mathrm{e}-11$ & $1.9 \mathrm{e}-05$ & $4 \mathrm{e}-06$ & $4 \mathrm{e}-05$ & $01.1 \mathrm{e}+05$ & 629 \\
\hline 100 & 07:15:11 & 0.0018 & 3.4 & $1.77 \mathrm{e}-11$ & $7.9 \mathrm{e}-12$ & $2.1 \mathrm{e}-05$ & $3 \mathrm{e}-06$ & 0.0001 & $01.3 \mathrm{e}+07$ & 577 \\
\hline 101 & $07: 15: 51$ & 0.00169 & 3.29 & $7.89 \mathrm{e}-12$ & $6.5 \mathrm{e}-13$ & $2.3 \mathrm{e}-05$ & 0 & $9.7 \mathrm{e}-05$ & $01.4 \mathrm{e}+05$ & 582 \\
\hline 102 & 07:16:31 & 0.00161 & 3.21 & $4.21 \mathrm{e}-11$ & $1.2 \mathrm{e}-11$ & $6 \mathrm{e}-05$ & $3 e-06$ & 0.00012 & $01.2 \mathrm{e}+05$ & 638 \\
\hline 103 & $07: 17: 11$ & 0.00154 & 3.15 & $2.32 \mathrm{e}-12$ & $2.5 \mathrm{e}-13$ & $3 \mathrm{e}-05$ & 0 & 0.00014 & $03.4 \mathrm{e}+04$ & 585 \\
\hline 104 & $07: 17: 51$ & 0.00148 & 3.08 & $2.4 \mathrm{e}-11$ & $2.8 \mathrm{e}-11$ & $5.2 \mathrm{e}-05$ & $1 \mathrm{e}-05$ & 0.00013 & $9 \mathrm{e}-05 \quad 1.2 \mathrm{e}+05$ & 1479 \\
\hline 105 & 07:19:43 & 0.00143 & 3.03 & $8.08 \mathrm{e}-12$ & $1.4 \mathrm{e}-12$ & $7.7 \mathrm{e}-05$ & $3 e-06$ & 0.00018 & $08.1 \mathrm{e}+03$ & 666 \\
\hline 106 & 07:20:13 & 0.0014 & 3 & $3.37 \mathrm{e}-11$ & $5.1 \mathrm{e}-12$ & 0.00011 & $4 \mathrm{e}-06$ & 0.00018 & $01.6 \mathrm{e}+03$ & 455 \\
\hline 107 & $07: 20: 41$ & 0.00137 & 2.97 & $2.18 \mathrm{e}-12$ & $2 \mathrm{e}-13$ & $5.1 \mathrm{e}-05$ & 0 & 0.00017 & $2 \mathrm{e}-132.2 \mathrm{e}+04$ & 518 \\
\hline 108 & $07: 21: 15$ & 0.00134 & 2.93 & $2.09 \mathrm{e}-11$ & $4.2 \mathrm{e}-12$ & $9.9 \mathrm{e}-05$ & $3 e-06$ & 0.0002 & $08.1 \mathrm{e}+03$ & 329 \\
\hline
\end{tabular}




\begin{tabular}{|c|c|c|c|c|c|c|c|c|c|c|}
\hline 9 & $07: 21: 33$ & 0.0013 & 2.9 & $2.06 \mathrm{e}-12$ & $4.2 \mathrm{e}-12$ & $7.3 \mathrm{e}-05$ & $4 \mathrm{e}-05$ & 0.00026 & $01.3 \mathrm{e}+04$ & 454 \\
\hline 10 & $07: 22: 07$ & 0.00128 & 2.86 & $2.98 \mathrm{e}-11$ & $1.7 \mathrm{e}-12$ & 0.00021 & $3 \mathrm{e}-06$ & 0.00039 & $0 \quad 9 \mathrm{e}+03$ & 354 \\
\hline 1 & $07: 22: 27$ & 0.00125 & 2.83 & $1.08 \mathrm{e}-11$ & $1.3 \mathrm{e}-12$ & 0.00011 & & 0.00018 & $8 \mathrm{e}-147.7 \mathrm{e}+04$ & 789 \\
\hline 2 & $07: 23: 26$ & 0.00126 & 2.84 & $4.51 \mathrm{e}-11$ & $1.8 \mathrm{e}-12$ & 0.00016 & $2 \mathrm{e}-06$ & $5.5 \mathrm{e}-05$ & $9 \mathrm{e}-10 \quad 6.9 \mathrm{e}+02$ & 1107 \\
\hline 113 & $07: 24: 38$ & 0.00131 & 2.9 & $6.48 \mathrm{e}-11$ & $5.3 \mathrm{e}-12$ & $5 \mathrm{e}-05$ & $1 \mathrm{e}-06$ & $2.2 \mathrm{e}-05$ & $6 \mathrm{e}-125.9 \mathrm{e}+02$ & 1332 \\
\hline 4 & $07: 26: 14$ & 0.00136 & 2.96 & $1.69 \mathrm{e}-10$ & $1 \mathrm{e}-11$ & $2.4 \mathrm{e}-05$ & $4 \mathrm{e}-07$ & $1.4 \mathrm{e}-05$ & $07.1 \mathrm{e}+02$ & 1185 \\
\hline 115 & $07: 27: 37$ & 0.00142 & 3.02 & $2.01 \mathrm{e}-10$ & $2.3 \mathrm{e}-11$ & $1.4 \mathrm{e}-05$ & $4 \mathrm{e}-07$ & $8.1 \mathrm{e}-06$ & $5 \mathrm{e}-107.9 \mathrm{e}+02$ & 992 \\
\hline 6 & $07: 28: 43$ & 0.00148 & 3.08 & $4.96 \mathrm{e}-10$ & $3 e-11$ & $8 \mathrm{e}-06$ & $1 \mathrm{e}-07$ & $5.4 \mathrm{e}-06$ & $2 \mathrm{e}-16 \quad 5.3 \mathrm{e}+02$ & 823 \\
\hline 7 & $07: 29: 33$ & 0.00156 & 3.17 & $5.36 \mathrm{e}-10$ & $2.8 \mathrm{e}-11$ & $5.7 \mathrm{e}-06$ & $5 \mathrm{e}-08$ & $2.7 \mathrm{e}-06$ & $5 \mathrm{e}-125.5 \mathrm{e}+02$ & 817 \\
\hline 8 & $07: 31: 39$ & 0.00169 & 3.29 & $1.16 \mathrm{e}-09$ & $4.4 \mathrm{e}-11$ & $3.2 \mathrm{e}-06$ & $8 \mathrm{e}-09$ & $1.7 \mathrm{e}-06$ & $1 \mathrm{e}-08 \quad 1.8 \mathrm{e}+03$ & 1534 \\
\hline 9 & $07: 32: 39$ & 0.00181 & 3.41 & $1.41 \mathrm{e}-09$ & $9.2 \mathrm{e}-11$ & $2 \mathrm{e}-06$ & $7 \mathrm{e}-09$ & $1.2 \mathrm{e}-06$ & $4 \mathrm{e}-097.5 \mathrm{e}+02$ & 796 \\
\hline 0 & $07: 33: 29$ & 0.00194 & 3.53 & $3.88 \mathrm{e}-09$ & $7.6 \mathrm{e}-10$ & $1.3 \mathrm{e}-06$ & $4 \mathrm{e}-09$ & $9.3 \mathrm{e}-07$ & $2 \mathrm{e}-095.3 \mathrm{e}+02$ & 591 \\
\hline 1 & 07:34:03 & 0.00218 & 3.74 & $2.94 \mathrm{e}-06$ & $8.1 \mathrm{e}-07$ & $9.7 \mathrm{e}-07$ & $1 \mathrm{e}-09$ & $5.7 \mathrm{e}-07$ & $8 \mathrm{e}-09 \quad 6.4 \mathrm{e}+02$ & 640 \\
\hline 122 & 06:08:07 & 0.00783 & 5.69 & $7.72 \mathrm{e}-10$ & 0 & $1.3 \mathrm{e}-06$ & $5 \mathrm{e}-08$ & $2.3 \mathrm{e}-06$ & $2 \mathrm{e}-132.6 \mathrm{e}+03$ & 155 \\
\hline 123 & 06:08:17 & 0.00773 & 5.65 & $4.51 \mathrm{e}-09$ & $7.8 \mathrm{e}-10$ & $2.1 \mathrm{e}-06$ & $6 \mathrm{e}-08$ & $2.4 \mathrm{e}-06$ & $03.8 \mathrm{e}+02$ & 152 \\
\hline 124 & 06:08:26 & 0.00763 & 5.62 & $2.8 \mathrm{e}-10$ & $1.4 \mathrm{e}-10$ & $1.5 \mathrm{e}-06$ & $1 \mathrm{e}-07$ & $2.5 \mathrm{e}-06$ & $01.3 \mathrm{e}+04$ & 152 \\
\hline 20 & 06:08:36 & 0.00752 & 5.58 & $5.24 \mathrm{e}-10$ & $1.8 \mathrm{e}-10$ & $2.1 \mathrm{e}-06$ & $1 \mathrm{e}-07$ & $3.7 \mathrm{e}-06$ & $0 \quad 4 \mathrm{e}+03$ & 155 \\
\hline 26 & 06:08:46 & 0.00742 & 5.54 & $4.3 \mathrm{e}-10$ & $2.7 \mathrm{e}-10$ & $2.7 \mathrm{e}-06$ & $3 \mathrm{e}-07$ & $4.7 \mathrm{e}-06$ & $05.4 \mathrm{e}+03$ & 57 \\
\hline 127 & 06:08:57 & 0.00732 & 5.5 & $1.57 \mathrm{e}-10$ & $1.1 \mathrm{e}-10$ & $3.3 \mathrm{e}-06$ & $3 \mathrm{e}-07$ & $5.5 \mathrm{e}-06$ & $09.4 \mathrm{e}+03$ & 147 \\
\hline 128 & 06:09:06 & 0.00723 & 5.47 & $1.76 \mathrm{e}-09$ & 0 & $6.3 \mathrm{e}-06$ & $4 \mathrm{e}-07$ & $2.5 \mathrm{e}-05$ & $1 \mathrm{e}-06 \quad 1.6 \mathrm{e}+04$ & 0 \\
\hline 129 & 06:09:16 & 0.00713 & 5.43 & $1.22 \mathrm{e}-10$ & $3.1 \mathrm{e}-11$ & $2.8 \mathrm{e}-06$ & 0 & $4.5 \mathrm{e}-06$ & $03.4 \mathrm{e}+03$ & 676 \\
\hline 20 & $06: 10: 10$ & 0.00704 & 5.39 & $1.06 \mathrm{e}-10$ & $2.9 \mathrm{e}-11$ & $3.7 \mathrm{e}-06$ & $4 \mathrm{e}-08$ & $1.1 \mathrm{e}-05$ & $06.2 \mathrm{e}+03$ & 4 \\
\hline 131 & $06: 10: 20$ & 0.00694 & 5.36 & $3.43 \mathrm{e}-10$ & $1.7 \mathrm{e}-10$ & $7.5 \mathrm{e}-06$ & $5 \mathrm{e}-07$ & $1.3 \mathrm{e}-05$ & $03.2 \mathrm{e}+04$ & 157 \\
\hline 132 & $06: 10: 30$ & 0.00685 & 5.32 & $2.12 \mathrm{e}-11$ & $3.2 \mathrm{e}-11$ & $4.9 \mathrm{e}-06$ & $3 \mathrm{e}-06$ & $1.8 \mathrm{e}-05$ & $05.1 \mathrm{e}+03$ & 147 \\
\hline 133 & $06: 10: 40$ & 0.00675 & 5.28 & $1.78 \mathrm{e}-10$ & $6.8 \mathrm{e}-11$ & $9.4 \mathrm{e}-06$ & $6 \mathrm{e}-07$ & $2 \mathrm{e}-05$ & $01.7 \mathrm{e}+04$ & 147 \\
\hline 134 & 06:10:50 & 0.00665 & 5.24 & $2.48 \mathrm{e}-10$ & $7.4 \mathrm{e}-10$ & $1.2 \mathrm{e}-05$ & $4 \mathrm{e}-06$ & $2 \mathrm{e}-05$ & $01.6 \mathrm{e}+04$ & 149 \\
\hline 135 & 06:11:00 & 0.00656 & 5.21 & $9.61 \mathrm{e}-11$ & $1.5 \mathrm{e}-11$ & $1.2 \mathrm{e}-05$ & $8 \mathrm{e}-07$ & $3.1 \mathrm{e}-05$ & $0 \quad 8 \mathrm{e}+03$ & 152 \\
\hline 136 & $06: 11: 10$ & 0.00647 & 5.17 & $7.19 \mathrm{e}-11$ & $1.9 \mathrm{e}-10$ & $1.3 \mathrm{e}-05$ & $6 \mathrm{e}-06$ & $2.7 \mathrm{e}-05$ & $07.1 \mathrm{e}+03$ & 152 \\
\hline 137 & $06: 11: 20$ & 0.00637 & 5.13 & $3.07 \mathrm{e}-10$ & $8.8 \mathrm{e}-11$ & $2.1 \mathrm{e}-05$ & $1 \mathrm{e}-06$ & $3.8 \mathrm{e}-05$ & $02.2 \mathrm{e}+04$ & 158 \\
\hline 138 & $06: 11: 30$ & 0.00628 & 5.1 & $9.41 \mathrm{e}-10$ & $3.7 \mathrm{e}-10$ & $3 \mathrm{e}-05$ & $1 \mathrm{e}-06$ & $3.9 \mathrm{e}-05$ & $05.6 \mathrm{e}+03$ & 166 \\
\hline 139 & $06: 11: 40$ & 0.00619 & 5.06 & $3.29 \mathrm{e}-10$ & $3.2 \mathrm{e}-10$ & $2.2 \mathrm{e}-05$ & $4 \mathrm{e}-06$ & $3.4 \mathrm{e}-05$ & $0 \quad 1.4 \mathrm{e}+03$ & 161 \\
\hline 140 & 06:11:50 & 0.0061 & 5.02 & $1.59 \mathrm{e}-10$ & $2.3 \mathrm{e}-11$ & $2.9 \mathrm{e}-05$ & $1 \mathrm{e}-06$ & $5.7 \mathrm{e}-05$ & $07.6 \mathrm{e}+04$ & 163 \\
\hline 41 & 06:12:00 & 0.00601 & 4.98 & $2.25 \mathrm{e}-10$ & $2.2 \mathrm{e}-10$ & $3 \mathrm{e}-05$ & $7 \mathrm{e}-06$ & $5.4 \mathrm{e}-05$ & $0 \quad 3 \mathrm{e}+03$ & 152 \\
\hline 142 & $06: 12: 10$ & 0.00592 & 4.95 & $1.03 \mathrm{e}-09$ & $1.5 \mathrm{e}-09$ & $4.5 \mathrm{e}-05$ & $4 \mathrm{e}-06$ & $5.2 \mathrm{e}-05$ & $09.5 \mathrm{e}+03$ & 174 \\
\hline 143 & $06: 12: 20$ & 0.00583 & 4.91 & $2.3 \mathrm{e}-10$ & $5.2 \mathrm{e}-11$ & 4.1e-05 & $4 \mathrm{e}-06$ & $6.3 \mathrm{e}-05$ & $08.1 \mathrm{e}+03$ & 172 \\
\hline 144 & $06: 12: 30$ & 0.00574 & 4.87 & $5.22 \mathrm{e}-10$ & $4.8 \mathrm{e}-10$ & $5.1 \mathrm{e}-05$ & $3 \mathrm{e}-06$ & $7.4 \mathrm{e}-05$ & $01.4 \mathrm{e}+04$ & 160 \\
\hline & $06: 12: 40$ & 0.00566 & 4.84 & $3.06 \mathrm{e}-10$ & $7.1 \mathrm{e}-11$ & $5.2 \mathrm{e}-05$ & $4 \mathrm{e}-06$ & $7 \mathrm{e}-05$ & $09.2 \mathrm{e}+03$ & 155 \\
\hline
\end{tabular}




\begin{tabular}{|c|c|c|c|c|c|c|c|c|c|c|}
\hline 16 & $06: 12: 50$ & 0.00557 & 4.8 & $6 \mathrm{e}-05$ & 0 & $5.9 \mathrm{e}-05$ & $3 \mathrm{e}-06$ & 0.00011 & $4 \mathrm{e}-06 \quad 1.9 \mathrm{e}+04$ & 163 \\
\hline 17 & 06:13:01 & 0.00548 & 4.76 & $1.96 \mathrm{e}-09$ & $1.2 \mathrm{e}-09$ & $6.8 \mathrm{e}-05$ & $5 \mathrm{e}-06$ & $6.6 \mathrm{e}-05$ & $01.5 \mathrm{e}+03$ & 240 \\
\hline 148 & $06: 13: 16$ & 0.0054 & 4.72 & $6.05 \mathrm{e}-10$ & $3.6 \mathrm{e}-10$ & $5.1 \mathrm{e}-05$ & $3 \mathrm{e}-06$ & $6.3 \mathrm{e}-05$ & $04.5 \mathrm{e}+03$ & 6 \\
\hline 149 & $06: 13: 31$ & 0.00531 & 4.69 & $2.46 \mathrm{e}-10$ & $5.1 \mathrm{e}-11$ & $5.1 \mathrm{e}-05$ & $1 \mathrm{e}-06$ & $6.9 \mathrm{e}-05$ & $04.7 \mathrm{e}+03$ & 231 \\
\hline 150 & $06: 13: 46$ & 0.00523 & 4.65 & $3.13 \mathrm{e}-10$ & $4.4 \mathrm{e}-11$ & $4.9 \mathrm{e}-05$ & $3 \mathrm{e}-06$ & $8.9 \mathrm{e}-05$ & $06.2 \mathrm{e}+03$ & 37 \\
\hline 51 & 06:14:01 & 0.00515 & 4.61 & $2.74 \mathrm{e}-10$ & $8.1 \mathrm{e}-11$ & $5.8 \mathrm{e}-05$ & $3 e-06$ & $9.1 \mathrm{e}-05$ & $05.6 \mathrm{e}+03$ & 245 \\
\hline 152 & $06: 14: 16$ & 0.00507 & 4.58 & $4.94 \mathrm{e}-10$ & $2 \mathrm{e}-10$ & $7.4 \mathrm{e}-05$ & $3 e-06$ & $9.4 \mathrm{e}-05$ & $03.6 \mathrm{e}+03$ & 6 \\
\hline 153 & $06: 14: 31$ & 0.00498 & 4.54 & $4.06 \mathrm{e}-10$ & $1.5 \mathrm{e}-10$ & $5.5 \mathrm{e}-05$ & $1 \mathrm{e}-06$ & $8.1 \mathrm{e}-05$ & $0 \quad 8 \mathrm{e}+02$ & 239 \\
\hline 154 & $06: 14: 46$ & 0.0049 & 4.5 & $1.57 \mathrm{e}-10$ & $3.6 \mathrm{e}-11$ & $6.9 \mathrm{e}-05$ & $1 \mathrm{e}-06$ & 0.00011 & $02.5 \mathrm{e}+04$ & 26 \\
\hline 5 & 06:15:01 & 0.00482 & 4.46 & $4.39 \mathrm{e}-10$ & $1.8 \mathrm{e}-10$ & $6.9 \mathrm{e}-05$ & $7 \mathrm{e}-06$ & $8.1 \mathrm{e}-05$ & $01.7 \mathrm{e}+03$ & 229 \\
\hline 6 & $06: 15: 16$ & 0.00474 & 4.43 & $2.23 \mathrm{e}-10$ & $7.5 \mathrm{e}-11$ & $6.5 \mathrm{e}-05$ & $5 \mathrm{e}-06$ & $9.6 \mathrm{e}-05$ & $01.5 \mathrm{e}+04$ & 236 \\
\hline 157 & $06: 15: 31$ & 0.00466 & 4.39 & $3.04 \mathrm{e}-10$ & $4 e-11$ & $7.8 \mathrm{e}-05$ & $4 \mathrm{e}-06$ & 0.00012 & $02.1 \mathrm{e}+03$ & 263 \\
\hline 8 & $06: 15: 46$ & 0.00458 & 4.35 & $3.59 \mathrm{e}-10$ & $2 \mathrm{e}-10$ & $7.9 \mathrm{e}-05$ & $8 \mathrm{e}-06$ & 0.00012 & $02.9 \mathrm{e}+03$ & 34 \\
\hline 159 & 06:16:01 & 0.0045 & 4.31 & $4.3 \mathrm{e}-11$ & $2.8 \mathrm{e}-12$ & $3.6 \mathrm{e}-05$ & 0 & $6.7 \mathrm{e}-05$ & $3 \mathrm{e}-137.9 \mathrm{e}+03$ & 894 \\
\hline 160 & $06: 17: 11$ & 0.00443 & 4.28 & $1.75 \mathrm{e}-10$ & $8 \mathrm{e}-12$ & $3.8 \mathrm{e}-05$ & $3 \mathrm{e}-07$ & $8.2 \mathrm{e}-05$ & $01.8 \mathrm{e}+04$ & 303 \\
\hline 161 & $06: 17: 26$ & 0.00435 & 4.24 & $2.51 \mathrm{e}-10$ & $3.4 \mathrm{e}-11$ & $7 \mathrm{e}-05$ & $1 \mathrm{e}-06$ & 0.0001 & $04.3 \mathrm{e}+03$ & 256 \\
\hline 02 & $06: 17: 41$ & 0.00427 & 4.2 & $2.63 \mathrm{e}-10$ & $4.8 \mathrm{e}-11$ & $8.8 \mathrm{e}-05$ & $2 \mathrm{e}-06$ & 0.00013 & $03.3 \mathrm{e}+03$ & 258 \\
\hline 163 & $06: 17: 56$ & 0.0042 & 4.16 & $1.5 \mathrm{e}-10$ & $3.1 \mathrm{e}-11$ & $9.1 \mathrm{e}-05$ & $8 \mathrm{e}-07$ & 0.00016 & $0 \quad 7 \mathrm{e}+03$ & 250 \\
\hline 164 & $06: 18: 10$ & 0.00413 & 4.13 & $5.57 \mathrm{e}-10$ & $4.7 \mathrm{e}-10$ & 0.00012 & $1 \mathrm{e}-05$ & 0.00018 & $07.5 \mathrm{e}+03$ & 240 \\
\hline 165 & $06: 18: 25$ & 0.00405 & 4.09 & $3.71 \mathrm{e}-09$ & $6.6 \mathrm{e}-10$ & 0.00015 & $3 e-06$ & 0.00016 & $03.5 \mathrm{e}+03$ & 264 \\
\hline 166 & $06: 18: 41$ & 0.00398 & 4.05 & $3.17 \mathrm{e}-10$ & $1.7 \mathrm{e}-10$ & 0.00013 & $9 \mathrm{e}-06$ & 0.00019 & $01.7 \mathrm{e}+04$ & 258 \\
\hline 167 & $06: 18: 56$ & 0.00391 & 4.02 & $2.67 \mathrm{e}-10$ & $6.4 \mathrm{e}-11$ & 0.00014 & $7 \mathrm{e}-06$ & 0.00018 & $05.3 \mathrm{e}+03$ & 245 \\
\hline 168 & $06: 19: 11$ & 0.00384 & 3.98 & $3.16 \mathrm{e}-10$ & $4.5 \mathrm{e}-11$ & 0.00014 & $5 \mathrm{e}-06$ & 0.00019 & $05.4 \mathrm{e}+03$ & 266 \\
\hline 169 & $06: 19: 26$ & 0.00376 & 3.94 & $1.39 \mathrm{e}-10$ & $4.1 \mathrm{e}-11$ & 0.00014 & $3 e-06$ & 0.0002 & $05.5 \mathrm{e}+03$ & 245 \\
\hline 170 & 06:19:41 & 0.00369 & 3.91 & $2.25 \mathrm{e}-10$ & $1.8 \mathrm{e}-10$ & 0.00012 & $2 \mathrm{e}-05$ & 0.00017 & $4 \mathrm{e}-15 \quad 5.8 \mathrm{e}+03$ & 348 \\
\hline 171 & $06: 22: 14$ & 0.00351 & 3.81 & $5.22 \mathrm{e}-10$ & $1.5 \mathrm{e}-10$ & 0.00011 & $2 \mathrm{e}-06$ & 0.00013 & $07.8 \mathrm{e}+03$ & 487 \\
\hline 172 & $06: 22: 34$ & 0.00344 & 3.77 & $4.89 \mathrm{e}-10$ & $1.5 \mathrm{e}-10$ & 0.00011 & $2 \mathrm{e}-06$ & 0.00016 & $01.3 \mathrm{e}+04$ & 335 \\
\hline 173 & $06: 22: 54$ & 0.00338 & 3.74 & $2.16 \mathrm{e}-10$ & $4.4 \mathrm{e}-11$ & 0.00015 & $7 \mathrm{e}-06$ & 0.00028 & $03.6 \mathrm{e}+03$ & 360 \\
\hline 174 & $06: 23: 14$ & 0.00331 & 3.7 & $2.78 \mathrm{e}-10$ & $1.1 \mathrm{e}-10$ & 0.00016 & $1 \mathrm{e}-05$ & 0.00024 & $02.2 \mathrm{e}+03$ & 332 \\
\hline 175 & $06: 23: 34$ & 0.00325 & 3.66 & $1.07 \mathrm{e}-09$ & $9.8 \mathrm{e}-10$ & 0.00019 & $1 \mathrm{e}-05$ & 0.00022 & $04.2 \mathrm{e}+03$ & 318 \\
\hline 176 & $06: 23: 54$ & 0.00318 & 3.63 & $1.49 \mathrm{e}-10$ & $2.8 \mathrm{e}-11$ & 0.00016 & $8 \mathrm{e}-06$ & 0.00025 & $06.3 \mathrm{e}+03$ & 283 \\
\hline 177 & $06: 24: 14$ & 0.00312 & 3.59 & $2.83 \mathrm{e}-10$ & $8.6 \mathrm{e}-11$ & 0.00018 & $8 \mathrm{e}-06$ & 0.00023 & $02.3 \mathrm{e}+03$ & 354 \\
\hline 178 & $06: 24: 34$ & 0.00305 & 3.55 & $1.26 \mathrm{e}-10$ & $4.6 \mathrm{e}-11$ & 0.00015 & $1 \mathrm{e}-05$ & 0.00025 & $02.6 \mathrm{e}+03$ & 346 \\
\hline 179 & $06: 24: 54$ & 0.00299 & 3.51 & $2.57 \mathrm{e}-10$ & $5.8 \mathrm{e}-11$ & 0.00017 & $8 \mathrm{e}-06$ & 0.00025 & $01.5 \mathrm{e}+03$ & 496 \\
\hline 180 & $06: 25: 41$ & 0.00293 & 3.48 & $1.16 \mathrm{e}-10$ & $3.2 \mathrm{e}-11$ & $9.2 \mathrm{e}-05$ & $5 \mathrm{e}-06$ & 0.00015 & $08.8 \mathrm{e}+03$ & 618 \\
\hline 181 & $06: 26: 21$ & 0.00287 & 3.44 & $4.31 \mathrm{e}-10$ & $2.3 \mathrm{e}-10$ & 0.00012 & $5 \mathrm{e}-06$ & 0.00015 & $02.3 \mathrm{e}+04$ & 689 \\
\hline 182 & 06:27:01 & 0.00281 & 3.4 & $1.86 \mathrm{e}-10$ & $6.5 \mathrm{e}-11$ & 0.00014 & $6 e-06$ & 0.00019 & $03.8 \mathrm{e}+03$ & \\
\hline
\end{tabular}




\begin{tabular}{|c|c|c|c|c|c|c|c|c|c|c|}
\hline 83 & $06: 27: 41$ & 0.00274 & 3.37 & $1.72 \mathrm{e}-10$ & $9.9 \mathrm{e}-11$ & 0.00014 & $9 \mathrm{e}-06$ & 0.0002 & $03.3 \mathrm{e}+03$ & 675 \\
\hline 184 & $06: 28: 21$ & 0.00269 & 3.33 & $1.95 \mathrm{e}-10$ & $4.6 \mathrm{e}-11$ & 0.00015 & $5 e-06$ & 0.00019 & $9 \mathrm{e}-15 \quad 6.1 \mathrm{e}+03$ & 657 \\
\hline 85 & 06:29:01 & 0.00263 & 3.29 & $1.11 \mathrm{e}-10$ & $1.7 \mathrm{e}-11$ & 0.00013 & $3 e-06$ & 0.0002 & $03.2 \mathrm{e}+03$ & 77 \\
\hline 186 & $06: 29: 41$ & 0.00257 & 3.26 & $3.19 \mathrm{e}-10$ & $1.5 \mathrm{e}-10$ & 0.00016 & $9 \mathrm{e}-06$ & 0.0002 & $01.3 \mathrm{e}+04$ & 670 \\
\hline 7 & $06: 30: 21$ & 0.00251 & 3.22 & $1.74 \mathrm{e}-10$ & $4 \mathrm{e}-11$ & 0.00016 & $3 e-06$ & 0.00023 & $04.6 \mathrm{e}+03$ & 679 \\
\hline 188 & 06:31:01 & 0.00245 & 3.18 & $1.35 \mathrm{e}-10$ & $4.1 \mathrm{e}-11$ & 0.00016 & $7 \mathrm{e}-06$ & 0.00023 & $08.2 \mathrm{e}+03$ & 673 \\
\hline 39 & $06: 31: 41$ & 0.0024 & 3.15 & $1.22 \mathrm{e}-10$ & $2.6 \mathrm{e}-11$ & 0.00015 & $5 e-06$ & 0.00022 & $05.5 \mathrm{e}+03$ & 846 \\
\hline 90 & $06: 33: 34$ & 0.00234 & 3.11 & $6.61 \mathrm{e}-11$ & $6.2 \mathrm{e}-12$ & 0.00012 & $4 \mathrm{e}-06$ & 0.00022 & $01.4 \mathrm{e}+04$ & 605 \\
\hline 1 & $06: 34: 14$ & 0.00228 & 3.07 & $3.26 \mathrm{e}-11$ & $6.1 \mathrm{e}-12$ & 0.00012 & $5 e-06$ & 0.00021 & $01.2 \mathrm{e}+04$ & 1615 \\
\hline 92 & $06: 36: 44$ & 0.00231 & 3.09 & $1.48 \mathrm{e}-09$ & $7 \mathrm{e}-11$ & 0.00014 & $1 \mathrm{e}-06$ & $9.7 \mathrm{e}-05$ & $9 \mathrm{e}-08 \quad 2.2 \mathrm{e}+03$ & 1408 \\
\hline 3 & 06:38:09 & 0.00241 & 3.16 & $8.62 \mathrm{e}-10$ & $6.5 \mathrm{e}-11$ & 0.0001 & $1 \mathrm{e}-06$ & $6.5 \mathrm{e}-05$ & $3 \mathrm{e}-13 \quad 1.4 \mathrm{e}+03$ & 1428 \\
\hline 94 & $06: 39: 40$ & 0.00252 & 3.23 & $1.39 \mathrm{e}-09$ & $1.3 \mathrm{e}-10$ & $7.2 \mathrm{e}-05$ & $6 \mathrm{e}-07$ & $5.4 \mathrm{e}-05$ & $4 \mathrm{e}-08 \quad 1.8 \mathrm{e}+03$ & 1634 \\
\hline 5 & $06: 42: 21$ & 0.00287 & 3.44 & $6.96 \mathrm{e}-05$ & $6.9 \mathrm{e}-05$ & $6 \mathrm{e}-05$ & $3 \mathrm{e}-07$ & $7 \mathrm{e}-06$ & $2 \mathrm{e}-08 \quad 9.3 \mathrm{e}+02$ & 978 \\
\hline 6 & $06: 42: 59$ & 0.00351 & 3.8 & 0.000138 & 0.00011 & $7.2 \mathrm{e}-06$ & $3 \mathrm{e}-08$ & $8.9 \mathrm{e}-07$ & $1 \mathrm{e}-08 \quad 1.5 \mathrm{e}+02$ & 289 \\
\hline 197 & $06: 43: 11$ & 0.00422 & 4.17 & $4.33 \mathrm{e}-09$ & $5.8 \mathrm{e}-10$ & $9.3 \mathrm{e}-07$ & $3 \mathrm{e}-08$ & $4.4 \mathrm{e}-08$ & $4 \mathrm{e}-123.1 \mathrm{e}+02$ & 405 \\
\hline 198 & 07:01:58 & 0.00605 & 5 & $1.59 \mathrm{e}-09$ & $3.9 \mathrm{e}-10$ & $2.7 \mathrm{e}-07$ & $1 \mathrm{e}-08$ & $4.4 \mathrm{e}-07$ & $3 \mathrm{e}-172.2 \mathrm{e}+03$ & 329 \\
\hline 199 & $07: 02: 13$ & 0.00587 & 4.93 & $1.3 \mathrm{e}-09$ & $5.4 \mathrm{e}-10$ & $3.5 \mathrm{e}-07$ & $6 \mathrm{e}-09$ & $5.5 \mathrm{e}-07$ & $03.3 \mathrm{e}+03$ & 248 \\
\hline 200 & $07: 02: 28$ & 0.0057 & 4.85 & $7.85 \mathrm{e}-10$ & $2.7 \mathrm{e}-10$ & $3.5 \mathrm{e}-07$ & $9 \mathrm{e}-09$ & $7.1 \mathrm{e}-07$ & $0 \quad 3 \mathrm{e}+03$ & 240 \\
\hline 201 & $07: 02: 43$ & 0.00552 & 4.78 & $2.1 \mathrm{e}-10$ & $8.4 \mathrm{e}-11$ & $3.7 \mathrm{e}-07$ & $5 \mathrm{e}-08$ & $9.7 \mathrm{e}-07$ & $08.3 \mathrm{e}+03$ & 234 \\
\hline 2 & $07: 02: 58$ & 0.00535 & 4.7 & $3.42 \mathrm{e}-10$ & $6.7 \mathrm{e}-11$ & $6.5 \mathrm{e}-07$ & $3 e-08$ & $1.6 \mathrm{e}-06$ & $03.7 \mathrm{e}+04$ & 226 \\
\hline 203 & 07:03:13 & 0.00518 & 4.63 & $7.85 \mathrm{e}-10$ & $9.4 \mathrm{e}-10$ & $1.1 \mathrm{e}-06$ & $3 \mathrm{e}-07$ & $2.2 \mathrm{e}-06$ & $05.3 \mathrm{e}+04$ & 206 \\
\hline 204 & $07: 03: 28$ & 0.00 & 4.55 & $9.75 \mathrm{e}-11$ & $1.4 \mathrm{e}-10$ & $9 \mathrm{e}-07$ & $5 \mathrm{e}-07$ & $3.1 \mathrm{e}-06$ & $0 \quad 1 \mathrm{e}+04$ & 9 \\
\hline 205 & $07: 03: 43$ & 0.00486 & 4.48 & $1.24 \mathrm{e}-10$ & $2.6 \mathrm{e}-10$ & $1.8 \mathrm{e}-06$ & $8 \mathrm{e}-07$ & $4.9 \mathrm{e}-06$ & $01.8 \mathrm{e}+04$ & 231 \\
\hline 206 & 07:03:58 & 0.0047 & 4.41 & $2.07 \mathrm{e}-11$ & $6.9 \mathrm{e}-12$ & $1.3 \mathrm{e}-06$ & 0 & $6.8 \mathrm{e}-06$ & $01.2 \mathrm{e}+05$ & 229 \\
\hline 207 & 07:04:13 & 0.00454 & 4.33 & $3.24 \mathrm{e}-11$ & $9.2 \mathrm{e}-13$ & $1.6 \mathrm{e}-06$ & 0 & $5.7 \mathrm{e}-06$ & $02.9 \mathrm{e}+04$ & 883 \\
\hline 208 & $07: 05: 23$ & 0.00439 & 4.26 & $1.86 \mathrm{e}-10$ & $3.3 \mathrm{e}-11$ & $4.5 \mathrm{e}-06$ & $9 \mathrm{e}-08$ & $1.1 \mathrm{e}-05$ & $03.1 \mathrm{e}+04$ & 575 \\
\hline 209 & $07: 05: 48$ & 0.00424 & 4.19 & $9.81 \mathrm{e}-11$ & $3 \mathrm{e}-11$ & $5.5 \mathrm{e}-06$ & $3 \mathrm{e}-07$ & $1.3 \mathrm{e}-05$ & $01.3 \mathrm{e}+04$ & 403 \\
\hline 210 & $07: 06: 13$ & 0.00409 & 4.11 & $4.56 \mathrm{e}-11$ & $7.4 \mathrm{e}-11$ & $4.6 \mathrm{e}-06$ & $2 \mathrm{e}-06$ & $1.6 \mathrm{e}-05$ & $03.6 \mathrm{e}+04$ & 367 \\
\hline 211 & 07:06:38 & 0.00394 & 4.04 & $2.73 \mathrm{e}-11$ & $7.9 \mathrm{e}-13$ & $4.6 \mathrm{e}-06$ & 0 & $1.4 \mathrm{e}-05$ & $0 \quad 3 \mathrm{e}+04$ & 1212 \\
\hline 212 & 07:08:11 & 0.0038 & 3.96 & $2.44 \mathrm{e}-10$ & $3.1 \mathrm{e}-11$ & $1 \mathrm{e}-05$ & $2 \mathrm{e}-07$ & $2.1 \mathrm{e}-05$ & $02.2 \mathrm{e}+05$ & 790 \\
\hline 213 & 07:08:51 & 0.00365 & 3.89 & $2.06 \mathrm{e}-10$ & $4.8 \mathrm{e}-11$ & $1.6 \mathrm{e}-05$ & $6 \mathrm{e}-07$ & $3 \mathrm{e}-05$ & $02.8 \mathrm{e}+04$ & 662 \\
\hline 214 & 07:09:31 & 0.00352 & 3.81 & $5.3 \mathrm{e}-11$ & $6.6 \mathrm{e}-11$ & $1.2 \mathrm{e}-05$ & $4 \mathrm{e}-06$ & $3.9 \mathrm{e}-05$ & $02.5 \mathrm{e}+05$ & 539 \\
\hline 215 & 07:10:11 & 0.00338 & 3.74 & $2.75 \mathrm{e}-10$ & $7.2 \mathrm{e}-11$ & $2.6 \mathrm{e}-05$ & $1 \mathrm{e}-06$ & $4.4 \mathrm{e}-05$ & $01.9 \mathrm{e}+05$ & 645 \\
\hline 216 & $07: 10: 51$ & 0.00325 & 3.67 & $1.19 \mathrm{e}-10$ & $6.2 \mathrm{e}-11$ & $2.9 \mathrm{e}-05$ & $2 \mathrm{e}-06$ & $6.2 \mathrm{e}-05$ & $04.6 \mathrm{e}+04$ & 607 \\
\hline 217 & 07:11:31 & 0.00312 & 3.59 & $1.71 \mathrm{e}-10$ & $3.1 \mathrm{e}-11$ & $3.5 \mathrm{e}-05$ & $2 \mathrm{e}-06$ & $7 \mathrm{e}-05$ & $02.5 \mathrm{e}+04$ & 618 \\
\hline 218 & $07: 12: 11$ & 0.00299 & 3.52 & $2.25 \mathrm{e}-10$ & $2.9 \mathrm{e}-11$ & $4.8 \mathrm{e}-05$ & $9 \mathrm{e}-07$ & $9 \mathrm{e}-05$ & $04.4 \mathrm{e}+04$ & 66 \\
\hline 219 & $07: 12: 51$ & 0.00287 & 3.44 & $1.79 \mathrm{e}-10$ & 7.1e-11 & $6.2 \mathrm{e}-05$ & $5 \mathrm{e}-06$ & 0.00012 & $01.1 \mathrm{e}+05$ & 627 \\
\hline
\end{tabular}




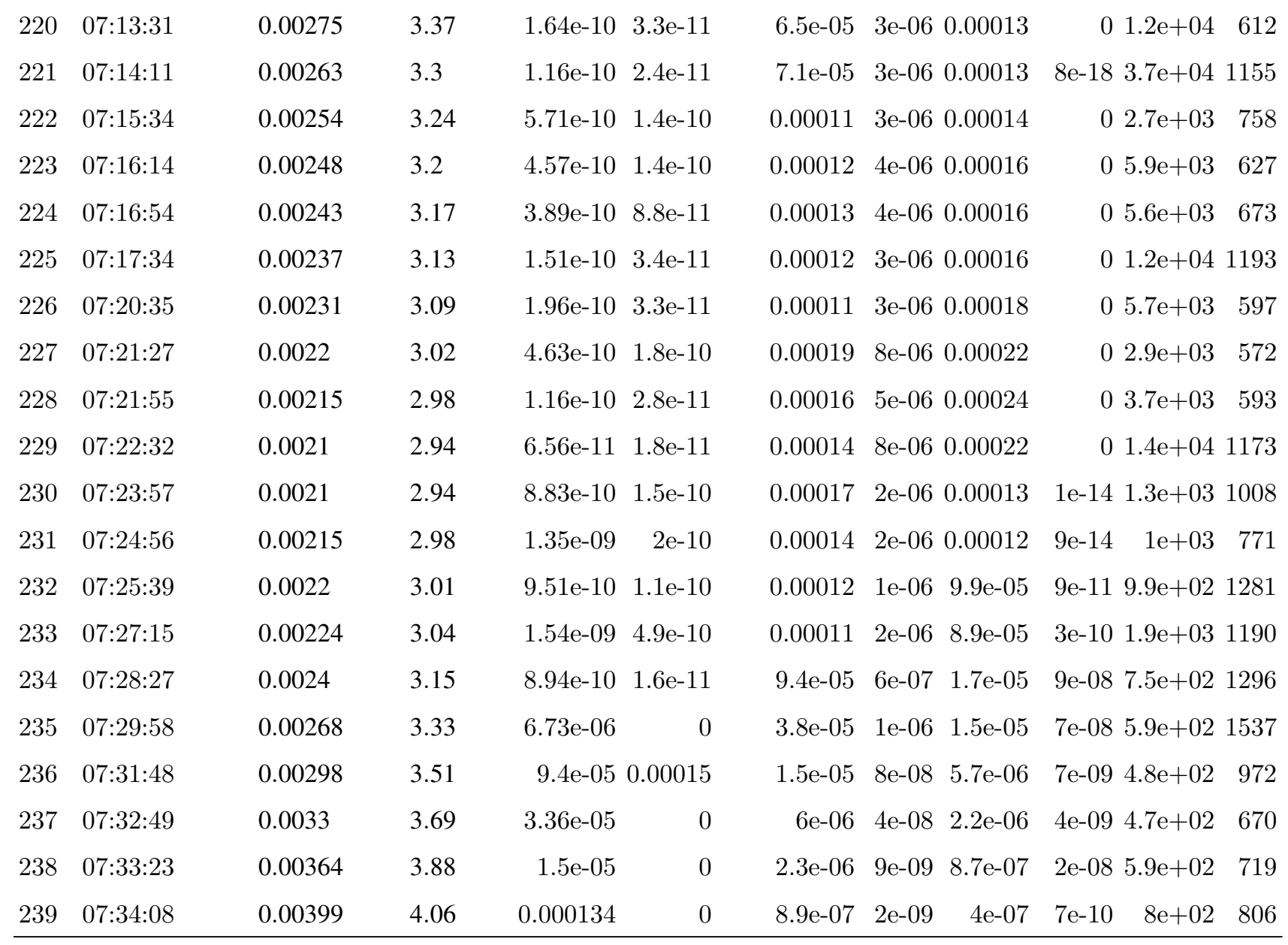

TABLE V: Fit results for each step. 


\section{Appendix D: R source code}

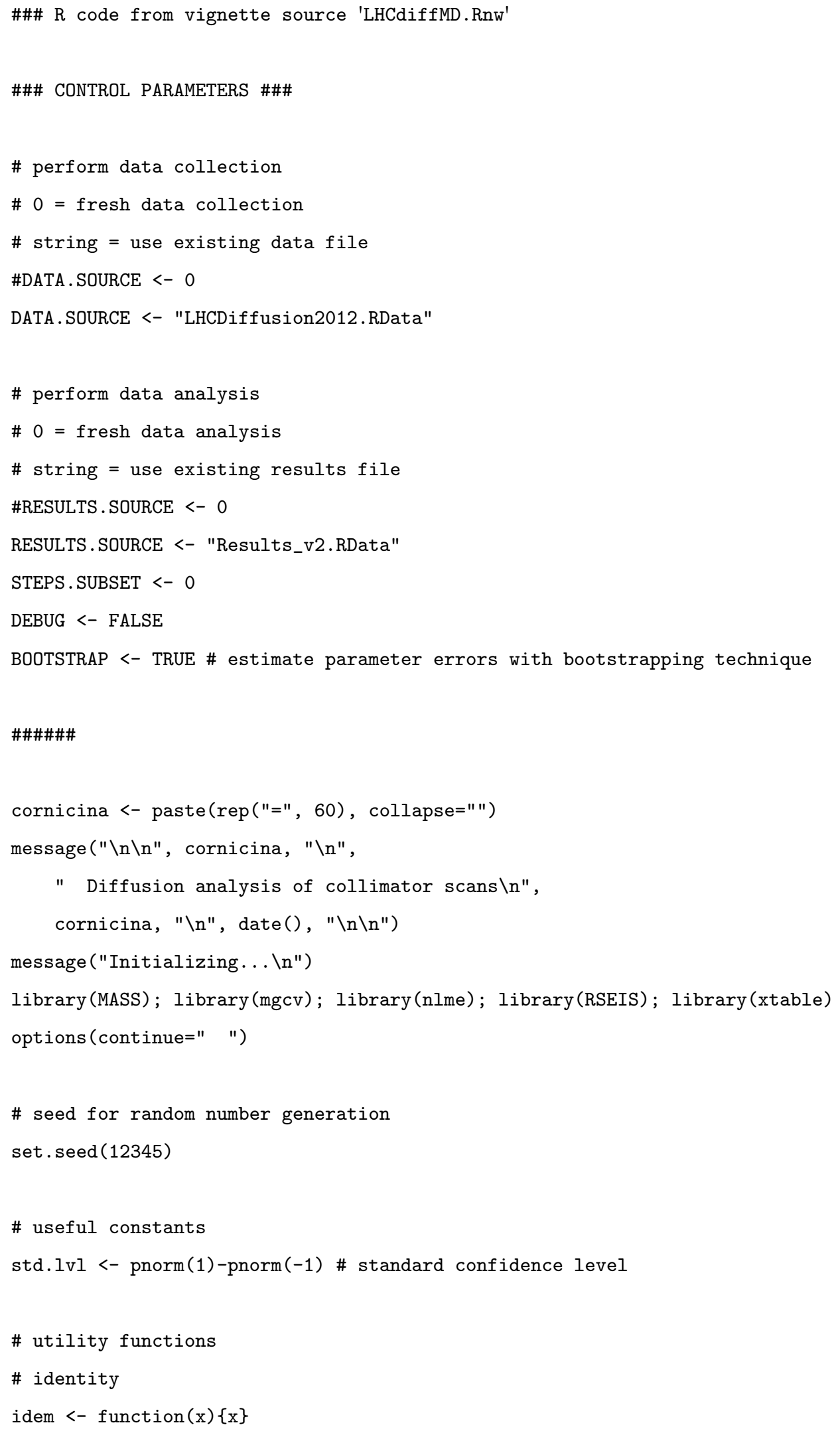




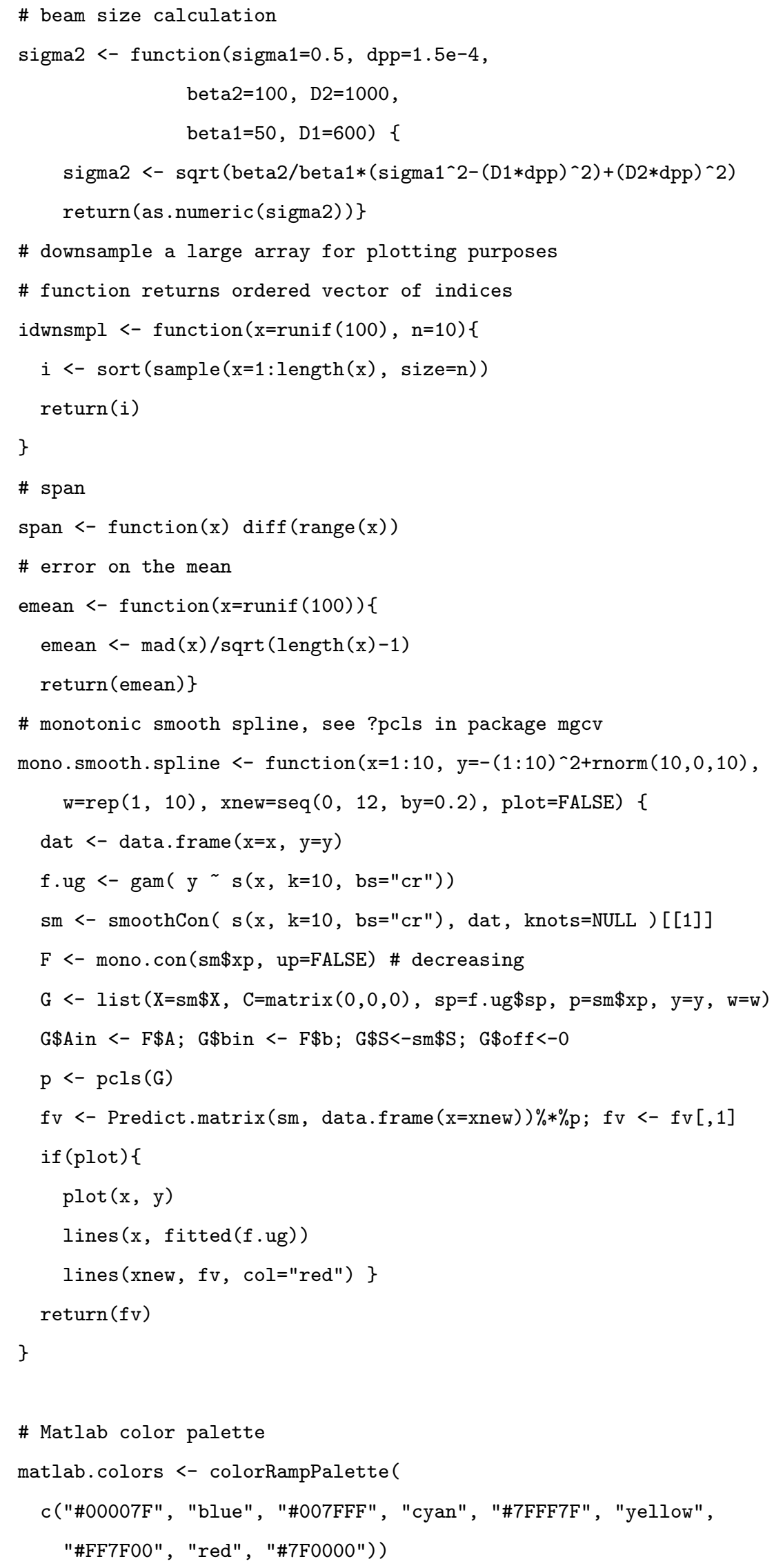




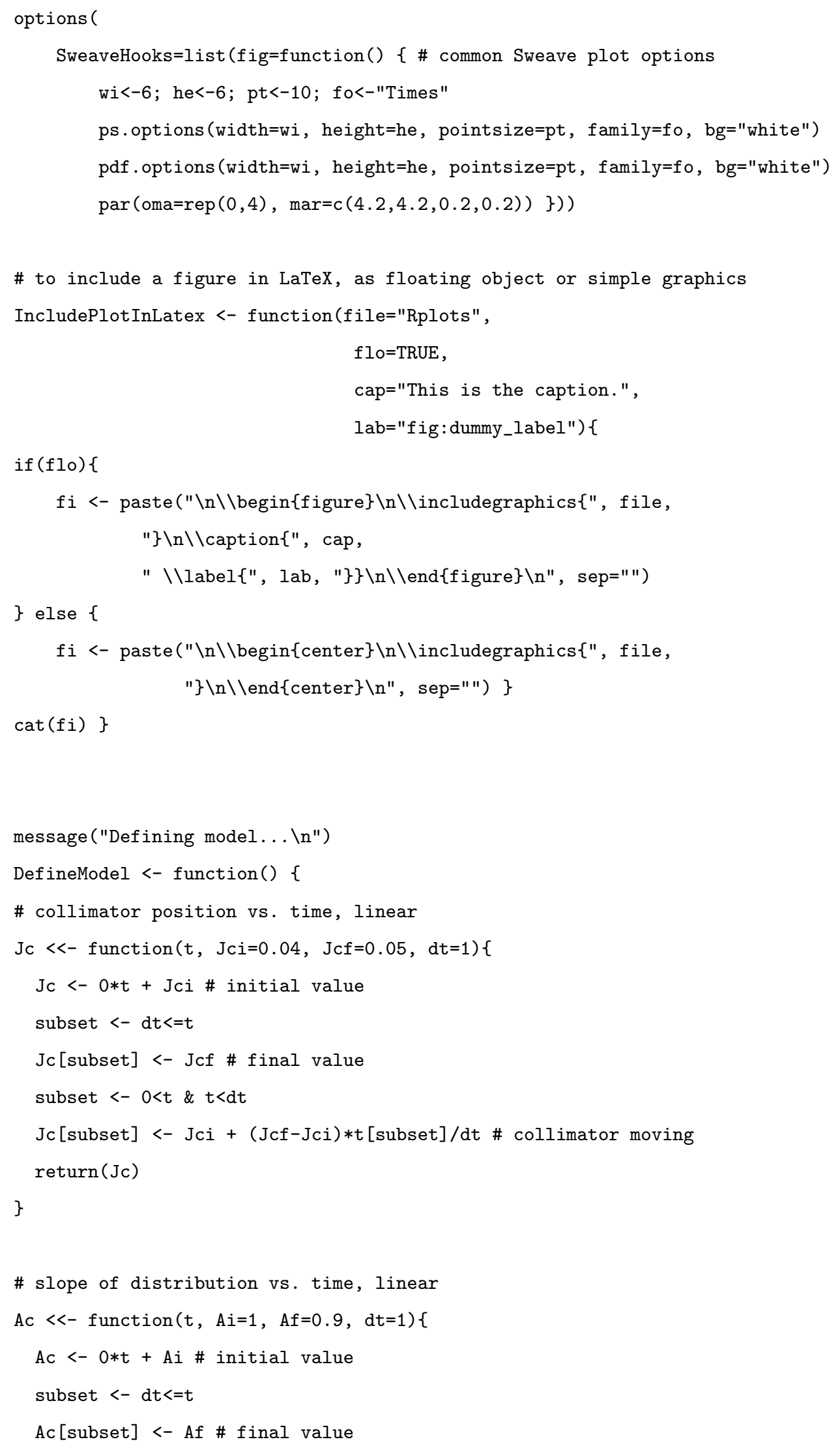




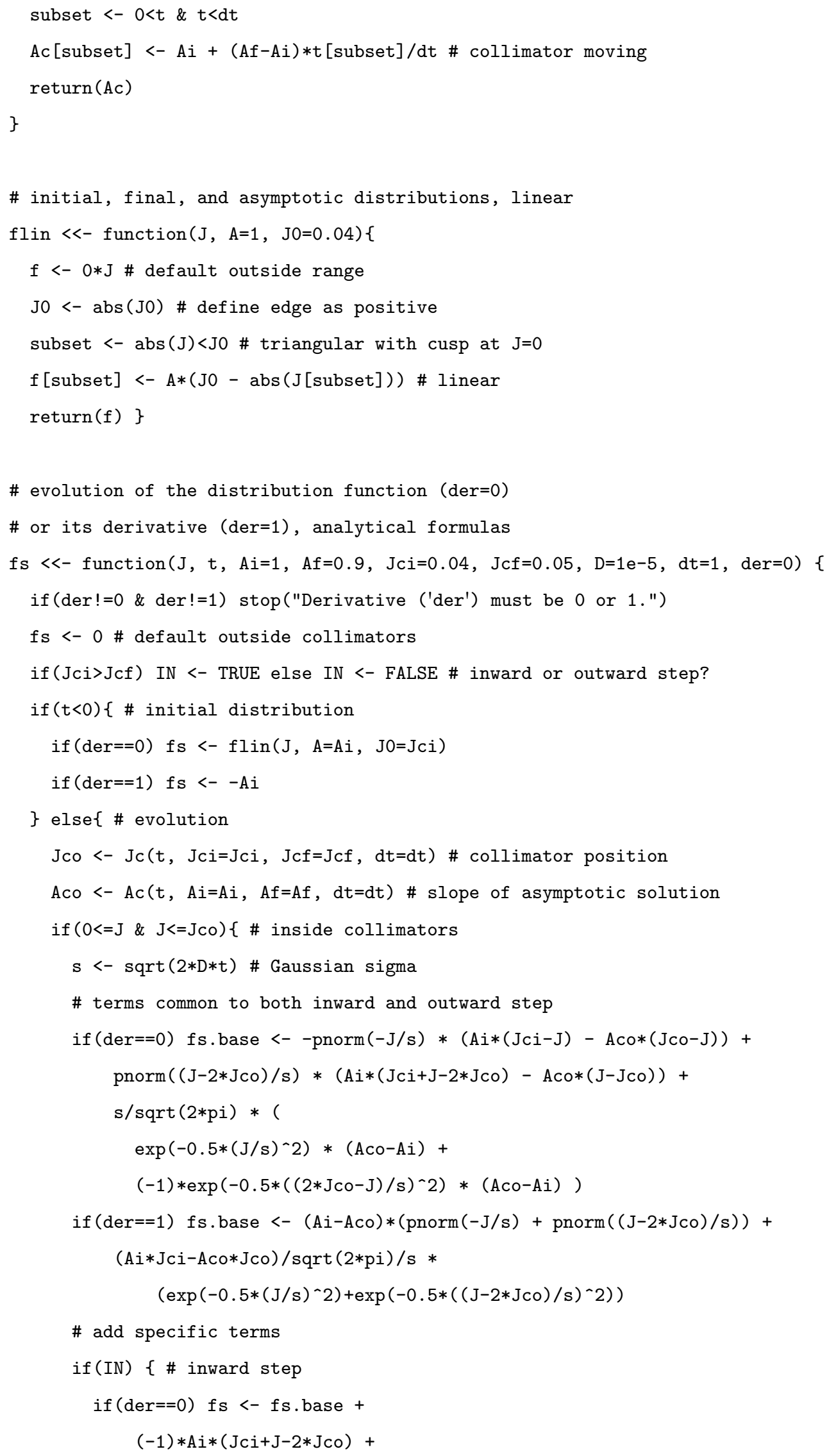




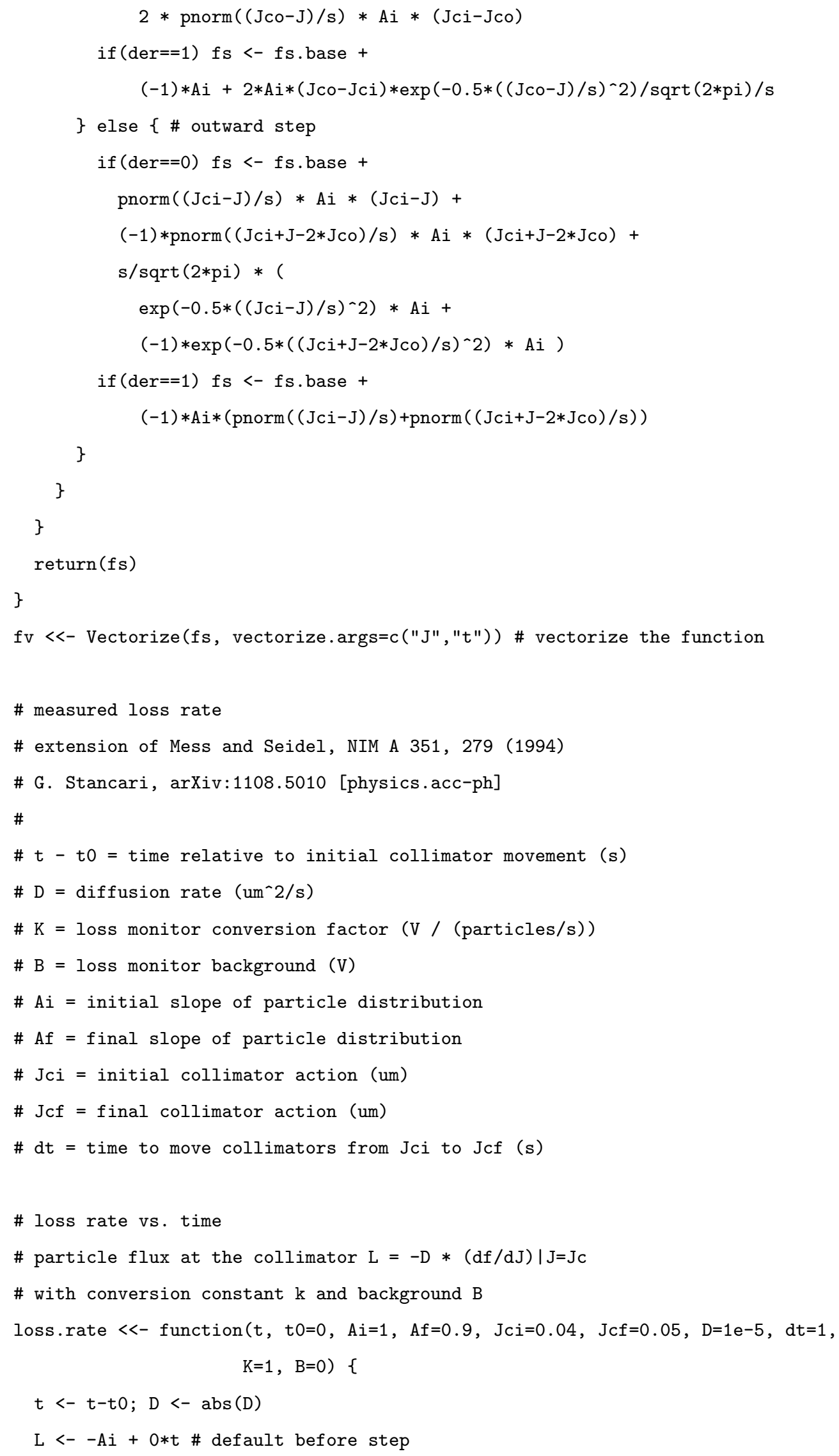




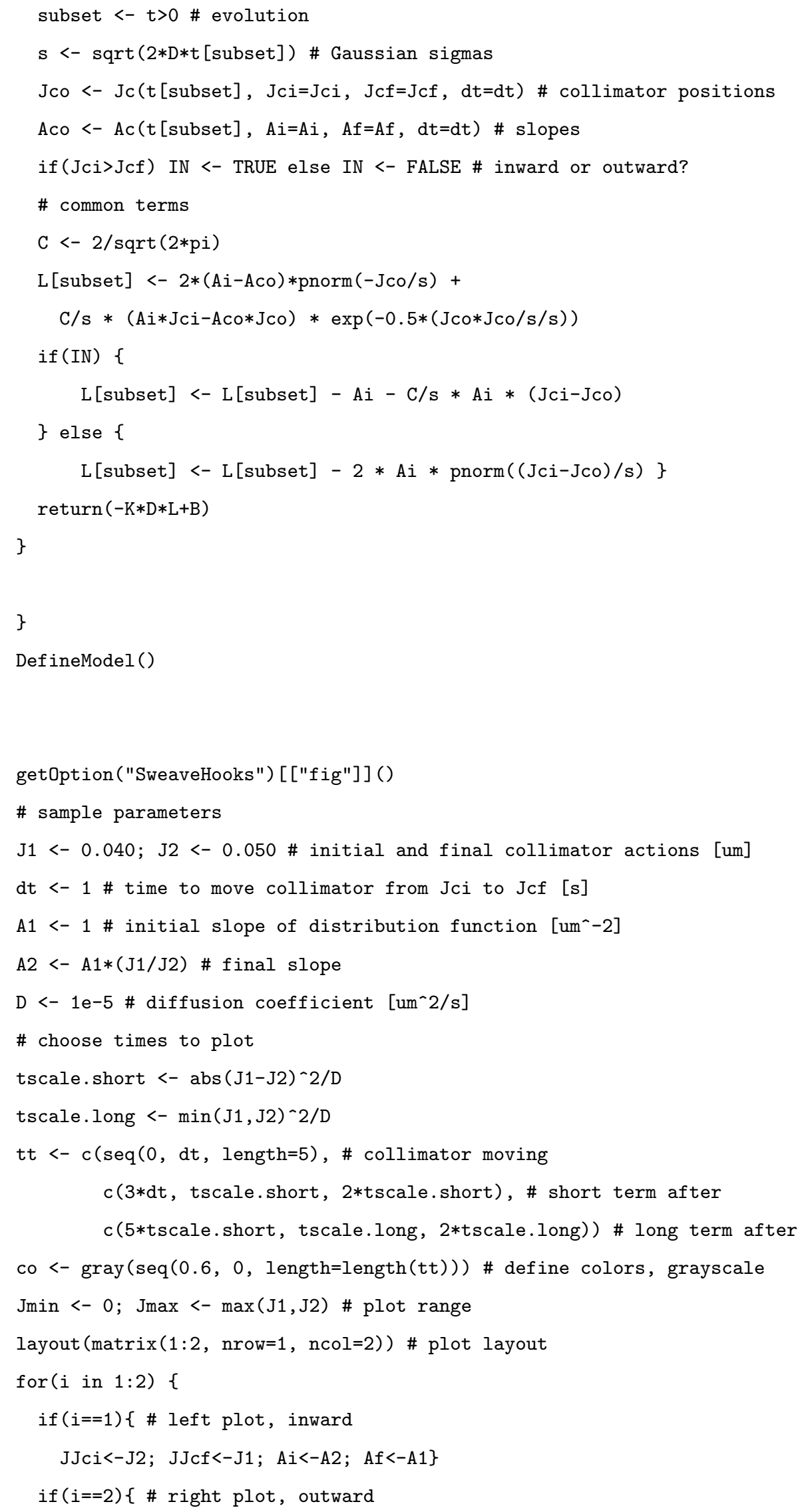




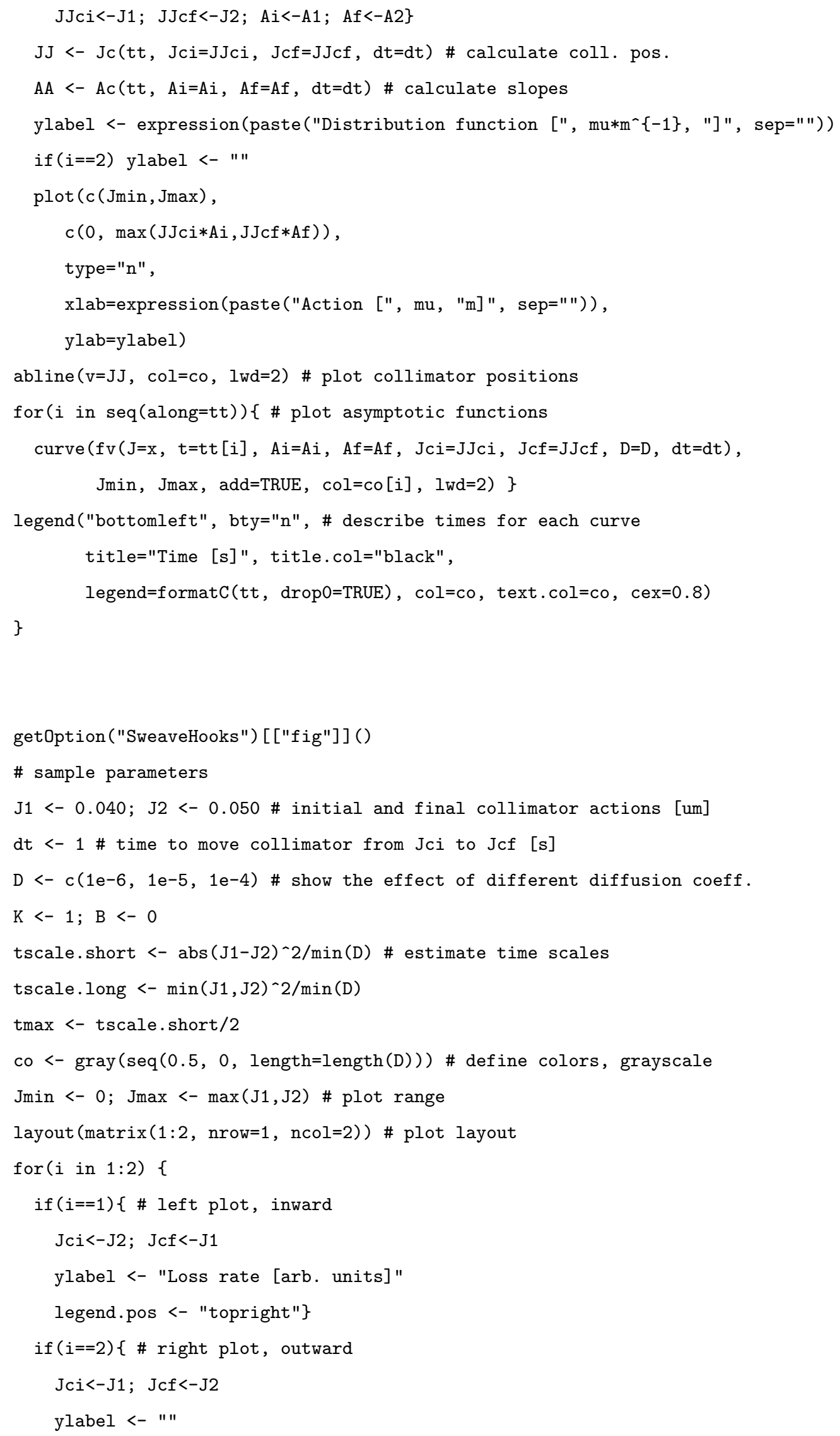




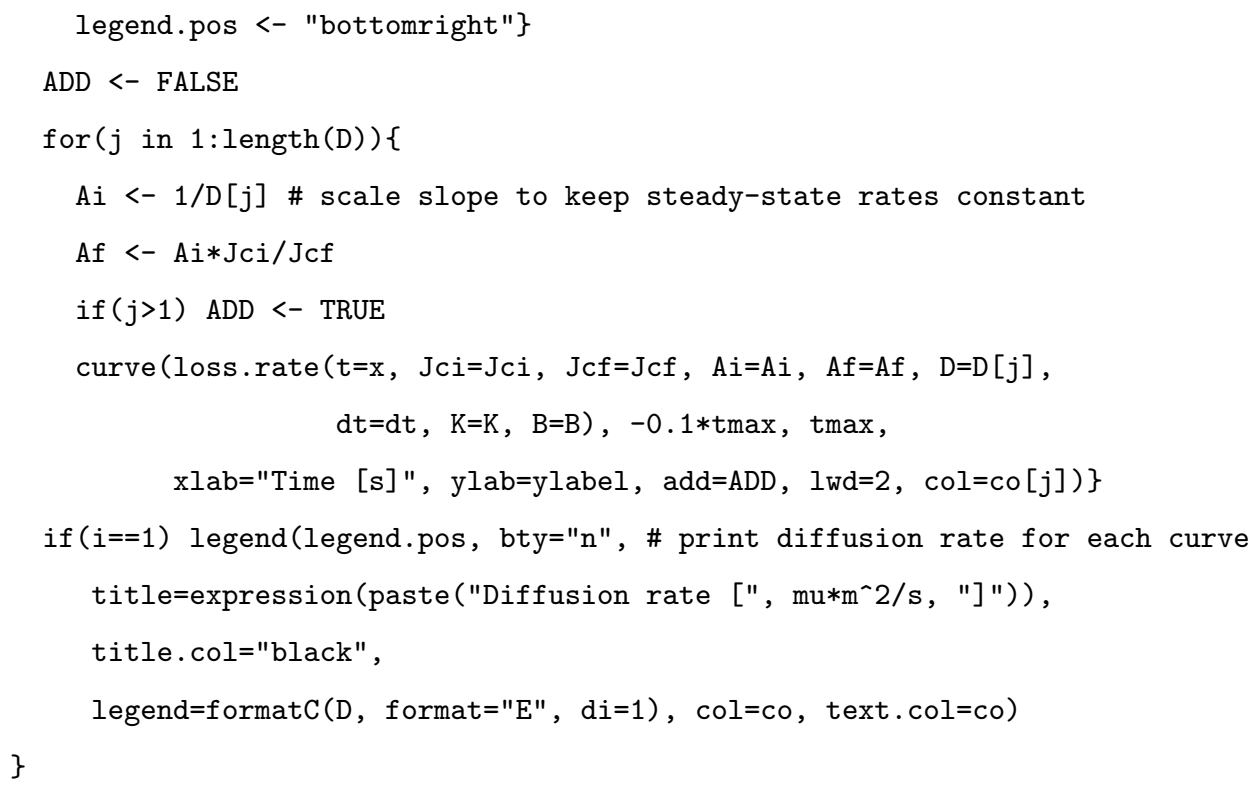




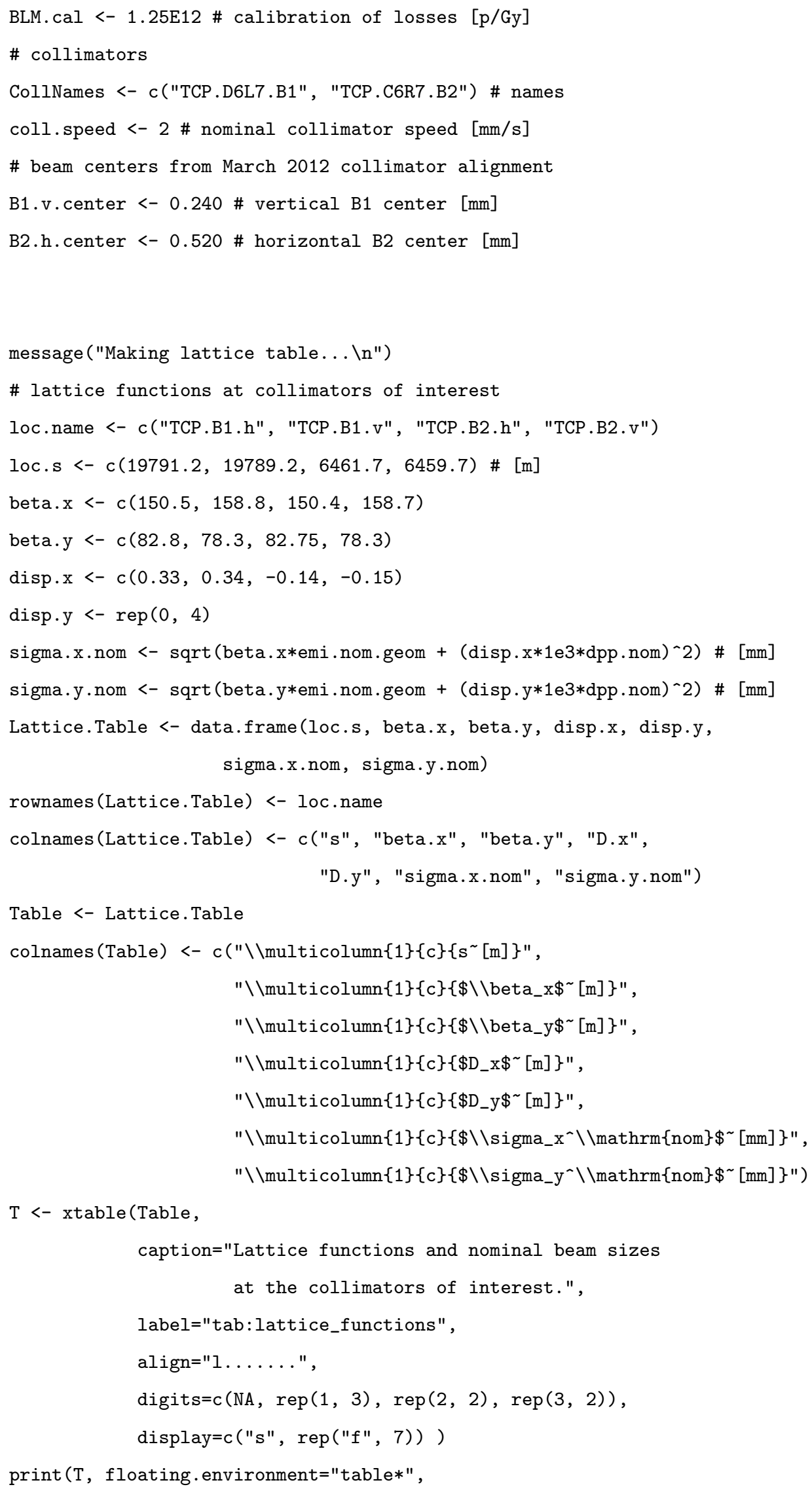


latex.environments=c("ruledtabular"), size="small",

hline.after $=0$, sanitize.text.function=idem)

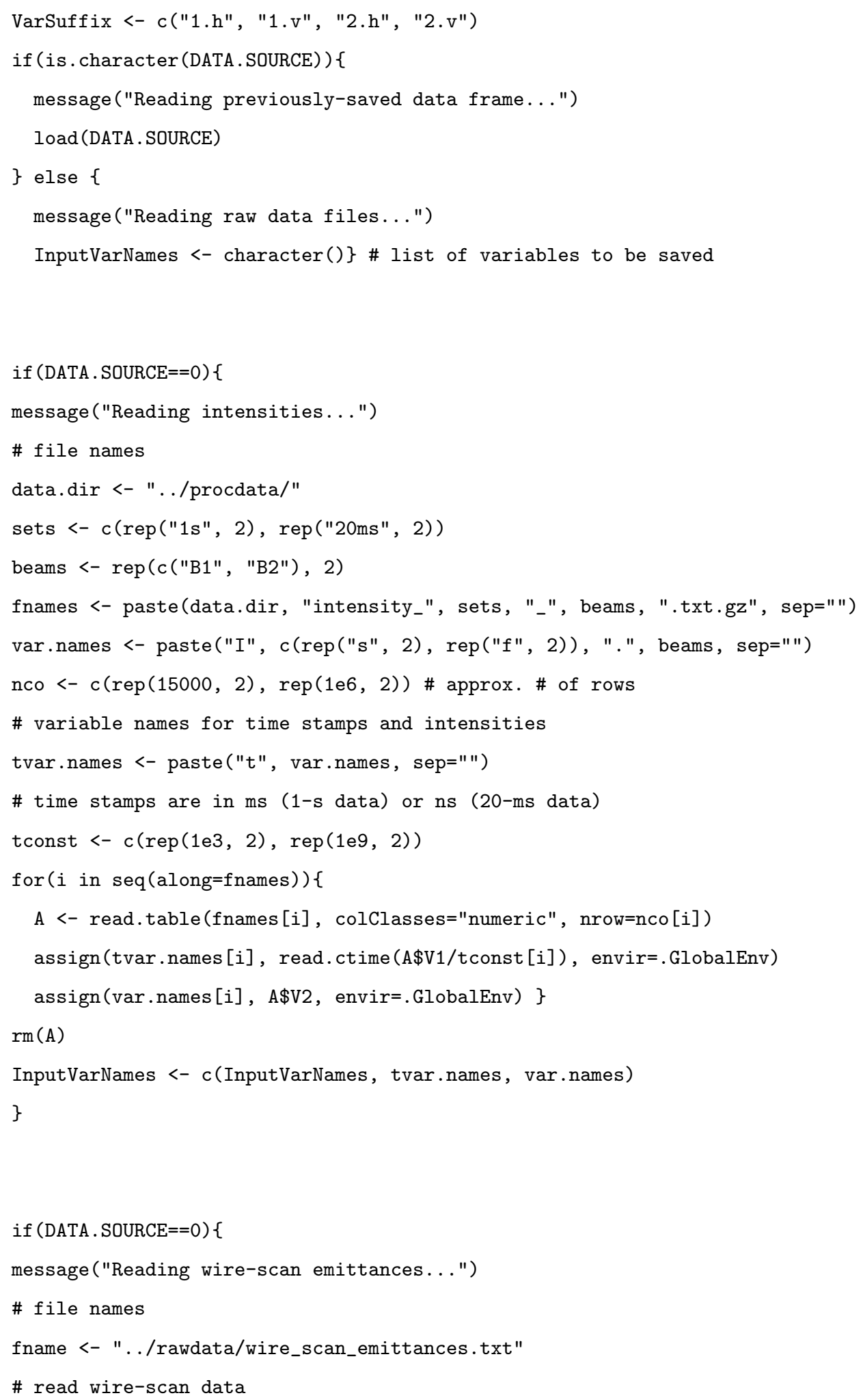




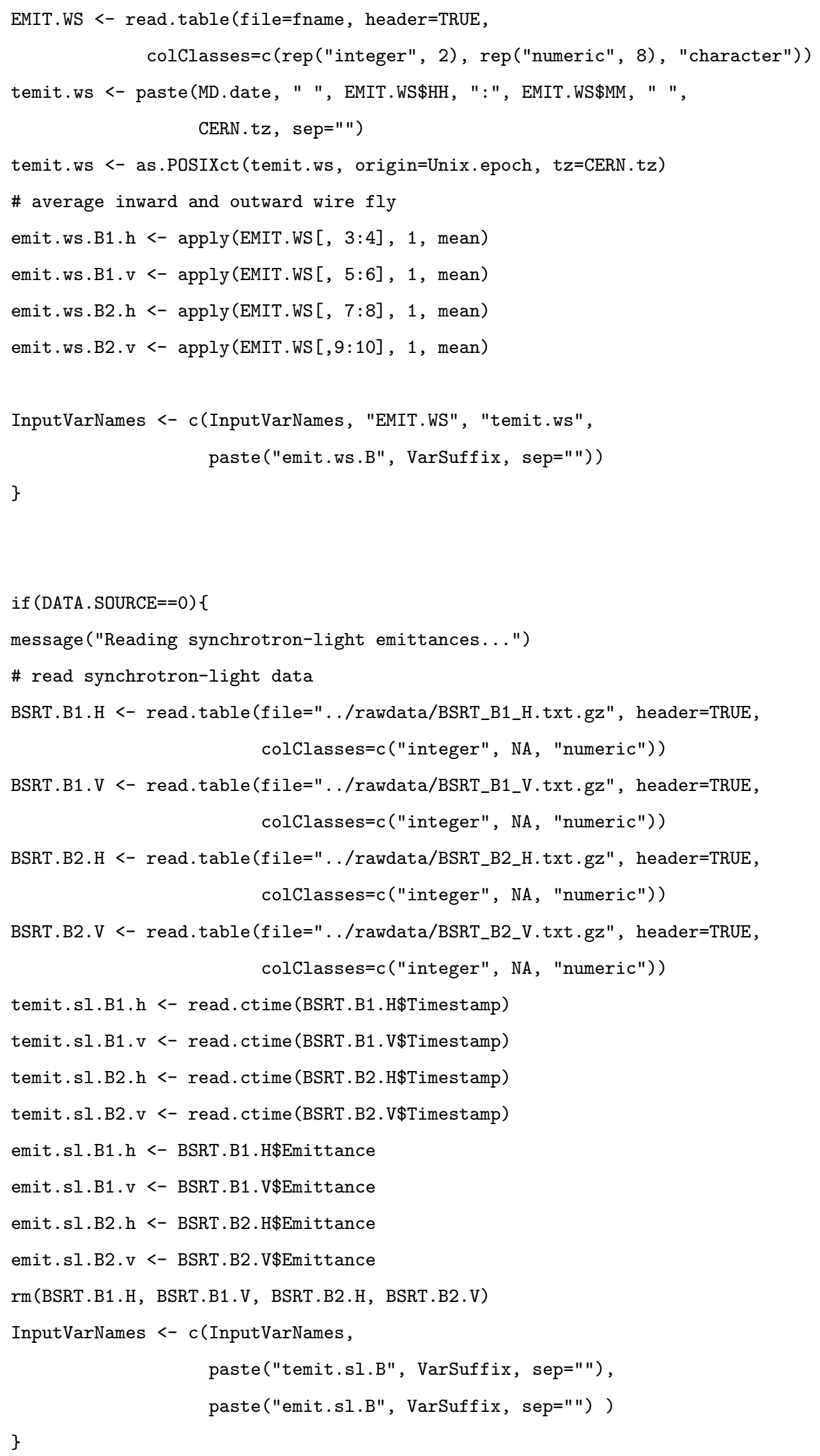




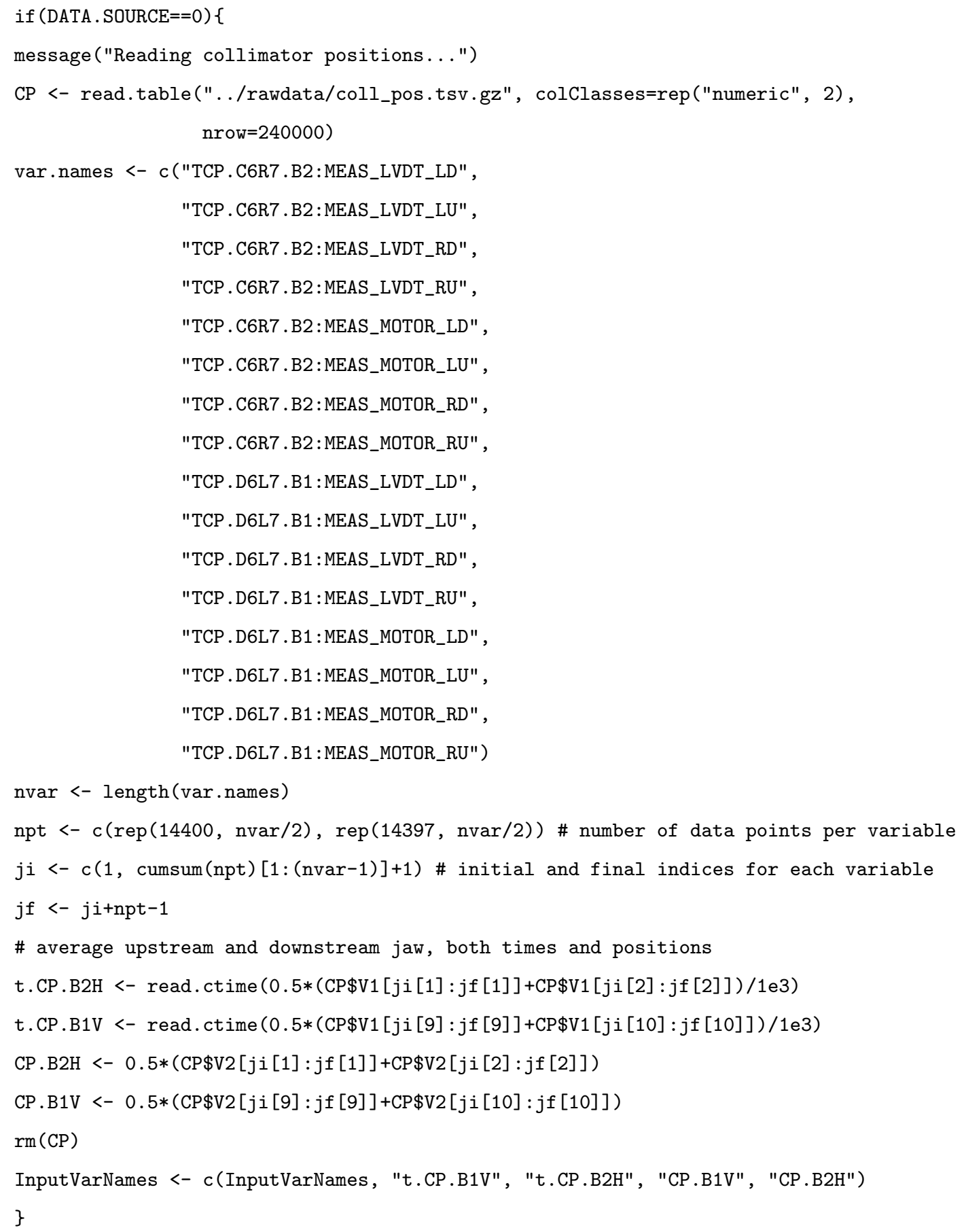




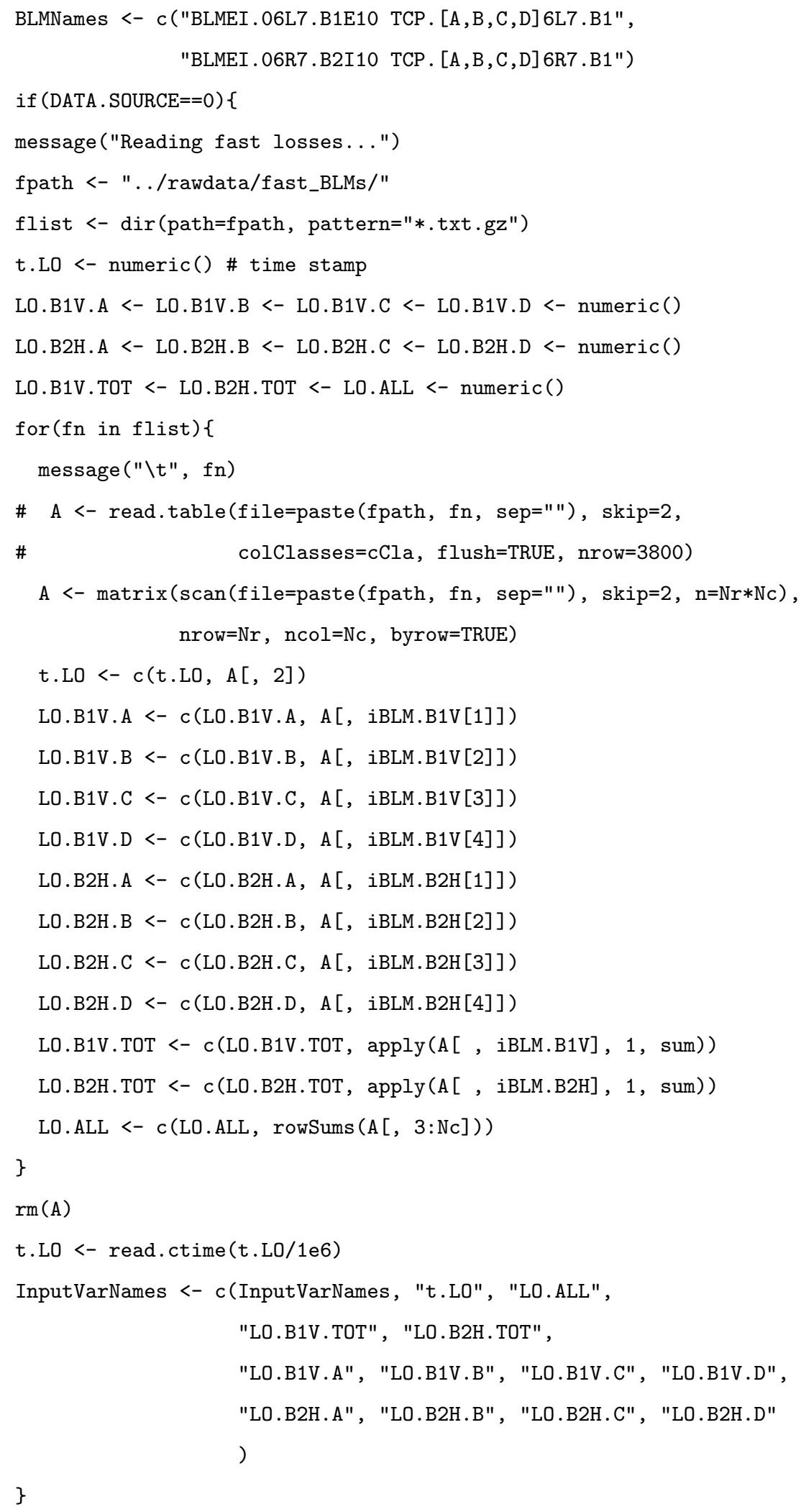




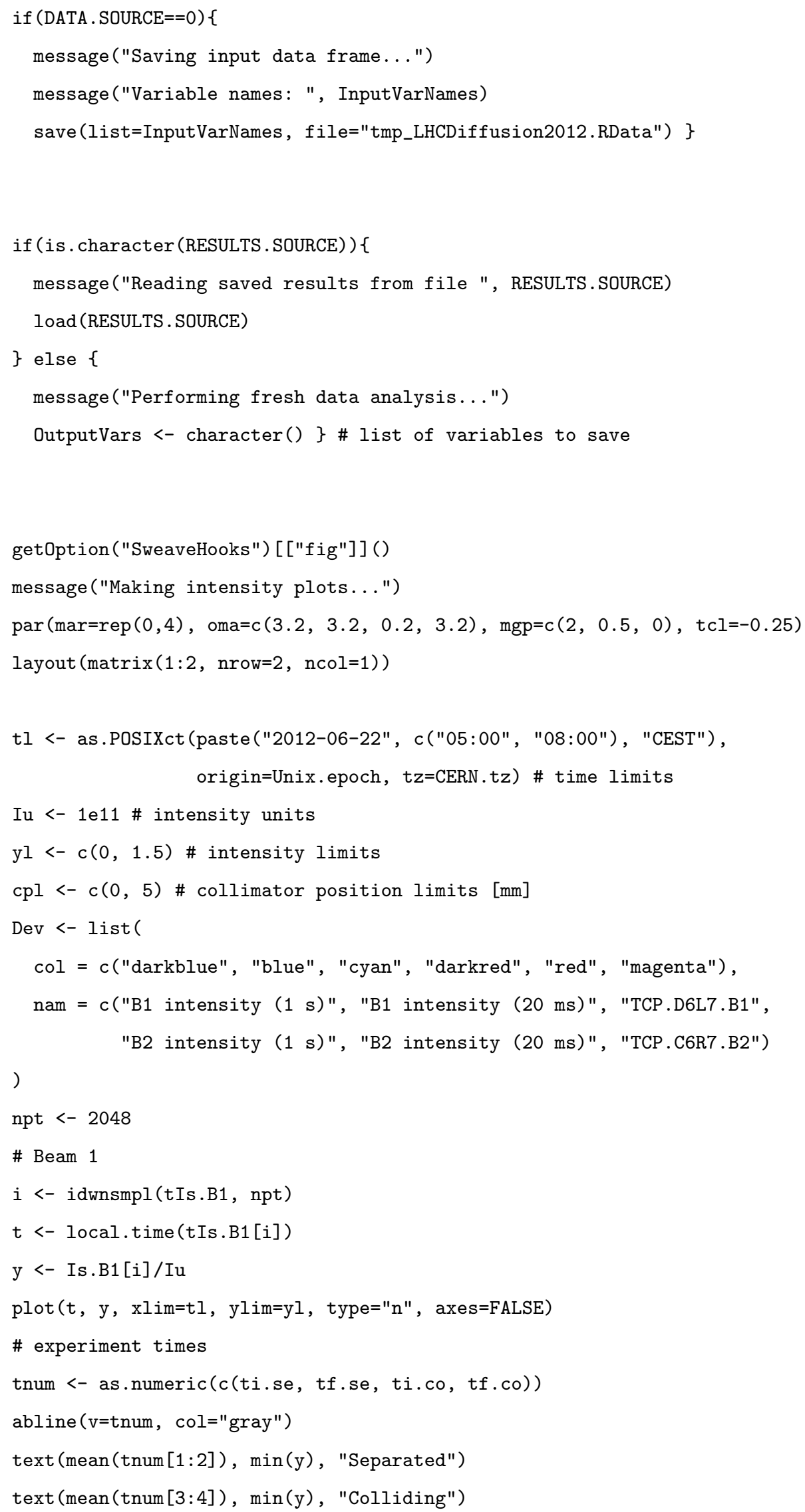




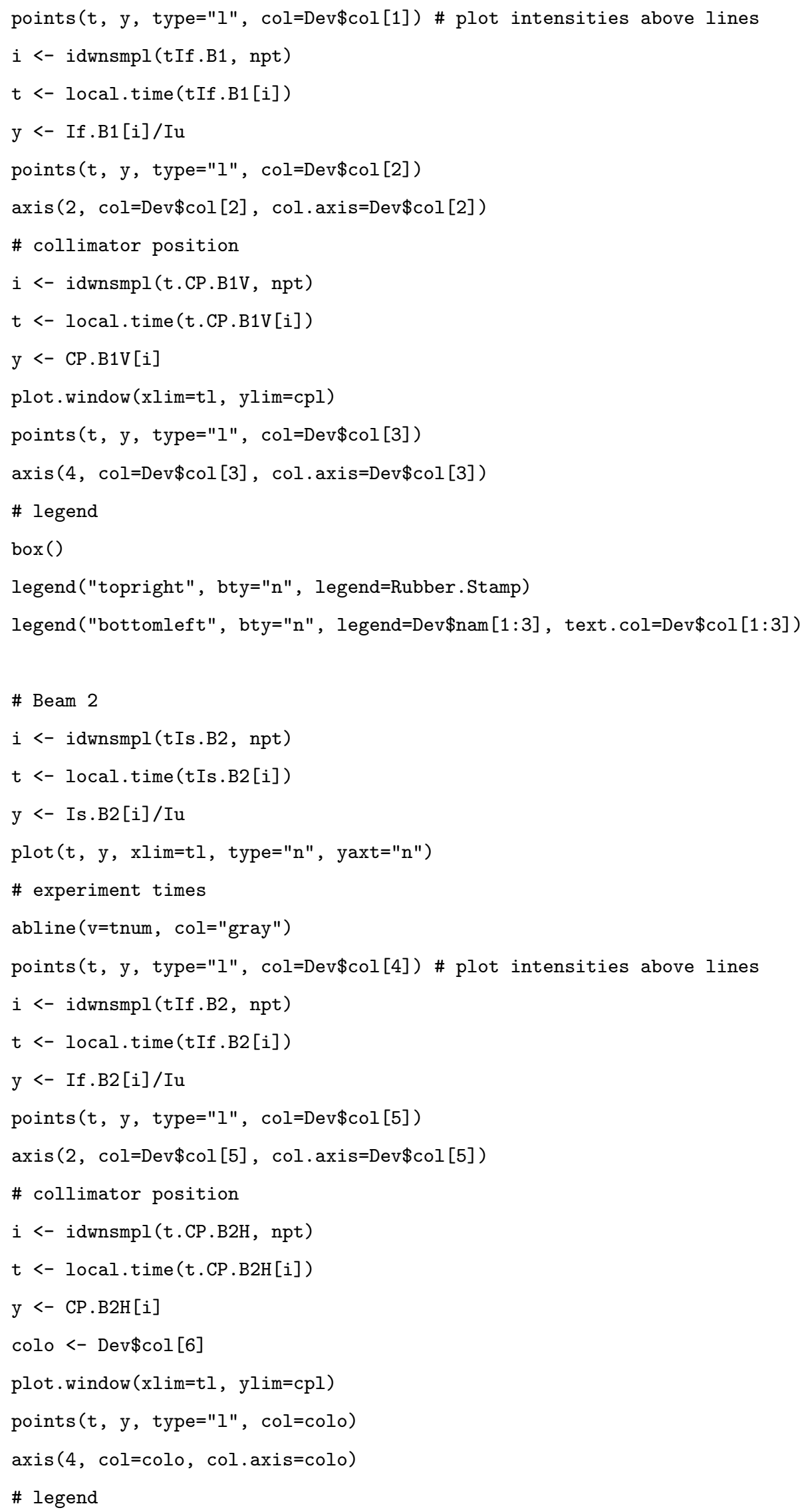




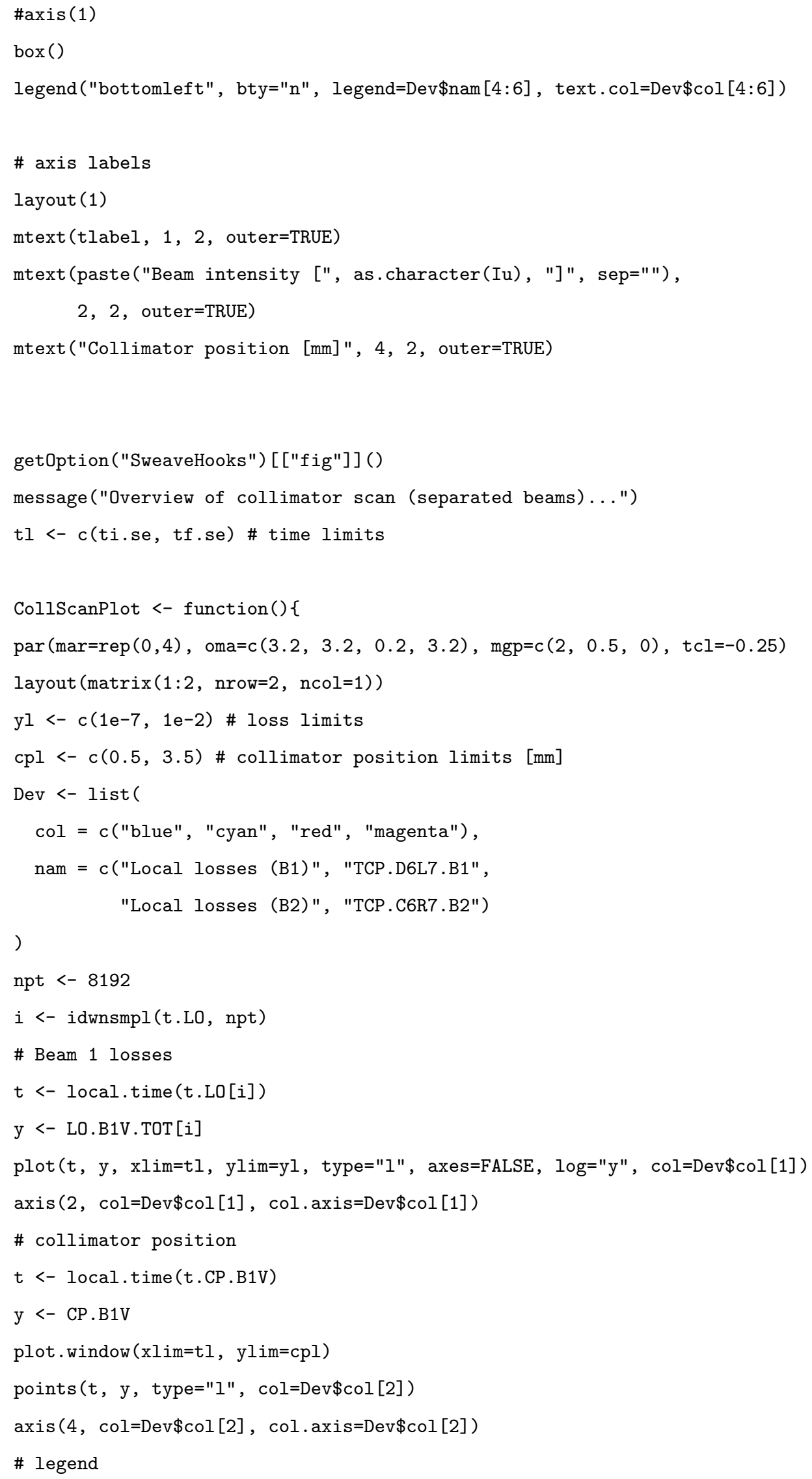




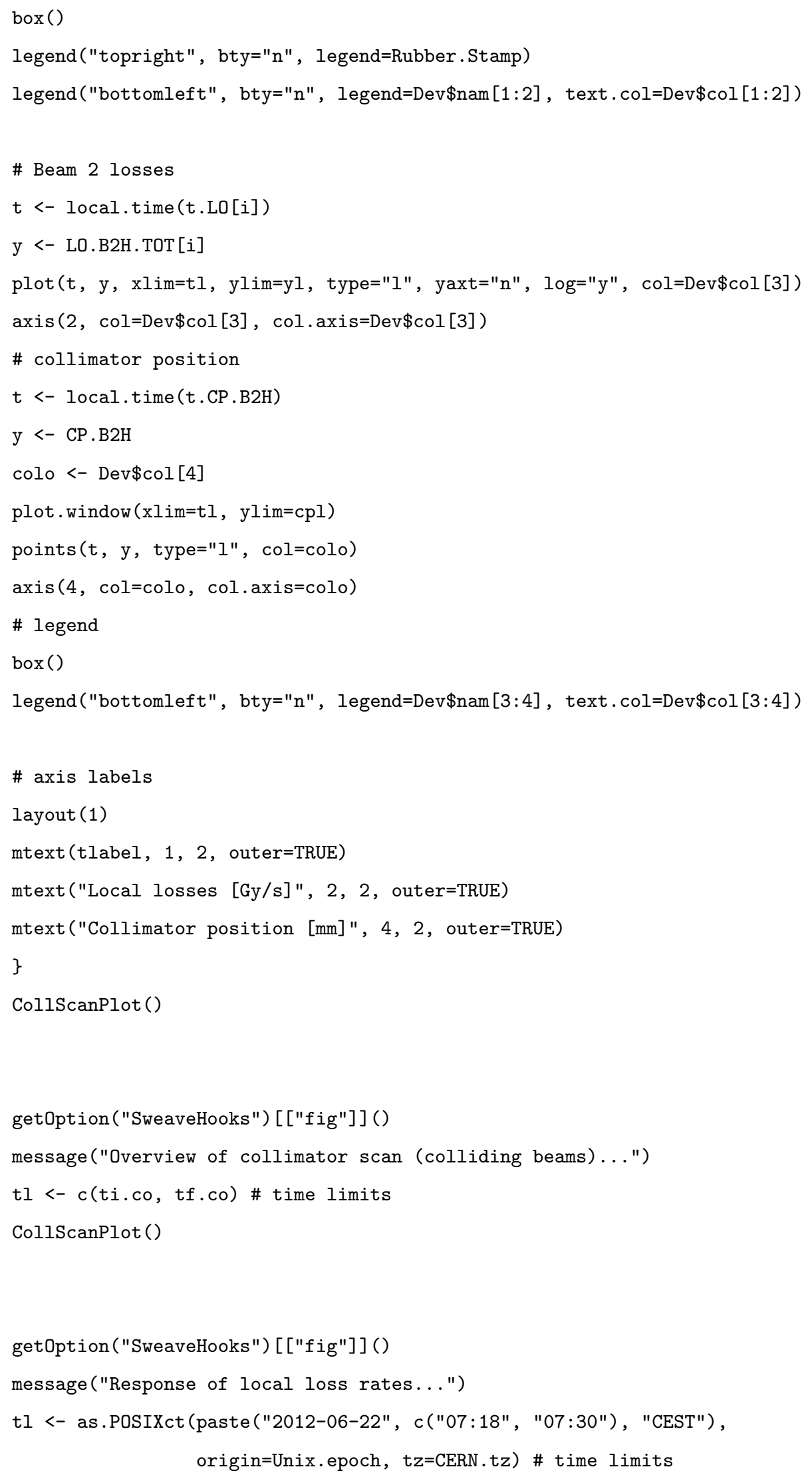




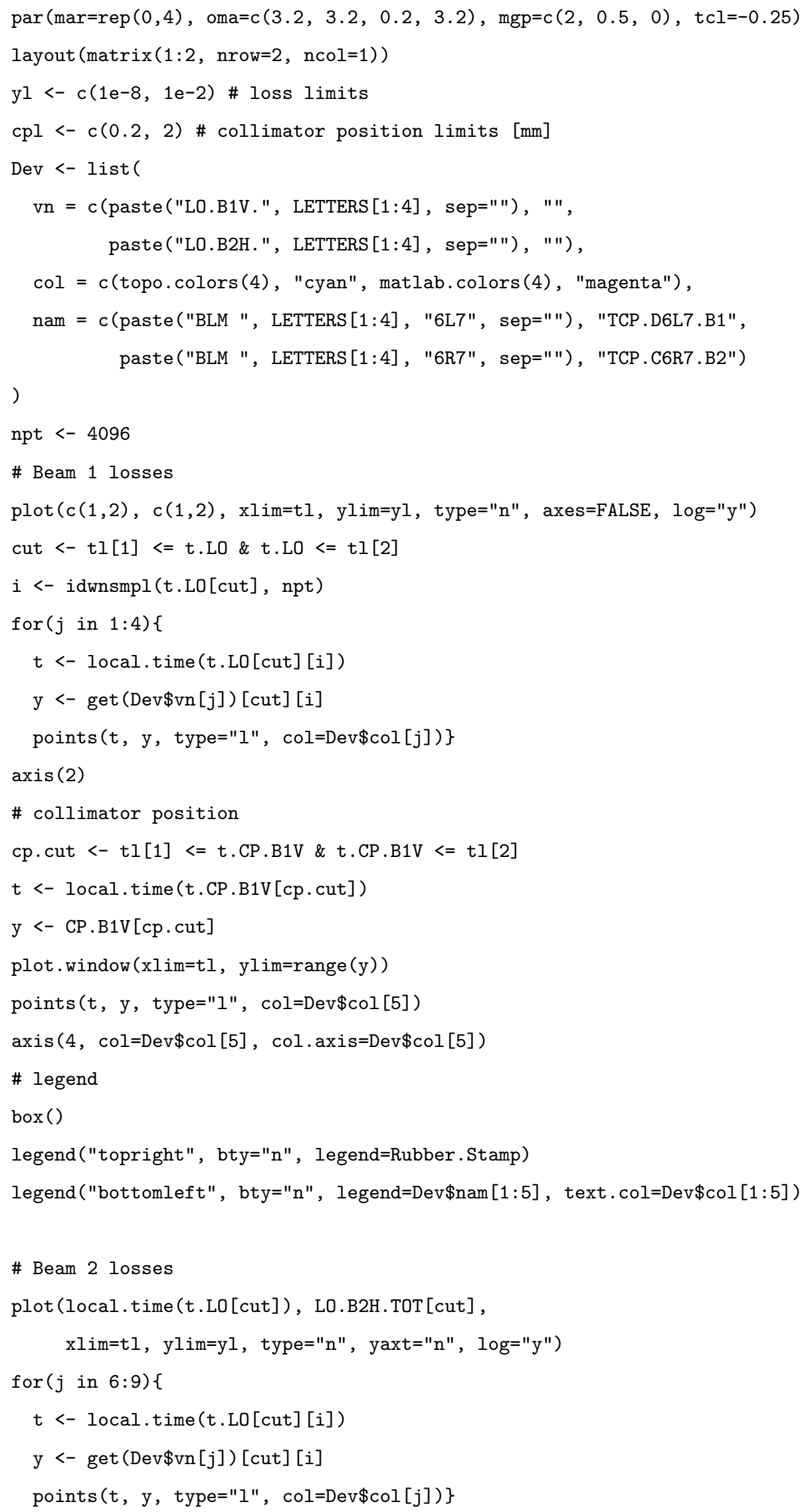




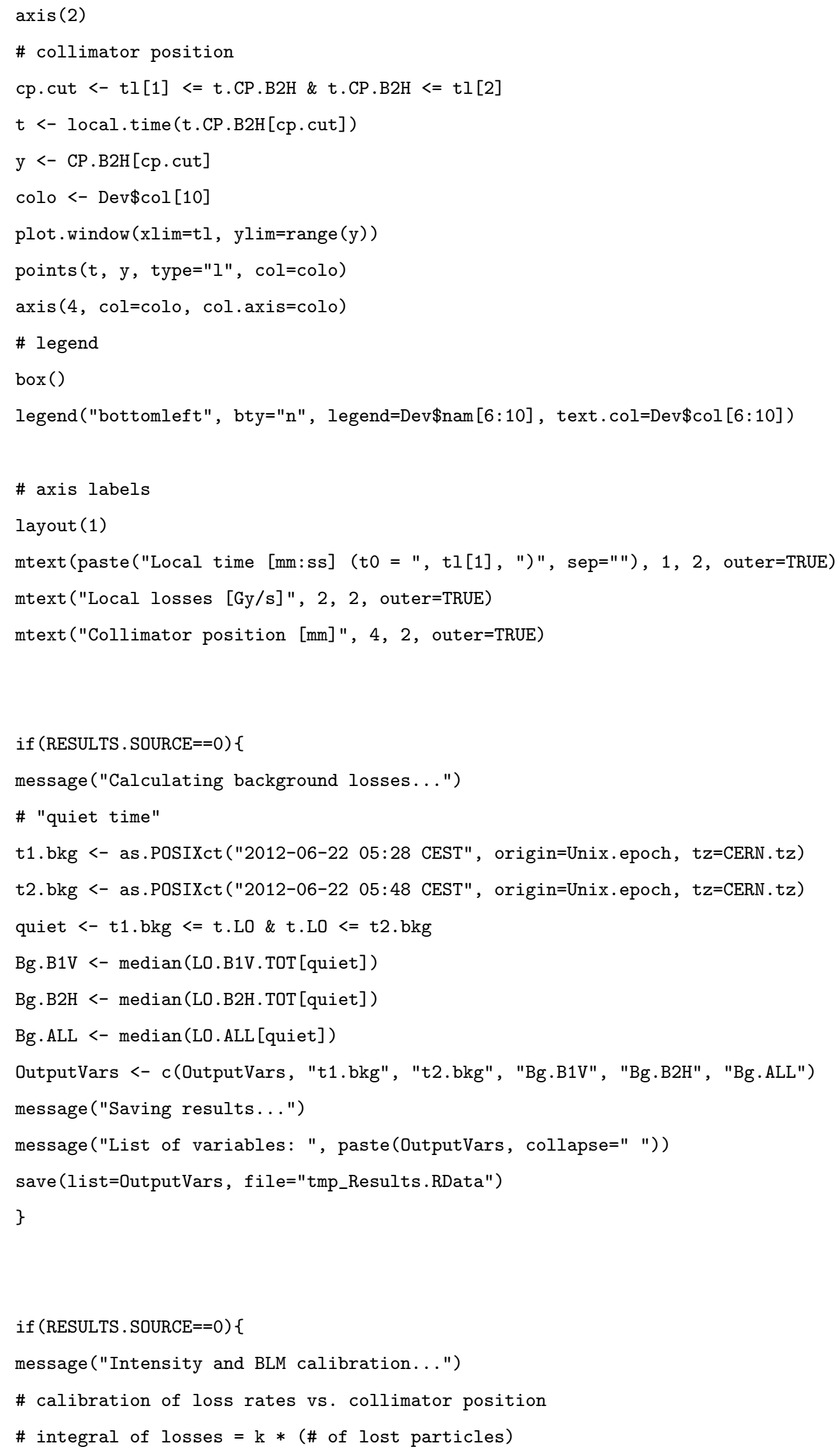




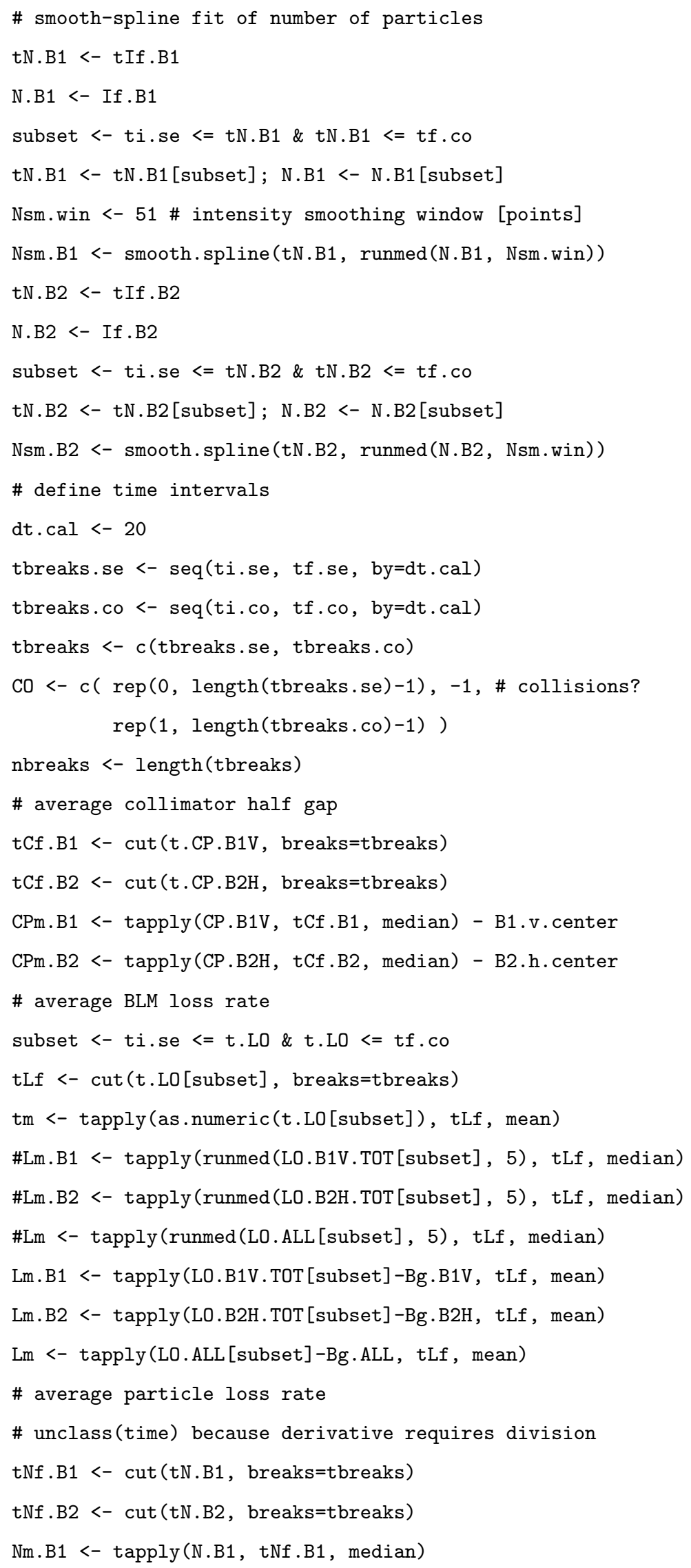




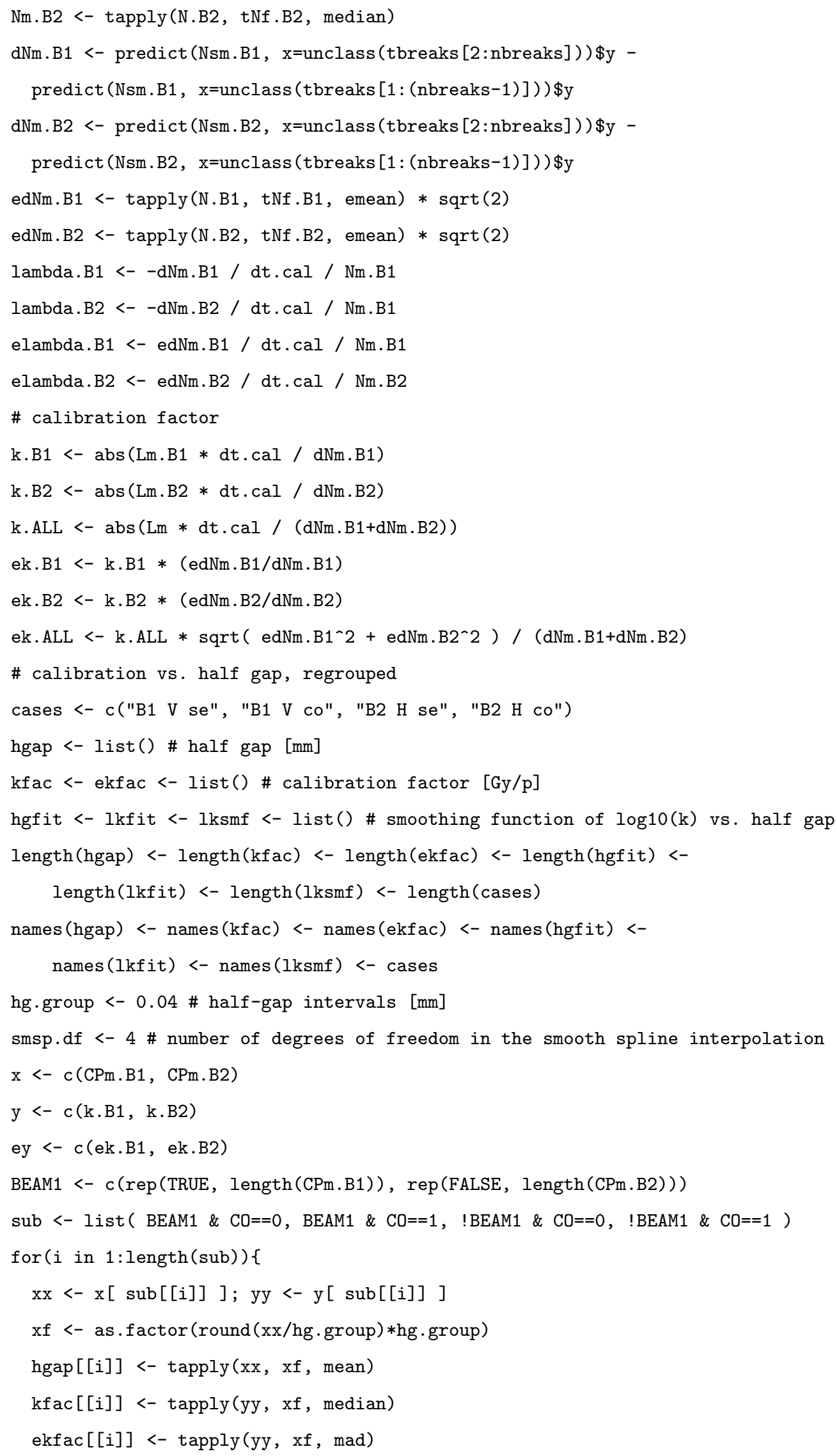




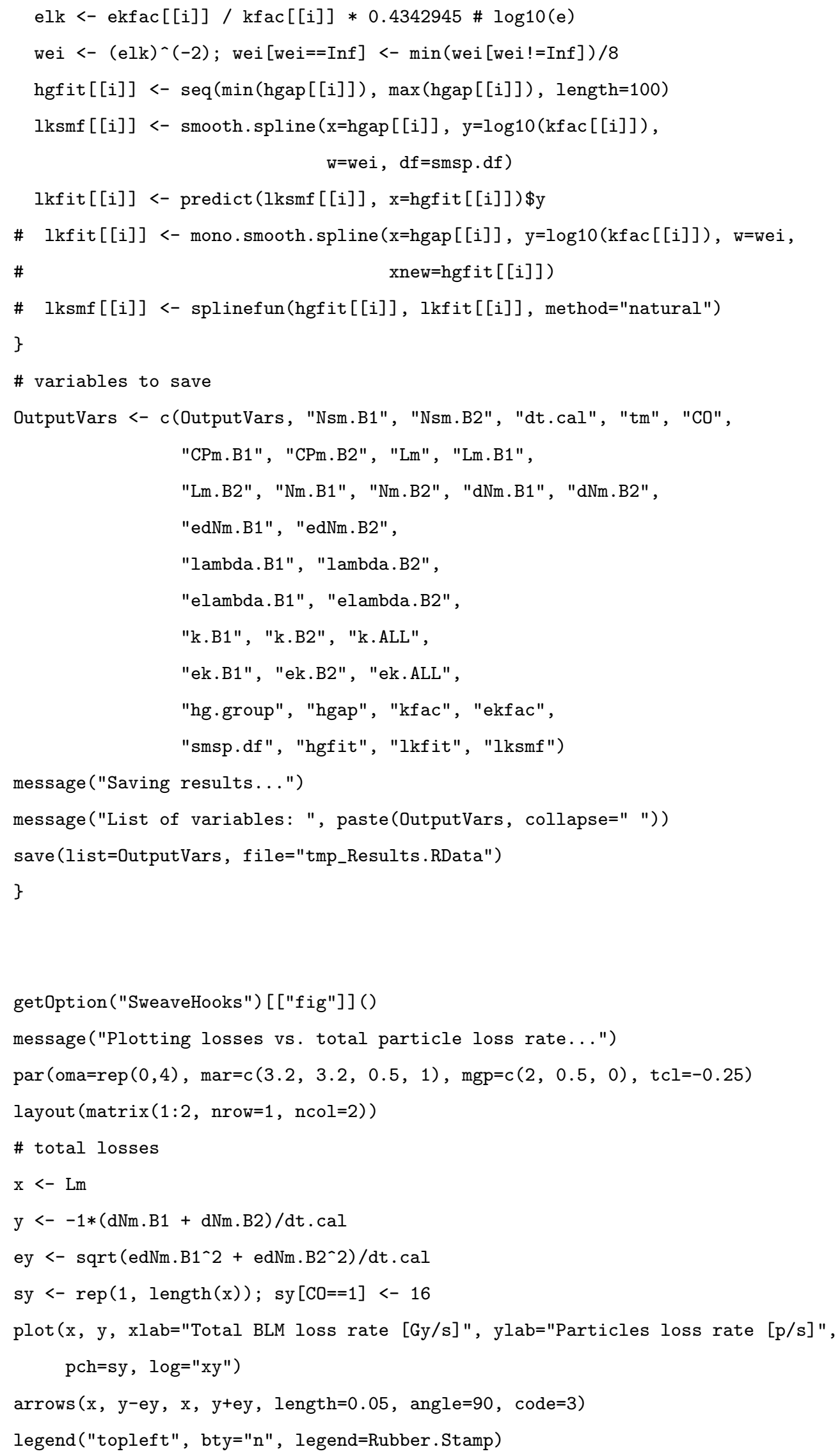




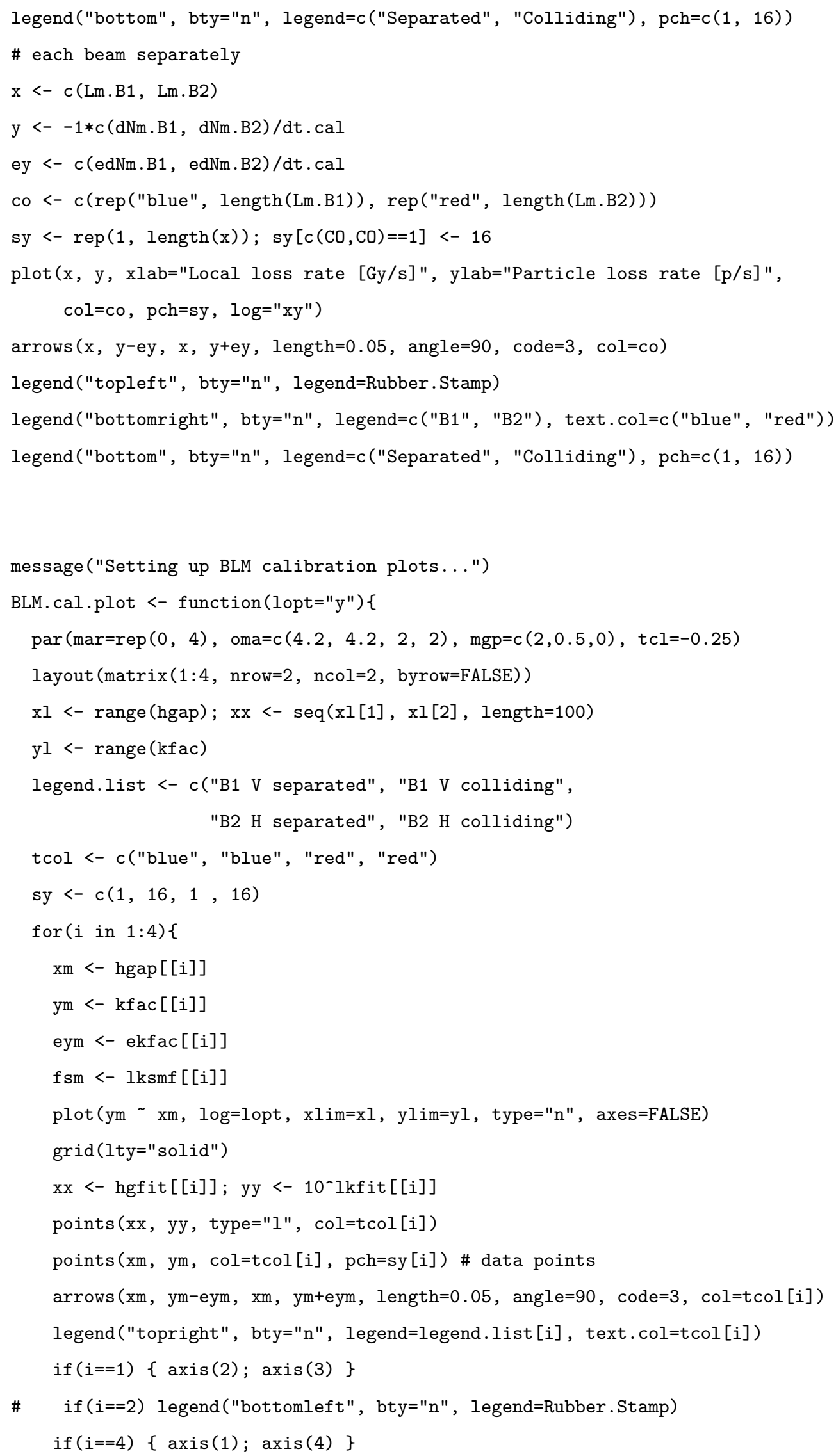




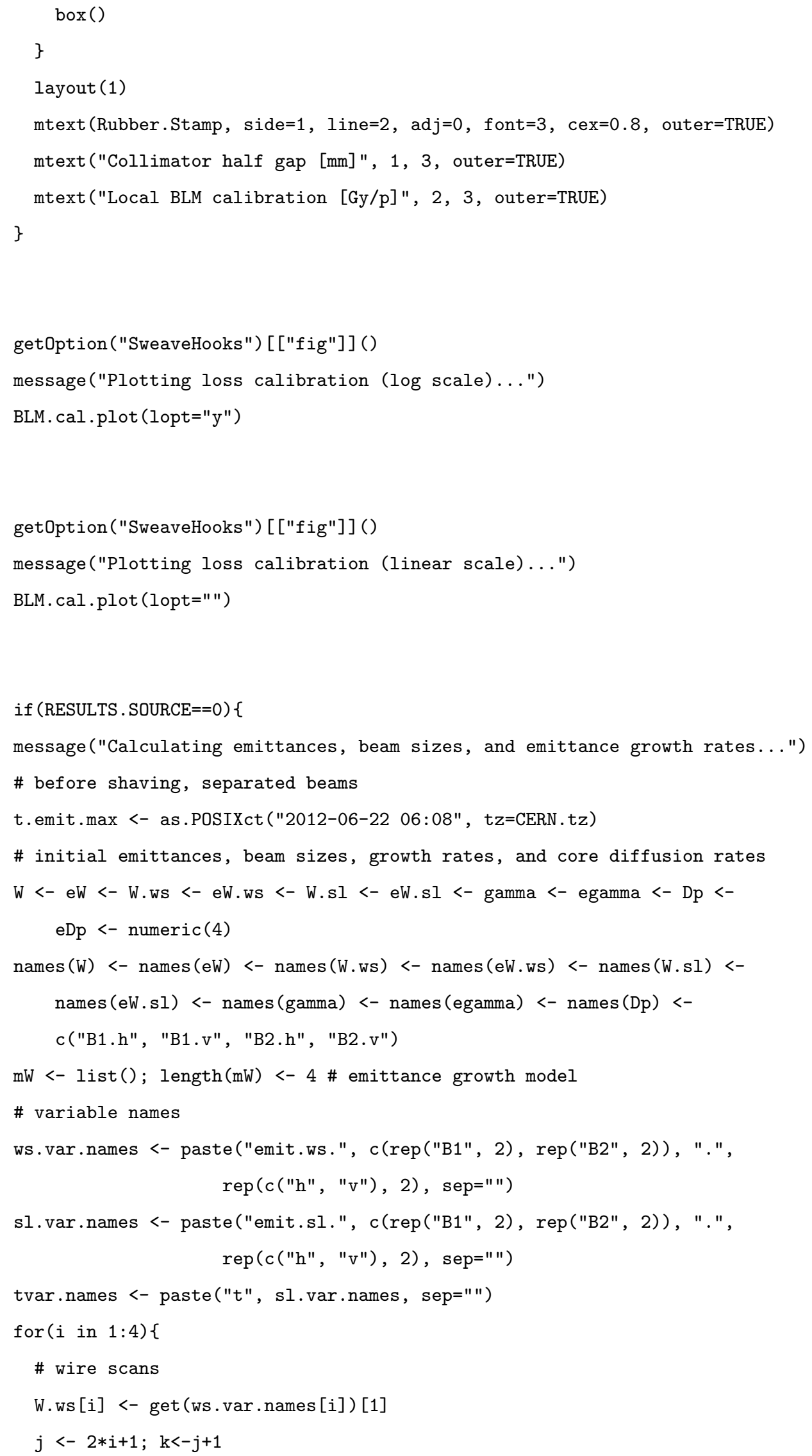




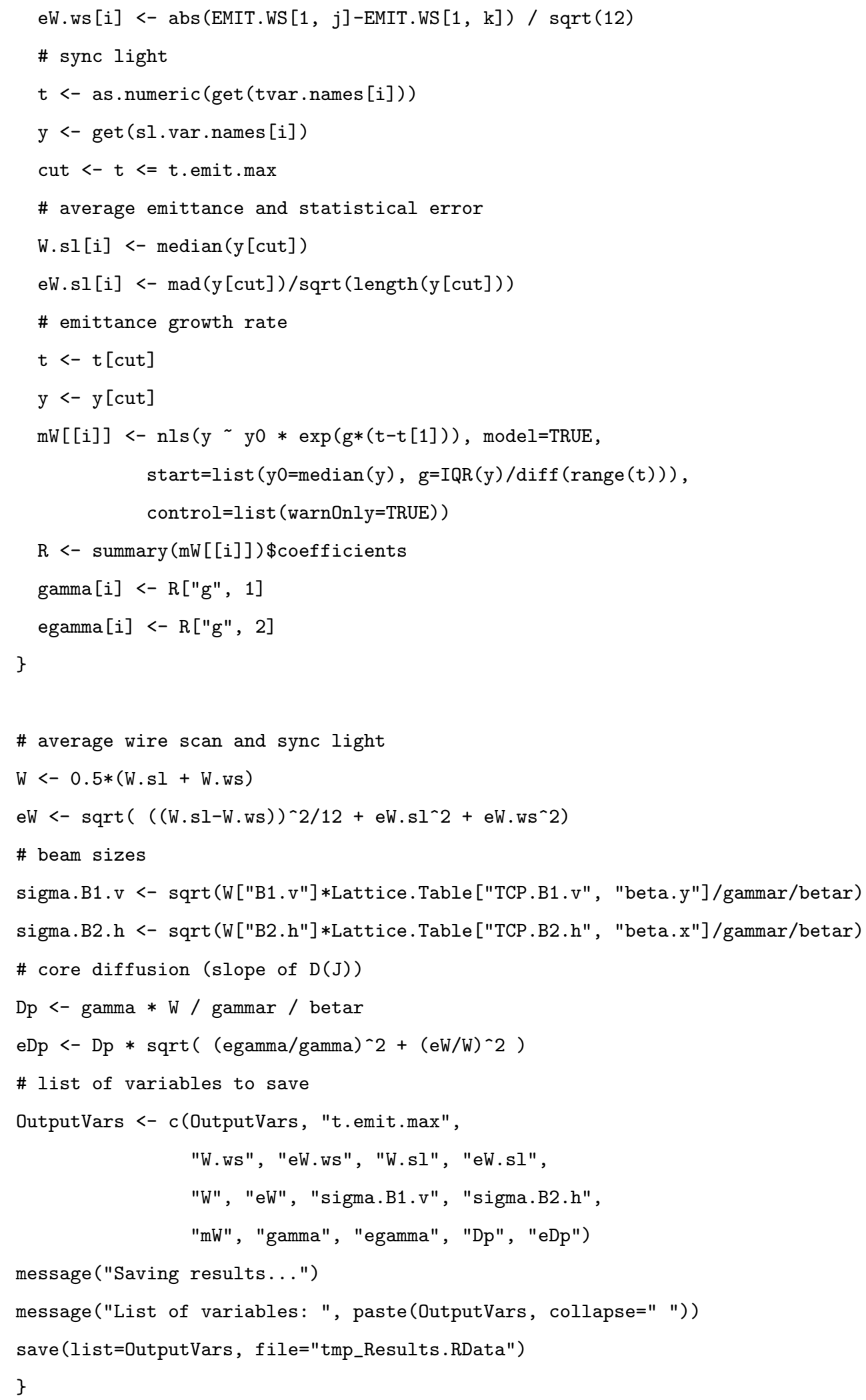




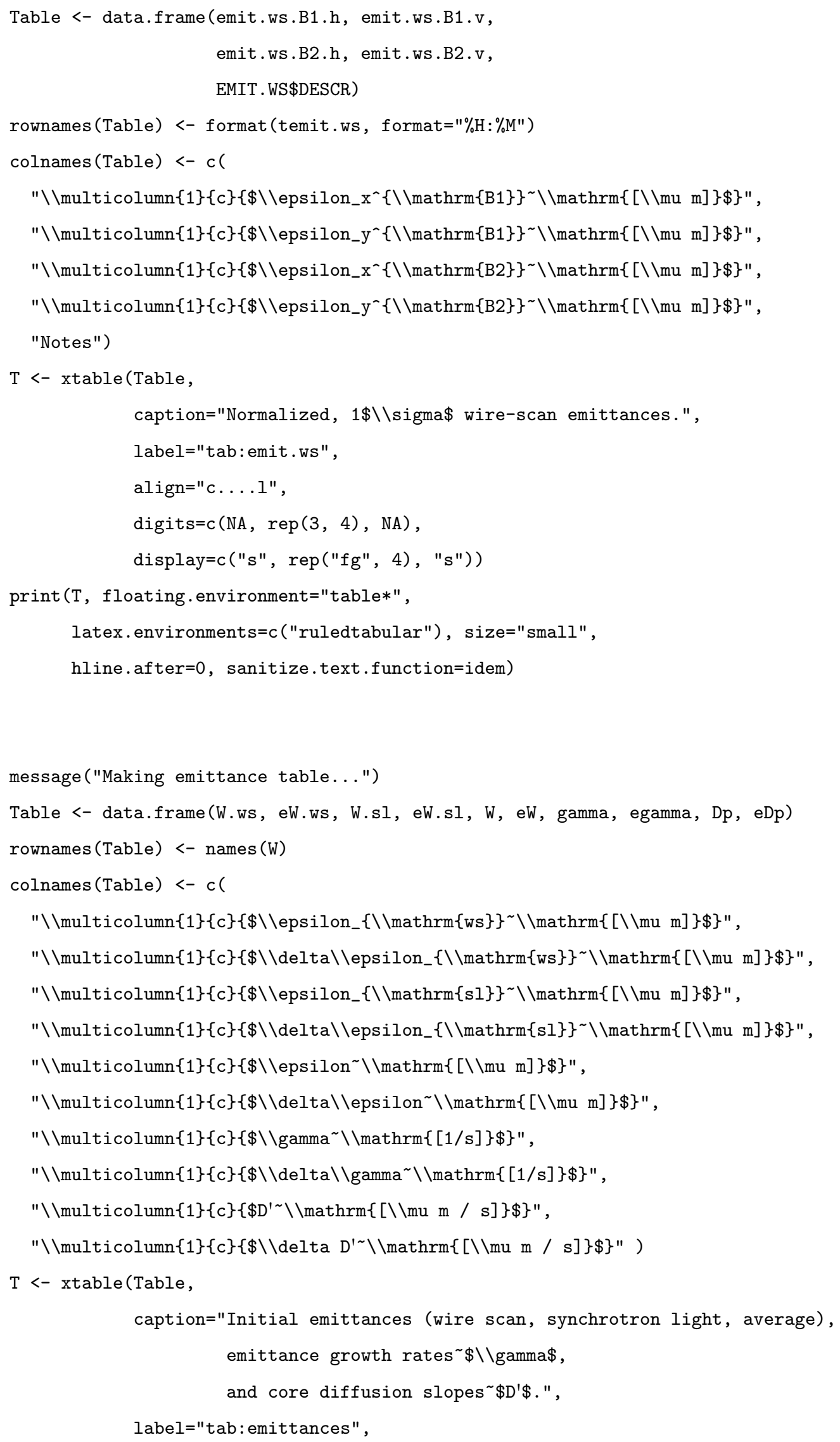




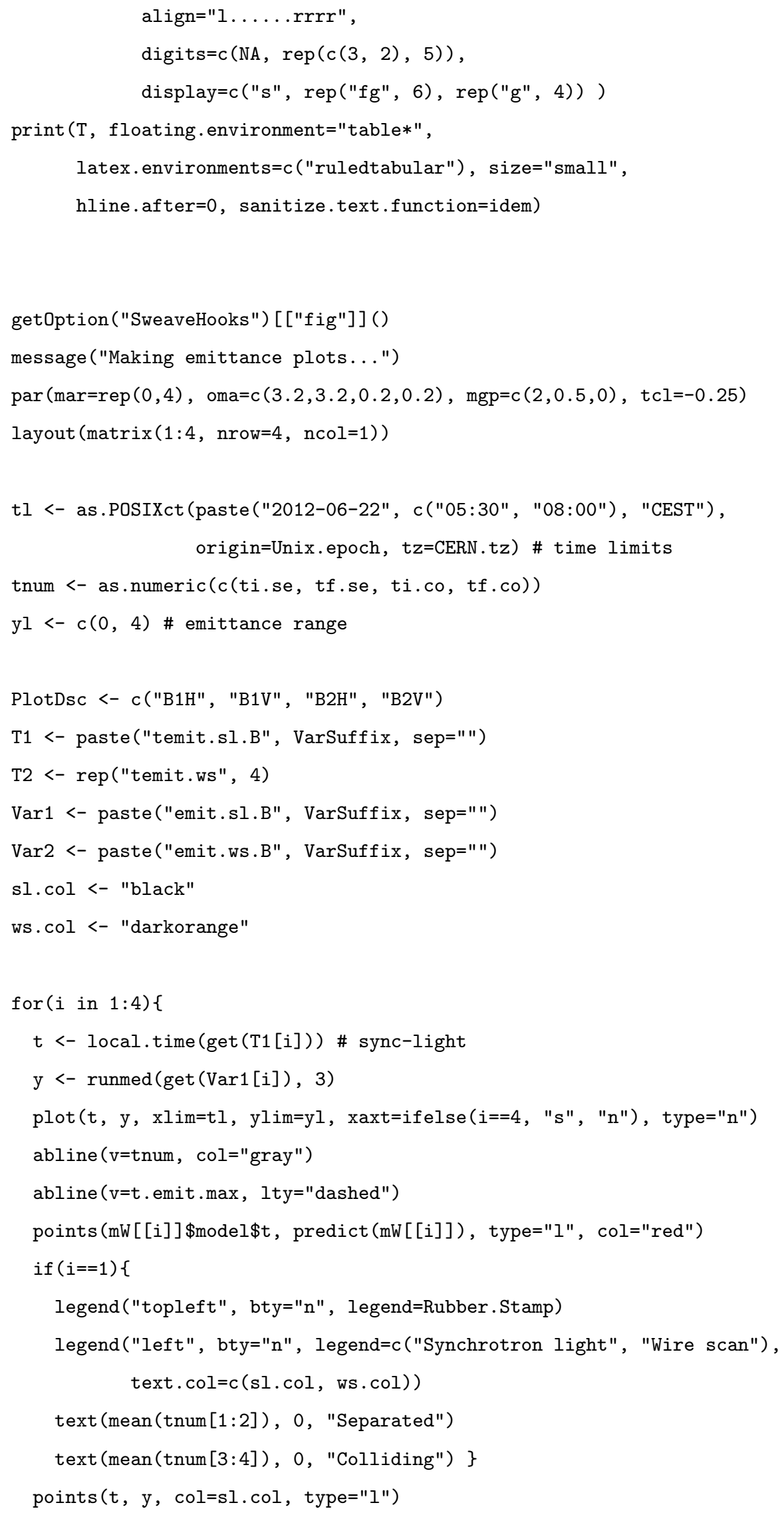




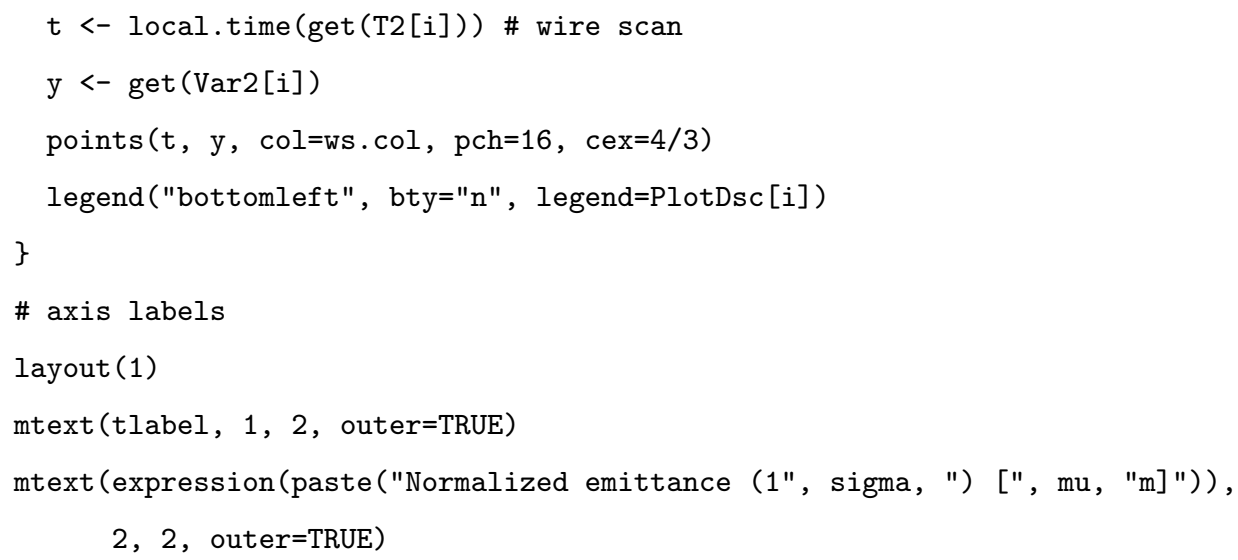




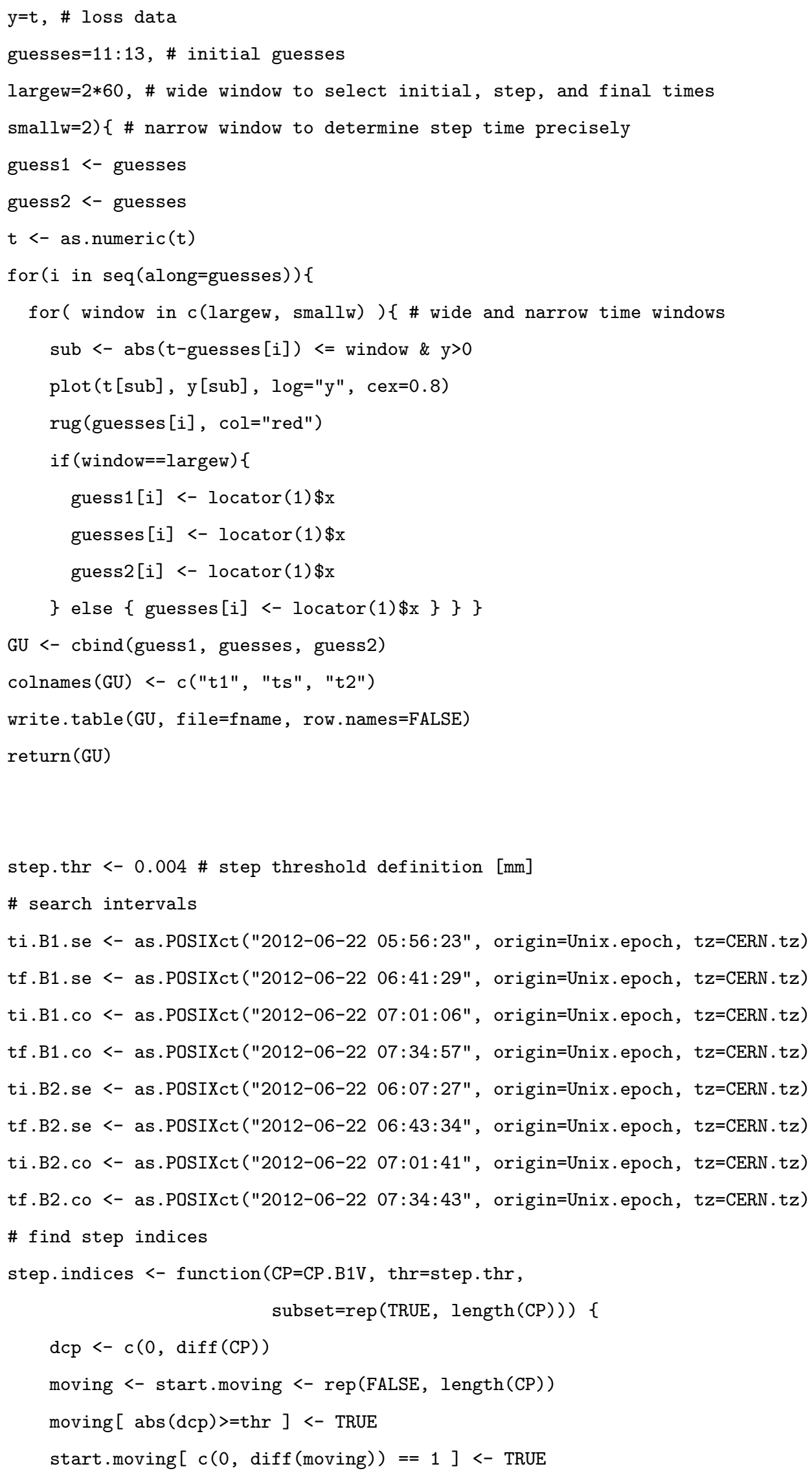




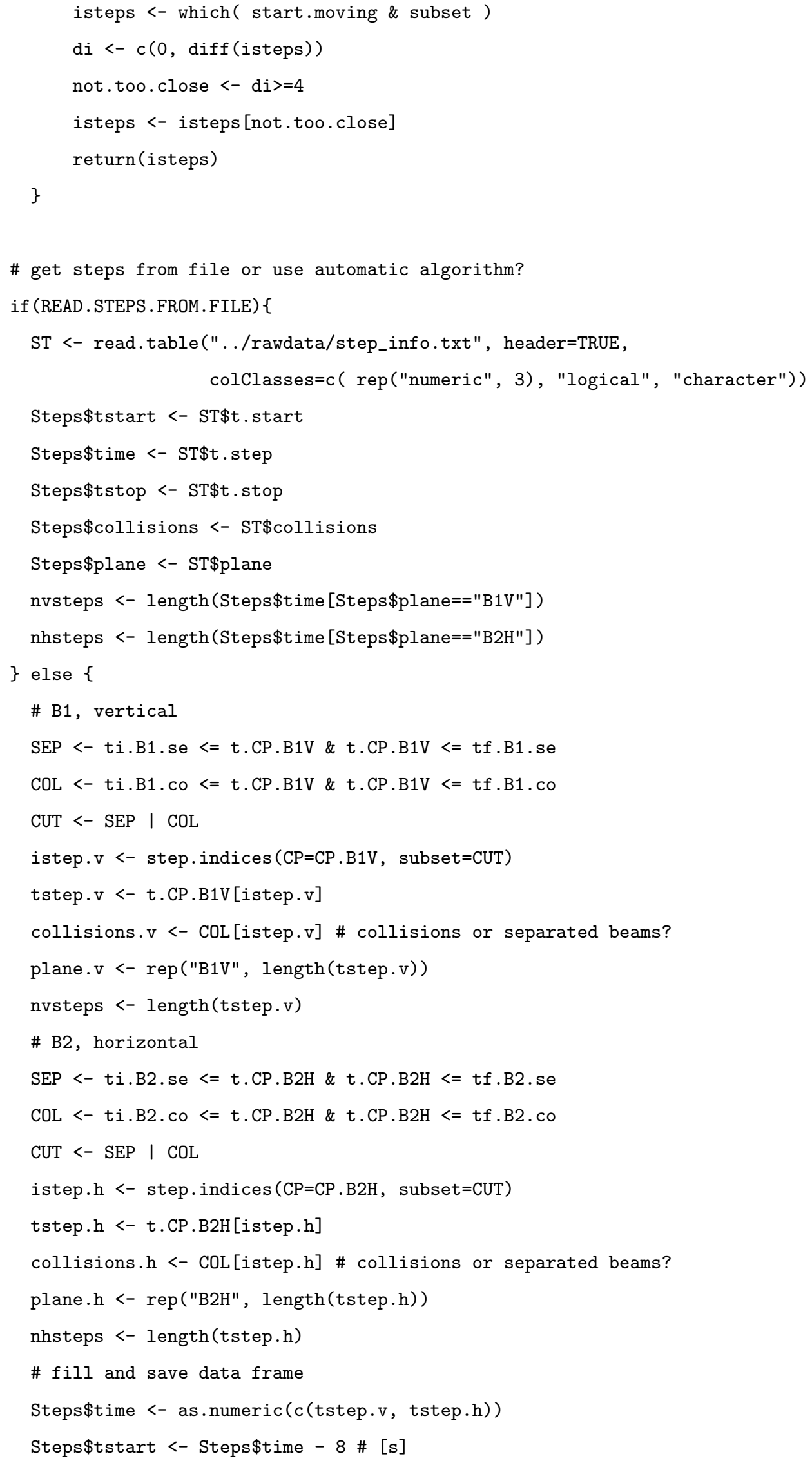




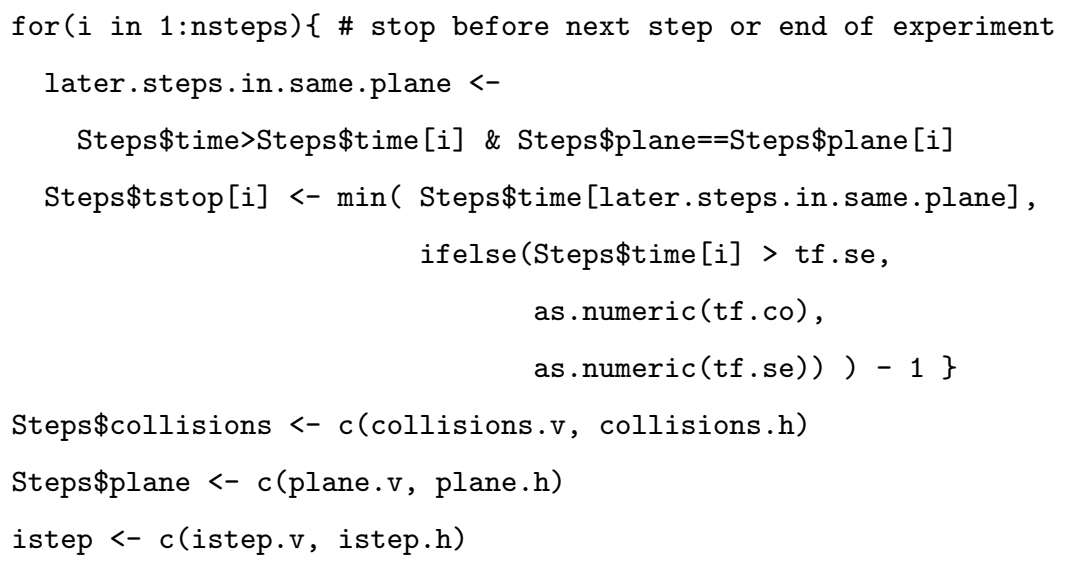




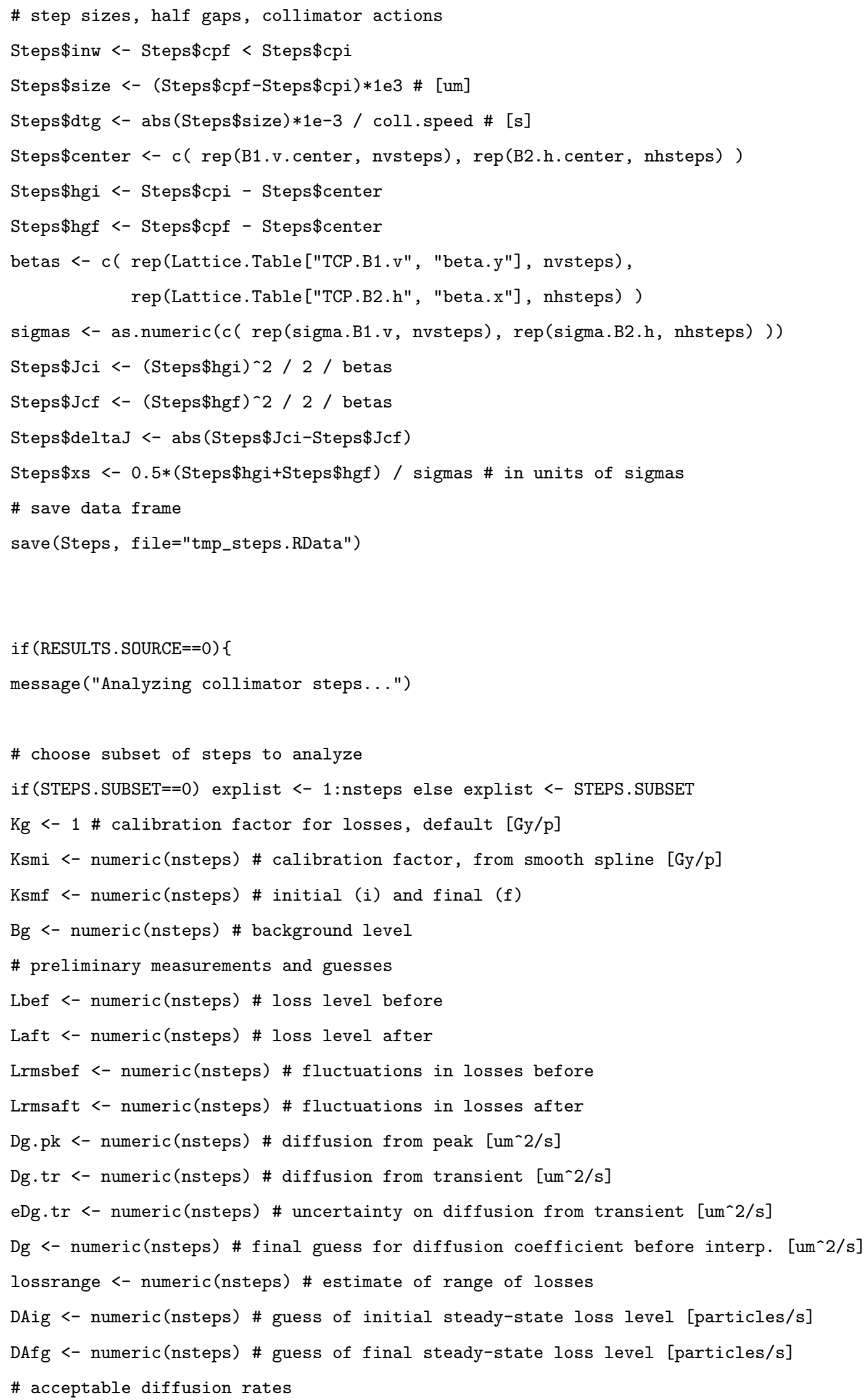




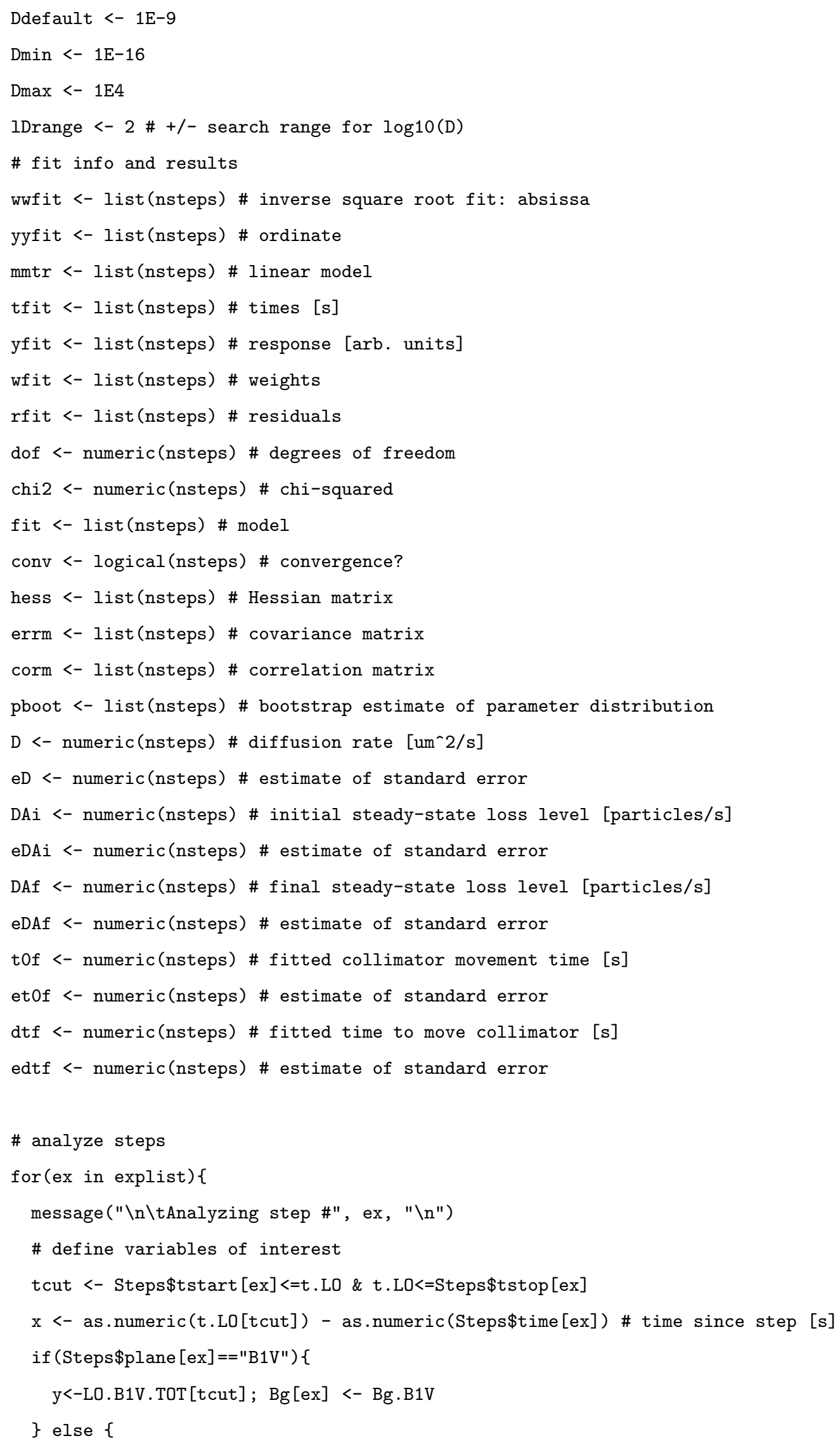




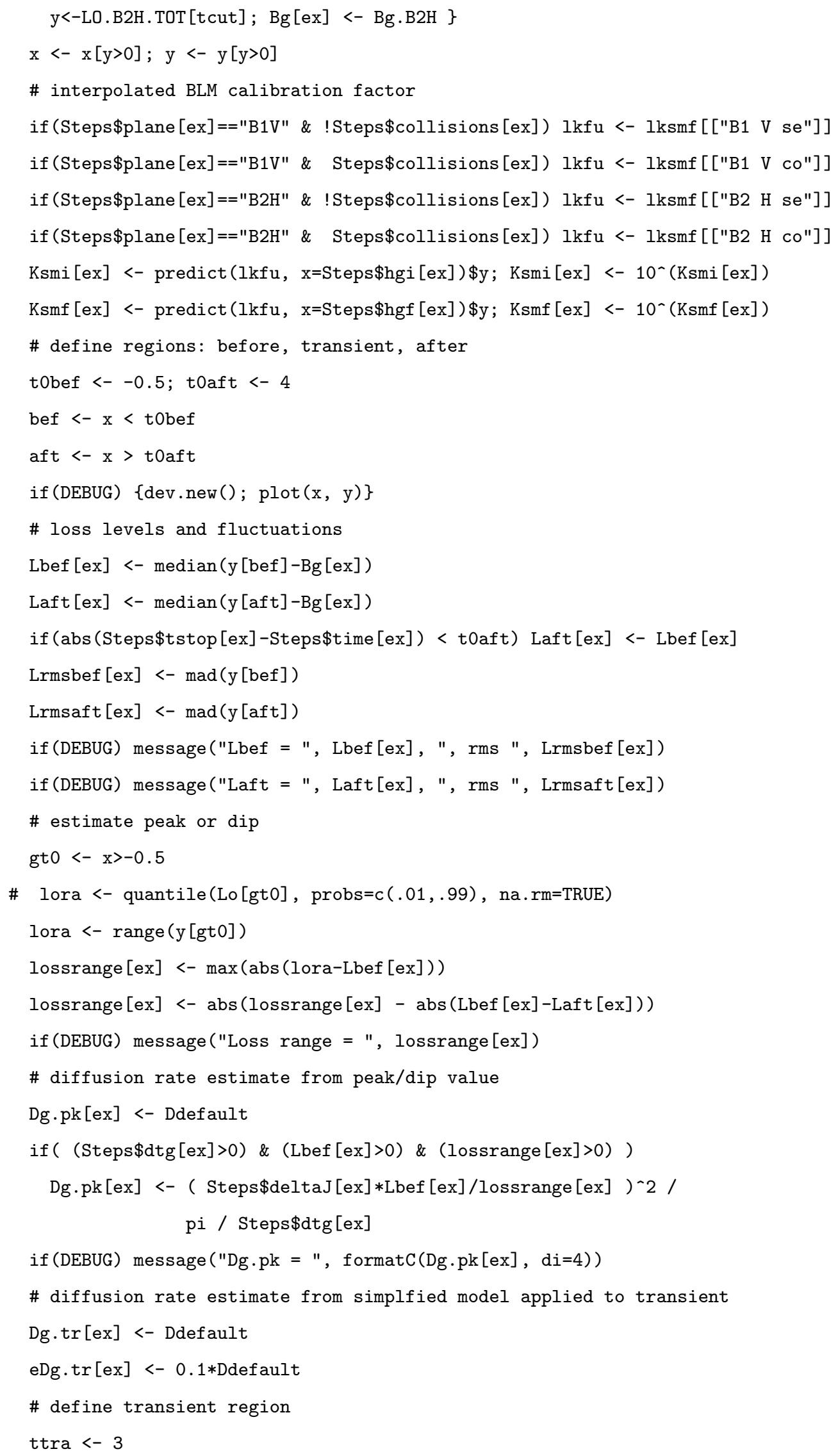




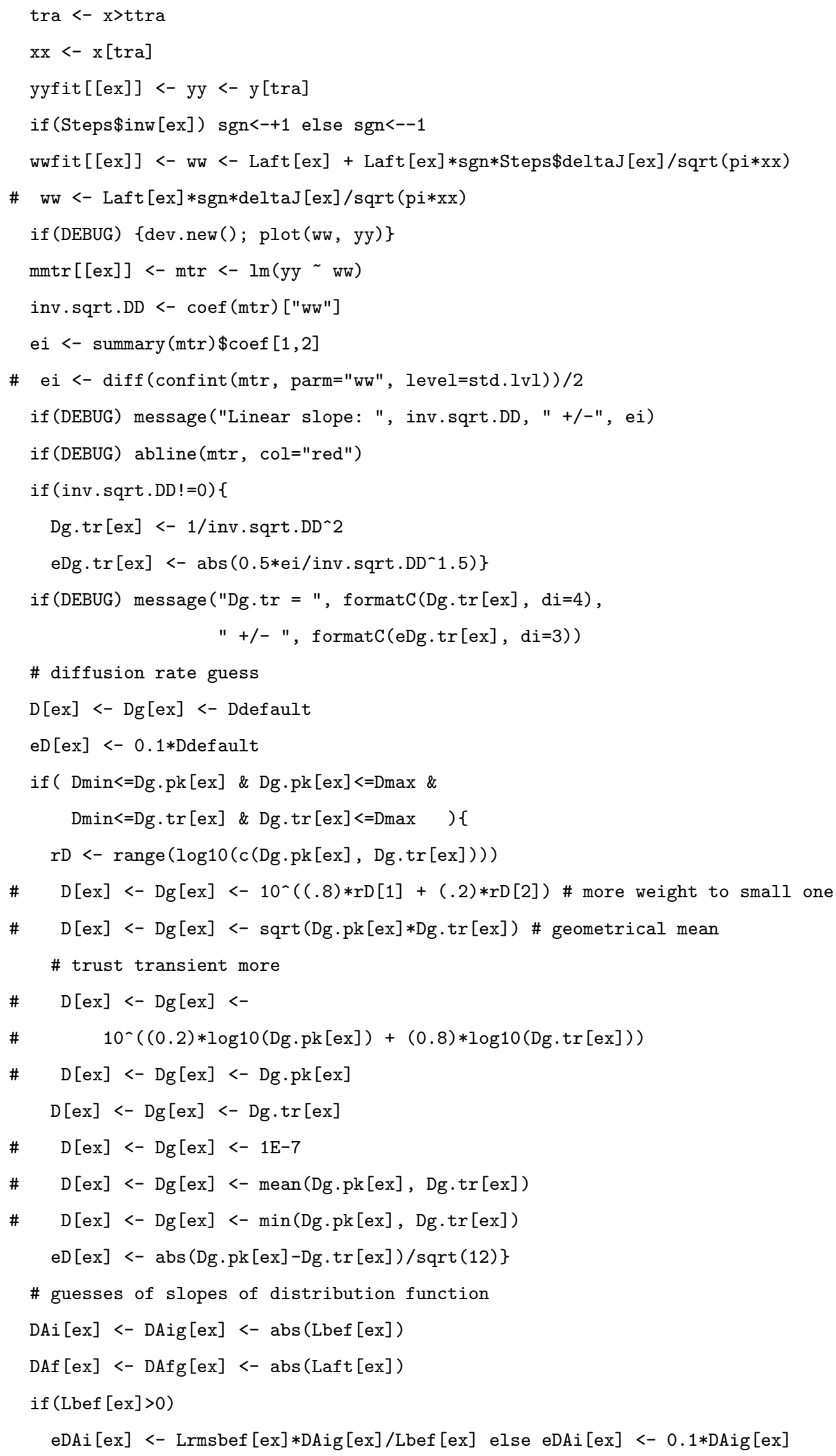




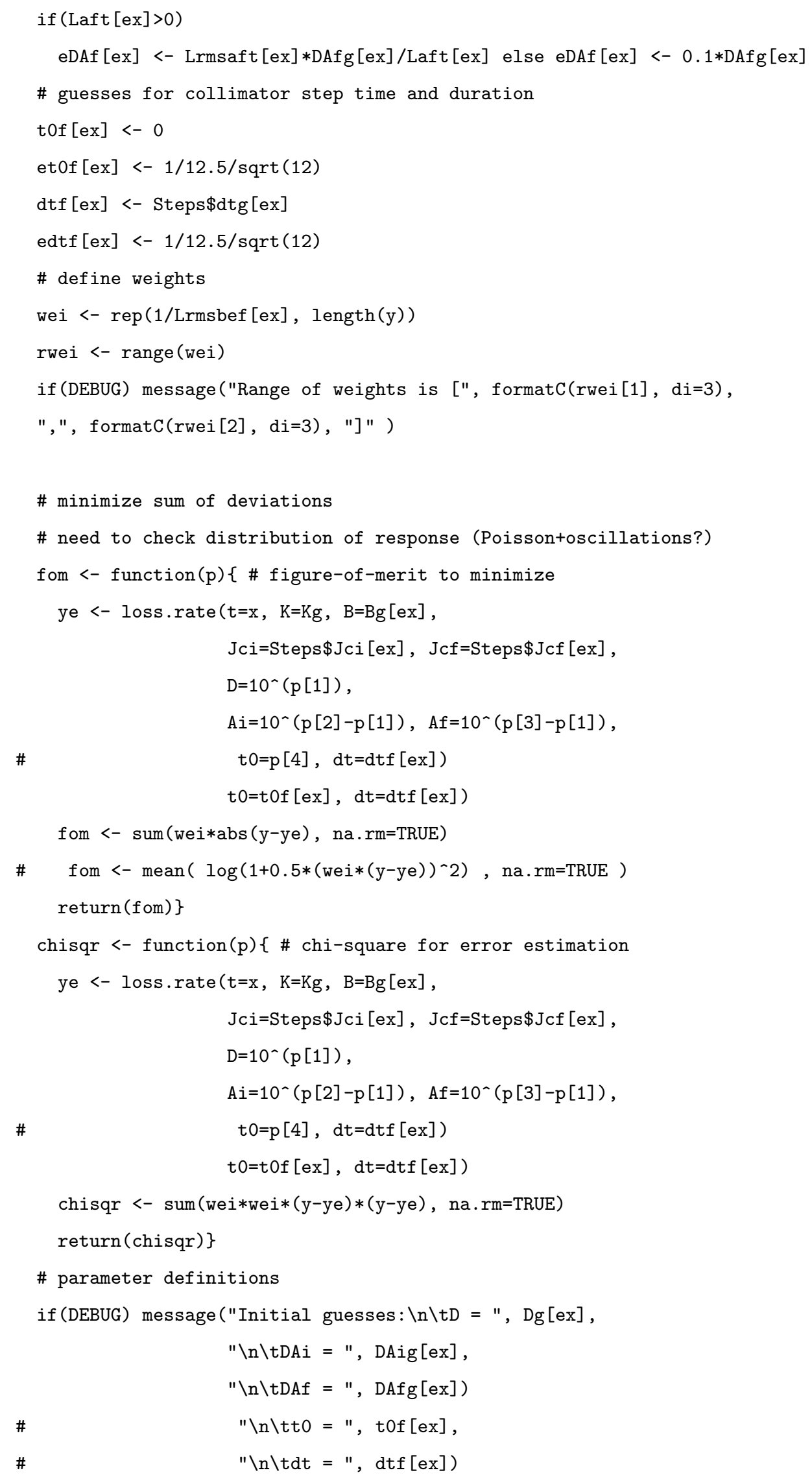




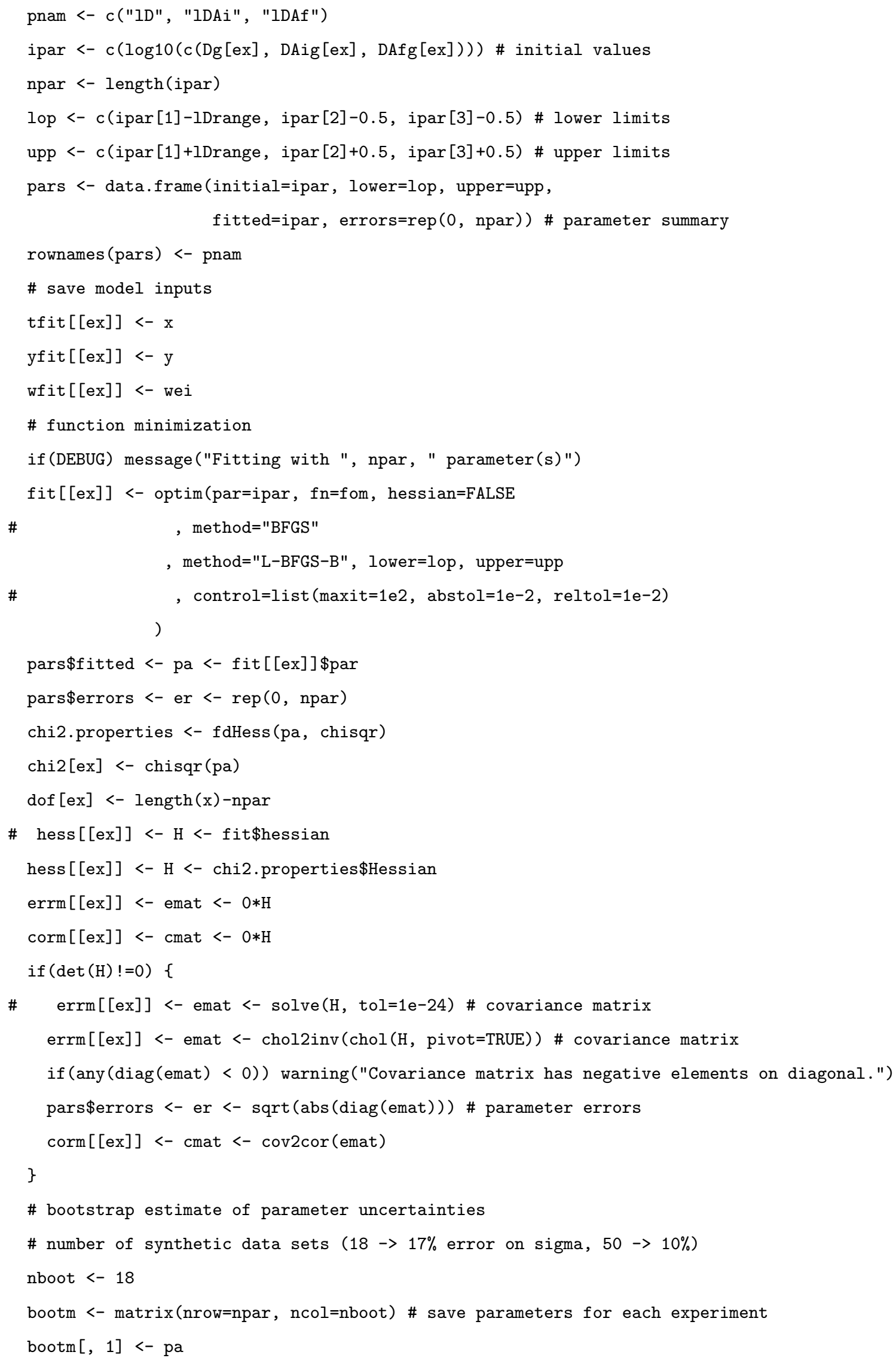




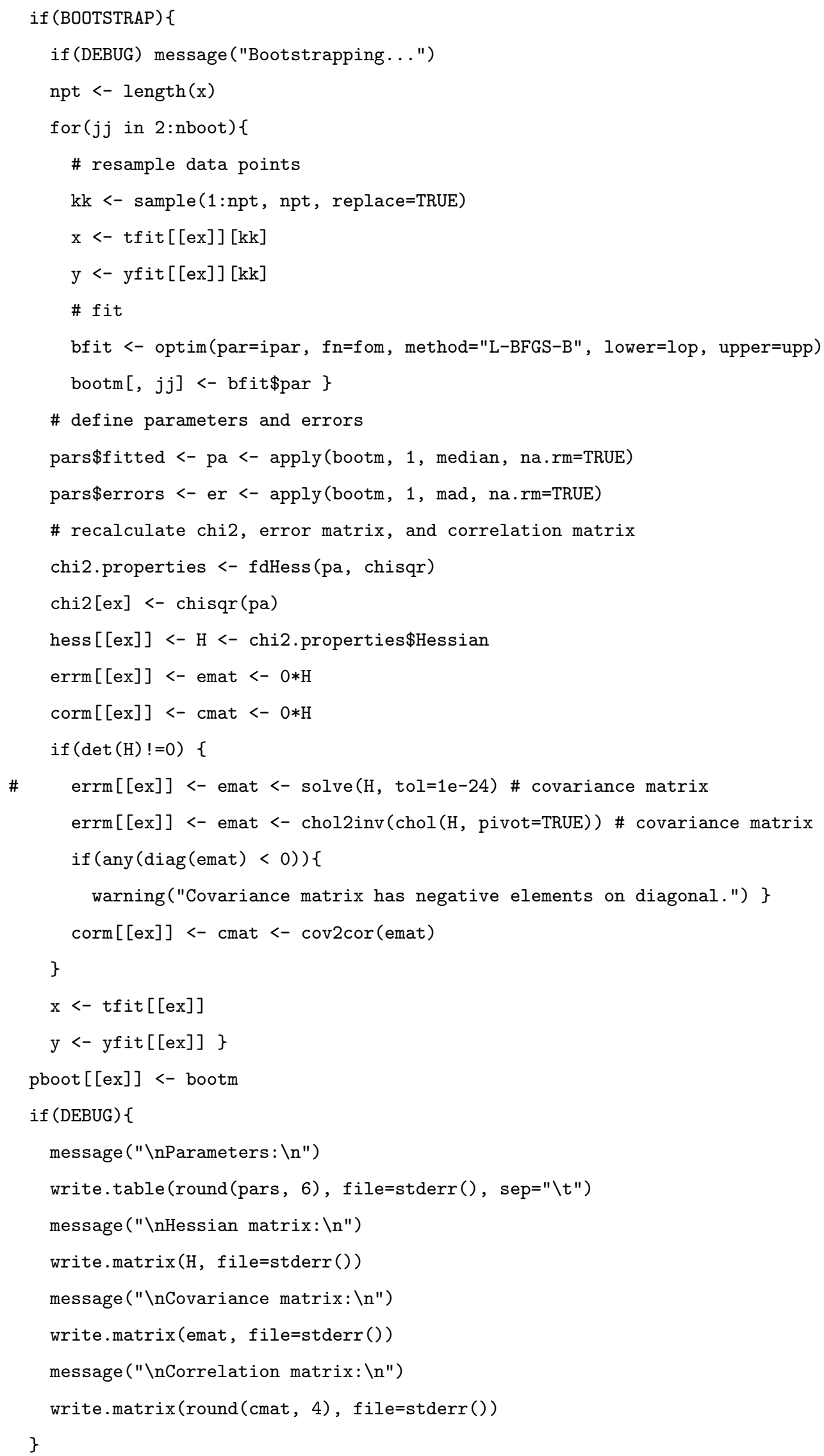




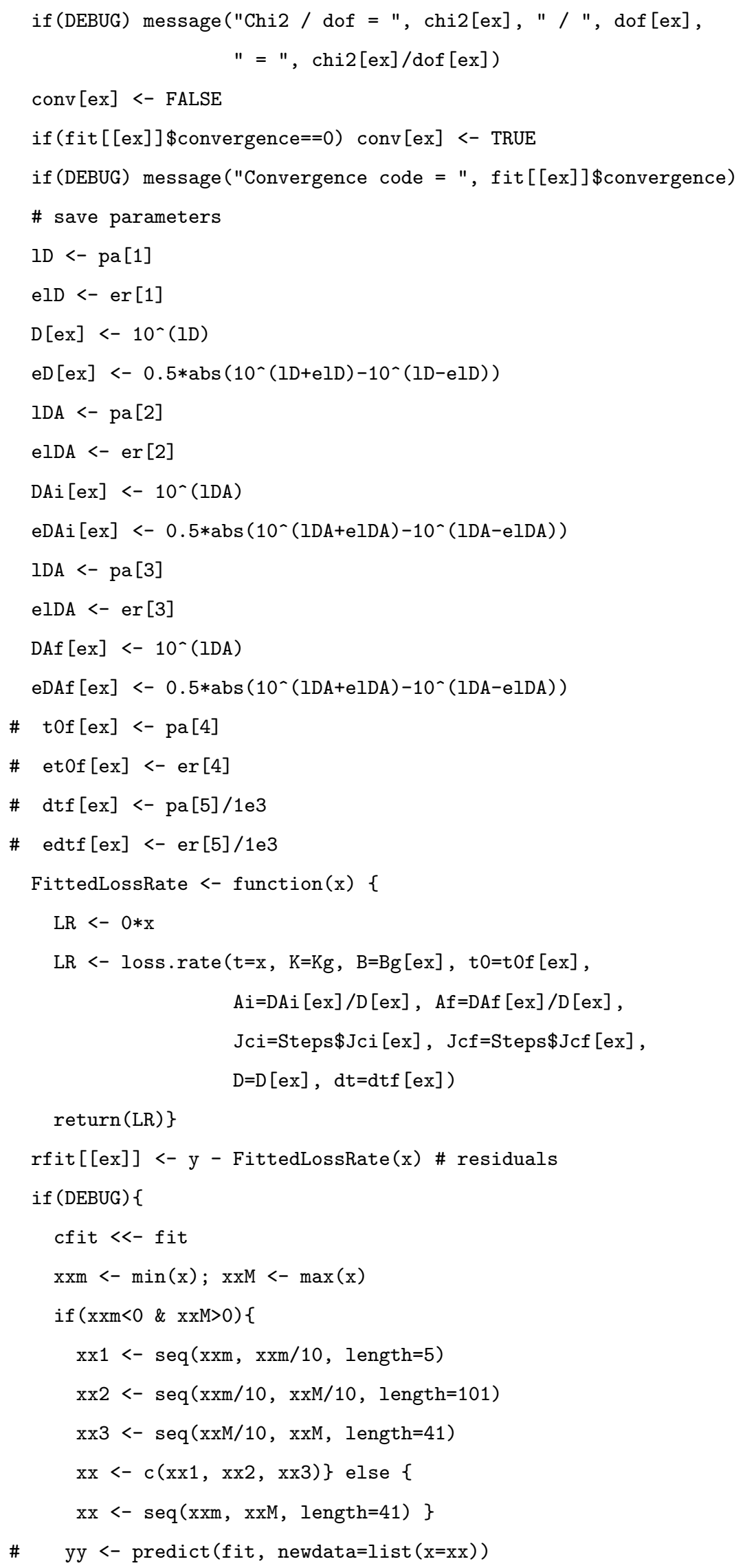




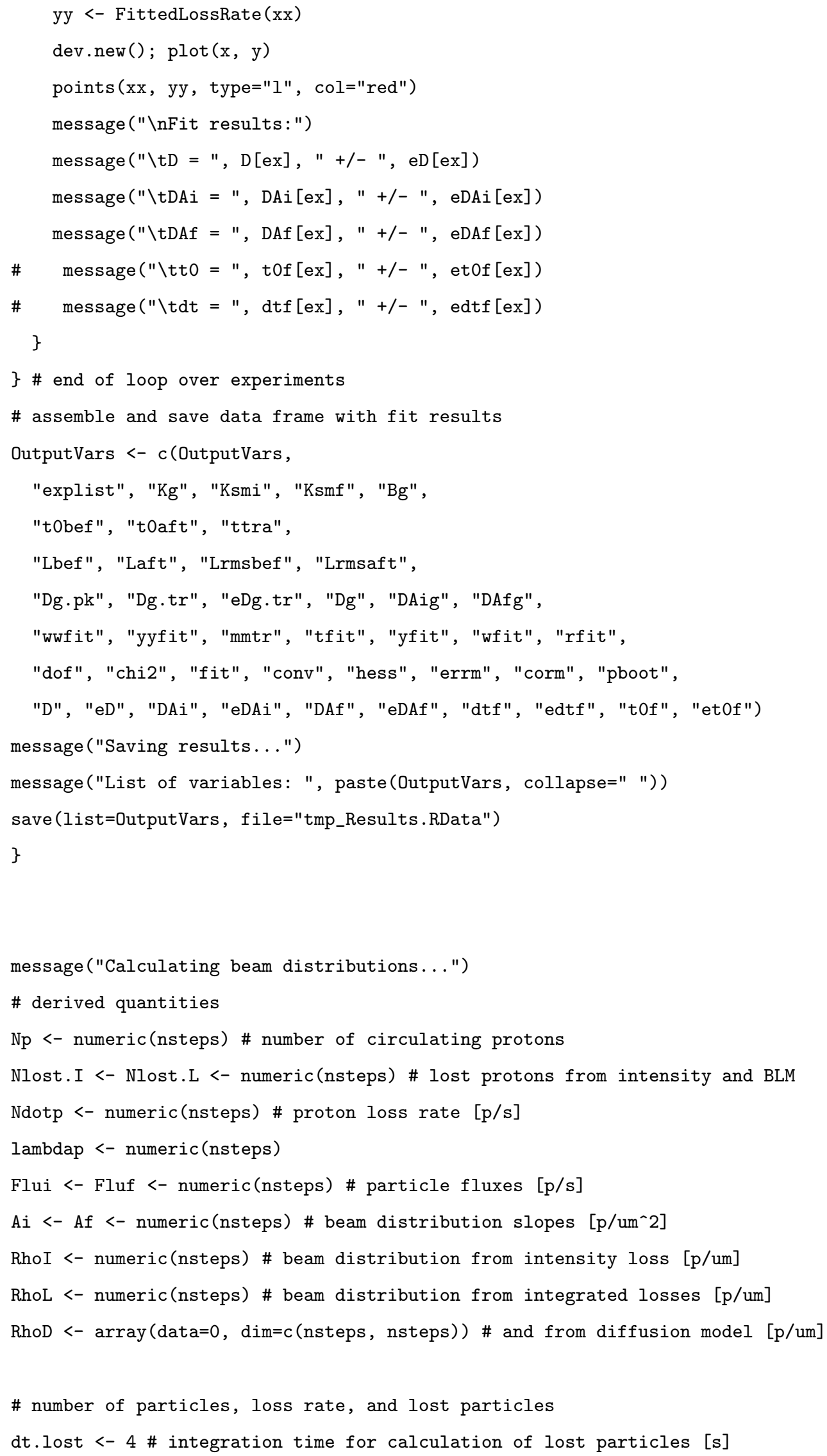




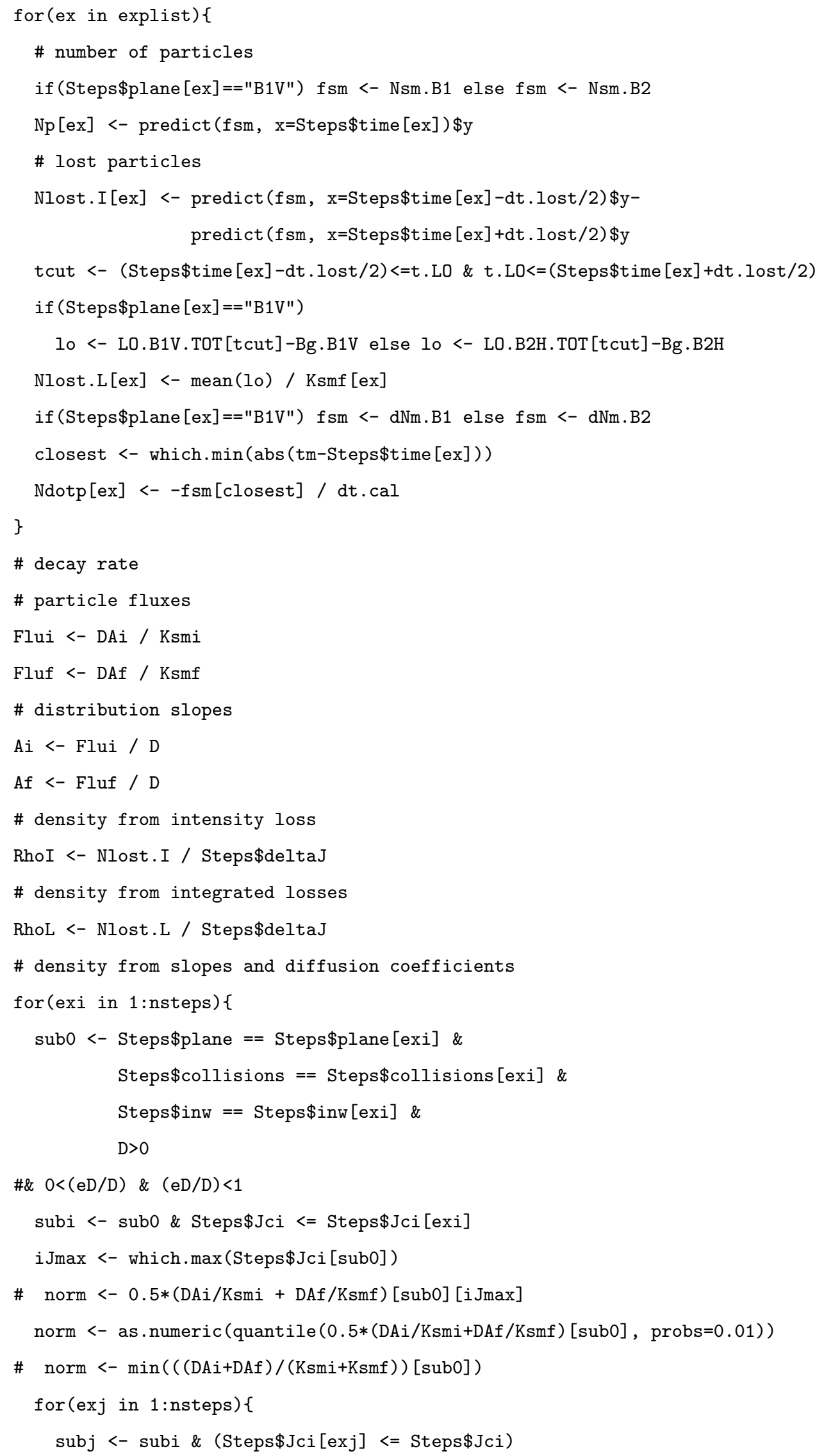




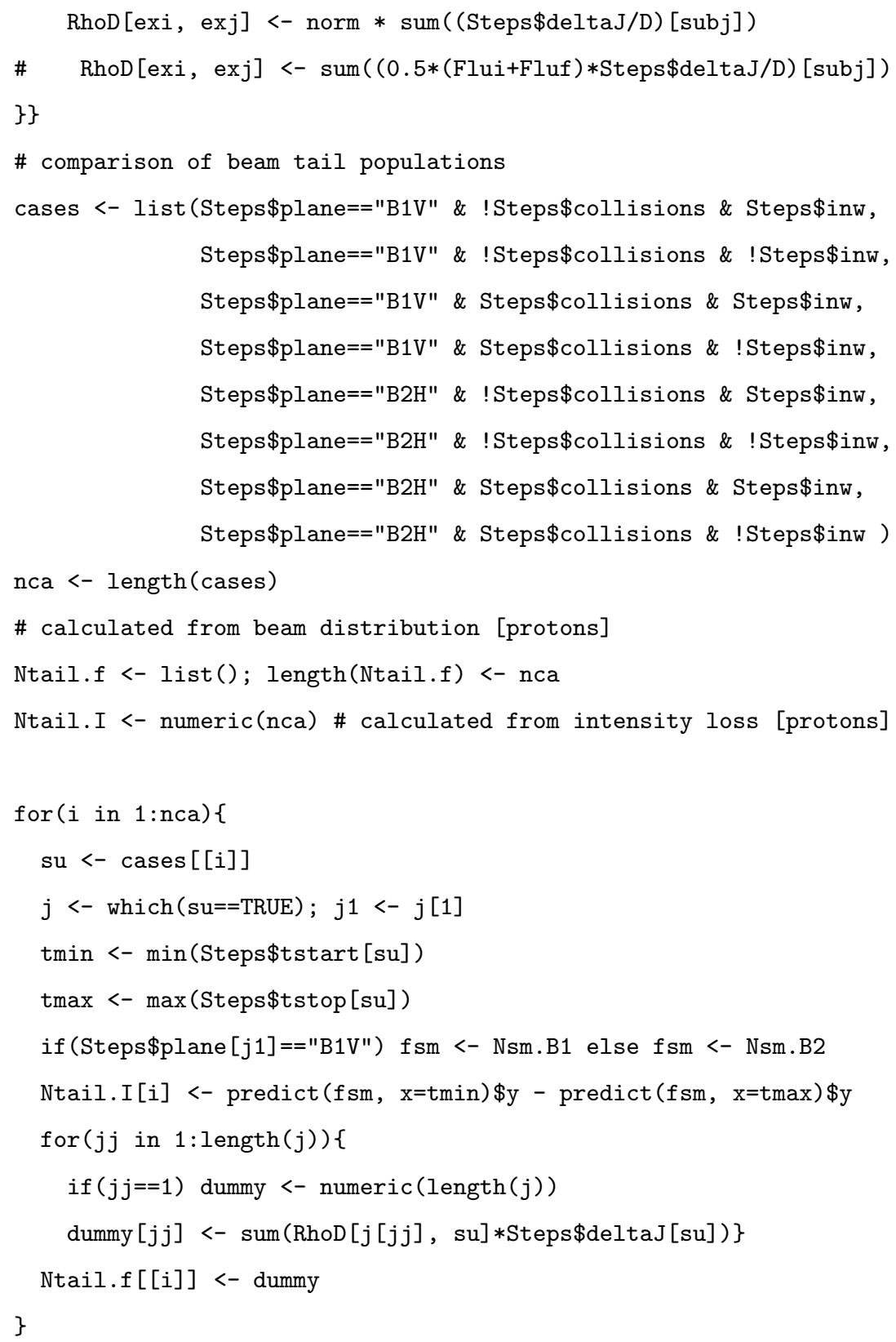




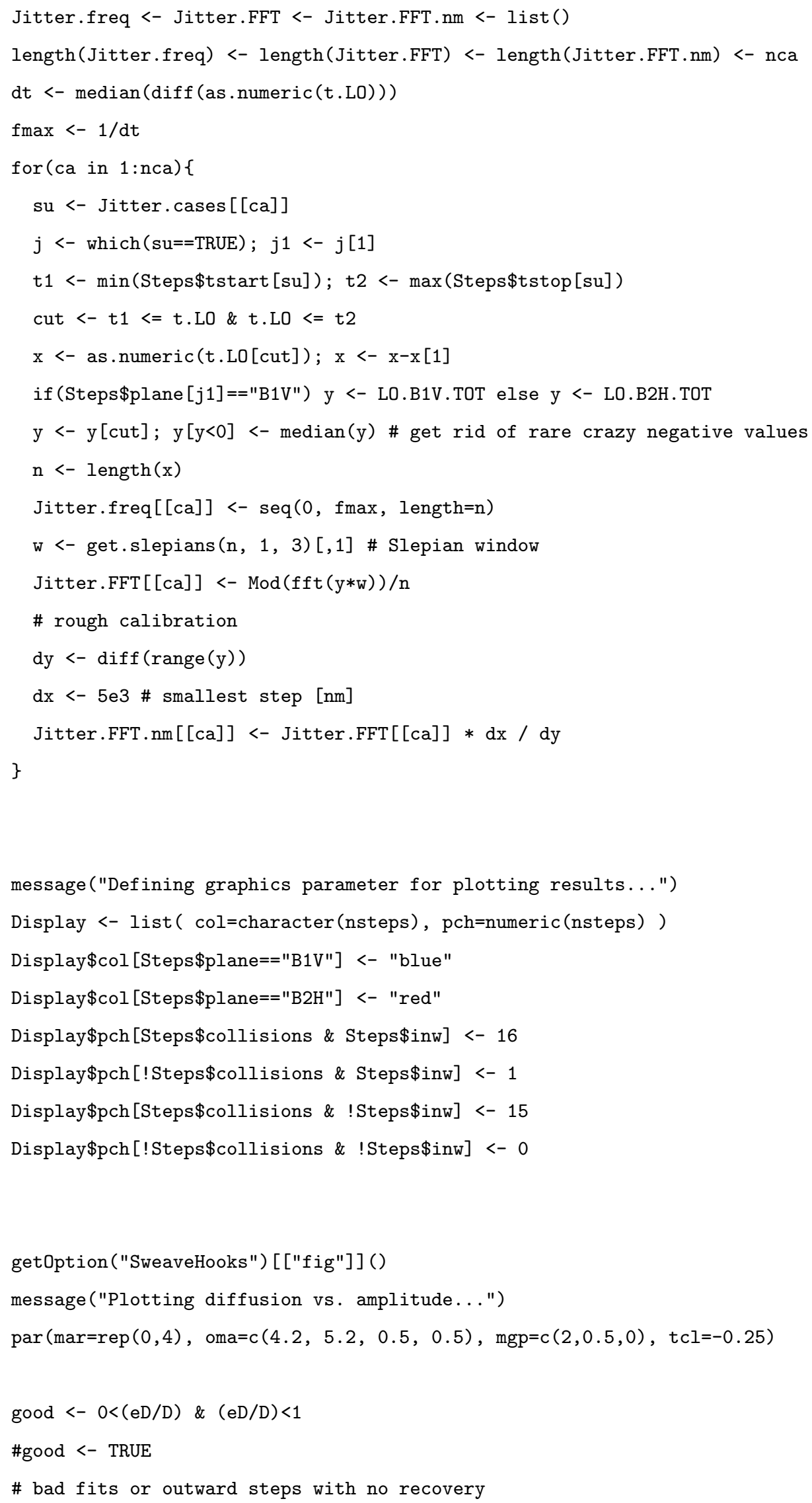




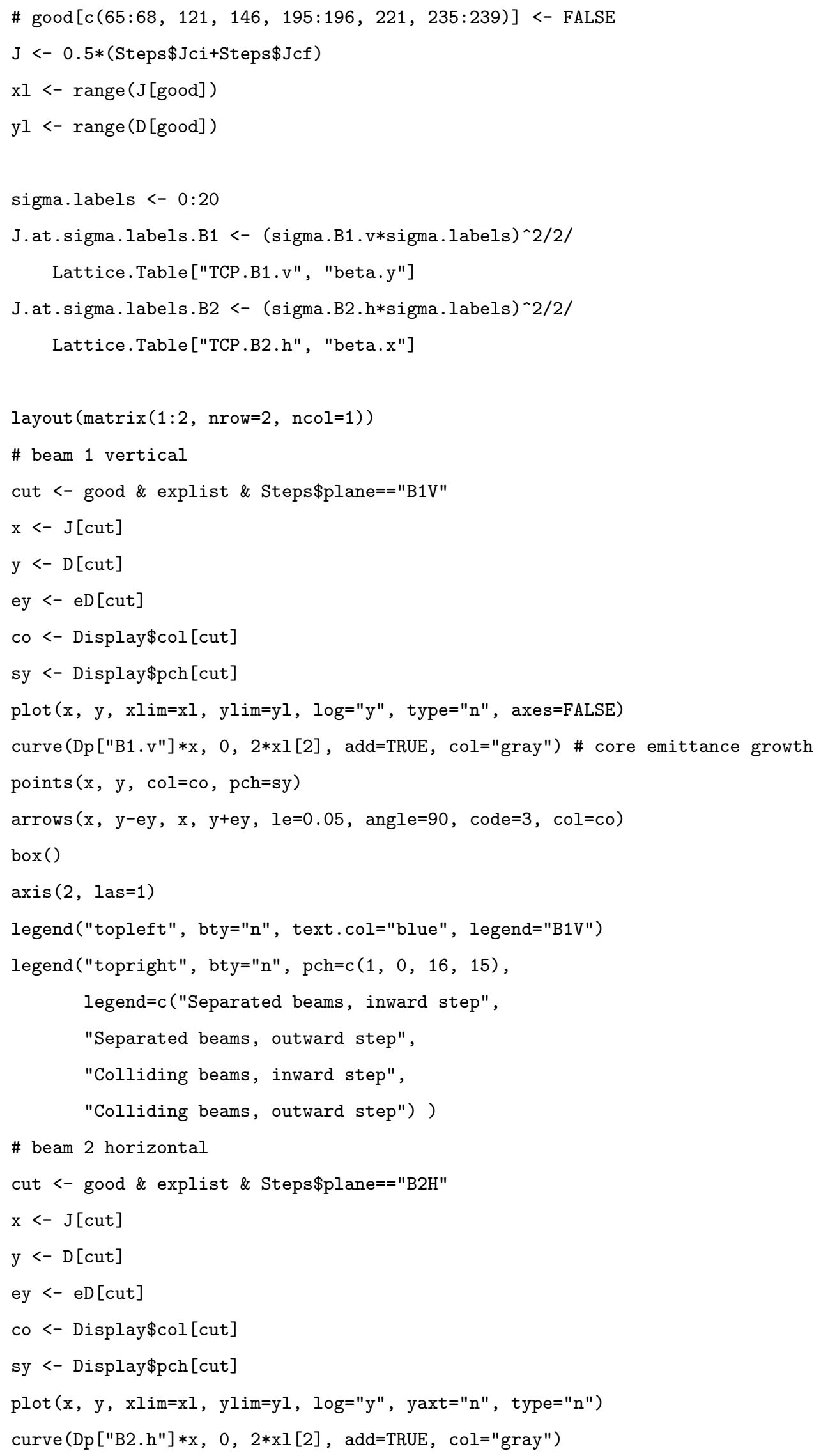




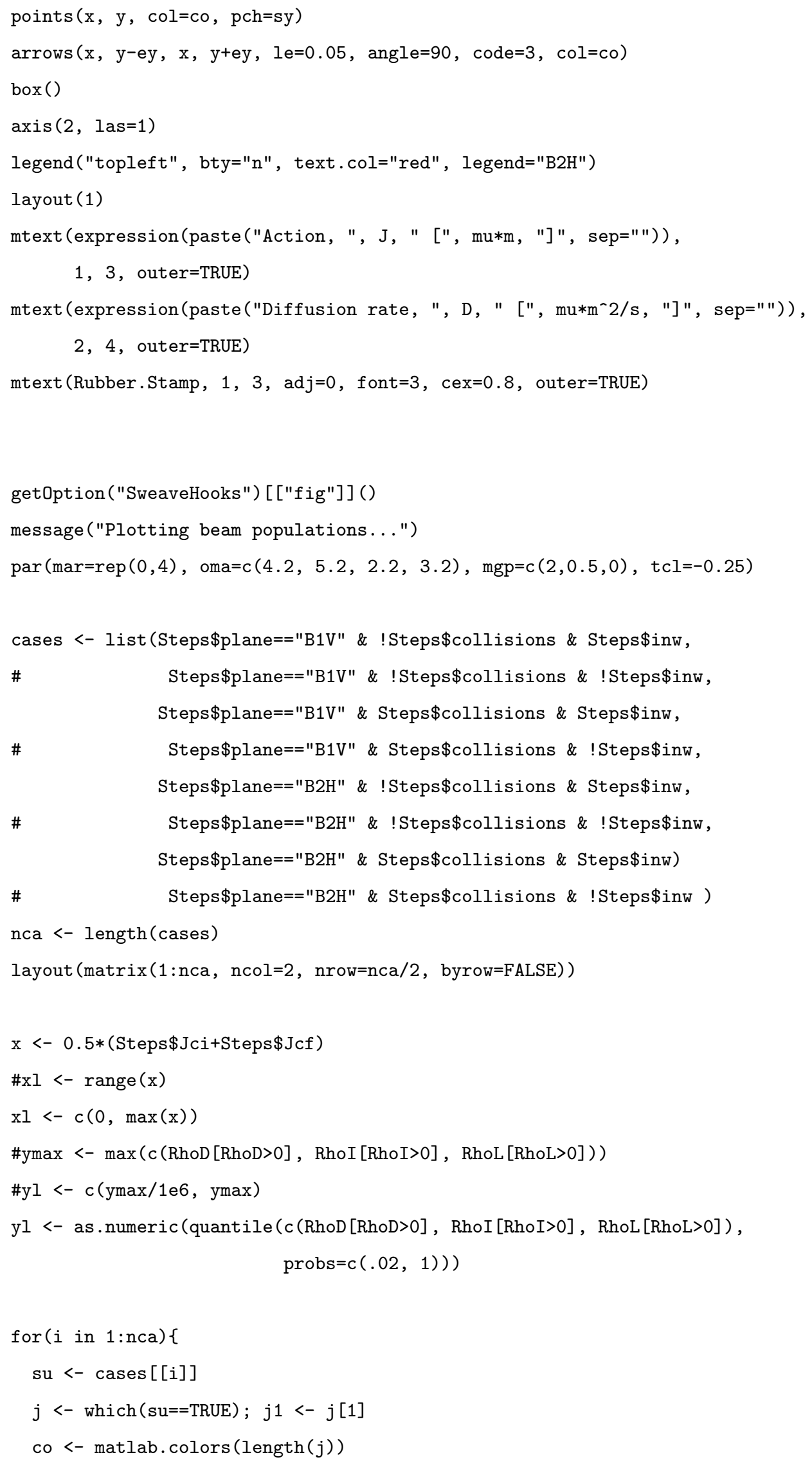




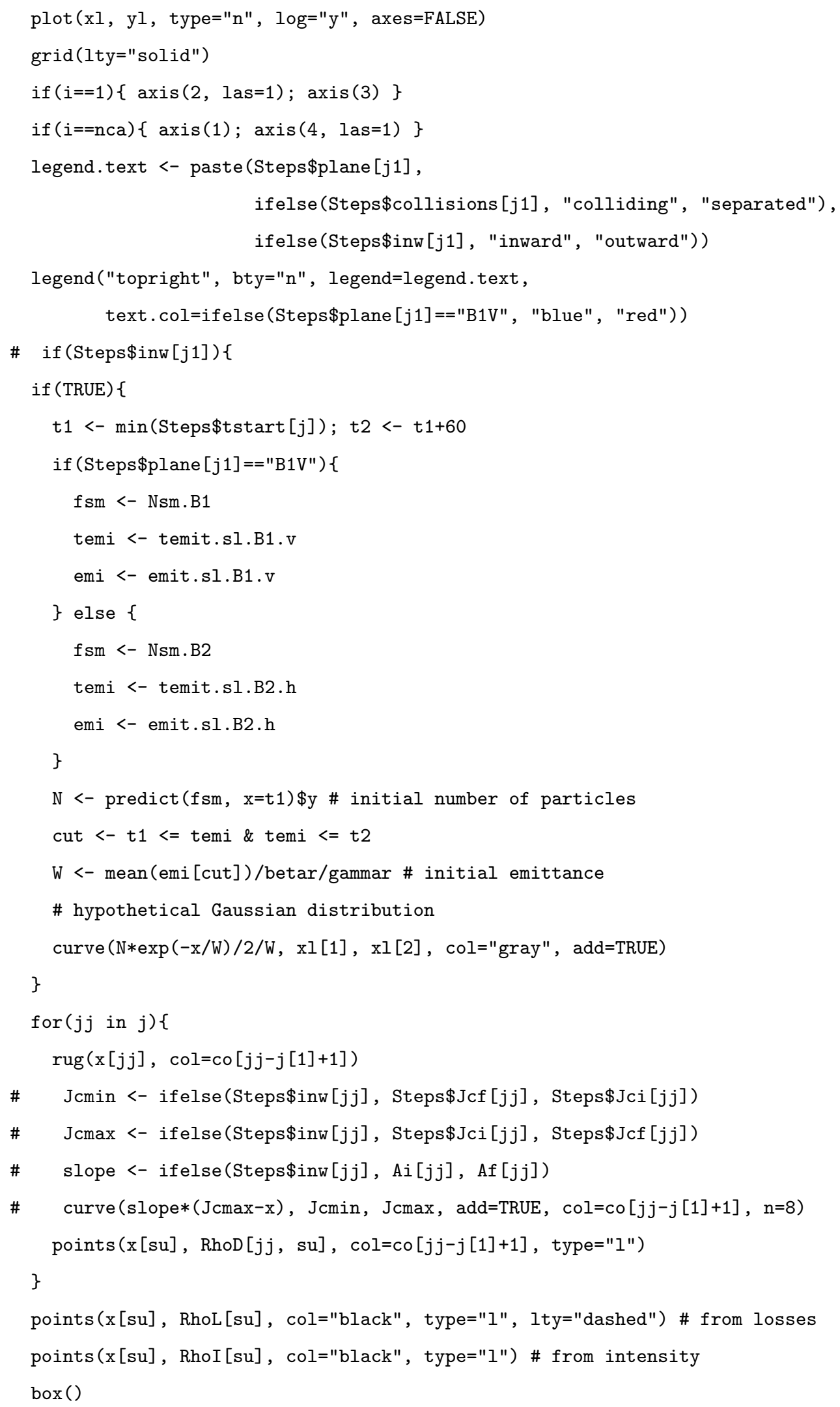




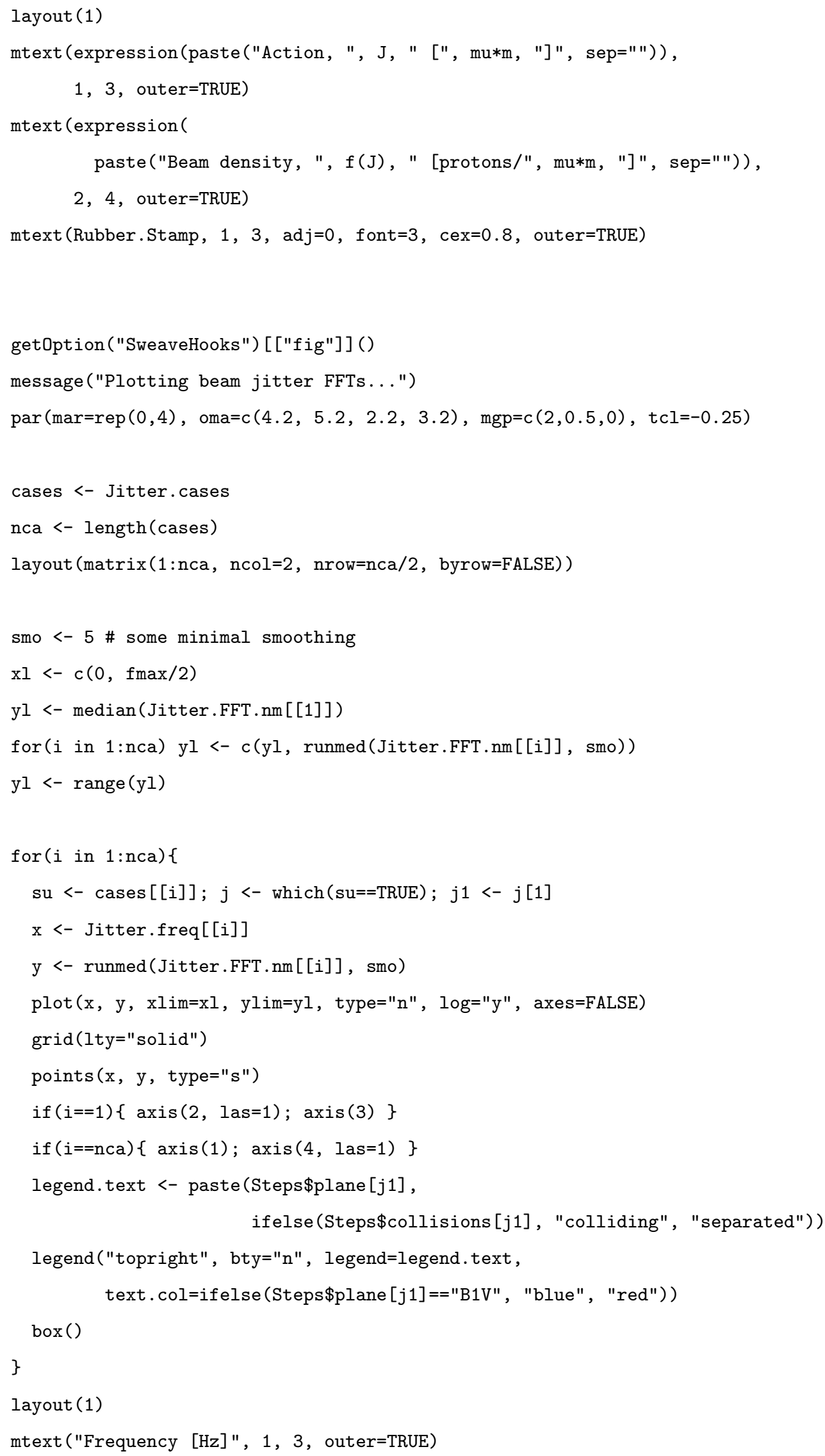




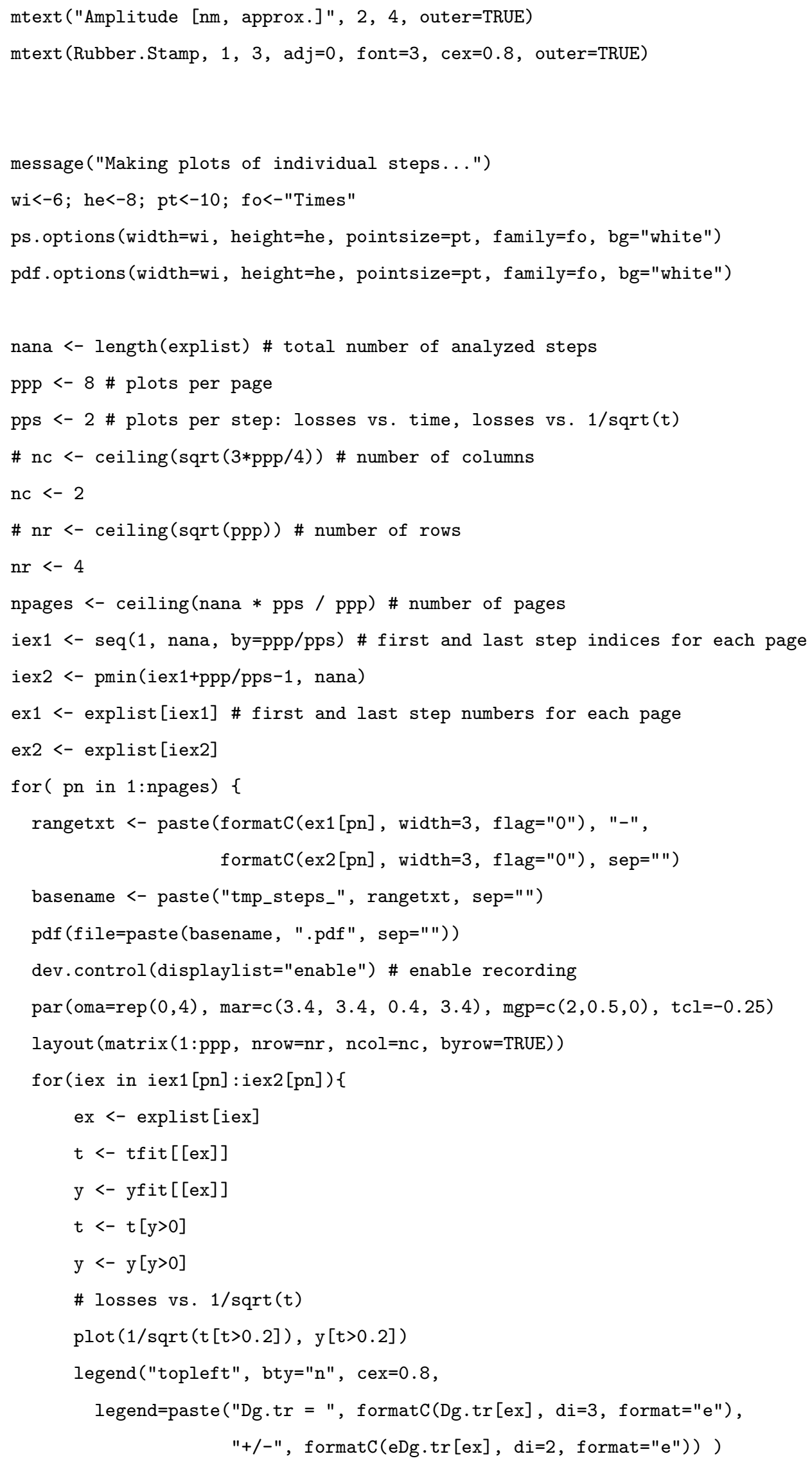




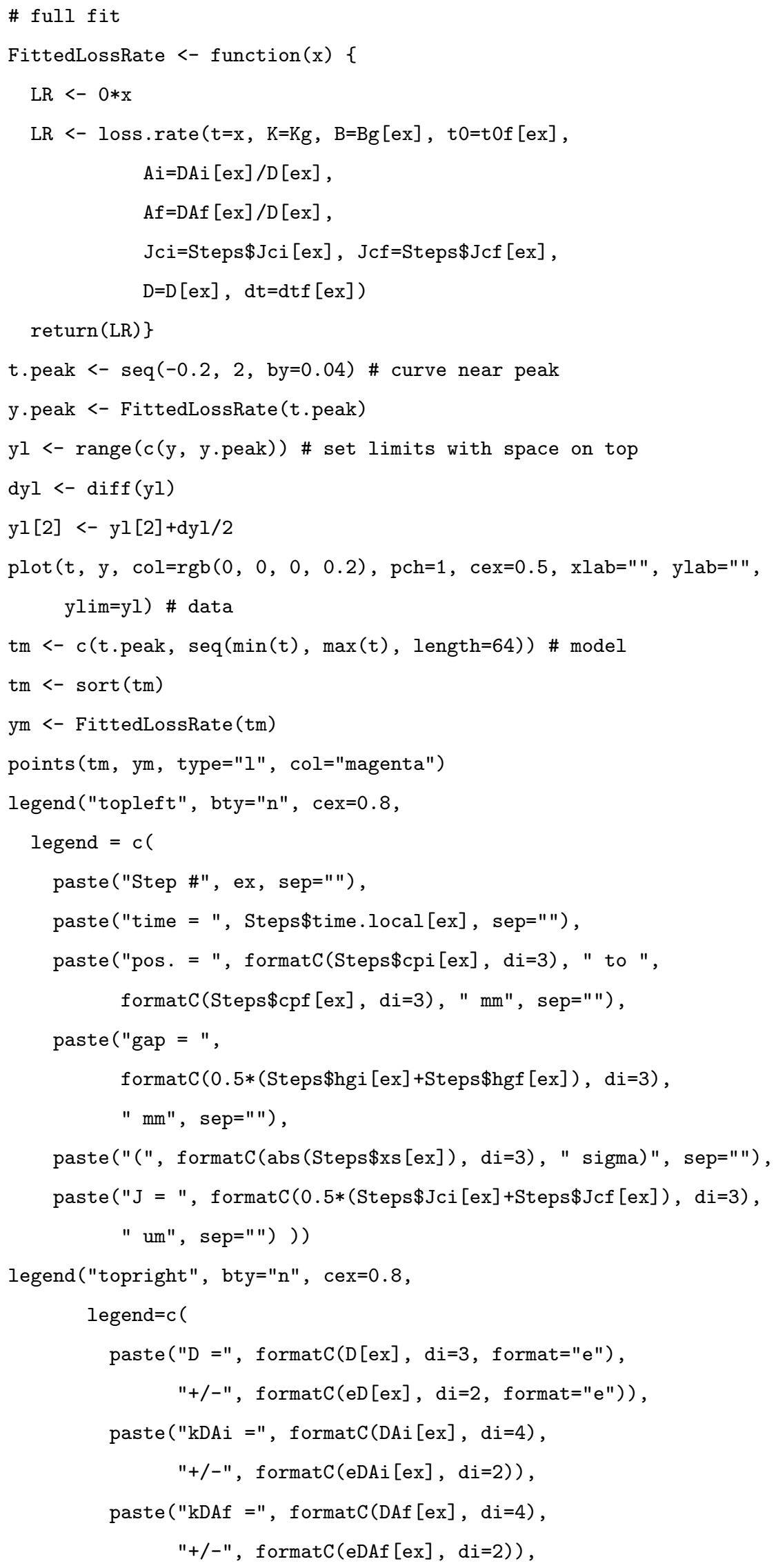




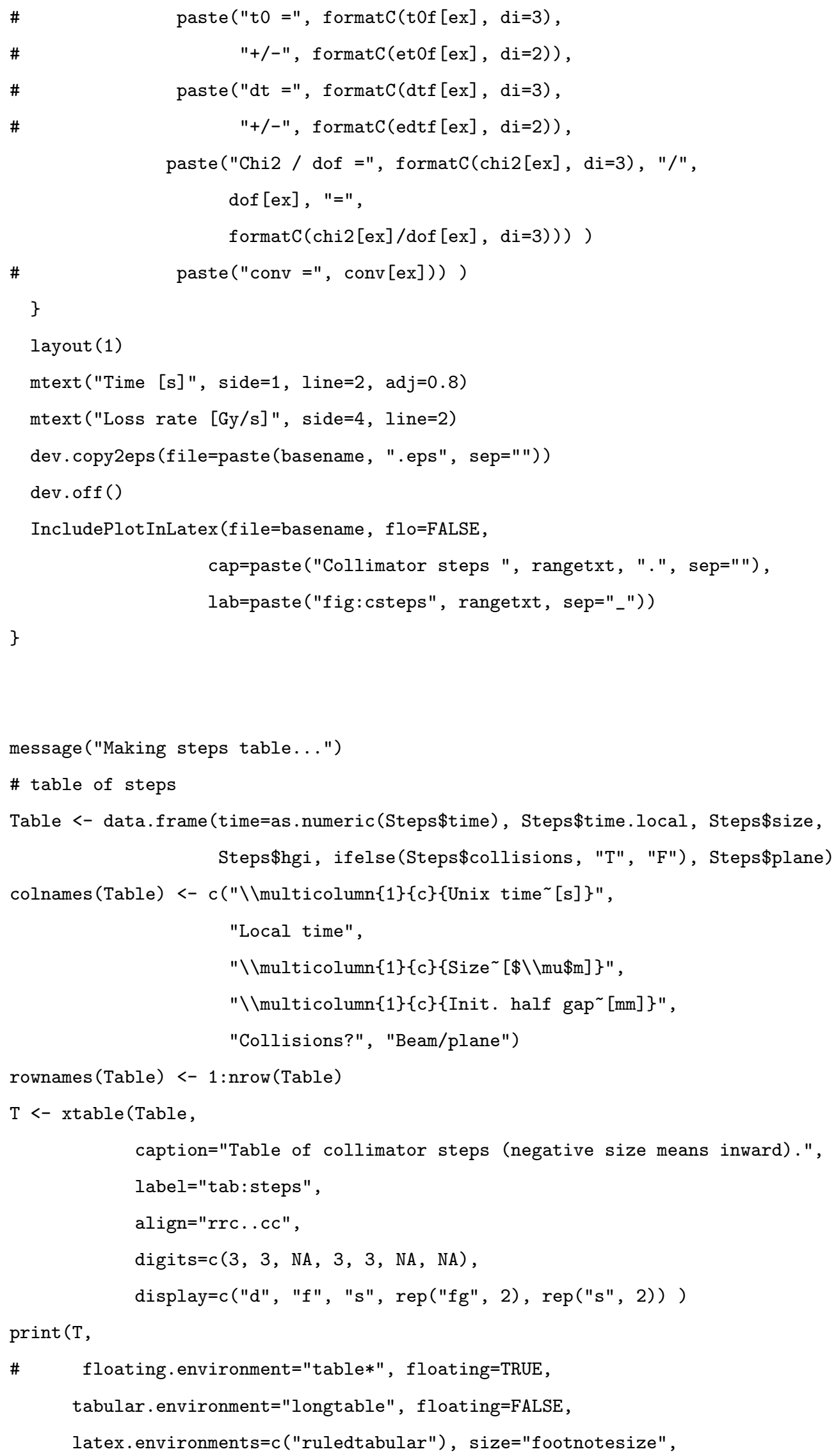


hline. after $=0$, sanitize.text.function=idem)

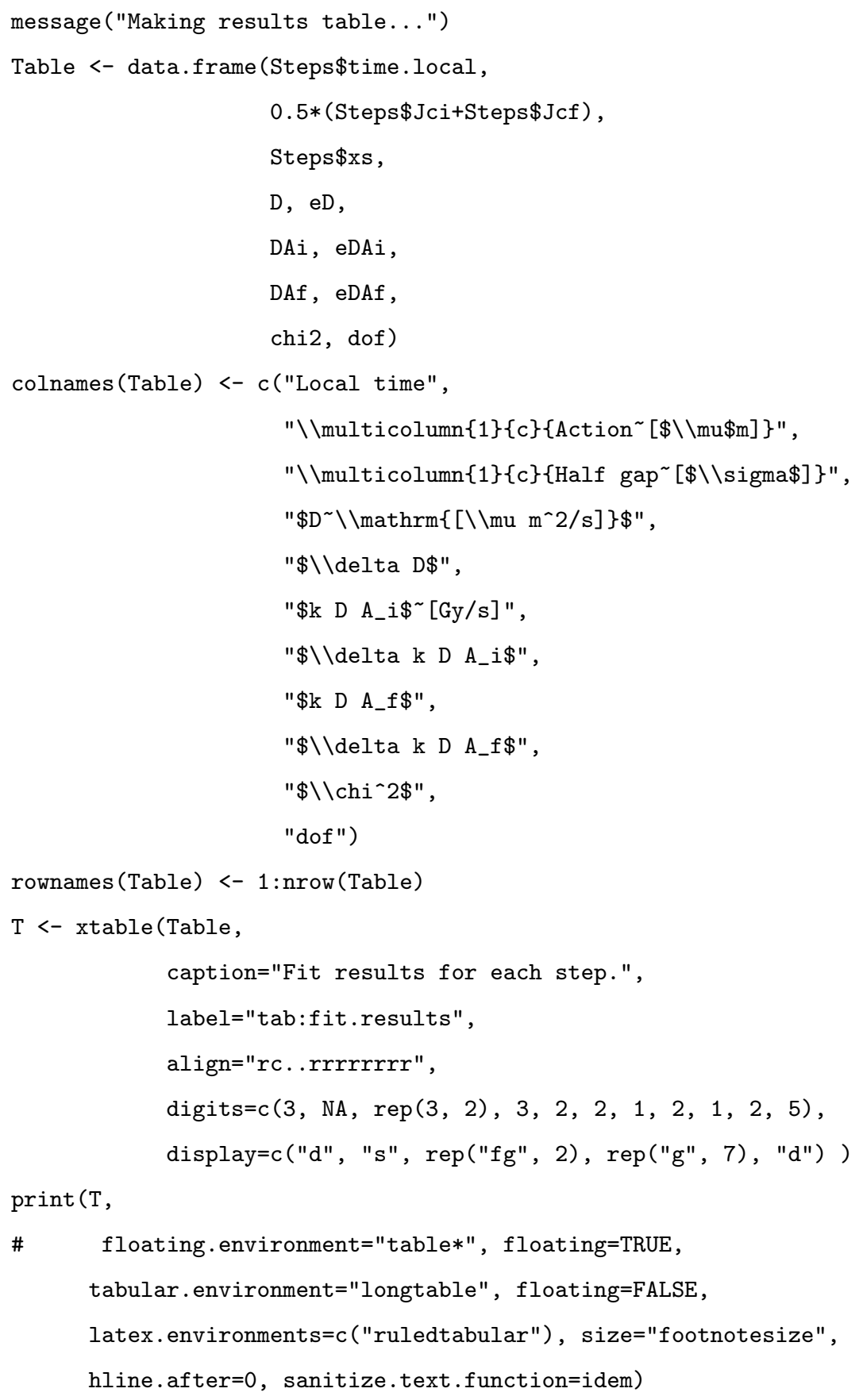


message ("Cleaning up...")

for (i in 1:3) gc()

message("\n\n", cornicina, "\n",

" End of diffusion analysis. \n",

cornicina, "\n", $\operatorname{date}(), " \backslash n \backslash n ")$ 
[1] A. J. Lichtenberg and M. A. Lieberman, Regular and Chaotic Dynamics (Springer-Verlag, New York, 1992), p. 320.

[2] T. Chen et al., Phys. Rev. Lett. 68, 33 (1992).

[3] A. Gerasimov, Report No. FERMILAB-PUB-92-185 (1992).

[4] F. Zimmermann, Part. Accel. 49, 67 (1995); Report No. SLAC-PUB-6634 (October 1994).

[5] T. Sen and J. A. Ellison, Phys. Rev. Lett. 77, 1051 (1996).

[6] N. Mokhov et al., JINST 6, T08005 (2011).

[7] L. Burnod, G. Ferioli, and J. B. Jeanneret, Report No. CERN-SL-90-01 (1990).

[8] R. P. Fliller III et al., in Proc. 2003 Part. Accel. Conf. (PAC03), p. 2904 (IEEE, Piscataway, NJ, 2003).

[9] G. Stancari et al., Phys. Rev. Lett. 107, 084802 (2011), arXiv:1105.3256 [physics.acc-ph].

[10] G. Stancari, Report No. FERMILAB-FN-0926-APC, arXiv:1108.5010 [physics.acc-ph].

[11] G. Stancari et al., Measurements of transverse beam diffusion rates in the Tevatron collider, Proc. 2nd Int. Part. Accel. Conf. (IPAC11), San Sebastián, Spain, 4-9 September 2011, p. 1882.

[12] K.-H. Mess and M. Seidel, Nucl. Instr. Meth. Phys. Res. A 351, 279 (1994); M. Seidel, PhD Thesis, Hamburg University, DESY 94-103 (June 1994).

[13] R Development Core Team, R: A language and environment for statistical computing (R Foundation for Statistical Computing, Vienna, Austria, 2010), ISBN 3-900051-07-0, www.R-project.org.

[14] Friedrich Leisch, Sweave: Dynamic generation of statistical reports using literate data analysis, in Compstat 2002 - Proceedings in Computational Statistics (Wolfgang Härdle and Bernd Rönz, editors), pp. 575-580 (Physica Verlag, Heidelberg, 2002), ISBN 3-7908-1517-9.

[15] G. Valentino et al., Halo diffusion MD proposal (2012, unpublished).

[16] G. Valentino et al., Halo scraping, diffusion and repopulation MD, CERN-ATS-Note-2012-XXX-MD (2012). 